\title{
Can I live the way I want in an organization? Self-identity in a retirement resort
}

by

\author{
Margot Haug
}

A thesis submitted to the Faculty of Graduate and Postdoctoral Affairs in partial fulfillment of the requirements for the degree of

Doctor of Philosophy

in

Management

Sprott School of Business

Carleton University

Ottawa, Ontario

(C) 2011, Margot Haug 
Library and Archives

Canada

Published Heritage

Branch

395 Wellington Street

Ottawa ON K1A ON4

Canada
Bibliotheque et

Archives Canada

Direction du

Patrimoine de l'édition

395 , rue Wellington

Ottawa ON K1A ON4

Canada
Your file Votre reférence

ISBN: 978-0-494-79628-3

Our file Notre référence

ISBN: 978-0-494-79628-3
NOTICE:

The author has granted a nonexclusive license allowing Library and Archives Canada to reproduce, publish, archive, preserve, conserve, communicate to the public by telecommunication or on the Internet, loan, distribute and sell theses worldwide, for commercial or noncommercial purposes, in microform, paper, electronic and/or any other formats.

The author retains copyright ownership and moral rights in this thesis. Neither the thesis nor substantial extracts from it may be printed or otherwise reproduced without the author's permission.
AVIS:

L'auteur a accordé une licence non exclusive permettant à la Bibliothèque et Archives Canada de reproduire, publier, archiver, sauvegarder, conserver, transmettre au public par télécommunication ou par l'Internet, prêter, distribuer et vendre des thèses partout dans le monde, à des fins commerciales ou autres, sur support microforme, papier, électronique et/ou autres formats.

L'auteur conserve la propriété du droit d'auteur et des droits moraux qui protège cette thèse. $\mathrm{Ni}$ la thèse ni des extraits substantiels de celle-ci ne doivent être imprimés ou autrement reproduits sans son autorisation.
In compliance with the Canadian Privacy Act some supporting forms may have been removed from this thesis.

While these forms may be included in the document page count, their removal does not represent any loss of content from the thesis.
Conformément à la loi canadienne sur la protection de la vie privée, quelques formulaires secondaires ont été enlevés de cette thèse.

Bien que ces formulaires aient inclus dans la pagination, il n'y aura aucun contenu manquant. 


\section{Abstract}

We work in organizations and live at home. But what happens if home is an organization? Can a person live the way they want? Residential organizations like prisons, mental hospitals and nursing homes have a reputation for being repressive. This study examines a new type of organization that has evolved since the 1960s, which has a non-institutional upscale feel and emphasizes customer satisfaction. The study calls this type of organization a communal lifestyle organization.

The study used Giddens' (1991) modernity and self-identity theory as a theoretical framework, supplemented by Goffman's total institution theory and a historical review of the literature on residential organizations. In using Giddens' theory, this study views self-identity as an ongoing socially constructed process. This descriptive multiple case study interviewed 30 persons living at a Canadian retirement resort where the average age is 85 . The study used a variety of qualitative and quantitative techniques: narrative analysis and statistical techniques to explore potential relationships.

The study found that about half of respondents notice changes in the way they see themselves: such as feeling old, better or happier. Most say they can live as they wish. There is, however, an assimilation effect. The longer respondents live at Lakelands (a pseudonym), the more their views resemble group views. This suggests that although self-identity is a matter of choice, communal lifestyle organizations shape self-identity. The study also found six conditions that predict agency vis-à-vis residential 
organizations. Increasing age, being married, poor health, not having family nearby, and increasing experience in residential organizations predict weakening agency.

The results indicate that Giddens' theory is analytically generalizable to other residential contexts. This may prove useful to researchers searching for an alternative to Goffman's total institution theory.

These findings have implications for organization theory, governments, the housing industry and for individuals. As populations age, more people may find themselves living in residential organizations. Self-identity - being able to live as one wishes without undue organizational restrictions - may become an important organizational, economic and political issue in the mid twenty-first century. 


\section{Acknowledgments}

I would like to thank the people at Lakelands who helped me with this study. Although it was not clear at the time how day-to-day living could be an important research topic, the people who live, work and own Lakelands supported this study from start to finish. I hope that this study will prove useful.

I would like to thank my research supervisor, Dr. Lorraine Dyke, who gave me the courage to explore this topic, and who provided me with kind and expert counsel throughout this long process. I could not have done this without her help and encouragement. Her wisdom has been my guiding light.

I would like to thank my thesis committee - Dr. David Cray and Dr. Louise Heslop - who carefully vetted the research plan before I went into the field, making sure it was well designed, suggesting relevant sources, and encouraging me to deepen my thinking. I would also like to thank my defence committee and external examiners - Dr. Behnam Behnia and Dr. Susan McDaniel - for their thought provoking questions.

I would like to thank my husband who endured my absence from day-to-day life for many long years. He was a patient and thoughtful advisor, and a source of great amusement for many people who live and work at Lakelands.

This thesis is dedicated to my mother - Mary Jean Haug - who died peacefully in her Lakelands' apartment July 10, 2006 at the age of 89, after a brief illness. To me, in later years, she became a guru. A quiet honest person, she was a keen observer of world

events. She had the mental acuity of a thirty-year-old. The day of her death a strong wind 
blew up. Jill, the palliative nurse, remarked that the Tibetans say this is the sign of a great soul passing ... My mother would have thought this fanciful. 


\section{Table of Contents}

$\begin{array}{ll}\text { Abstract ii } & \\ \text { Acknowledgments } & \text { iv } \\ \text { List of Tables } & \text { xi } \\ \text { List of Tables in Appendices xiv } \\ \text { List of Figures xiv } \\ \text { List of Appendices } \\ \text { Preface xvii }\end{array}$

1 Introduction 1

2 Literature review 7

Modernity and self-identity theory 7

2.01 Modernity 9

2.02 Self-identity and the reflexive project of the self 14

2.03 Institutions, organizations and sequestration 22

2.04 Emancipatory and life politics 28

Total institution theory $\quad 31$

A history of residential organizations for older people $\quad 39$

2.05 Premodern organizations 40

2.06 Modern period up to the 1960s 41

2.07 The 1960s and beyond 48

2.08 Today's communal lifestyle organizations 52

Summary $\quad 61$

3 Methods 65

Research questions and linkages to theoretical notions

3.01 Who am I? 66

3.02 Am I what I consume? 66

3.03 How do I describe the organization? 
3.04 Who am I when I live in an organization? 67

Research design $\quad 69$

3.05 A descriptive multiple case study 70

3.06 The unit of analysis 71

3.07 An emphasis on language: Qualitative and quantitative data 71

3.08 Multiple sources of evidence 73

3.09 Ethical conduct of the research 74

3.10 The communal lifestyle organization: Lakelands Retirement Resort 76

Data analysis 87

3.11 Qualitative analysis: Narrative analysis 87

3.12 Narrative analysis plan 94

3.13 Case summary 97

3.14 Quantitative analysis 98

3.15 Coding 98

The data $\quad 100$

3.16 Data collection 100

3.17 Replication logic: The case selection strategy 104

3.18 The process: Selecting cases 110

3.19 The data and narrative classification methods 113

3.20 Narrative variability 115

3.21 Coding: Reliability and validity 116

3.22 Rigour of the analysis 119

Summary 122

$4 \quad$ Who am I? 124

People's characteristics $\quad 124$

Moving 131

Life-planning 134

Summary 139 
$5 \quad$ Am I what I consume? 140

Why choose Lakelands? $\quad 140$

5.01 The attractions $\quad 141$

5.02 My home defines me: Lifestyle fit 143

$\mathbf{5 . 0 3}$ Staying put 146

5.04 Shifting self-identities 148

Organizational reflexivity and self-identity 153

5.05 We were sold a cruise ship. We weren't sold walkers!

5.06 Shaping the organization's lifestyle 157

Summary $\quad 160$

6 How do I describe Lakelands Retirement Resort? 163

6.01 Describing Lakelands: Discursive consciousness 163

6.02 Talking about Lakelands: Practical consciousness 167

6.03 Is Lakelands my home? 169

$\mathbf{6 . 0 4}$ Is it a suite? 173

6.05 Language of sequestration 175

Summary 181

7 Who am I when I live in an organization? Adaptation 183

7.01 Factors that help and hinder adaptation 184

A. Lakelands' effect on adaptation 186

B. Self-control and adaptation 190

C. Fateful moments in the context of adaptation

193

D. Situational factors and adaptation 201

7.02 Adaptation: An ongoing process 203

7.03 Adaptation and self-identity 205

Summary 207 
8 Who am I when I live in an organization? My self-identity 209

8.01 Feeling old 216

8.02 Feeling proud, blossoming, love 217

8.03 Meaningful self-actualization 220

Summary 221

9 Who am I when I live in an organization? Naming conventions

Summary 228

10 Who am I when I live in an organization? Living with others 229

10.01 Privacy 231

10.02 Eating in the dining room 236

10.03 War and peace 240

10.04 Pure relationships 242

Summary 246

11 Who am I when I live in an organization? Rules and conventions

11.01 Active retirement 250

11.02 The seating debate 258

11.03 Friendliness 262

11.04 Dress regimes and identity switching 264

Summary $\quad 268$

12 Who am I when I live in an organization? Living as I like

Summary $\quad 278$

13 Who am I when I live in an organization? Suggesting changes 280

13.01 "I don't want to complain" 282

13.02 Institutional reflexivity 287

Summary 289 
14 Who does the organization want me to be? Assimilation

Summary 293

15 Towards a typology: Communal lifestyle organizations 295

15.01 Typical communal lifestyle organizations 304

15.02 Atypical communal lifestyle organizations 307

Summary $\quad 310$

16 Analytic generalization 313

16.01 Self-identity and the reflexive project of the self 316

16.02 Lifestyle 318

16.03 Bodily appearance 320

16.04 Organizational sequestration 320

16.05 Life-planning 322

16.06 Fateful moments 323

16.07 Pure relationships 324

16.08 Power 325

16.09 Emancipatory politics and life politics 325

16.10 Gaps in the theory 327

Summary $\quad 329$

17 Discussion of the findings 330

Who am I? 331

17.01 Respondent characteristics and agency 332

Am I what I consume? 338

How do I describe the organization? 341

Who am I when I live in an organization? 344

17.02 Adaptation 345

17.03 Self-identity change 348

17.04 Naming conventions 351

17.05 Living with others 354

17.06 Rules and conventions $\quad 356$ 
17.07 Live as I like 359

17.08 Suggestions for change 361

17.09 Assimilation 363

A communal lifestyle organization typology $\quad 366$

Analytic generalization $\quad 368$

Summary $\quad 370$

18 Conclusions 373

Conclusions and contributions of the research $\quad 373$

Limitations of the study $\quad 376$

Suggestions for future research $\quad 377$

Implications for entrepreneurs, marketers and managers $\quad 379$

Implications for governments $\quad 383$

Summary $\quad 387$

$19 \quad$ References 388

\section{List of Tables}

Table 2.1 Differences between emancipatory and life politics 30

Table 3.1 Lakelands' vision, goals, mission and values 77

Table 3.2 Independent living residence cost 2009: Unfurnished 1 bedroom apartment, 3 meals per day 81

Table 3.3 Canadian seniors median income 2003: By sex and marital status 81

Table 3.4 Cost of nursing homes in selected Canadian provinces $2009 \quad 82$

Table 3.5 Structural narrative analysis 93

Table 3.6 The analytical plan: Narrative analysis tasks 95

Table 3.7 Definition of typical, contrasting and discrepant narratives 105

Table 3.8 Predicted narratives by case selection criteria 107

Table 3.9 Resident case selection targets and results 108

Table 3.10 Years resident: Study group 109 
Table 3.11 Lakelands' population compared to the study group: Marital status by sex 109

Table 3.12 Age of study group 110

Table 3.13 Narrative variability 116

Table 3.14 Intercoder agreement statistics 119

Table 4.1 Respondents' primary occupational history 126

Table 4.2 Family living nearby 127

Table 4.3 (Great) grandchildren living nearby 127

Table 4.4 Study group's health 128

Table 4.5 Respondents using walking aids 129

Table 4.6 Respondents' personalities: Extrovert or introvert 130

Table 4.7 Type of residence prior to Lakelands 131

Table 4.8 Reasons for moving 132

Table 5.1 Why choose Lakelands? 142

Table 5.2 Typical, contrasting and discrepant narratives: Image or appearance 142

Table 5.3 Looking for the right place 144

Table 6.1 Descriptions of Lakelands' organizational model 164

Table 6.2 Words used to talk about Lakelands 168

Table 6.3 Association between extroversion and use of the word "home"

Table 6.4 Words to describe resident's living quarters 174

Table 6.5 Language of sequestration versus the alternatives 177

Table 6.6 Association between marital status and use of the word "in here/outside" 179

Table 6.7 Associations with "in here/outside" 179

Table 7.1 Typical, contrasting and discrepant narratives: Adaptation 184

Table 7.2 Factors that help and hinder residents' adaptation 187

Table 7.3 Number of crises respondents experienced: Before and after the move 194

Table 7.4 Type of crises: Before and after the move 195

Table 7.5 Associations with "adaptation required" 196

Table 8.1 Typical, contrasting and discrepant narratives:

Self-identity change 210 
Table 8.2 Associations with self-identity change 212

Table 8.3 Number of previous residential organizational experiences 213

Table 8.4 Self-identity changes 215

Table 9.1 Typical, contrasting and discrepant narratives:

Naming conventions 224

Table 10.1 Typical, contrasting and discrepant narratives: Privacy 232

Table 10.2 Respondents' meal plans 237

Table 10.3 Typical, contrasting and discrepant narratives: Dining 238

Table 10.4 Respondents' assessment of people at Lakelands 242

Table 11.1 Typical, contrasting and discrepant narratives: Rules 249

Table 12.1 Typical, contrasting and discrepant narratives: Living as one likes 272

Table 12.2 Living as I like: Restrictions outside Lakelands' control 274

Table 12.3 Positive experiences at Lakelands 275

Table 12.4 Relationships with "can live as I like" 276

Table 13.1 Typical, contrasting and discrepant narratives: Suggestions for change $\quad 281$

Table 13.2 The relationship between not complaining and making suggestions to management 287

Table 14.1 Associations with narrative 291

Table 15.1 Communal lifestyle organizations and total institutions 296

Table 15.2 Types and conditions of communal lifestyle organizations 302

Table 15.3 Characteristics of communal lifestyle organizations 305

Table 15.4 Characteristics of typical nursing homes 309

Table 15.5 Comparing all types of residential organizations 310

Table 16.1 Giddens' notions: Generalizability and theoretical refinements 314

Table 17.1 Key findings related to the question: Who am I? 331

Table 17.2 Correlations with respondent characteristics 334

Table 17.3 Who am I and agency 337

Table 17.4 Key findings related to the question: Am I what I consume? 338

Table 17.5 Key findings related to the question: How do I describe the organization? 342

Table 17.6 Key findings regarding adaptation $\quad 345$

Table 17.7 Key findings regarding self-identity change 348 
Table 17.8 Key findings regarding naming conventions 352

Table 17.9 Key findings regarding living with others 354

Table 17.10 Key findings regarding rules and conventions 356

Table 17.11 Key findings regarding living as I like $\quad 359$

Table 17.12 Key findings regarding suggestions for change 362

Table 17.13 Key findings regarding assimilation 364

Table 17.14 Key findings regarding a communal lifestyle organization typology $\quad 366$

Table 17.15 Key findings regarding analytic generalization 369

\section{List of Tables in Appendices}

Table H.01 Interview questions, answers and type of narrative response, by case $\quad 461$

Table I.01 Typical, contrasting and discrepant narratives for 10 major interview questions $\quad 469$

Table J.01 Classifying narratives at the case level: Decision rules 473

Table L.01 Statistical relationships with contrasting answers 478

\section{List of Figures}

Figure 3.1 Photograph from a Lakelands' calendar 85

Figure 11.1 Identity switching 267 


\section{List of Appendices}

Appendix A: Glossary 414

Appendix B: Internet advertising: Selected companies

418

Appendix C: Participant recruitment 422

C.01 Letter to residents 422

C.02 Letter to management

C.03 Consent form \#1 426

C.04 Consent form \#2 427

Appendix D: Photographs of Lakelands 428

Appendix E: Interview protocols 431

E.01 Interview protocol: People who live at Lakelands 431

E.02 Interview protocol: Lakelands' management and owners 434

Appendix F: Implementing the analytical plan: Narrative analysis tasks 438

Appendix G: Coding: List of quantitative variables and qualitative codes 441

Appendix H: Major interview questions, answers and type of narrative $\quad 460$

Appendix I: Creating narrative categories $\quad 468$

Appendix J: Narrative types: Creating a case level measure 473

Appendix K: An example of structural analysis 474 
Appendix L: Statistical relationships with contrasting answers

Appendix M: Summary of statistical relationships 


\section{Preface}

One day in the Spring of 2002 my mother called. She said she could not handle the house and garden anymore. She and her friend Betty had visited a place in town called Lakelands Retirement Resort (a pseudonym). She wanted to sell the house and move there. My mother wanted me to see Lakelands before signing on the bottom line.

So I flew out to see her. Having visited a few nursing homes in my life, I was pessimistic. Nothing prepared me for what I saw. I could not have been more surprised. Although I did not know it, that is when this research began.

It was like walking into a four-star hotel. It did not look or feel institutional, only the walkers in the lobby suggested otherwise. I met the manager and we took the grand tour. My mother's apartment was spacious, with a balcony overlooking a forest and creek. I was enchanted by the theatre - a miniature version of a commercial cinema with stars on the ceiling and a red popcorn machine in the lobby. They invited us for a superb lunch.

Things moved rapidly after that. We sorted through 52 years of family life. I never asked my mother, but moving day seemed the worst part of the whole experience. On the surface everything seemed fine. She sat in the living room and watched the movers work. The next day her back seized up like a vice. She could not walk and had to be taken to the hospital. Sent home with pain killers and muscle relaxants she went downhill. It took months to heal. Although happy with her new apartment and surrounded 
by her paintings, furniture and books, in the first few months she seemed like a plant that had been ripped out of the soil and replanted. She had lost her home, her garden and her cats. It took time to heal, and thankfully she did, as growing conditions were rich.

My mother enjoyed life at Lakelands. A quiet person, she could retreat to her apartment for privacy. She went to the dining room for breakfast, lunch and dinner, the library to read the Globe and Mail and the beauty salon for her weekly hair appointment. She had a car, but usually preferred to take the Lakelands' bus for errands. She went for walks with her cousin Vona, who also lived at Lakelands. Occasionally she went to exercise class, the cinema, or special events. Lakelands' housekeeping cleaned her apartment once a week, and if she became ill, she called a private sector health care aide to help.

I visited about twice a year, living in my mother's Lakelands' apartment for lengthy periods of time - spending in total over a year at Lakelands from 2002 until my mother's death in 2006. One day the Lakelands' receptionist asked me what I did in life. I told her about the Ph.D. program and my planned dissertation. Her response was: "why not study Lakelands?" That was when this work began in earnest. 


\section{CHAPTER ONE}

\section{Introduction}

Who am I? Giddens' (1991) self-identity theory suggests the answer was simple in premodern times when kinship and religion dictated social roles. Even people's names described their identity (e.g., Farmer, Merchant, Priest, Lord, Lady). In the industrialized West of the early twenty-first century, self-identity is a matter of choice. Forces such as technology, globalism and capitalism create a multitude of shifting possibilities. No longer a fixed collection of traits reflecting a traditional social role, self-identity is a thoroughly reflexive process. Self-identity is socially constructed and conveyed by the stories people tell about themselves. People continuously revise their biographical narratives in an effort to produce a coherent sense of self (Giddens, 1991).

Given that self-identity is a matter of choice in late modernity, what happens when a person lives in an organization? Who am I when I live in an organization? This seemingly simple question raises a number of issues: Am I what I consume? (Kleine, 2006; Saren, 2007; Sayre \& Horne, 1996) Who does the organization want me to be? (Alvesson \& Willmott, 2002; Goffman, 1961) Where is the "me" among the "we"? (Kreiner, Hollensbe \& Sheep, 2006). Giddens' theory predicts a reflexive relationship between self-identity and society: 
Reflexivity refers to the notion that both individuals and society are defined not just by themselves but in relation to each other, and must continually redefine themselves in reaction to others and new information (Polity Press, 2007).

This suggests that for seniors, self-identity is influenced by the retirement industry and by the organizations where people live. In turn, people influence these organizations and industries. Self-identity and organizing are co-creations.

Previously in Western societies, the answer to "Who am I when I live in an organization?" was predictable and tightly controlled by organizational administrators. Organizations where people lived and worked such as monasteries, work houses, prisons, orphanages, mental asylums, hospitals, ships and the military, often reflected characteristics of what Goffman (1961) calls a total institution. Goffman found if people live in an organization with prison-like conditions - a total institution - the organization strips them of their self-identity, replacing it with an organizational identity. The methods used by administrators, especially in places with a prison-like atmosphere, include but are not limited to: eliminating personal possessions, privacy and contact with the outside world; obliging everyone to follow the same organizational schedule; subjecting people to body shaming rituals; restricting sexual relations; and replacing individual clothing with organizational clothing, and names with numbers. Despite this, people like soldiers and monks, voluntarily seek out these living conditions.

What can organizational theorists tell us about self-identity in modern domiciliary organizations that do not resemble total organizations? What can they tell us about new private sector organizations like retirement resorts, which seem to be a product of the 
consumer lifestyle movement? The answer is organizational researchers know little about how people construct self-identity in these new organizations.

This gap in the literature is relevant to organizational researchers for four reasons. First, significantly more North Americans live in residential organizations than in the past, especially older people. Statistics Canada reports that in $2001,32 \%$ of Canadians aged 85 and over (175,000 persons) lived in hospitals and nursing homes (Turcotte \& Schellenberg, 2007). Demographics suggest these numbers may greatly increase:

If these rates persist, Statistics Canada's latest population projections suggest that the number of beds required in long-term health care facilities could rise from 184,300 in $1996 / 97$ to over 565,000 in 2031 (Trottier, Martel, Houle \& Berthelot, 2000 , p. 49).

If one adds people living in independent and assisted living, (which are not included in these statistics), the percentage will be much higher. Additionally, since Baby Boomers have fewer children to depend on than the current generation of Canadians 85 and older, the percentage of older people living in organizations by 2056 may be much greater than now (Harvard University Joint Center for Housing Studies, 2000). Given the number of individuals affected, it is important to understand the impact of these organizations on self-identity.

A second reason this topic is relevant to business researchers is that North American and European governments are downsizing and shifting hospital and nursing home ownership and management to the private sector (Canadian Broadcasting Corporation Marketplace, 2001, March 20; DuHigg, 2007c, September 23; Estes \& 
Associates, 2001; McDaniel, 1999; Phillipson, 1998; Harvard University, Joint Center for Housing Studies, 2000). In the United States, this growing industry now owns as many units as the hotel industry (Laposa \& Singer, 1999). This important economic sector has not received much attention.

A third reason this topic is relevant is it points to organizational change or code breaking (Rao \& Giorgi, 2006). Traditional organizing philosophies in seniors housing, such as the custodial and medical services model, are being challenged by customer service or hospitality models (Harrington, 1994). Entrepreneurs are breaking up former organizing paradigms - the suburban home, seniors' apartments, nursing homes, the hotel and cruise ships - and recombining them in new ways such as gated communities, continuing care communities, resorts and luxury hotel living, especially in the United States Sunbelt where older people tend to migrate. New partnerships are being created between the health care, housing, insurance and hotel industries to create these new organizations - communal lifestyle organizations - as they are called in this document. As well, boundaries between industries are blurring.

A final reason this topic is relevant is that it points to a reconceptualization of older persons' identities. Notions such as successful aging, active retirement, freedom, choice, resort lifestyles, fun, and leisure are appearing in marketing messages. A body of literature explores these changes (Baltes, 1996; Biggs, 1999; Blaikie, 1999; Blakely \& Snyder, 1999; Fitzgerald, 1986; Jacobs, 1974; Katz, 2005; Laws, 1995, 1997; McHugh, 2003; McHugh \& Larson-Keagy, 2005; Phillipson, 2007; Rowe \& Kahn, 1997; Rudman, 2006; Streib, Folts \& La Greca, 1985; Ylänne-McEwen, 2000), however, more research 
is required to explore how these self-identities may be constructed by people living in a communal lifestyle organization.

Given the ongoing changes in this sector, this study is timely. This study addresses the question: How do people construct self-identity when they live in a private sector communal lifestyle organization? This question is broken into the following four sub-questions: Who am I? Am I what I consume? How do I describe the organization? and Who am I when I live in an organization (Kreiner, Hollensbe \& Sheep, 2006)? This is a descriptive case study - a study which describes a new organizational phenomena in its context. The study uses theory to guide enquiry (Yin, 2003). It describes the application and limits of Giddens' modernity and self-identity theory. The focus is on older people living at Lakelands Retirement Resort, a Canadian private sector communal lifestyle organization with a hotel-like atmosphere and hospitality service philosophy.

The study employs Giddens' (1991) theory to direct concept development, research questions and data analysis. This theory addresses issues such as the ways modern Western society influences self-identity, the importance of lifestyle and lifestyle choices, implications for self-determination, and the issue of segregated residential organizations. By using Giddens' theory as a lens, this study adopts a social constructivist approach, viewing self-identity as an ongoing constructed process, rather than a stable unchanging essence. The study documents and communicates people's interpretation of self-identity, an interpretation expressed in language and action that moves and changes over time. 
While Giddens' theory serves as an interpretive framework, Riessman's (2008) narrative analysis theory, guides interviewing, analysis and reporting. A branch of discourse analysis, narrative analysis is often used in identity research (Riessman, 2008). Riessman's theory blends well with the ontological and epistemological premises of Giddens' theory, his views on agency, language, definition of self-identity, and reflexivity.

This document is divided into 18 chapters. Chapter 2, (following this introductory chapter), describes Giddens' modernity and self-identity theory, Goffman's total institution theory and the history of residential organizations for older people. Chapter 3 describes the research strategy, methods and the context - Lakelands Retirement Resort. Chapters 4 to 14 describe the research findings for the questions: Who am I? Am I what I consume? How do I describe Lakelands Retirement Resort? and Who am I when I live in an organization? Chapter 15 sets out a communal lifestyle organization typology. Chapter 16 examines the analytic generalizability of Giddens' modernity and self-identity theory. Chapter 17 discusses the research findings and Chapter 18 explores the study conclusions, its limitations, suggestions for future research and implications for practice. 


\section{Literature Review}

The purpose of this literature review is to discuss the theory and empirical research relevant to this study. The review explores the concept of self-identity, and describes Giddens' explanation of how and why modernity affects the way people construct selfidentity, irrespective of whether they live in organizations or not. Then the review moves to a discussion of total institution theory and its importance for self-identity in residential organizations. Finally, the document discusses the history of older peoples' experiences in Western residential organizations, along with the implications for self-identity. Appendix A contains a glossary of theoretical terms used in this chapter and the thesis.

\section{Modernity and self-identity theory}

Modernity and self-identity theory provides a sophisticated explanation of how people construct self-identity in modernity. Giddens' theory was selected as the interpretive lens for this study because it has a number of advantages over alternative self-identity theories (Ashforth \& Mael, 1989; Erikson, 1959; Foucault, 1997; Gergen, 1991; Goffman, 1961; Tulle \& Mooney, 2002). First, Giddens' theory predicts a reflexive interaction between micro and macro phenomenon. This permits a multi-level analysis that explains how 
industries and residential organizations shape self-identity and how self-identity shapes modern organizations and industries:

Modern institutions differ from all preceding forms of social order in respect of their dynamism, the degree to which they undercut traditional habits and customs, and their global impact. However, these are not only extensional transformations: modernity radically alters the nature of day-to-day social life and affects the most personal aspects of our experience. Modernity must be understood on an institutional level; yet the transmutations introduced by modern institutions interlace in a direct way with individual life and therefore with the self. One of the distinctive features of modernity, in fact, is an increasing connection between the two extremes of extensionality and intentionality: globalising influences on the one hand and personal dispositions on the other (Giddens, 1991, p. 1).

Most self-identity theories do not have this reflexive micro-macro focus thus limiting analysis to either a micro or a macro level of analysis.

Second, Giddens' theory is useful because it considers self-identity from an historical perspective - comparing self-identity in pre-modern and modern times. This is helpful in understanding why self-identity in present day organizations may not resemble self-identity in traditional residential organizations. It also helps to explain organizational change. Many self-identity theories do not provide this historical perspective.

Third, Giddens' theory is useful because it considers the relationship between capitalism, consumerism, lifestyle and self-identity. This is useful since this study examines a new type of private sector organization, one that is a product of the consumer lifestyle industry in late modernity. Some alternative theories do not consider consumerism and lifestyles. For instance, although Goffman's total institution theory 
considers self-identity in residential organizations, it does not consider the implications of capitalism, consumerism and lifestyle on self-identity or organizations.

Fourth, Giddens' theory is useful since it considers issues of power and identity politics. It argues that self-identity is an important political issue in late modernity. This addresses a frequent criticism of organizational research - that it ignores issues of power: individualizing problems and taking an ahistorical, apolitical view of the world. Giddens' theory explains why self-identity matters, from a personal and political standpoint; why it is important to self-determination.

In addition to the many advantages that Giddens' theory has over alternative selfidentity theories, this theory helps to guard against ageism - viewing older people as dependent passive agents (Cole, 1992). Giddens' theory is premised on the idea that people are active, knowledgeable and competent, and that they shape circumstances, particularly their immediate social surroundings. Although Giddens is frequently criticized for having an overly optimistic view of the power of human agency (Adams, 2004; Jary \& Bryant, 1996; Tucker, 1998; Webb, 2004), this theory has the scope and historical breadth to explain how consumerism in late modernity influences self-identity in communal lifestyle organizations.

\subsection{Modernity}

Giddens' main argument is that modernity (the industrialized world), and in particular late modernity (the late twenty-first century), changes the way people construct self- 
identity. In pre-modern times people relied on tradition, kinship and religion to answer the question: Who am I? Modernity eliminates traditional answers, and since modernity is in constant flux, self-identity requires constant revision.

Modernity differs from pre-modern or pre-Enlightenment times in terms of its "scope" (world wide impact), "dynamism" (power) and the ability to deeply affect social relations (organizations and self-identity, Giddens, 1991, pp. 15-16). Giddens attributes this to the forces of modernity: the separation of time from space; disembeddedness (the separation of social relations from local space); and institutional reflexivity (the changing nature of modern institutions like capitalism, institutional surveillance, and the military).

In pre-modern times people's understanding of time differed from our modern understanding of time. One looked at the stars, the sun, or physical markers to determine time at a particular location. Space and time were co-located. During the industrial revolution time was universalized and standardized; time was separated from space. A new understanding of time evolved with the invention of mechanical clocks, calendars, maps and standardized time zones. Now one can look at a clock in New York and know the time in Edinburgh, Toronto or Delhi.

Similarly in pre-modern times, social relations were embedded in local space. In modern times, although people still live in a local space, their experience of the world is different because disembeddedness "lifts social relations from local contexts and recombines them across infinite time/space distances" (Giddens, 1991, p. 244). This disembeddedness is due to the rise of abstract systems. 
Giddens explains that there are two types of abstract systems: symbolic tokens (e.g., money), and expert systems (e.g., medicine, engineering, management sciences). Symbolic tokens are "media of exchange that have standard value and are thus interchangeable across an indefinite variety of contexts" (Giddens, 1991, p. 244). Money permits long distance financial transactions, separating buyers and sellers. Similarly, expert systems separate knowledge from local context and persons possessing expertise. Expert knowledge stands on its own. It is not a mystery or art passed down through generations, as in pre-modern times. Expertise can be acquired by anyone given time, resources and intelligence.

An important characteristic of abstract systems is that they are internally referential. This means decisions in abstract systems are guided by intrinsic criteria that are internal and perhaps unique to a system of thought, like risk calculation or control, rather than extrinsic criteria like tradition, and moral or existential issues. In late modernity, internal referentiality profoundly affects our approach to the social and natural world. Expert systems extend human control over all aspects of life, without consideration of the moral or existential implications:

There has taken place a marked acceleration and deepening of human control of nature, directly involved with the globalisation of social and economic activity. The 'end of nature' means that the natural world has become in large part a 'created environment', consisting of humanly structured systems whose motive, power and dynamics derive from socially organised knowledge-claims rather than from influences exogenous to human activity (Giddens, 1991, p. 144). 
In modernity, the separation of space, time and social relations plus the influence of abstract systems reduces tradition's influence and increases thoroughgoing reflexivity, which affects self-identity. Scientific progress creates radical doubt rather than certainty, and all knowledge is contested in modern times (Giddens, 1991, pp. 2-3). At the level of the self there are two types of reflexivity: innate and thoroughgoing reflexivity. The first has always existed; people observe and change their actions as they learn new information. The second type - thoroughgoing reflexivity - is unique to modernity. People must constantly revise their social activities and relationship with nature in response to new information and knowledge, especially scientific knowledge.

One might point to the importance of religion as evidence that tradition still exists in the West. Giddens argues that the difference today is that people know their religious beliefs are one among many possible beliefs, whereas in pre-modern times choice was rarely possible. In late modernity people try to renew traditions because they are discontented with the moral vacuity of internally referential abstract systems:

Today, we see a definite tendency to seek to re-establish vanished traditions or even construct new ones ... [the] return to sources of moral fixity in day-to-day life, in contrast to the 'always revisable' outlook of modern progressivism, is a phenomenon of some importance. Rather than constituting a regression towards a Romantic refusal of modernity, it may mark an incipient move beyond a world dominated by internally referential systems (Giddens, 1991, pp. 206-207). The forces of modernity (the separation of time, space, and social relations plus reflexivity) create conditions unlike previous eras. They profoundly affect organizations and self-identity (Giddens, 1991). Tradition has little impact. Consequently, modern 
social conditions are discontinuous with previous eras. They no longer follow an evolutionary model of social change (Giddens, 1991, p. 16; Tucker, 1998). As a result, the what if nature of modernity, makes change difficult to predict. One can no longer determine future outcomes or self-identities, based on tradition.

As the forces of modernity can empower individuals by freeing them from tradition, these forces can also limit agency, or the ability to act and to influence. Although Giddens emphasizes agency, he acknowledges that there are two factors that limit agency in modernity: the dislocation of time and space from local relations and abstract systems' “deskilling effects” (Giddens, 1991, pp. 22, 137-8, 192). Globalization of the world's financial systems is an example of the dislocation of time and space from the local. The 2008 financial crisis demonstrated that one cannot "opt out" of this system, nor can one necessarily influence this system (Giddens, 1991, p. 22). Abstract systems' deskilling effects can also limit agency. Since there are so many, people can only have expertise in a few of these abstract systems. As a result, people's sphere of control, even if they are experts, is limited.

Although Giddens acknowledges that these two factors can limit agency, he emphasizes possibilities for reappropriation of agency in modernity. In the case of the global financial system, he argues that although people have no direct control over this system, it provides new opportunities for wealth generation (Giddens, 1991, p. 193). We cannot say that all forms of expropriation necessarily provide the possibility of reappropriation, certainly on the level of individual conduct. Many of the processes transformed by disembedding, or reorganised in the light of the intrusion of abstract systems, move beyond the purview of the situated actor. On 
the other hand, others make possible forms of mastery over life circumstances unavailable in pre-modern situations (Giddens, 1991, p. 192).

In sum, Giddens argues there is a complex relationship between the expropriation and reappropriation of agency in modernity: "Powerlessness and reappropriation intertwine variously in different contexts and at varying times" (Giddens, 1991, p. 192). This has implications for self-identity. The forces of modernity do not determine selfidentity, as was the case in pre-modern times. Instead, people constantly revise selfidentity in light of new information.

\subsection{Self-identity and the reflexive project of the self}

This raises the question: What is self-identity? Popular theory sees it as a person's essence or soul - their true self (Czarniarskwa, 1998, p. 43). This view tends to separate the notion of "self" from "identity". Functionalist theory defines it as a person's traits or social role (Ashforth \& Mael, 1989). Postmodern theory argues that there is no enduring sense of self, it is continually fractured by the social forces of late modernity (Gergen, 1991). Giddens' theory has a number of advantages over popular, functionalist and postmodern views. It explains personality changes, something that is not considered in popular theories that see the self as unchanging. It is more complex than a person's traits or social role, as the following discussion will illustrate. Finally, Giddens' definition of self-identity considers agency, which is de-emphasized in postmodern theory.

Giddens defines self-identity as a person's story - a coherent reflexive biography. Self-identity is: 
... the self as reflexively understood by the individual in terms of his or her biography. Identity here still presumes continuity across time and space; but selfidentity is such continuity as interpreted reflexively by the agent (Giddens, 1991, p. 53).

This definition of self-identity assumes self-consciousness. To construct selfidentity the self must be conscious of itself. Giddens argues that this self-consciousness consists of three elements: discursive consciousness, practical consciousness, and the unconscious. Discursive conscious consists of "the conscious reasons that people give to explain their behaviors and motivations" (Tucker, 1998, p. 81). Practical consciousness consists of the "unarticulated beliefs and knowledges people use to orient themselves to situations and interpret the actions of others" (Tucker, 1998, p. 81). The unconscious consists of "that which cannot easily be put into words and resides beneath our conscious existence" (Tucker, 1998, p. 81). People convey self-identity through discursive consciousness or autobiographical "story telling." Practical consciousness also informs self-identity by providing tacit information that motivates behavior, which is critical to reflexivity, monitoring behaviour, and reconstructing self-identity (Giddens, 1991, pp. 35-6). The unconscious is tied to memory (Tucker, 1998, p. 81; Giddens, 1991, pp. 3536).

In addition to assuming consciousness, constructing self-identity assumes reflexivity. Reflexivity refers to a continuous reciprocal relationship between an individual's interpretation of social life, the effect of the interpretation on the person's biography, and the effects that changes in self-identity have on social life. People are conscious of life. They interpret and integrate new information. They change their self- 
identity, which in turn changes social life, which brings about further changes in people's self-identities ... and so on and so on.

Giddens' definition of self-identity presumes a continuous coherent narrative of the self. To maintain ontological security, people create "logical, understandable, and consistent" life stories. Discontinuity points to an ontologically insecure person. Being ontologically secure is to: "possess, on the level of the unconscious and practical consciousness, answers to fundamental existential questions which all human life in some way addresses" (Giddens, 1991, p. 47). Answers to these questions form the "unarticulated beliefs and knowledges" of practical consciousness, which is the “cognitive and emotive anchor" (Giddens, 1991, p. 36) of ontological security. Being ontologically secure allows one to go on, or to function in social life, without fear of chaotic reality:

On the other side of what might appear to be quite trivial aspects of day-to-day action and discourse, chaos lurks. And this chaos is not just disorganisation, but the loss of a sense of the very reality of things and of other persons. Garfinkel's 'experiments' with ordinary language connect very closely here with philosophical reflection about the elemental characteristics of human existence. To answer even the simplest everyday query, or respond to the most cursory remark, demands the bracketing of a potentially infinite range of possiblities open to the individual. What makes a given response 'appropriate' or 'acceptable' necessitates a shared - but unproven and unprovable - framework of reality. A sense of the shared reality of people and things is simultaneously sturdy and fragile.

As ontological security is important to self-identity, so too is control over the body. A sense of self-identity depends on "the persistence of feelings of personhood in a 
continuous self and body" (Giddens, 1991, p. 55). As children, people learn how to keep "close, complete and continuous" control over the body (Giddens, 1991, p. 56). This is necessary to feel ontologically secure and to appear to be a normal adult. The need for bodily control is not unique to modern times: "bodily discipline is intrinsic to the competent social agent; it is transcultural rather than specifically connected with modernity" (Giddens, 1991, p. 57).

There are two areas of control or discipline over the body: the daily routine of "going on," which is governed by practical consciousness; and regimes, which consist of organic needs such as eating, sleeping and bathing. Regimes require self-discipline and "tight control" of the body. Regimes can range from deprivation to indulgence. Regimes are dictated by social conventions, taste and habit (Giddens, 1991, p. 62).

Bodily appearance (dress) and bodily demeanor (appropriate bodily behaviour and dress) are related to routines and regimes. Both play a role in constructing selfidentity. In pre-modern times social identity determined appearance whereas in modern times personal identity determines appearance, although social convention, class and advertising are influential. We expect people to adjust body appearance, to dress and act appropriately for the social setting (e.g., the opera or the golf course), while maintaining a constant coherent style that fits their personal narrative, such as dressing for their social class. As with routines and regimes, loss of control over appearance and demeanor disrupt ontological security and raise questions about one's competence.

The need to feel comfortable and in control of one's body and appearance has not changed since pre-modern times. What has changed in modern times is that self-identity 
becomes an ongoing task. In pre-modern times, tradition defined a person's identity, and tradition was stable and unchanging, hence identity changed little. In modern times, abstract systems replace tradition as authoritative guideposts and produce conflicting information that creates modernity's thoroughgoing reflexivity. This thoroughgoing reflexivity produces the reflexive project of the self:

... the sustaining of coherent, yet continuously revised, biographical narratives, [which] takes place in the context of multiple choice as filtered through abstract systems (Giddens, 1991, p. 5) . . The reflexive project of the self: [is] the process whereby self-identity is constituted by the reflexive ordering of self-narratives (p. 244).

Giddens (1991) argues that the body in modernity is not a passive vessel, as Foucault suggests. Instead, it is an action system that is part of the reflexive project of the self (Giddens, 1991). For example, the pressure to control aging - to create an ageless body - is strong in the West. This requires reflexive control over the body and the mind: diet, activity, and stress levels. Abstract systems, such as medicine, urge people to control their bodies. This information, which is popularized by the media and self-help books, is continually revised and updated.

In addition to tailoring the body, lifestyle is key to the reflexive project of the self in late modernity. Lifestyle refers to a routine style of life:

... a more or less integrated set of practices which an individual embraces, not only because such practices fulfill utilitarian needs, but because they give material form to a particular narrative of self-identity . . . Lifestyles are routinised practices, the routines incorporated into habits of dress, eating, modes of acting and favoured milieux for encountering others; but the routines followed are 
reflexively open to change in the light of the mobile nature of self-identity (Giddens, 1991, p. 81).

Giddens distinguishes lifestyle from the popular advertising definition: consumption patterns of the affluent. Lifestyle, in Giddens' sense, applies to the poor or to the affluent. Both adopt lifestyles. In contrast to pre-modern times when there was little choice, modernity produces variety. One must make choices. One has no choice but to make a lifestyle choice. Choices, however, may be limited by a number of factors including personal wealth, geographic location and commodity standardization.

Disparities in power also limit lifestyle choice: "emancipation from situations of oppression is the necessary means of expanding the scope of some sorts of lifestyle option[s] ..." (Giddens, 1991, p. 86). This is particularly relevant for groups experiencing discrimination. In modernity, lifestyle choice and life chances operate reflexively. As life chances (the resources at one's disposal) determine lifestyle choices, so lifestyle choices determine life chances: "In late modernity, access to means of selfactualisation becomes itself one of the dominant focuses of class division and the distribution of inequalities more generally" (Giddens, 1991, p. 228). An example, is access to medical care. Although both the well-to-do and the poor have access to Canada's health care system, the well-to-do can afford to purchase unsubsidized goods and services. This can result in better life chances for the wealthy.

As modernity produces diverse lifestyles, it also produces diverse lifestyle sectors defined as: "a time/space slice of an individual's overall activities, within which a fairly consistent set of social practices is followed" (Giddens, 1991, p. 243). This contrasts with 
pre-modern times, when lifestyle sectors were fairly homogenous, limited and closely connected. Whole families might live in the same home for generations and travel little. Today, this is rare, and serves as an example of how social relations are disembedded from space in modern times. Lifestyle sectors are more varied, and people can travel great distances from one lifestyle sector to another - Canadian Snowbirds are an example.

As lifestyle reflects self-identity, so does the lifespan. Giddens argues that the concept of the life cycle, which is often used in functionalist theories of aging, is no longer valid in late modernity. Life cycle theory views the life span as a cycle promising renewal, with each generation following the next. Each generation has a role with respect to previous generations (Erikson, 1959). Giddens argues that as tradition loses hold, the life cycle and generational renewal become inappropriate. Rather than being "cyclic," with each generation walking in the steps of their ancestors, the life span becomes an internally referential "trajectory" (Giddens, 1991, p. 147).

In modernity, the life span is dislocated from time, space, and tradition. It becomes part of the reflexive project of the self and is thus affected by lifestyle choices. We reflexively create our lives based on internally referential criteria: "we are not what we are, but what we make of ourselves" (Giddens, 1991, p. 75). In late modernity, traditional functional identities like elder, grandfather and widower make room for new identities like Snowbird, world traveler and volunteer.

Consequently, in modernity, people plan their lives. This includes a search for self-development and authenticity, which is characteristic of the modern reflexive project 
of the self. Rather than passing through rites of passage as in pre-modern times, the modern self passes through stages, or the trajectory of the self. Each stage produces an identity crisis. Self-development being internally referential, people rely on personal beliefs, rather than tradition, to guide conduct. "Their first loyalty is to themselves" (Giddens, 1991, p. 80). Self-development in modernity can be a morally stunted process when people succumb to consumerism or repress existential issues, such as death and dying. Self-development in modernity can also offer unique opportunities for mastery, due the absence of strictures like custom and tradition (Tucker, 1998, p. 205; Giddens, 1991, pp. 9-10).

As people plan self-development, they plan lifestyle options. Life-planning is: "the strategic adoption of lifestyle options, organised in terms of the individual's projected lifespan, and normally focused through the notion of risk" (Giddens, 1991, p. 243). Life-planning stabilizes the immediate future and reduces risk. This is particularly salient in older people's housing choices, where people assess the risks of needing care.

The disruption of people's life plans can produce psychological crisis. Disruptions in preferred lifestyles can produce psychological discomfort, distress and existential anxiety - although, some people may carry on as if nothing has happened. Giddens calls these disruptions fateful moments or times of consequential change: ... the individual is likely to recognise that she is faced with an altered set of risks and possibilities. In such circumstances, she is called on to question routinised habits of relevant kinds, even sometimes those most closely integrated with self-identity (Giddens, 1991, p. 131). 
Fateful moments illustrate the fragility of self-identity in modernity. For older people, fateful moments can include death of a spouse, a decline in financial resources and health, and moving from one's home to a residential organization.

\subsection{Institutions, organizations and sequestration}

This section describes Giddens' theories on institutions, organizations and sequestration. It explores the ways capitalism, consumerism, institutional surveillance and organizational sequestration reach into the very heart of people's lives, thereby affecting self-identity.

The notion of reflexivity is key to this discussion. Giddens argues that institutions and organizations are reflexive structuring processes "which exist only in actual social practices" [emphasis mine] (Tucker, 1998, p. 84). People create these structuring processes, which exist in a particular form, only so long as people repeat these social practices. Institutions and organizations are shaped by, and shape, individual behaviour, rather than being deterministic (Tucker, 1998). This differs from functionalism, which describes organizations as stable bounded entities, as things separate from people, social contexts and social practices (Baum \& Rowley, 2002). Giddens argues that functionalism reifies structuring processes, transforming ideas into material things and creating a false dichotomy between human agency (i.e., the ability to act) and structure (Tucker, 1998).

Giddens' point is that agency and structure are reflexive, and in modernity, institutions and organizations become thoroughly reflexive. Abstract systems and the 
separation of space, time and social relations erode tradition. This produces thoroughgoing reflexivity or institutional reflexivity, which is "the routine incorporation of new knowledge or information into environments of action that are thereby reconstituted or reorganised" (Giddens, 1991, p. 243). The notion of institutional reflexivity combined with the notion of internally referential abstract systems, explains the likelihood of discontinuous change, rather than evolutionary change, in the institutions and organizations of late modernity.

Given the importance of reflexivity to modern institutions and organizations, the term institutions of modernity does not refer to an organizational form, such as a hospital, but rather to the four structuring processes of modernity: industrialism, industrialization of war, capitalism, and institutional surveillance. Industrialism refers to "material power and machinery in production processes" (Giddens, 1991, p. 15). Industrialization of war refers to "control of the means of violence" (Giddens, 1991, p. 15). Capitalism refers to "a system of commodity production involving both competitive product markets and the commodification of labour power" (Giddens, 1991, p. 15). Institutional surveillance refers to "the supervisory control of subject populations, whether this supervision is visible in Foucault's sense, or invisible, as in the use of information to coordinate social activities" (Giddens, 1991, p. 15). Of the four institutions of modernity, capitalism and institutional surveillance are the most relevant to this study.

In modernity, capitalism helps shape self-identity and self-actualization. An indicator is the way capitalism defines individual rights and freedoms as consumer choice. "Market-governed freedom of individual choice becomes an enveloping 
framework of individual self-expression" (Giddens, 1991, p. 197). This relationship between self-expression and consumption, is evident in late modernity where commodification and consumption are key to capitalist expansion and to continued economic growth. Many areas of social reproduction (e.g., housekeeping, food preparation, personal care, security) become commodities, sweeping aside tradition and existing social relations. Money, as a symbolic system, uncouples use value from a commodity's exchange value and social relations. In late modernity, commodities are increasingly standardized, mass produced and repackaged, but in sufficient quantity and variety that people can individualize consumption, creating personalized lifestyles.

Being internally referential, capitalism promotes internal criteria such as "appearance," "novelty" and "success," which to the avid consumer, have more value than the product's use value (e.g., the designer purse). Advertising shapes consumer preferences for the lifestyles of the affluent - people considered successful. This is done through standard forms of advertising, as well as media stories, and infomercials. These advertising stories are designed to help people coherently integrate new products and lifestyles into their own narratives of the self (Escalas, 2004).

Giddens does not, however, go so far as to argue that capitalism "determines" self-identity and self-actualization, due to his views on agency (i.e., people are creative, knowledgeable and powerful): "The reflexive project of the self is in some part necessarily a struggle against commodified influences, although not all aspects of commodification are inimical to it (Giddens, 1991, p. 200). 
In addition to capitalism, institutional surveillance is relevant to the study of selfidentity in residential organizations for older people. Consisting of visible or invisible "supervisory control of subject populations," or "the use of information to coordinate social activities," institutional surveillance is central to modern organization (Giddens, 1991, p. 15):

What distinguishes modern organisations is not so much their size, or their bureaucratic character, as the concentrated reflexive monitoring they both permit and entail. Who says modernity says not just organisations, but organisation - the regularised control of social relations across indefinite time-space distances (Giddens, 1991, p. 16).

As space and social relations are dislocated from one another, and global capitalism influences local organizations, organizational control can be exercised over vast distances, populations and industries, such as in the case of multinational corporations.

Organizational sequestration is an example of how modern organizations control social relations. Many things considered outside human control in pre-modern times, are socially controlled in modern times. Sickness and death were endemic and considered God's will in pre-modern times, however, by the early eighteenth century being old, sick, disabled, insane or a criminal was considered a moral problem needing social control, and organizational sequestration become the solution. The purpose of organizational sequestration is to create ontological security:

Broadly speaking, my argument will be that the ontological security which modernity has purchased, on the level of day-to-day routines, depends on an institutional exclusion of social life from fundamental existential issues which raise central moral dilemmas for human beings (Giddens, 1991, p. 156). 
In addition to physically separating these people from society, organizational sequestration is often accompanied by institutional surveillance. As a result, control and surveillance practices in sequestered organizations, such as routines, supervision, and treatment, support reflexive self-control. They are a means to "reform" or "cure" the sequestered individual (Giddens, 1991, p. 159-60). Consequently, "they [the frontiers of sequestered experience] are battlegrounds, sometimes of a directly social character, but often within the psychological field of the self" (Giddens, 1991, pp. 167-168).

In addition to affecting the reflexive project of the self, organizational sequestration affects social relations between people: family, friendship and marriage relationships. Giddens argues that relationships are important to the construction of selfidentity: "self-identity is negotiated through linked processes of self-exploration and the development of intimacy with the other" (Giddens, 1991, p. 97). Giddens describes two types of social relationships in modern times: the traditional, and the modern or pure relationship. Traditional relationships, like parent-child relationships, are based on external criteria like kinship and duty. They tend to endure no matter what the circumstances. In contrast, modern or pure relationships consist of "a social relation which is internally referential, that is, depends fundamentally on satisfactions or rewards generic to that relation itself" (Giddens, 1991, p. 244). Pure relationships are based on internally referential criteria such as romantic love, choice, freedom, commitment, and reflexivity. These relationships are "good until further notice" (Giddens, 1991, p. 187). In modernity, pure relationships are part of the reflexive project of the self: 
... The pure relationship is a key environment for building the reflexive project of the self, since it both allows for and demands organised and continuous selfunderstanding - the means of securing a durable tie to the other (Giddens, 1991, p. 186).

Organizational sequestration may disrupt or encourage traditional and pure relationships. Since sequestration is designed to conceal ontologically disturbing issues from society, it tends to disrupt relationships between those living inside and outside segregated organizations. Organizational sequestration may also encourage relationships, especially pure relationships, as people are in frequent contact with one another when living in an organization. Giddens identifies five factors that promote the creation and maintenance of pure relationships: reciprocity, common lifestyles, privacy, mutual trust and shared histories. To the extent these factors exist in a sequestered organization, pure relationships may flourish.

Organizational sequestration may also have political implications. Giddens (1991) notes that although society's less powerful tend to be subjected to sequestration, organizational sequestration does not necessarily result in a loss of power:

The site of oppression, its exclusionary characteristics normally carry connotations of hierarchical differentiation and inequality. The frontiers of sequestered experience are faultlines, full of tensions, and poorly mastered forces; or to shift the metaphor, they are battlegrounds. . (Giddens, 1991, p. 168) . . . it would be wrong to understand the sequestration of experience as all-enveloping and homogeneous, which it is not. It is internally complicated, throws up contradictions, and also generates possibilities of reappropriation (p. 167).

This suggests that although organizational sequestration may expropriate power, it may also create opportunities to reappropriate power and revise self-identity. 


\subsection{Emancipatory and life politics}

Giddens provides a way of thinking about personal power and the politics of self-identity in residential organizations. Giddens defines personal power as "ability" - the ability to get things done, and the ability to achieve one's wishes, even against the desires of others (Tucker, 1998 p. 82). Powerlessness refers to the inability to achieve one's wishes: "The experience of powerlessness, considered as a psychic phenomenon, naturally always relates to aims, projects or aspirations held by the individual, as well as to the composition of the phenomenal world" (Giddens, 1991, p. 193). For an older person, being able to live or move where one wishes, being able to get the goods and services one needs, and having control over self-identity is an expression of power.

Giddens suggests power in personal relationships may be more important to people than social power: "Powerlessness experienced in a personal relationship may be psychologically more damaging and consequential than powerlessness felt in relation to more encompassing social systems. Of course these may feed into each other in various ways" (Giddens, 1991, p. 193). This highlights the importance of relationships with family, friends and service providers for older people's self-determination and happiness.

Giddens describes two ways of thinking about power and the politics of selfidentity in modern times: emancipatory politics and life politics. Emancipatory politics comes from traditional radical, liberal and conservative theory on how to "release underprivileged groups from their unhappy condition, or to eliminate the relative differences between them" (Giddens, 1991, p. 211). Emancipatory politics assumes power is hierarchical. One group or individual dominates others. 
Giddens argues that Western governments, especially the welfare state, are motivated by emancipatory politics and have not grappled with the implications of life politics, which attempts to "move beyond a world dominated by internally referential systems" (Giddens, 1991, pp. 206-207). Emerging in late modernity, life politics addresses moral and existential issues previously excluded from political debate: issues such as globalization, environmental degradation, the threat of nuclear catastrophe and identity issues (e.g., feminism, gay rights). Life politics is about personal decisions having moral or existential overtones: "It is a politics of self-actualisation in a reflexively ordered environment, where the reflexivity links self and body to systems of global scope" (Giddens, 1991, p. 214). Life politics assumes that power is generative, reflexive and transformative rather than hierarchical and causal, as in emancipatory politics. Life politics can produce thorough dramatic change. To exist, life politics requires emancipation - basic social, political and economic emancipation - however, emancipation does not necessarily lead to life politics. Table 2.1 summarizes and contrasts emancipatory politics and life politics.

Emancipatory and life politics are relevant to older people living in residential organizations. Emancipatory politics argues that older people have rights that should be respected. For example, they should not be subject to abuse. Life politics points to the potential power of organizations and industries to control self-identity, life chances and self-actualization. Life politics argues that older people should have the opportunity and freedom to form a self-identity of their own choosing. Life politics argues that older 
people should have lifestyle choices - choices that permit and promote self-actualization.

Table 2.1. Differences between emancipatory and life politics

\begin{tabular}{|c|c|}
\hline Emancipatory politics & Life politics \\
\hline $\begin{array}{l}\text { 1. The freeing of social life from the } \\
\text { fixities of tradition and custom. }\end{array}$ & $\begin{array}{l}\text { 1. Political decisions flowing from } \\
\text { freedom of choice and generative power } \\
\text { (power as transformative capacity). }\end{array}$ \\
\hline $\begin{array}{l}\text { 2. The reduction or elimination of } \\
\text { exploitation, inequality or oppression. } \\
\text { Concerned with the divisive } \\
\text { distribution of power/resources. }\end{array}$ & $\begin{array}{l}\text { 2. The creation of morally justifiable } \\
\text { forms of life that will promote self- } \\
\text { actualisation in the context of global } \\
\text { interdependence. }\end{array}$ \\
\hline $\begin{array}{l}\text { 3. Obeys imperatives suggested by the } \\
\text { ethics of justice, equality and } \\
\text { participation. }\end{array}$ & $\begin{array}{l}\text { 3. Develops ethics concerning the issue } \\
\text { "how should we live" in a post- } \\
\text { traditional order and against the } \\
\text { backdrop of existential questions. }\end{array}$ \\
\hline
\end{tabular}

Note. Based on Giddens (1991, p. 215).

To summarize, modernity and self-identity theory has a number of strengths that make it a good choice for this study. While emphasizing the power of structure to influence agency, the theory also considers the ways that agency shapes structure. This approach gives the theory broad applicability and permits the type of multi-level analysis that is necessary for this study. As well, the theory takes an historical perspective. It explains the historical forces that shape and support the continued existence of 
sequestered organizations while discussing modernity's potential to produce discontinuous transformative changes in organizations and the self. As well, the theory discusses the notion of lifestyle, including its commercial ramifications, a notion that is essential for understanding communal lifestyle organizations and new self-identities for older persons.

\section{Total institution theory}

Whereas Giddens' self-identity and modernity theory provides a useful base for understanding self-identity in general, Goffman's (1961) total institution theory highlights the way a specific type of organizational sequestration - the prison-like total institution - which disrupts the reflexive project of the self. As the antithesis of communal lifestyle organizations like Lakelands Retirement Resort, the total institution is a heuristically useful contrasting case.

Goffman's notion of organization is based on ethnomethodology (Garfinkel, 1967), which argues that social reality is not a given. People work hard to construct shared collective views of society. This view is shared by Giddens who argues that "the orderliness of day-to-day life" is constructed from daily routines (Giddens, 1991, p. 52).

For Goffman, organization is not a singular static reality. It is a multitude of simultaneously existing realities in constant flux: realities that can disappear. Goffman links social and organizational practices to social identity. Similar to Giddens' argument 
that disrupted life plans create psychological crisis and disrupt self-identity, Goffman describes how changes in social practices can shatter self-identity:

... the new inpatient finds himself cleanly stripped of many of his accustomed affirmations, satisfactions, and defenses, and is subjected to a rather full set of mortifying experiences; restriction of free movement, communal living, diffuse authority of a whole echelon of people [staff], and so on. Here one begins to learn about the limited extent to which a conception of oneself can be sustained when the usual setting of supports for it are suddenly removed (Goffman, 1961, p. 148). In ethnomethodology, taken for granted day-to-day organizational routines and social conventions create reality. They help control and shape organization members' identities. Goffman shares Giddens' view of a reflexive relationship between human agency and structuring forces such as organizing. To the extent that routines are repeated by agents (staff and patients), a seemingly solid organization emerges as well as a solid identity. If breaks occur, structures and self-identities change. This perspective explains why Goffman's theory of total institutions is based on lengthy field work as well as a wealth of literature describing life in organizations such as monasteries, ships and concentration camps. This field work was necessary to document day-to-day life and to demonstrate how certain types of change disrupt the self (Tucker, 1998).

Goffman's year long observational study of a United States mental asylum illustrates what can happen when traditional boundaries between work, organization and home disappear - when people find themselves living in a residential organization where management and staff exercise rigid control over every aspect of life, including bodily regimes (e.g., food, washing) and appearance. In this extreme case, an organization strips 
adults of "self-determination, autonomy and freedom of action" (Goffman, 1961, p. 43). People are deprived of even the smallest pleasures, and "indulgences" are doled out as a way of controlling or rewarding appropriate behaviour. Living conditions are “stigmatizing" (Goffman, 1963); people's self-identities are often irrevocably "contaminated," "stigmatized or "marked" by the experience (e.g., a criminal record). These depriving and stigmatizing conditions can disrupt personal security, produce psychological crisis and have disastrous consequences for self-identity.

Goffman describes the characteristics of total institutions that produce these repressive living conditions:

First all aspects of life are conducted in the same place and under the same single authority. Second, each phase of the member's daily activity is carried on in the immediate company of a large batch of others, all of whom are treated alike and required to do the same thing. Third, all phases of the day's activities are tightly scheduled, with one activity leading at a prearranged time into the next, the whole sequence of activities being imposed from above by a system of explicitly formal rulings and a body of officials. Finally, the various enforced activities are brought together in a single rational plan purportedly designed to fulfill the official aims of the institution ... The handling of many human needs by the bureaucratic organization of whole blocks of people - whether or not this is necessary or an effective means of social organization in the circumstances - is the key fact of total institutions (Goffman, 1961, p. 6).

Many organizations possess characteristics of total institutions, but this does not make them total institutions (Goffman, 1961). When people are free to participate or not in organizational activities, when organizations do not exercise authority over people's free will, then they are not total institutions. 
Lack of freedom and an antagonistic relationship between staff and inmates are two characteristics of total institutions. Inmates are not told, or consulted about "decisions affecting their fate" (Goffman, 1961, p. 9). The objective of total institution staff is surveillance and control: to ensure inmates do as they are told. Because every inmate is supposed to be doing the same thing, those who do not conform stand out. Reflexive self-control is the objective. Staff have authority and control over the minutia of everyday life, including an inmate's bodily regimes: from asking permission to go to the bathroom, to eating, to the clothes an inmate may wear. Every staff member, no matter what their organizational level, has the authority to discipline an inmate. This provides little freedom from the organization's "gaze" (Foucault, 1975). Staff and inmates view each other with suspicion thereby creating two separate, antagonistic organizational cultures.

Goffman identifies three time periods or phases in a mental patient's life: the preentry meeting(s), entry into the organization, and the adaptation phase. Each phase has implications for self-identity. The pre-entry phase is unique to total institutions where entry is voluntary, such as hospitals. It would not apply to prisons where entry is involuntary. It is at the pre-entry meeting between the patient and mental hospital administrators that patients come to believe that they have been betrayed by family and friends. When organizations treat relations and friends as surrogate decision-makers without patients' consent, they undermine patient competency, autonomy, and the mutual trust necessary for pure relationships. This in turn disrupts patient self-identity. 
The second stage - entering the organization - is common to all total institutions. It is marked by stripping self-identity. The objective is to disrupt a person's sense of ontological security; to take control. To strip identity the organization uses strategies that target bodily regimes, possessions, relationships and space. This includes stripping off clothing in humiliating initiation rituals, obliging inmates to wear organizational dress, confiscating personal possessions, forbidding or limiting contacts with former friends and family, creating fear, repeating physical or social indignities, forcing people to adopt discordant social roles or actions, shaming, mixing people who would normally avoid each other, and invading personal space (Goffman, 1961).

Entry activities target the person's self-image producing a disconnect between their previous social standing and self-identity experienced outside the organization and the new, usually drastically reduced and stigmatized social standing, inside the organization. Goffman contends people put a great deal of effort into creating selfidentity. In essence, people perform identity. This notion is similar to Giddens' idea that people use appearance, bodily demeanor, lifestyles and lifestyle sectors to define selfidentity. As Tucker (1998) states in referring to Goffman's theories:

Our sense of self is a product of the public roles that we play, not a cause of them. Though we impute our sense of self to an unchanging core personality, it is in reality a dramatic effect (p. 77).

This point distinguishes Goffman and Giddens' views from functionalist selfidentity theory. Identity is not a given, or a social role, it is constructed and reconstructed. In total institutions, being consigned to a meager physical space with little control over relations, routines, and bodily regimes, strips a person of their self-identity, previous 
social status and self-perception of being an autonomous adult. Inmates find themselves at the bottom of the social ladder with little to no possibility of altering the situation.

Whereas this second stage represents a loss of identity and status for the inmate, in the third or adaptation phase the inmate adopts behaviours conforming to and undermining organizational conventions. Goffman describes in great detail the ways inmates get around the organization's plans and assumptions about what an organizational member "should do, what he should get, and who he should be" (Goffman, 1961, p. 173). Examples include; physically escaping, mentally escaping by becoming mute, refusing to participate in activities, frequenting physical locations having little to no supervision (free spaces), mocking guards, adopting a detached aloof attitude, and engaging in sexual activities or other activities that are not permitted.

Total institutions anticipate and defuse indirect protest in a number of ways. Prisons often encourage inmate newspapers where humour and mild disrespect are tolerated. Direct protest meets with punishment. Mental hospitals interpret patient protest as symptomatic of their illness, which in turn rationalizes medical treatment such as shock therapy, being put in solitary confinement, or being downgraded to a worse ward.

Protest signals an inmate's refusal to adapt to an organizational self-identity. Even taken for granted aspects of organizational life, such as decisions about whether or not to comply with minor activities, help define an inmate's self-identity. By participating, either willingly or unwillingly in organizational life, an inmate accepts or rejects the identity the organization has chosen for its members: 
I am interested in the fact that expected activity in the organization implies a conception of the actor and that an organization can therefore be viewed as a place for generating assumptions about identity ... To forego prescribed activities, or to engage in them in unprescribed ways or for unprescribed purposes, is to withdraw from the official self and the world officially available to it. To prescribe activity is to prescribe a world; to dodge a prescription can be to dodge an identity (Goffman, 1961, pp. 186-187).

In addition to the ways people adapt to their organizational identity (e.g., cooperative or difficult mental patient), Goffman discusses service, and in particular medical services received by patients. He observes: "Mental patients can find themselves crushed by a service ideal that eases life for the rest of us" (Goffman, 1961, p. 368). Goffman argues that mental hospitals are not delivering a medical service, they are delivering a punishing custodial regime, which perversely, uses medical service ideals to rationalize institutional surveillance and force people to exercise increasing levels of reflexive self-control:

The more "medical" and the more progressive a mental hospital is - the more it attempts to be therapeutic and not merely custodial - the more he [the patient] may be confronted by high-ranking staff arguing that his past has been a failure, that the cause of this has been within himself, that his attitude to life is wrong, and that if he wants to be a person he will have to change his way of dealing with people and his conceptions of himself. Often the moral value of these verbal assaults will be brought home to him by requiring him to practice taking this psychiatric view of himself in arranged confessional periods, whether in private sessions or group psychotherapy (Goffman, 1961, p. 150).

Although a mental hospital's official objective is curing psychiatric illnesses, Goffman finds patients receive little treatment. Instead, they experience a behaviourially based 
system of rewards and punishments meant to control their disturbing presence $-\mathbf{a}$ system that strips self-identity, humiliates and produces fear and anxiety.

Total institutions serve society by sequestering morally troubling issues like insanity, disease and death. People in total institutions are usually not free to come and go, or accept or reject services. Their body and self-identity are captive. This is the antithesis of customer service - the idea that customers come first, that organizations exist to serve customers, and that satisfied customers are key to organizational survival. This is also the antithesis of consumerism which encourages people to live their dreams and enhance pleasure, self-image and status.

Goffman's theory describes the extreme case of institutional surveillance, organizational control and sequestration (Clegg, 2006). It raises moral and ethical questions about the right to preserve one's self-identity and to exercise self-determination while living in an organization. Whereas democracy influences Western political organization's conduct, most public and private sector organizations, including residential organizations, remain untouched by democracy. As an internally referential system of thought, the management sciences consider internal criteria such as profits to be important but may exclude external moral criteria like freedom from organizational control. Given the absence of a democratic tradition in Western residential organizations, the question 'Who does the organization want me to be"' (Alvesson \& Willmott, 2002), is a salient issue for management debate. As Clegg (2006) notes, the management literature ignores Goffman (1961), Foucault (1975) and Bauman's (1989a,b) research on total institutions and disciplinary mechanisms. Only a few recent articles examine total 
institutions (Schenkar, 1996), or domiciliary organizations where workers live and work (Ngai, 1999, 2007; Hershatter, 1986; Smith, 2003).

Goffman's theory is not only important for the moral questions it raises, but also for understanding the history of residential organizations for older people. Although Goffman focuses on organizations such as mental asylums and prisons, he notes that nursing homes and geriatric clinics can also be total institutions (Goffman, 1961, p. 364). In the following section, which describes the history of residential organizations for older people, the total institution emerges as a common model for housing older people.

\section{A history of older people living in organizations in the Western world}

This history begins with early Christian organizations and ends with today's communal lifestyle organizations. The literature focuses on public sector organizations, especially as represented in the gerontology literature, however, this review also includes private sector organizations. The objective of this review is to identify and describe similarities and differences between traditional and new forms of Western residential organizations for older people.

\subsection{Pre-modern organizations}

In the third and fourth centuries Middle Eastern Christian churches created three organizations: Gerontochia for older people, Ptochia for the helpless poor, and Nosocomia for the sick (Townsend, 1962). The purpose was to give charity, compassion, 
mercy and brotherly love to those needing help. Charity was considered a path to salvation by which one was "washed of sins and spiritually enriched" (Townsend, 1962). Being a Good Samaritan was a "test of the spirit," (Carlson, 2001, p. 73). This tradition of Christian charity and hospitality continued into Medieval times:

In medieval Europe, before the poor and other groups such as the 'mad' were stigmatized, hospice or a place of hospitality was a central part of European society in which a stranger - often poor, sometimes a wanderer - was welcomed (Wagner, 2005, p. 4).

Western Medieval society recognized the need to care for strangers and people without family. Although charity was everyone's responsibility, the Church and monasteries provided most charity for the poor. These hospitality organizations were the early precursors of the modern hotel, hospital, and nursing home (Wagner, 2005).

\subsection{Modern period up to the 1960s}

In Europe, a shift occurred at the beginning of the Enlightenment period. A series of events - crop failures, plagues, the decline of feudalism, reformation of the Western Christian Church, the rise of nation states - led to new ideas about what should be done for the poor, including the elderly poor (Stearns, 2001). The intellectual roots of these changes stem from Christian humanism, and in particular Erasmus' (1469-1536) and Juan Luis Vives' (1492-1540) writings on poverty relief (Slack, 1995). In De subventione pauperum, published in 1526, Vives advocates "securalizing Christian acts of mercy" 
(Norena, 1970, p. 220) arguing public authorities and individual citizens are ethically obliged to reform the poor. Moral training was the primary objective:

The first obligation of the individual is to train others in virtue and to impart to all an education directed to moral wisdom (Norena, 1970, p. 221 citing Vives M, IV, 472; R, I, 394) ... If they cannot be made tailors, they should learn to be shoemakers. If they are too old or incapable of learning those or similar skills, they should be taught to draw water from wells, to dig in the fields, to move things with a little wagon, to run errands for the magistrates of the city, to take care of rental horses... (p. 196).

Over the next four hundred years Western poverty relief was based on four notions: charity should have a rational purpose rather than the donors' satisfaction or spiritual salvation; it should alleviate poverty and morally reform the poor, often through punishment; public authorities, rather than church officials should be responsible for charity and do a thorough job of it; and, charity should protect society from the "contaminating effects of the poor" (Slack, 1995; Townsend, 1962; Wagner, 2005).

From the mid 1500s to the end of World War II, the poor house or work house achieved these goals (Davies, 2001; Townsend, 1962; Wagner, 2005). Since poverty was endemic to older people, especially those too sick to work, a large percentage of the work house population was made up of older people without family. Until the late nineteenth and early twentieth century, poor houses sheltered the elderly, the sick, the mentally ill and criminals (Townsend, 1962). Poor houses were odious and repressive. They were 
designed to deter people from living in them (Slack, 1995; Townsend, 1962). These conditions existed in Britain, North America and Europe (Wagner, 2005; Katz, 2005).

In Victorian times, the British Minority Report of the Royal Commission on the Poor Laws described two types of elderly persons in work (or poor) houses: the deserving poor, or those who deserve reward for having contributed to society; and the undeserving poor, or those who deserve punishment for irresponsible behaviour such as "excessive drink" or a "misspent life" (Townsend, 1962, p. 24). Cole (1992) argues that Western society views old age in dualistic (positive/negative) terms. Speaking about the United States he says:

... middle-class American culture since the 1830s has responded to the anxieties of growing old with a psychologically primitive strategy of splitting images of a "good" old age of health, virtue, self-reliance, and salvation from a "bad" old age of sickness, sin, dependency, premature death, and damnation (Cole 1992, p. 230).

After the Second World War, emancipatory politics (Giddens, 1991) began to influence British and North America government policies (Phillipson, 1998; Davies, 2001). The welfare state created a new moral order. It shifted resources from haves to have nots, with the objective of creating fairness, justice and social equity. For older people, two new terms came into use - senior citizen and retirement - marking a shift in social views about older peoples' rights and identities. In an effort to create this new society, Western countries eliminated the poor house and created a new organizational model called the old age home, old folks home or nursing home. The word "home" was a powerful symbol after the War; a word referring to one's country and dwelling place 
(Davies, 2001). It suggested older people living in "Homes" would be respected, safe and well taken care of. In 1948, the British Minister of Health described Britain's new residential strategy for old people:

We have decided to make a great departure in the treatment of old people. The workhouse is to go. Although many people have tried to humanize it, it was in many respects a very evil institution . . . local authorities are busy planning and opening small, comfortable Homes, where old people, many of them lonely, can live pleasantly and with dignity. The old "master and inmate" relationship is being replaced by one more nearly approaching that of an hotel manager and his guest (Townsend, 1962, p. 32).

Similarly, Canada created homes where senior citizens were to be treated with respect and dignity: "residential facilities for elderly public patients were no longer to be a punishment for a life of irresponsibility, but a respectable 'home' for worthy Canadian citizens in their old age" (Davies, 2001, p. 156). Rather than creating hotel-like surroundings, Canadian provinces renovated former poor houses and built new buildings reflecting a compromise between hospitals and middle class Canadian homes (Davies, 2001). From 1930 to 1950 , many of these organizations adopted a medical service model focusing on professional treatment and care of the aged. Poor house inmates became patients, and senior citizens replaced the image of the deserving and undeserving poor (Davies, 2001; Phillipson, 1998).

Although post-war policies heralded gentler times, a number of authors observe conditions remained unchanged. Davies (2001) argues that the medical service model in Canadian old age homes actually increased, rather than decreased institutional surveillance over older people's bodies and self-identities: 
In the reformed old age home, these professionals now had the power to make judgements concerning the diagnosis and treatment of elderly residents, a kind of cultural control that superintendents and staff of older poor law institutions never had (p. 169).

This observation - that control actually increased rather than decreased - is not surprising given Goffman's research. As Goffman notes, a total institution with a medical service ideal supports more thoroughgoing reflexive self-control than custodial organizations ever did (Goffman, 1961, p. 150).

In Britain, fifteen years after the new legislation, Townsend (1962) found important vestiges of the poor law system in residential organizations for older persons regulated under The National Assistance Act of 1948. The worst conditions were in larger organizations, which housed a quarter of all older people. Townsend (1962) and his team surveyed a random sample of 173 institutions out of a total of 3000 English and Welsh homes. These institutions included large former workhouses, smaller local authority postwar homes mostly built after 1948 , homes run by voluntary associations such as the Catholic Church, and for-profit homes run by private individuals and regulated by local authorities.

Townsend (1962) found that physical arrangements, management styles and language differed by organization. Styles ranged from authoritative to humane. The language used to describe persons in charge of these organizations varied from "warden," (suggesting a prison-like culture), to "matron," (suggesting a medical model), to "manager," (suggesting a hotel or work-like setting). Townsend found the lower classes lived predominately in the more bleak authoritarian former workhouses and the middle 
classes in the more comfortable post-war, voluntary and private homes. No policy explained this social discrimination. Overall, the large organizations provided a custodial type of setting like the traditional poor house, and a few private for-profit homes provided hotel-like surroundings. The medical service model was largely absent from the four types of housing regulated under the $\mathrm{Act}$.

As for identity, Townsend (1962) found most older people experienced an identity loss on entering a home, especially former workhouses. Identity loss was associated with a loss of privacy in bathrooms and living space, loss of personal possessions (e.g., clothing, furniture), loss of occupational pastimes, loss of personal relationships (e.g., family, friends, community), and loss of autonomy associated with authoritative rules characteristic of Goffman's total institution. In former work houses older people were more likely to be depressed and apathetic and to isolate themselves from fellow residents than in other types of organizations. Townsend (1962) observes that former workhouses were more likely to impose initiation rituals designed to establish organizational authority and control over the new resident - what Goffman calls identity stripping:

In nearly all institutions [former workhouses] an immediate bath was an invariable rule. As one warden put it, 'They have to be broken in when they come into a communal Home - I've been choked off for saying this, but [it] is true. There's a team of three men in the bathrooms - one dries, the other undresses them and the third baths them.' He meant that the bath was a kind of initiation. But it represented more than a desire to impose personal cleanliness. It represented the change to an entirely new style of life (Townsend, 1962, p. 90). 
In some voluntary organizations, older persons had more privacy and autonomy, received greater respect from management, and were able to maintain more of their former status and self-identity than in former poor houses:

That the relationships between staff and residents in some [voluntary] homes were founded on a basis of mutual respect is attributable in part to the women in charge looking on themselves as manageresses or housekeepers rather than as matrons, and also to the feeling among the residents that they had retained a large measure of their former individuality and status (Townsend, 1962, p. 170).

A similar situation existed in about a third of all private homes where older people received greater respect, privacy and amenities than those living in former poor houses:

The more expensive [private] Homes with a larger (and better qualified) staff often provided more privacy and respect for individual pride and identity, partly because single rooms, toilet facilities and other amenities were more common (Townsend, 1962, p. 198).

Townsend (1962) observes that physical space supported the construction of selfidentity and was used by administrators to discipline and control people via institutional surveillance. Those who "made trouble" were warned, and if they continued, were "demoted" to organizations with worse living conditions and a lower social standing. The most powerful threat was a move to former poor houses. Goffman (1961) found a similar practice in mental asylums.

Townsend found peoples' self-identity was not challenged when living conditions resembled previous living arrangements. Some people were homeless or came from other organizations, such as orphanages, mental hospitals and prisons. This, however, was not 
the case for most people. For most, life in an old age home precipitated a psychological crisis - an identity crisis. Townsend notes many people could live independently with support, however, once they moved to these organizations, they could not go back as their homes had been sold or rented.

In addition to an identity crisis on entering, social isolation was common in all four types of organizations. Organizational routines and lack of privacy disrupted or hampered traditional and pure relationships between people. Townsend notes some residents, embarrassed about losing personal status, stopped reciprocating behaviour: a necessary condition for creating and building pure relationships (Giddens, 1991). As one woman stated: "I wouldn't dream of asking any of my neighbours or friends to come. I wouldn't like them to see me like this" (Townsend, 1962, p. 345). Despite their loss of privacy, loss of contact with friends, or length of stay in an organization, Townsend (1962) notes most older people he interviewed "show a surprising capacity to resist the prolonged erosion of their self-respect" (p. 339) and "maintain a tenacious hold on their individuality" (p. 370). This suggests, as Giddens argues, that people are knowledgeable, and fight back, even under repressive conditions.

Townsend's study demonstrates that although British post-war policies promoted positive views and treatment of older people, implementation fell short of intent. Governments continued to tolerate repressive organizations (Cole, 1992; Phillipson, 1998; Townsend, 1962). Where medical service models became the standard, institutional surveillance over older people's bodies and self-identities increased (Davies, 2001; Goffman, 1961). 


\subsection{The 1960s and beyond}

Since the 1960s changes have occurred, and especially since the 1990s (Phillipson, 1999; Timmermann, 2006). Just as the poor house model split in the late 1800s and 1900s into more specialized organizations (e.g., the prison, the hospital, and the nursing home), the nursing home model split into new organizations, illustrating Giddens' notion of institutional reflexivity. Various terms are used to classify these new organizations (Biggs, Bernard, Kingston \& Nettleton, 2000; Folts \& Muir, 2002; Giarchi, 2002; Golant; 2001; Marans, Feldt, Pastalan, Hunt \& Vakalo, 1983). Four housing categories describing a housing and care continuum frequently appear in the literature: independent living (houses, apartments, mobile homes); congregate living (independent living with private living space with common dining, housekeeping and recreation spaces); long-term care or nursing homes; and, continuing care (a mixed model of the previous categories in one physical location).

A number of factors fuel this proliferation of models: people are wealthier, they are living longer, they do not wish to be a burden on their families and they are looking for lifestyle sectors congruent with their self-identity (Freedman, 1999; Groger \& Kinney, 2006; Golant, 2001; Harrington, 1994; Krout, Moen, Holmes, Oggins \& Bowen, 2002; Laws, 1996; Phillipson, 1998; Townsend, 1962; Williams \& Ylänne-McEwen, 2000).

Along with new housing options, organizational ownership or management is changing. As it shifted in the 1500 s and 1600 s from the church to the state, it is shifting from the state to private enterprise. In the 1980s and 1990s, as Western governments 
downsized budgets and services and partially dismantled the welfare state, private sector nursing home ownership and management increased, especially in the United States. This was aided by large government construction and welfare subsidies (Golant, 2001; Phillipson, 1998; Kaffenberger, 2001; Laposa \& Singer, 1999). In the United States, Medicare and Medicaid paid nursing homes over \$75 billion in 2006 (DuHigg, 2007c, September 23). In the Canadian province of Ontario, every nursing home bed is subsidized - $\$ 10.35$ per bed per day over 20 years for new construction and $\$ 100$ per bed per day for operations (Canadian Broadcasting Corporation Marketplace, 2001).

A global industry now exists, made up of private investment firms, publicly traded corporate giants from the health care, insurance and hotel industry, not-for-profit companies (e.g., churches, cooperatives) and small private sector firms. Overall, the industry is large and growing. For instance, in the United States in 1997, the industry owned as many units as the hotel industry (about 3,500,000 units), with a capitalized market value of $\$ 206$ billion and a total estimated revenue of over $\$ 100$ billion (Laposa and Singer, 1999). ${ }^{1}$ In the United States, corporate concentration is increasing, fueled by acquisitions. Private investment firms own the largest share of the for-profit industry (American Senior Housing Association, 2007; DuHigg, 2007a, November 16; DuHigg, 2007b, October 24; DuHigg, 2007c,September 23). Of the fifty largest market-rate or unsubsidized housing property owners, $48 \%$ were for-profit privately held entities, $24 \%$

1 This figure includes congregate residences (independent living with communal services such as dining), board and care, assisted living (housekeeping, meals, but not nursing care), nursing homes and continuing care communities. It does not include independent living without communal services. 
publicly traded companies and $28 \%$ not-for-profit organizations (American Senior Housing Association, 2007).

A New York Times study (DuHigg, 2007c, September 23) finds a similar trend among nursing home owners who receive government subsidies. Private investment groups own six of the ten largest United States nursing home companies, which manage 9 percent of all United States nursing home beds (DuHigg, 2007c, September 23). Overseas, private investment firms are buying up nursing homes and seniors housing developments (BUPA, 2008; New York Times, 2008, January 15).

Within this global industry, there are various ways of describing seniors housing. Folts and Muir (2002) state that the industry has evolved along two paths with different philosophies: a private sector or proprietary model and a situational needs model. The first emphasizes "life enjoyment" and "life enhancement" (Estes, 1991; Folts \& Streib, 1994), whereas the second emphasizes "necessary services":

Although not systematically verified, it is nonetheless conceptually useful to view the development of elderly housing in the United States as proceeding along two distinct paths. The first was a decidedly proprietary direction involving the active marketing of housing alternatives to a more or less well-defined target group. Examples of these communities include such well-known and well-studied sites as Sun City and Leisure World. The second developmental path can be viewed as a response to the situational need for more-or-less supportive housing. The result was the development of a wide array of alternatives designed to meet a variety of locally specific housing needs. One of the important distinguishing characteristics of these two paths of development is that the proprietary ventures appear to have been developed around a specific set of amenities chosen for the purpose of enhancing a resident's enjoyment of the living arrangement. The situational path, 
on the other hand, was characterized by a very flexible and need-specific amenities package. Although different in application, operation, and underlying philosophy, both of these paths of development are important to understanding the context of elderly housing (Folts \& Muir, 2002, p. 12).

Another way of describing the industry is to distinguish between profit models: $a$ cost minimization and a revenue maximization model (Advocat, 2007, para. 5). Cost minimization is associated with subsidized nursing home care. Governments regulate services and standards and subsidize clients. Revenue maximization is common to private sector unsubsidized organizations where private sector companies offer a range of amenities to unsubsidized clients with the objective of generating profits.

The academic literature has focused a great deal of attention on older persons in subsidized and public sector housing. Since much has been written on publicly funded organizations, this study looks at unsubsidized housing organizations that fall into the profit generating private sector model where the emphasis is the consumer's "life enjoyment." These types of upscale private sector organizations are refereed to in this study as communal lifestyle organizations.

\subsection{Today's communal lifestyle organizations}

This study uses the following working definition of a communal lifestyle organization: A planned age-restricted community with a resort-like upscale appearance and leisure lifestyle. The organization may be non-profit or revenue maximizing. Often owned and 
managed by corporations, communal lifestyle organizations may also be resident owned and managed (Hunt, Feldt, Marans, Pastalan \& Vakalo, 1984; Peconic Landing, 2010).

The term "communal lifestyle organization" underlines the point that people define self-identity through their lifestyle decisions. In moving to such an organization people are choosing an affluent lifestyle - one which people aspire to (Giddens, 1991, p. 199). The term recognizes the importance of capitalism as a force for defining identity: "In late modernity, access to means of self-actualisation becomes itself one of the dominant focuses of class division and the distribution of inequalities more generally" (Giddens, 1991, p. 228). Therefore, different types of housing for older people help to define and reinforce different class identities:

"Active seniors" are emplaced in the resortlike setting of Sun City, the "frail elderly" in nursing homes, and "poor elderly people" in inner-city section 202 housing. People adopt particular spatial contexts because of their self perceptions of who they are. But their identities are also shaped by those spatial settings (Laws, 1996, p. 175).

One of the first communal lifestyle organizations, which opened in 1960, was Del Webb's Sun City: a private sector retirement gated community located in Arizona. A readaptation of the suburban dream, and built to attract physically active seniors interested in a leisure lifestyle (Folts \& Streib, 1994; Folts \& Muir, 2002; Lucas, 2002), today's gated communities are ubiquitous in places where retirees and snowbirds migrate: the southern and western United States; and the Canadian west, especially British Columbia. Also called retirement communities, retirement villages (Mangum, 1994), active adult communities, adult living, master-planned communities, and leisure-oriented retirement 
communities (Folts \& Streib, 1994), these are age restricted planned communities. They may be subdivisions, or towns in themselves. They may consist of a walled compound with bungalows, apartments, condominiums and common recreation buildings and services. Although they could be called independent living communities, gated communities are much more than this functional description suggests. Designed to attract middle and upper middle class retired North Americans, they are exclusive age restricted lifestyle sectors (Giddens, 1991), attracting those who want to pursue a leisure lifestyle (Folts \& Streib, 1994). Often winning architectural and urban planning awards, gated communities offer attractive, modern, low maintenance housing, manicured landscapes, protection from crime, friendship networks and leisure activities (e.g., parties, golf, marinas etc.).

The academic literature suggests that self-identity is shaped in many ways in gated communities: through marketing messages, physical spaces, landscaping, recreation activities, and social conventions. For instance, Del Webb Corporation's advertising is designed to dispel negative stereotypes of aging (McHugh \& LarsonKeagy, 2005). People absorb and repeat Del Webb's marketing messages: "we hear seniors sounding the mantra, affirming that retirement communities foster active, healthy aging and impart feelings of belonging and worth" (McHugh \& Larson-Keagy, 2005, p. 252).

Positive stereotypes in advertising are not unique to Del Webb corporation. McHugh's (2003) study of Arizona retirement community advertising, and Katz's (2005) study of Florida retirement communities, found positive stereotypes like anti-aging, 
successful aging, and agelessness to be common advertising themes for retirement communities. This advertising promises self-actualization or the freedom to express oneself, to explore long repressed desires, and to answer the question "Who am I?": Retirement is the serious business of choosing a style of leisurely living (from many choices), pursuing your choice with gusto and, in the process, finally discovering who you really are (McHugh, 2003, p. 178).

Retirement community advertising offers to remake self-identity by dislocating the aging body from time and local space, and placing it in "perfect settings": "The retirement industry in Arizona and other Sunbelt locales offers a most alluring mask, the ageless self located in idyllic settings outside time and change" (McHugh, 2003, p. 169). Physical space, especially its appearance, is important in remaking self-identity. In many gated communities, physical space (i.e., architecture, decorating and landscaping) is beautifully constructed. It is perfect, idyllic and manicured (McHugh, 2003; McHugh \& Larson-Keagy, 2005; Katz, 2005). The photograph of one of Del Webb's gated communities in Appendix B gives some indication of this beauty. A woman, living in a

Del Webb community, describes her reaction to this perfect space:

When you live in Sun City for a while and you are going along and you see a weed, you want to pull it out, or you see a piece of paper on the ground ... and, you know. Even the birds fly upside down in Sun City so they don't mess anything up here ... You see, there are rules and regulations ... You know I am very picky now (McHugh \& Larson-Keagy, 2005, p. 250).

The point is that physical space in many of these communities, especially upscale communities, is controlled; space is planned and micro-managed. In modernity, organization implies management control, reflexive self-control, and institutional 
surveillance (Giddens, 1991). Gated communities are organizations, perhaps not in the traditional sense of a building with four walls, however, they are designed by a masterplanner and controlled on a day-to-day basis either by developers or residents. These perfect, idyllic and manicured spaces "support" thoroughly reflexive self-control and help constitute positive identities. They help reassure people, both inside and outside the community that the aging body is under control (Giddens, 1991).

In addition to perfectly controlling space, in these communities, home is often dislocated from local space and family relationships. This has implications for selfidentity. Dislocating space from local social relations creates opportunities for reconstituting or "refurbishing" self-identity (Blaikie, 1999). Katz (2005) describes how middle class white seniors retreat to seniors' friendly communities to build pure relationships and find personal freedom in a society that discriminates against seniors: Joan and Bill enjoy their time at MLE [Maple Leaf Estates] because of the social network, the volunteer opportunities for people to help each other, and the freedom to feel one's age apart from the expectations of the younger society that exists back in Canada . . . To Joan and Bill their life in Canada is more constrained than it is in Florida. Besides the colder weather, work and family configure their social relations in Canada, while in Florida the mobile sense of a retirement community allows them the freedom to do things they could not do otherwise (Katz, 2005, p. 227).

McHugh and Larson-Keagy (2005) found similar results in an Arizona gated community.

A number of academic writers comment on how unreal gated communities appear (Katz, 2005; Jacobs, 1974; Laws, 1996). Laws (1996) calls them plastic and imagineered spaces. This relates to Giddens' notion of place as phantasmagoric, where local spaces 
are "thoroughly invaded by, and reorganised in terms of, distanciated social relations" (Giddens, 1991, p. 146).

As physical space is important to self-identity in gated communities, so are activities (Haggard \& Williams, 1992) and bodily demeanor. As Goffman (1961) points out: "expected activity in the organization implies a conception of the actor ... an organization can therefore be viewed as a place for generating assumptions about identity" (p. 186). In gated communities, older people are identified as active. Whole communities can revolve around a particular activity like golfing (Folts \& Streib, 1994). A number of authors (Fitzgerald, 1986; Katz, 2005) have remarked on how homogeneous people appear in gated-communities. Not only do they have the same leisure interests and political values, they are usually white, of similar age, and wear the same clothing style.

Although gated communities can promote new friendships and self-identities, something that Giddens predicts, they also bring residents face to face with moral and existential issues, something that he does not discuss. Organizational sequestration conceals moral and existential issues from society and concentrates these issues in sequestered organizations. Katz (2005), in his study of Florida retirement communities, notes residents continually experience losses: "One of the most poignant realizations for Joan and Bill Charles is that 'eighty percent of the people that were here when we first came are no longer here ... it is always sad when we come back" (Katz, 2005, p. 228). The implications for self-identity are unclear.

Many of the observations in the literature about how gated community advertising, space and social conventions shape self-identity may also apply to other 
forms of communal lifestyle organizations like independent living residences, assisted living, and continuing care communities. Less academic research exists on these communities than on gated communities, at least literature relating to organizational behaviour issues like self-identity (Golant, 2001; Moen, Erickson \& Dempster-McClain, 2000). Therefore, to provide some sense of how these organizations operate, I rely not only on the academic literature but also on industry websites.

Independent living residences and assisted living attract older less active seniors than gated communities. Originating in Scandinavia as a type of nursing facility, assisted living appeared in the United States in the 1980s. In North America the best of these organizations have a hotel-like feel and hospitality service philosophy (Blaikie, 1999; Golant, 2001; Harrington, 1994). Both tend to consist of private sector rental apartments combined with all inclusive housekeeping, dining and recreation services. As the name suggests, assisted living also offers nursing or unskilled health care services. Both types of housing may be operated and managed by the private sector for middle and upper income persons, although U.S. state and federal governments are trying to make assisted living accessible to low-income persons (Golant, 2001). In Canada and the United States, independent living residences may be subsidized (Care Planning Partners Inc., 2010; Rotary International, 2010). In the United States most assisted living organizations are regulated by state governments. In Canada, only British Columbia regulates assisted living (Spencer, 2008; Community Care and Assisted Living Act [SBC 2002] c. 75). In the United States, between 1991 and 1998 the number of assisted living organizations 
increased by $50 \%$. By 1999 , there were an estimated 27,300 organizations with 777,800 beds (Golant, 2001).

Appendix B contains quotes from two companies: Leisure Care Retirement Communities, which provides both independent and assisted living; and an assisted living company called Assisted Living Concepts. Leisure Care's website (Leisure Care, 2010) emphasizes fun, choices, convenience, self-actualization, and a resort lifestyle. It employs language such as: "choice is not a luxury," "ignoring the rules," "elegant and fun."

Assisted Living Concepts' website (Assisted Living Concepts, 2010) also emphasizes luxury and community: "gracious living," "life just got easier," "a chance to cultivate personal interests" and "lasting friendships." It reformulates the active living theme into less physically demanding language such as "unmatched ease." New themes emerge such as "caring help when you need it," "good things are possible," "safety," and "security of mind." These websites illustrate similarities and differences with gated communities. Similarities include upscale hospitality service, friendship networks, selfactualization, hotel-like spaces and positive images of aging. Differences include the theme of failing health and having care "when you need it."

Continuing care communities often follow a similar hotel-like model (see Appendix B for examples). These mixed models provide housing for active seniors plus health care for those that need it. Housing and services range from independent living residences and assisted living to long-term care, all in one physical location. People move as their needs change (Brecht, 1994). Although continuing care existed in the United 
States before the $1970 \mathrm{~s}$, numbers have increased rapidly in the latter part of the $20^{\text {th }}$ century (Brecht, 1994). Originally developed mostly by non-profit organizations, today both profit (Streib, 2002) and non-profit (Mandy, 2010) communities exist. Many are subject to state regulation. Continuing care is not usually subsidized in the United States, whereas in Canada it may be, depending on a person's financial situation.

In the United States, these communities can be luxurious and expensive. Although arrangements vary, they can offer housing, dining, recreation, health insurance and care services, usually at the cost of a one time up-front payment and a monthly fee. These communities sell peace of mind and reduce risks associated with aging (e.g., having to move, controlling health care costs, and being separated from one's spouse). This approach to housing illustrates Giddens' notion of life-planning which he defines as "the strategic adoption of lifestyle options, organised in terms of the individual's projected lifespan, and normally focused through the notion of risk" (Giddens, 1991, p. 243).

Another recent development in this industry is the involvement of hotels. In the United States, Classic Residence by Hyatt offers luxury accommodation, hospitality service and health care in the form of rental apartments and continuing care communities (Adler, 2007; Hyatt Corporation, 2008). Canadian hotels are also entering this market. The Quebec hotel chain, Hôtel des Gouverneurs, recently built Lux Gouverneurs in Montreal; Club-Med style apartments for active retirees offering upscale amenities such as a 300 seat theatre, sports center, health spa, fine dining, room service and health services (Guimont, 2007; Gouverneurs Inc., 2008). As with gated communities, the hotel industry emphasizes "perfect" "hotel-like" spaces. A recent textbook on hotel design and 
planning (Rutes, Penner \& Adams, 2001) talks about residences for retirees: “The primary design concern . . . is for them not to look like a nursing home and to avoid all trappings of institutional care" [italics added] (Rutes, Penner \& Adams, 2001, p. 219). Like gated communities, residential organizations owned by hotels are designed to dispel negative stereotypes associated in people's minds with nursing homes: stereotypes of decline, dependency and disease. Hotel chains, with their hospitality service philosophy, are opportune sites for challenging traditional service models such as custodial and medical service models.

Apart from the involvement of hotels, another development is a fragmentation in the market place revolving around self-identity. This illustrates the institutional reflexivity of communal lifestyle organizations and the importance of life-political issues. Developers are building new organizations that appeal to older people whose identities do not "fit the typical mold" (Van den Hoonaard, 2002). For instance, there are communities for ex-military personnel and communities for gays and lesbians (Edwards, 2007; Gay Retirement Guide, 2008; Shore, 2007). See Appendix B for excerpts from Air Force Village West and Rainbow Vision's website advertisements.

Retirement communities for gays and lesbians illustrate Giddens' notion of emancipatory and life politics. Being able to openly self-identify as gay is a human rights issue for gays living in residential organizations, as the following quote suggests:

Recent articles in the New York Times and Vancouver's Xtra West contain tales of fear, rejection and even suicide for openly gay seniors who end up in nursing homes where they are harassed or moved from the general living area and placed 
with severely disabled or mentally ill residents to quiet the protests of homophobic seniors (Shore, 2007, para. 6).

These types of experiences illustrate the continuing relevance of Townsend (1962) and Goffman's (1961) research findings. Organizational administrators can and do employ physical space to control and discipline people who contradict organizational plans and assumptions about who they should be.

\section{Summary}

This historical review identifies a number of continuities and discontinuities in housing for older people. The first continuity, since Enlightenment times, is an emphasis on reflexive self-control. The original rationale for work houses was to encourage selfreform, the belief being that organizations could teach people to be productive citizens. The medical model serves a similar purpose; the prevention, rehabilitation and cure of disability and disease through "working on the body and the self" (Goffman, 1961). The literature argues that communal lifestyle organizations also work on the self. They emphasize successful aging, consumer lifestyle maximization, and body optimization (Rudman, 2006). This emphasis on the reflexive project of the self, highlights the importance of the study question: Who does the organization want me to be? The literature suggests that communal lifestyle organizations do not dispel this question, they simply shift the focus of reflexive self-control.

A second continuity since the 1500 s is the organizational sequestration of older people: first in total institutions and now increasingly in communal lifestyle 
organizations. Whereas organizational sequestration in total institutions was often unwelcome, today people often choose to sequester themselves in communal lifestyle organizations.

Many discontinuities occur in late modernity. Although older people with money have lived in hotel-like residential organizations in the past (Townsend, 1962), a number of things are new: an emphasis on self-actualization, positive aging identities, private sector mass production of standardized age restricted living spaces, affluent lifestyles, consumer choice, the commodification of community membership, and older people as active consumers rather than dependent service users (Laws, 1996; Rudman, 2006). The marketing message "you deserve it, you've earned it" is poignant for the current generation of older people who have lived through the Depression and World War II. This marketing message, and its emphasis on consumerism, raises a new self-identity question: Am I what I consume? (Kleine, 2006; Saren, 2007; Sayre \& Horne, 1996). Apart from revealing continuities - reflexive control and sequestration - and discontinuities - the commodification of affluent living spaces and self-identity - this review identifies a number of gaps in the literature. The first is the importance of space to self-identity: especially the appearance of space. Residential space reflects and reinforces negative or positive stereotypes about older people. The negative stereotype of the odious nursing home can be immediately dispelled with a design and decorating scheme that "avoids all trappings of institutional care" (Rutes, Penner \& Adams, 2001, p. 219). Space conveys social status, self-identity, and an organization's objectives. It can convey a prison-like atmosphere where inmates are warehoused, a medical space where patients 
are "treated," or a resort-like or hotel-like atmosphere where residents purchase a leisure lifestyle. Space conveys degrees of luxury and social class, for example a five-star versus a three-star space. Space can also camouflage ontologically painful realities. Despite the importance of space to self-identity, authors do not always write about "the feel" or appearance of space in communal lifestyle organizations.

A second gap in the literature relates to how people shape day-to-day life in residential organizations. As Bernard, Bartlam, Sim and Biggs (2007) observe, much of the literature, especially studies of public housing, take a structuralist viewpoint deterministic structures shape passive older people (Townsend, 1981). Although advertising emphasizes the active consumer, the literature does not always explore the ways in which older people may actively change residential organizations.

A third gap in the current research is the absence of "older people's voices"their theories about self- identity and organizational life (Oldman, 1999). What people say about their experiences - their exact words rather than a researcher's interpretation is largely missing from the literature. A comment like "birds flying upside down" (McHugh \& Larson-Keagy, 2005, p. 250) conveys a powerful message about the scope of control in some communal lifestyle organizations.

This literature review underlines the fact that more research is needed on communal lifestyle organizations. Gaps in the literature point to important research questions, which this study attempts to address. The next section discusses how this study looks at self-identity in a communal lifestyle organization. 


\section{CHAPTER THREE}

\section{Methods}

This section describes the study methods: the research questions, study design, analytical framework, the data, and steps for ensuring rigour. The intent is to discuss how the methods strive to achieve the study objectives.

\section{Research questions and linkages to theoretical notions}

This study explores issues arising from Giddens' theory and the literature on residential organizations for older people. The main research question is: How do people construct self-identity when they live in a private sector communal lifestyle organization? This question can be broken into four sub-questions: Who am I? Am I what I consume? How do I describe the organization? and Who am I when I live in an organization? This last question is further broken down into two specific questions about self-identity in an organization: Who does the organization want me to be? Where is the "me" among the "we"? The following section expands upon these questions and relates these questions to Giddens' theoretical notions plus other theories from the literature. 


\subsection{Who am I?}

This question explores people's lives before they moved to Lakelands: their background and moving history. It explores functional notions of self-identity such as kinship and socio-economic status, as well as social constructivist notions of self-identity such as a person's narrative. It also explores the notion of life-planning (Giddens, 1991).

\subsection{Am I what I consume?}

This question examines the ways people employ consumption practices to define or perform the reflexive project of the self (Belk, 2003; Giddens, 1991; Saren, 2007). It examines issues such as: how does the decision to live in an upscale physical space like Lakelands shape self-identity; how does moving to a sequestered organization - an organization where older people live - affect self-identity; and what happens to selfidentity when a lifestyle sector changes - when an organization changes in ways that no longer fit a person's preferred self-identity. This research question taps notions such as perfect or idyllic physical spaces (Conlon, Van Dyne, Milner, \& Ng, 2004; McHugh \& Larson-Keagy, 2005; Laws, 1995, 1997), lifestyle choice, lifestyle sectors (Giddens, 1991), and negative and positive stereotypes of aging (McHugh, 2003; McHugh \& Larson-Keagy, 2005; Katz, 2005). 


\subsection{How do I describe the organization?}

Wallenmac and Sims (1998) state sensemaking can be difficult for organizational members. Describing Lakelands may be difficult given the newness of the communal lifestyle model and a lack of language. Czarniawska (1997) describes this problem:

Whichever way one looked among Western cultures at the beginning of the 1990s, one could see some sort of puzzling institutional transformation on the go.

Things were bursting out of their labels, and words grew short of events (p. 1).

Consequently, I asked residents and management to describe Lakelands. This gave people an opportunity to talk about organizational identity, to use positive and negative stereotypes of aging and space (e.g., hotel-like, prison-like), to compare and contrast Lakelands with other organization types. As well, this provided information about the ways in which management and residents think and talk about Lakelands; in both conscious and unconscious ways.

\subsection{Who am I when I live in an organization? (Who does the organization want me} to be? Where is the "me" among the "we"?)

This question focuses on the study's central issue. It examines the extent to which people construct self-identity as they wish and live their lives as they wish - free from control from management and other residents. This question taps notions such as emancipatory and life politics, self-actualization, organizational control, lifestyle choices, the reflexive project of the self, and organizational sequestration (Giddens, 1991). 
The question, "Who am I when I live in an organization?" is further broken down into two questions: "Who does the organization want me to be?" and "Where is the 'me' among the "we'?" To explore the first of these two questions (i.e. Who does the organization want me to be?) I asked respondents three questions: whether they have had to adapt to life at Lakelands; whether they can live as they would like, free of restrictions from Lakelands' management and residents; and whether their self-identity has changed since moving. These questions gave respondents the opportunity to discuss issues such as the importance of rules and social conventions for governing behaviour, organizational policies such as active retirement (Katz, 2005), and the importance of bodily appearance and demeanor (Giddens, 1991).

In order to explore the question "Where is the 'me' among the 'we'?" I asked respondents what it is like to live with other people. This question gave people the opportunity to discuss issues such as privacy and pure relationships (Giddens, 1991).

To learn management's perspective, especially explicit and implicit management assumptions about residents' self-identity (Goffman, 1961), I asked managers about Lakelands' service philosophy and marketing efforts (McHugh, 2003; Katz, 2005; Laws, 1996; Rudman, 2006; Ylänne-McEwen, 2000). I also explored implicit assumptions in naming conventions. Townsend (1962) and Davies (2001) argue that organizations use names to convey something about people's organizational status and identity. I asked residents and management for their views on the use of first names at Lakelands and the practice of calling people "residents." The purpose was to understand how these assumptions might influence how residents see themselves. 
In addition to the ways in which Lakelands may shape resident self-identity, the study focuses on how residents may be shaping Lakelands (Giddens, 1991). I asked managers as well as residents to relate examples of resident complaints and outcomes. This taps the notion of organizational reflexivity - the ways that organizations continually adapt to new conditions and information (Giddens, 1991).

In sum, these four questions "Who am I?" "Am I what I consume?" "How do I describe the organization?" and "Who am I when I live in an organization?" attempt to answer the main research question "How do people construct self-identity when they live in a private sector communal lifestyle organization?"

\section{Research design}

The intent of this section is to describe the study methods, and explain why these methods are appropriate for answering the research questions. This section discusses a number of topics: the rationale for employing a descriptive case study with multiple cases, the unit of analysis, the study's emphasis on language and mixed methods (qualitative and quantitative), the use of multiple sources of evidence (interviews combined with observation), managing the data collection process (pilot testing the interviews, and project control), and the study context - Lakelands Retirement Resort. 


\subsection{A descriptive multiple case study}

This research is a descriptive case study - a case study that explores the "scope" and "depth" of a phenomena in its context, and is based on theory (Yin, 2003, p. 5, 23). Although this study does, in some cases, explore causal relationships, this is not the primary objective. The objective is to answer the research questions, generalize findings to theory (analytic generalization; Yin, 1994), and refine Giddens' theory.

Although survey research is an effective method for exploring phenomena, Yin (2003) argues that case studies are more appropriate when the study "investigates a contemporary phenomenon within its real-life context, especially when ... the boundaries between phenomenon and context are not clearly evident." (Yin, 2003, p. 13). This study explores this type of situation: the reflexive relationship between agency (selfidentity) and structure (a communal lifestyle organization). As well, case studies are useful for studying phenomenon and relationships that have received little attention (Voss, 2002). As the literature review indicates, not a great deal is known about how people construct self-identity in communal lifestyle organizations.

Case studies have many benefits. They are useful for developing, refining, and extending theory (Yin, 2003) - one of the objectives of this study. As well, case studies are capable of producing influential theory: the work of Galileo, Newton, Darwin, Marx and Freud are all prime examples (Riessman, 2008).

As explained below, this study treats multiple individuals as multiple cases. Although single case studies are valuable, multiple case studies are preferable. Multiple case studies increase confidence in results. They reduce researcher bias and offer more 
opportunities to explore the limits of theory (Miles and Huberman, 1994; Voss, 2002; Yin, 2003).

\subsection{The unit of analysis}

Yin (2003) states that the primary unit of analysis is reflected in the research question. This study's research question focuses on self-identity: How do people construct selfidentity when they live in a private sector communal lifestyle organization? Since selfidentity is defined as the narrative of the self (Giddens, 1991), the primary unit of analysis is a person's narrative about their life at Lakelands.

\subsection{An emphasis on language: Qualitative and quantitative data}

Since the unit of analysis in this study is the narrative of the self, this study focuses on language use. To learn how people construct identity, the study must rely on what people say about themselves - both explicit and implicit language use. Another reason for focusing on language is that the literature review indicates that language plays an important role in the history of residential organizations for older people. Changes in the way older people are described, along with changes in descriptions of the places they live, signal changes in organizing strategies, public policy, and social views.

A focus on language is not new in organizational research. Organizational scholars have taken a narrative approach to organizational sensemaking (Weick, 1995), communication (Boje, 1995; Stutts \& Barker, 1999), change (Brown \& Humphreys, 
2003; Meyer, 1995), learning (Abma, 2000), strategy (Barry \& Elmes, 1997), social control (Clegg, 1993), power (Brown \& Jones, 1998) and identity (Humphreys \& Brown, 2002). The contribution has been both epistemological and ontological. A focus on language places emphasis on "plurality, reflexivity, subjectivity and temporality" in organizations (Rhodes \& Brown, 2005, p. 177). This study builds on this tradition.

The present study primarily collected qualitative information, since it focuses on the narrative of the self, and since it asks questions that elicit qualitative answers "what" "how" and "why" questions. Despite this emphasis, some of this qualitative data can be quantified (Yin, 2003).

The purpose of quantitative analysis in this study is to support qualitative analysis: to verify and corroborate findings and to test relationships. Using qualitative and quantitative analyses has a number of benefits. It gives the reader multiple sources of information to assess potential researcher bias and determine the credibility of the study findings (Miles and Huberman, 1994, p. 252). As well, it combines the strengths of each method. Quantitative analysis can produce complex cross-case analyses - analyses that are difficult in qualitative analysis. In contrast, qualitative methods are excellent for studying cases in depth, especially sequences of events and reflexive relationships.

\subsection{Multiple sources of evidence}


In addition to combining qualitative and quantitative analysis, this study employs multiple sources of data. Since the unit of analysis is a person's self-identity narrative, resident interviews are the primary data source - specifically verbatim interview transcripts. Other data sources include diary observations of day-to-day life at Lakelands, plus interviews with Lakelands' management. The purpose of these additional data sources is to understand intricate reflexive relationships between agency (self-identity) and structure (the communal lifestyle organization). The analytical objective is to triangulate information: resident narratives, management interviews and observational data.

The observational study consisted of observing and documenting (in a diary) dayto-day organizational life, routines and social conventions. This was necessary given Giddens' and Goffman's emphasis on social conventions and routines. Although observational data included unusual events, the primary focus was to document takenfor-granted daily routines and conventions that constitute organization life, plus collect information to guide case selection (Giddens, 1991; Goffman, 1961).

In addition to the observational study, I interviewed selected managers. The purpose was threefold: first, to collect background information on the organization and industry; second, to glean management's assumptions about resident identity and the services they should receive; and third, to be able to contrast management and residents' responses to questions such as "Who does the organization want me to be?" and "How do I describe the organization?" Interviews were limited to key managers: persons who set the organization's tone (i.e., objectives, philosophy, routines). The goal was to interview 
4 to 5 managers - senior and junior managers - from a variety of functional areas within the organization so as to have an overview of the organization.

\subsection{Ethical conduct of the research}

Confidentiality is an issue, especially when conducting in-person interviews. The TriCouncil policy statement: Ethical conduct for research involving humans requires special procedures to protect vulnerable persons defined as: "those whose diminished competence and/or decision-making capacity make them vulnerable" (Canadian Institute of Health Research, Natural Sciences and Engineering Research Council of Canada, \& Social Sciences and Humanities Research Council of Canada, 2005 p. i.5). Lakelands' residents do not fall into this category. To live at Lakelands, people must be physically and mentally able to look after themselves.

Although people who live at Lakelands are not defined as vulnerable persons, some have disabilities. To take disabilities into account, the interview was short, about one hour, although sometimes interviews were much longer if the person wished - over 2 hours in a number of cases. I did not rush the conversation. I encouraged people to stop if they experienced fatigue, or for any reason they desired. No one did. Although I offered to use a sound amplifier to amplify my voice, no one asked for the amplifier. No one seemed to have difficulty hearing my voice. Overall, I was impressed by respondents' vivacity, awareness and intelligence.

It was fairly easy to guarantee confidentiality to people living at Lakelands, however, it was difficult to do the same for management, given the small number of 
people involved. Therefore, the letter sent to management asked potential management participants to think carefully about participating and to not volunteer if they believed the risks would exceed the benefits. Although this study did not depend on management participation, it was enhanced by this participation.

Since the qualitative analysis technique that I used in this study - narrative analysis - depends on collecting and reporting tape recorded conversations, I used a twostep consent process. If a person agreed to an interview, I asked them to sign a consent form giving me permission to conduct and tape record the interview. After the interview, I asked the respondent to review the typed interview transcript, crossing out anything they did not wish to see in print, and to sign a second consent form if they wanted to give me permission to quote their revised interview transcript. Appendix $\mathrm{C}$ contains samples of these consent forms (See C.03 and C.04).

In addition to these measures, I took a number of steps to ensure confidentiality when reporting resident narratives. First, I only quoted stories that have happened to a number of people. Second, I used pseudonyms. Third, even if a resident approved a narrative for quotation, if the material was sensitive (i.e., it might create harm), I do not report a story that would allow another resident or a manager to identity that person. As well, I often eliminated identifying information from quotations such as place names, references to family members, and sometimes the gender or pseudonym of the persons involved.

\subsection{The communal lifestyle organization: Lakelands Retirement Resort}


The context for this study was Lakelands Retirement Resort (a pseudonym). To situate the findings in context, it is helpful to understand what Lakelands is like. This section describes Lakelands' operating philosophy, physical layout, management and services.

Lakelands' advertising messages are similar to other communal lifestyle organizations - for example those described in Appendix B. Lakelands' advertising emphasizes affordable luxury, fine dining, amenities and a resort lifestyle. In keeping with this emphasis on luxury, Lakelands' operating philosophy (Table 3.1) states that Lakelands is committed to customer service and to providing residents with an environment that is "significantly more stimulating, interesting and enriching" than they could experience anywhere else. Lakelands' operating philosophy is posted at the front entrance to the building for everyone to see.

Lakelands' building reflects "pride of place" as mentioned in Lakelands" operating philosophy as a core values. It resembles an upscale apartment complex, with a gated entranceway, circular driveway, fountain, large portico, landscaped gardens, and Craftsman style architecture ${ }^{2}$. On entering through two large sliding glass doors, one has the impression of a resort or country club with open plan architecture, high ceilings, large windows, high backed chairs, oriental vases, dark carpets and modern paintings. Professionally decorated, the building's interior and exterior blend together, radiating

2 Agrest \& Sennott (2000) describe this style as:

... informed by both European and Japanese architectural design . . . characterized by the use of natural building materials, such as brick, stone and regionally available woods ... use of exposed joinery on both the exterior and interior of buildings ... ample porches enhanced with rough stones or masonry ... dramatic windows (p. 321). 
harmony and elegance. Not surprisingly, Lakelands has received a number of housing and gardening awards.

Table 3.1. Lakelands' vision, goal, mission and values

Our Vision

Lakelands' residents are able to enjoy significantly more stimulating, interesting and enriching lives than they could experience anywhere else.

Our Goal

To maximize the enjoyment and enrichment of life for our residents.

Our Mission

To significantly and positively impact the lives of our residents in everything that we do.

Our Core Values

Pride in Lakelands, as a place to live and a place to work.

Understanding our residents and anticipating their needs.

Respect for all; residents and staff.

Positive team effort.

Although this is a planned lifestyle sector (Giddens, 1991), with a controlled appearance, it is not perfectly manicured. There is room for imperfection. Nature and day-to-day wear and tear make inroads; ducks and geese walk the grounds leaving gifts; the moles regularly kill shrubs; and, furniture and walls may show small signs of wear. 
As for physical layout, there are common and private areas, suggesting the possibility of a private life apart from the community. Administration, reception and many amenities (e.g., the dining room, beauty salon, health spa, tuck shop, bar, library, sports lounge, computer room and country kitchen) are located in a central two story common area. Apartments are located in two four story wings, located at each end of the common area, thereby offering privacy. Additionally, the theatre, woodworking shop and multi-purpose room are located in the basement of one of the wings.

The dining room, which is separated from the lobby by a grand two story staircase, looks and operates much like a restaurant in a four-star hotel. Set under a cathedral ceiling topped with a cupola that is lit at night, the dining room can seat over two hundred people, if necessary. A fireplace, sofas, chairs and a bar are located at one end. Dramatic two story floor-to-ceiling windows cover one wall and look onto gardens and a large patio. At breakfast (6:30 to 9:45) and lunch (11:30 to 12:45), diners choose their own seats, sitting at two and four seat tables covered with good table cloths, china, goblets and a full set of cutlery (including both salad and dinner fork). At dinner (4:30 to 6:30), diners are seated by a Maître d' who offers a wine service. Waiters and waitresses bring the daily menu, which is printed on high grade bond paper and inserted in a leather folio. The menu usually includes a choice of two appetizers, three entrees and three to four desserts. The food could be described as California gourmet cuisine and Canadian favourites (e.g., roast beef and Yorkshire pudding, southern fried chicken, ribs). For an example of a daily menu see Appendix D. 
As for private living spaces, each floor in the two wings contains about twenty apartments; a spa consisting of a large bathroom with jet tub; and a laundry room with two washers and dryers, iron and ironing board. Hallways are spacious, carpeted, decorated with occasional tables and Chinese vases, and usually take the shape of an "L" for additional privacy. A handrail runs along the walls. A small sitting area with rattan couches and a walkout balcony is usually found at the end of each hallway.

In total, Lakelands can accommodate over 200 people in one and two bedroom rental apartments plus a number of penthouse suites. A typical one bedroom apartment is spacious, with a large living room, a small kitchen with cabinets, bar fridge and microwave, a large bedroom with walk-in closet, a bathroom with walk-in shower, a storage room, a hall and closet. The only hint this apartment might be for an older person are the emergency pull cords in the bathroom and bedroom, plus the walk-in shower. Once furnished, each apartment takes on the owner's persona.

Lakelands' prices are highly competitive. At the time of the study, the lowest price for a one bedroom apartment, for one person with three meals a day, was about $\$ 2,300$ month, based on a one year minimum occupancy. This price includes a weekly cleaning service, use of all facilities including the Lakelands' bus, access to all social activities, cable television, heating and electricity. This is not the lowest price at Lakelands. Studio apartments rent for less, and people are not obliged to purchase three meals a day. The basic plan includes all evening meals and three continental breakfasts a week. Although there are opportunities to purchase additional services and amenities (e.g., lunches, additional breakfasts, additional housekeeping services, cable, medic alert 
bracelets, hair dressing, massages, pedicures), the cost of these amenities is reasonable and competitive. Home support services (e.g., unskilled nursing) can be purchased through private sector contractors of one's choice.

Tables 3.2, 3.3 and 3.4 compare Lakelands' prices to, respectively, two similar Canadian organizations, to 2003 income levels for Canadian seniors, and to the costs of nursing homes in Canada. Of the three independent living residences, only Lakelands is close to being affordable for the average Canadian senior. Table 3.2 indicates that independent living residence costs are comparable or higher than public sector nursing home costs. In British Columbia, private nursing home costs (Table 3.4) can far exceed the cost of independent living residences.

These data suggest a large potential market for places like Lakelands, if prices fall. From my quick survey ${ }^{3}$, prices in most Canadian metropolitan areas are considerably higher than Lakelands. I asked a Lakelands' manager to explain this price difference and was told that it is probably due to market inertia and differences in pricing structure. Whereas Lakelands bases their price on the cost of an apartment plus additional services, other companies seem to have based their price on the cost of a nursing home minus the cost of nursing. The latter approach produces a higher price.

3 In addition, a resident who had lived in an independent living residence in a large Canadian city, told me that they paid $\$ 1000$ a month more than at Lakelands, for similar accommodation. 
Table 3.2. Independent living residence cost 2009 : Unfurnished 1 bedroom apartment, 3 meals per day

\begin{tabular}{lcc}
\hline Independent living residence & Cost 1 person & Cost 2 persons \\
\hline Lakelands & $\$ 2,260 /$ month, & $\$ 2,720 /$ month, \\
& $\$ 27,120 /$ year & $\$ 32,640 /$ year \\
The Parkside $^{\mathrm{a}}$ & $\$ 3,800 /$ month, & $\$ 4,480 /$ month, \\
& $\$ 45,600 /$ year & $\$ 53,760 /$ year \\
The Riverside & $\$ 3,350 /$ month, & $\$ 4,100 /$ month, \\
& $\$ 40,200 /$ year & $\$ 49,200 /$ year \\
\hline
\end{tabular}

Note. Like Lakelands, The Parkside and The Riverside are pseudonyms.

${ }^{a}$ Prices at Lakelands and Riverside Place include social activities, housekeeping, weekly linen and towel change, free transportation, whereas the Parkside price only includes social activities.

Table 3.3. Canadian seniors median income 2003: By sex and marital status

\begin{tabular}{lccc}
\hline & \multicolumn{3}{c}{ Marital status and sex } \\
\cline { 2 - 4 } $\begin{array}{l}\text { After-tax } \\
\text { median income }\end{array}$ & Couple & Unattached single women & Unattached single men \\
\cline { 2 - 4 } & $\$ 36,500$ & $\$ 18,200$ & $\$ 20,200$ \\
\hline
\end{tabular}

Note. From Schellenberg and Turcotte (2006, p. 64). A Portrait of Seniors in Canada. Ottawa: Statistics Canada. 
Table 3.4. Cost of nursing homes in selected Canadian provinces 2009

\begin{tabular}{|c|c|c|c|c|}
\hline Province & Type & Subsidies & Daily & Monthly \\
\hline Ontario & $\begin{array}{l}\text { Private room in } \\
\text { government } \\
\text { nursing home. }\end{array}$ & $\begin{array}{l}\text { Subsidy available for } \\
\text { basic accommodation } \\
\text { only. }\end{array}$ & $\$ 69.73$ & $\$ 2,161.71$ \\
\hline Manitoba & $\begin{array}{l}\text { Room in } \\
\text { government } \\
\text { nursing home. }\end{array}$ & $\begin{array}{l}\text { Costs depend on } \\
\text { after-tax income and } \\
\text { marital status. }\end{array}$ & $\begin{array}{l}\text { From } \$ 30.60 \text { to } \\
\$ 71.80 / \text { day based } \\
\text { on income. }\end{array}$ & $\begin{array}{l}\text { Up to } \\
\$ 2,225.88\end{array}$ \\
\hline \multirow[t]{2}{*}{$\begin{array}{l}\text { British } \\
\text { Columbia }\end{array}$} & $\begin{array}{l}\text { Room in } \\
\text { government } \\
\text { nursing home. }\end{array}$ & $\begin{array}{l}\text { Cost depends on } \\
\text { after-tax income. }\end{array}$ & $\begin{array}{l}\text { From } \$ 30.90 \text { to } \\
\$ 74.30 \text { daily } \\
\text { based on income. }\end{array}$ & $\begin{array}{l}\text { Up to } \\
\$ 2,303.39\end{array}$ \\
\hline & $\begin{array}{l}\text { Private room in } \\
\text { private nursing } \\
\text { home. }\end{array}$ & No subsidy. & - & $\begin{array}{l}\$ 2,895 \text { to } \\
\$ 8,200\end{array}$ \\
\hline
\end{tabular}

Note. Source of data: Manulife Financial 2010a, 2010b, 2010c.

Although Lakelands' pricing may differ, it resembles the industry in many ways. Traditional divisions between the nursing home, housing and hospitality industries are blurring at Lakelands. Over the years, Lakelands has been managed by a nursing home administrator, a nurse, a hotel manager and restauranteur, and most recently by a financial services professional. Lakelands is owned by a partnership between two companies: a local nursing home/assisted living provider, and a local gated community developer.

Although Lakelands is typical in many ways of communal lifestyle organizations and the retirement industry in general, it has also adapted to local conditions. It is wholly owned by private investors who are long standing members of the community. In addition, there is a personal element to the way Lakelands is run. Over the years, relatives 
of staff and management have lived at Lakelands. At the time of the study, the mother of one of the owners, the father of one of the receptionists, the mother of another receptionist, and the mother of a former manager all lived at Lakelands.

As for day-to-day operations, about 50 people work for Lakelands on a full and part-time basis. There is the front office (General Manager, Accounts Manager, Marketing Director, Receptionists and Security/Night staff), the dining room (the Chef, Sous-chefs, Maître d', waiters and waitresses), the health spa (Activity Coordinator) and the residence staff (housekeeping staff and maintenance). Changes in management, particularly the General Manager and Activity Coordinator, change the lifestyle or feel of day-to-day life at Lakelands. For example, the former General Manager introduced many practices common to the hotel industry. Changes in the Activity Coordinator affect the amount and type of fun going on. A change in Chef would be significant, however, the same Chef has managed the dining room since Lakelands opened in 2000. Changes in Sous-Chefs affect the menu, as each one introduces their specialties.

The region where Lakelands is located is primarily made up of a white English speaking population, with a large percentage of people over $65-19 \%$ in $2001-$ (Statistics Canada, 2001a) compared to the Canadian average of 13\% in 2001 (Statistics Canada, 2001b). The area also has a small immigrant population - mainly Europeans who came to Canada after the Second World War. It has a small French speaking population and a small non-white population - Aboriginal peoples, Chinese, Japanese and East Indians. A resort area to which people migrate from other parts of Canada, the region is popular with retirees and young people and has grown rapidly since the 1960 s. 
Apart from being a resort area, an influx of wealth has pushed up land prices.

Noted for conspicuous consumption, the area has a hedonistic, materialistic quality in the summer. In addition to the very rich, there is a large middle class and a working class. Politically, the area is conservative. It has many churches, especially Evangelical and traditional Protestant churches. Crime is a problem and is linked to drug addiction and homelessness. Lakelands is located in a suburban area and has had few security problems.

Lakelands is located on a street where agricultural land was converted to housing. This street has four lifestyle sectors, each one loosely corresponding to different time periods in the lifespan from young singles and couples to families, active seniors, and older seniors. Lakelands is situated at the eastern end of the street and is flanked on the north, south and west by two large upscale gated communities made up of bungalows. Next to Lakelands there is a condominium complex targeted to singles and young couples. Across the street from the condominium there is a small mall with a bank, bakery and coffee shop. A four lane highway divides the eastern part of the street from the western part, which is made up of single family homes and town houses.

Neither Lakelands nor this street are unique. The region has many gated communities and other seniors housing options, ranging from traditional nursing homes, to seniors apartments, condominiums, communal residences and continuing care. Organizational styles vary widely: from the traditional medical service model to communal lifestyle organizations like Lakelands. Organizational ownership also varies, from church sponsored and privately owned nursing homes, to government and large 
private sector nursing home chains like Extendicare and property owners/managers like Holiday Retirement Homes.

The photograph below gives a glimpse of Lakelands' front entrance. This photograph, which comes from a fund-raising calendar, shows the local mayor (also Chairman of the fund-raising committee) surrounded by four women who live at Lakelands. This humourous picture challenges traditional ideas about older women's sexual identities. As well, it alludes to older people's importance to local politics. Appendix D contains additional photographs of Lakelands

Figyre 3, Photograph from a 'akelands' salenda*

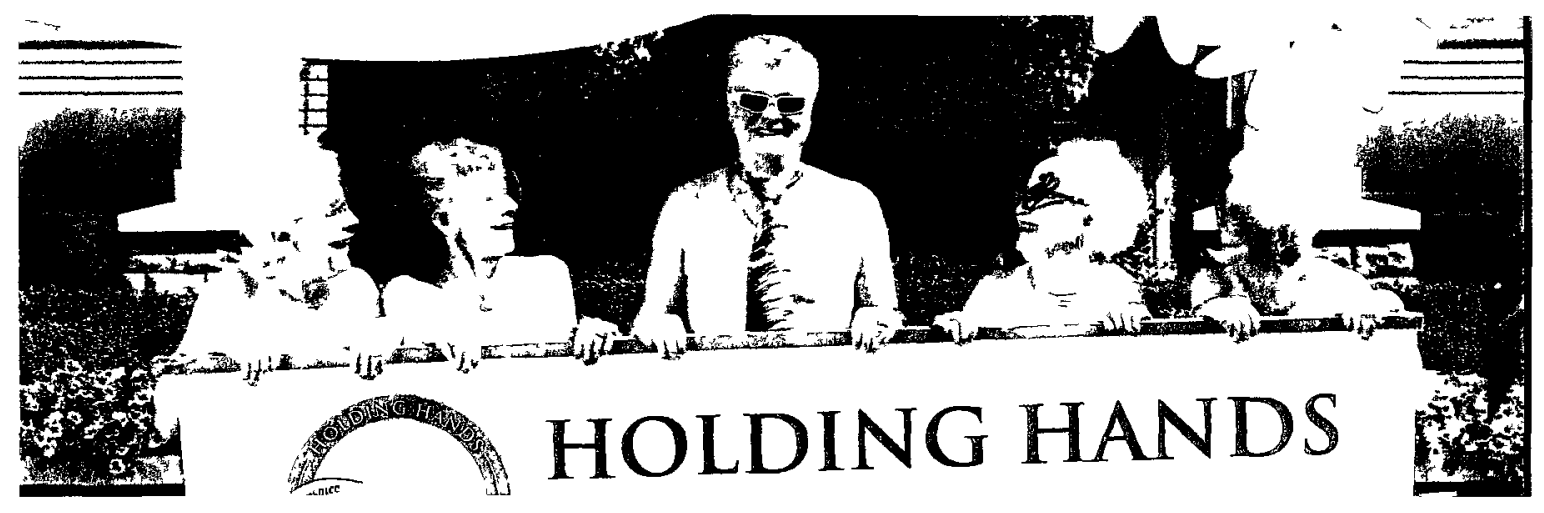

Lakelands is a good site for a case study of self-identity in a communal lifestyle organization. It has clear lifestyle objectives (Table 3.1), a history of being well run, and is backed by a management group experienced in seniors' living. Organizations, however, are internally referential. They are not stable unchanging entities. At times, an 
organization's strength and resilience can be severely tested by events. Prior to and during data collection, Lakelands faced external and internal challenges that tested everyone: management, staff and residents. Externally, the world economy was in crisis. In the Fall of 2008 the economy fell into a recession precipitated by the subprime crisis. The Canadian stock market tumbled and investors saw their retirement savings evaporate. Normally full, vacancy rates at Lakelands rose during the Fall of 2008 and the Winter of 2009. People who wanted to move to Lakelands could not do so, as they had trouble selling their homes.

Not only was Lakelands being buffeted by a severe economic crisis and a rising vacancy rate, it was also experiencing staff and management changes. In 2007 the General Manager fell ill, but continued to work. By the summer of 2008 his situation was serious and in December 2008 he passed away. During his absences, and after his death, one of the owners filled in as Interim Manager. In the Winter of 2009 the search began for a new manager and by April 2009 the new manager began work, just a week before the end of my stay.

In addition to the death of the former manager, there were other important personnel changes. The former Activity Coordinator and Assistant Activity Coordinator - key persons at Lakelands - left under circumstances of conflict in the summer of 2008. The new Activity Coordinator had been in the job for about 8 months when I began data collection in February 2009. In addition to these losses, a number of staff left in the Fall of 2008: maintenance, housekeeping staff, and dining room staff. As well, a kitchen staff 
member died while I was at Lakelands. While Lakelands lost many experienced staff it also retained a core group of experienced staff who maintained organizational continuity.

These challenges introduced conditions not contemplated in the research plan. This did not diminish the results, but rather emphasized Lakelands' major strength: people's ability to maintain "grace under fire." Despite external, organizational and personal crises, life "goes on" at Lakelands. Staff and residents experience these upheavals, but seem to ride the waves with grace, humour and a fairly detached attitude. This remarkable grace in the face of adversity is one of Lakeland residents' notable characteristics. Perhaps this is the gift of advanced age, the ability to greet the joys and troubles of the world with good will and equanimity (Grant, 2007).

\section{Data analysis}

The research design - a study of self-identity narratives in a natural setting - requires data analysis methods that are capable of analyzing language use, interpreting reflexivity, and making cross-case comparisons. This section discusses the two approaches to data analysis used in this study: qualitative narrative analysis and quantitative data analysis.

\subsection{Qualitative analysis: Narrative analysis}

To analyze interview and observational data, I used narrative analysis - a technique wellsuited to exploring self-identity (Riessman, 2008). There are many approaches to narrative analysis, approaches coloured by academic disciplines (e.g., linguistics, literary 
analysis, anthropology) and by epistemology (e.g., positivism, postmodernism). This study employs narrative methods recommended and employed by Riessman (1990, 1993, $2000,2002 a, b, 2004,2008)$, a sociologist and expert in narrative analysis with a social constructivist perspective.

The decision to use Riessman's approach is based on its epistemological and ontological congruence with Giddens' theory. As Miles and Huberman (1994) argue, methods should be congruent with theory. Riessman sees self-identity as a reflexive process involving self, social context, interpretation and continual revisions to selfidentity. Giddens and Riessman have similar views on self-identity, the reflexivity of micro and macro social life, and the importance of context to self-identity construction:

Whether personal narratives are spoken, written, or visual, they do not generate unmediated and unclassed portraits of an "essential" self. Such a singular self doesn't exist (in my view). An investigator cannot elicit an autobiographical story that is separable from wider conditions in which it is situated and constructed (Riessman, 2008, p. 177).

Riessman's method stays close to the case and reveals contextual conditions (Katz, 2005; Pentland, 1999), temporality (Rhodes \& Brown, 2005), event sequencing, cause and effect, people's theories about self and life, and reflexive micro-macro dynamics.

Riessman argues that informants construct narratives of the self at a particular point in time for a particular audience. This performance changes depending on conditions, as Riessman explains: 
If constructing the self is an ongoing project of daily living that happens through storytelling, attention moves away from "who I am" to questions of "when, where and how I am" (Riessman, 2008 p. 37).

Consequently, this study pays close attention to the conditions (i.e., the when, where, and how) that influence the reflexive project of the self.

Not only does Riessman's approach emphasize temporality, it emphasizes plurality and researcher subjectivity. Plurality preserves narrative diversity. It guards against, but does not preclude, master narratives (Boje, 2001). Subjectivity is related to plurality. It points to the narrative plurality that can exist in a research study with both respondent and researcher narratives. Riessman (2008) argues that interpretive narrative analysis is a co-creation between informants and researchers. Informants interpret their situation and communicate this to the researcher, who in turn, "interprets the interpretation," writing it up in narrative form. Riessman argues researchers should be reflexive, self-aware and distinguish between their narratives and participants' narratives. Riessman's definition of narrative reflects these layers of subjective analysis and interpretation:

The term narrative in the human sciences can refer to texts at several levels that overlap: stories told by research participants (which are themselves interpretive), interpretive accounts developed by an investigator based on interviews and fieldwork observation (a story about stories), and even the narrative a reader constructs after engaging with the participant's and investigator's narratives (Riessman, 2008, p. 6). 
Riessman's approach to narrative analysis shapes data collection, transcription and analysis. For instance, interviewing is influenced by the way narrative analysis privileges agency and story telling:

It is a common experience for investigators to carefully craft interview questions, only to have participants respond with lengthy accounts - long stories that appear, on the surface, to have little to do with the question ... Subsequently, I realized that participants were resisting our efforts to fragment their lived experience into thematic (code-able) categories - our attempts to control meaning (Riessman, 2000, p. 1).

To avoid this, both the resident and management interview protocols are designed to follow a conversational format. The interview protocol questions (Appendix E) are openended and general, encouraging informants to relate their narrative of the self. Respondents are encouraged to talk at length. Rarely did I try to illicit short answers. Although the protocol includes general, as well as prompt questions, I usually did not ask prompt questions, as people provided this information over the course of the interview.

In addition to interview methods, Riessman's theory can affect interview transcription methods. Riessman argues that transcription is data analysis. She recommends that transcripts convey contextual information such as the conditions of performance, the narrator and informant's words as they were spoken, even if they are not grammatical. Therefore, when transcribing interviews, I transcribed the entire conversation, with the exception of personal information that could identify the respondent. The transcript included my questions, respondents' answers, plus emotional 
responses (such as laughter and pauses) ${ }^{4}$. By doing this, the co-creation of narrative becomes more transparent to the reader.

In addition to interview transcription, Riessman's approach also influences analysis. To analyze interview transcripts, this study uses two methods recommended by Riessman (2008): thematic and structural narrative analysis. Thematic analysis focuses on what is said, or themes within each case. A theme is defined as a dominant subject or a prominent or frequently reoccurring idea (Barber, 2004). In this study, thematic analysis is used to analyze observational data and interview transcripts.

Although thematic analysis is similar to grounded theory, there are important differences. Whereas thematic analysis is case centred, grounded theory is concept centred. Grounded theory discourages a priori concepts, at least in the early stages of analysis, whereas thematic analysis looks for themes emerging from a priori theory (Riessman, 2008). Thematic analysis keeps stories intact, preserving temporal sequence and context, whereas grounded theory breaks data into small pieces, abstracting events from time and space, and generating a "stable set of concepts" across cases (Riessman, 2008; Miles \& Huberman, 1994).

Thematic analysis has strengths. It is intuitive, straightforward and applicable to all forms of data (i.e., interview and observational data). It also has two limitations. First, if used in cross-case analysis, as in this study, thematic analysis may emphasize similarities and minimize differences - for instance, emphasizing similarities between

4 This transcription was not as detailed as linguistic transcription. 
residents, or similarities between residents and management. Second, thematic analysis does not examine how things are said, or the performance aspects of narrative.

To remedy this, this study also employs Labov's structural analysis, which analyzes how things are said (Labov \& Waletzky, 1967; Labov, 1972). Whereas thematic analysis identifies narrators' explicit meanings, structural analysis explores implicit meanings. Thematic analysis focuses on discursive consciousness, or "the conscious reasons that people give to explain their behaviors and motivations" (Tucker, 1998, p. 81) whereas structural analysis focuses on practical consciousness or the "unarticulated beliefs and knowledges people use to orient themselves to situations and interpret the actions of others" (Tucker, 1998, p. 81).

Adapted from literary analysis, and a "touchstone" in narrative inquiry (Riessman, 2008, p. 15), Labov's structural analysis is appropriate for analyzing short narratives, such as interview question responses, where narrative conforms to a typical story structure. Labov defines six elements in a story, as outlined in Table 3.5.

This study uses Labov's method to analyze selected answers in resident interview transcripts. Employing verbatim transcripts, I coded the narratives, identifying the story function performed by independent clauses in the narrative (Labov, 1972). I then asked: How is the narrative structured? How does this serve the narrator's strategic objective? What are the implications for meaning?

\section{Table 3.5. Structural narrative analysis}




\begin{tabular}{|c|c|c|}
\hline Narrative element & Answers the question... & Function \\
\hline Abstract & What was this about? & Summary and/or point of the story. \\
\hline Orientation & $\begin{array}{l}\text { Who, when, what, } \\
\text { where? }\end{array}$ & $\begin{array}{l}\text { Orientation to time, place, characters, } \\
\text { situation. }\end{array}$ \\
\hline $\begin{array}{l}\text { Complicating } \\
\text { action }\end{array}$ & Then what happened? & $\begin{array}{l}\text { Event sequence, plot, usually with a } \\
\text { crisis or turning point. }\end{array}$ \\
\hline Evaluation & So what? & $\begin{array}{l}\text { The soul of the narrative. Narrator } \\
\text { steps back from action, conveys } \\
\text { emotions, comments on meaning. }\end{array}$ \\
\hline Result, resolution & $\begin{array}{l}\text { What finally } \\
\text { happened? }\end{array}$ & The plot outcome. \\
\hline Coda & $\begin{array}{l}\text { Is meant to put off the } \\
\text { "So what?" question. }\end{array}$ & $\begin{array}{l}\text { Ends the story, brings action back to } \\
\text { the present. }\end{array}$ \\
\hline
\end{tabular}

Note. From Labov (1972, p. 370) and Riessman (2008, p. 84).

Structural analysis has a number of benefits. Riessman notes: "Examining strategic placement can be of enormous aid in interpreting the relation between meaning and action" (Riessman, 2008, p. 89), especially in the early stages of analysis. In addition structural analysis keeps the story intact; points to micro and macro social forces influencing self-identity; is useful in tracing causes, conditions and outcomes in process theory (Pentland, 1999); uncovers emotion; and can detect language patterns. 
In addition to its strengths, structural analysis has limitations. It focuses on case specific analysis, information that is not necessarily repeated in other cases. Although some findings may not be generalizable to other cases, this may point to the limitations of Giddens' theory, that is, experiences that may not be theoretically generalizable to other cases.

Given the limitations of each, combining structural and thematic analysis strengthens the results. The strengths of one method compensate for the limitations of the other. Multiple methods produce multiple perspectives and enrich the study findings. It "forces investigators to look beyond initial impressions and see evidence through multiple lenses" (Eisenhardt, 1989, p.533).

\subsection{Narrative analysis plan}

As rigorous research implies systematic analysis, Riessman (2008) suggests investigators develop a systematic approach to thematic and structural analysis, since variability exists within these approaches. She recommends documenting analytical plans and making narrative analysis transparent to readers. Table 3.6 sets out such a plan. 
Table 3.6. The analytical plan: Narrative analysis tasks

Thematic analysis tasks

1. Identify themes, sequence, timing, causality, conditions.

2. Identify informant theories.

3. Identify similarities, differences (residents).

4. Assess similarities, differences between residents and management.

5. Assess possible communal lifestyle organizational typology.

6. Assess consistency in the lifestyle concept.

7. Identify gaps in Giddens' theory.

Structural analysis tasks

8. Structurally analyze selected typical and atypical answers for the research question "Who am I when I live in an organization?" (Research questions in chapters 7 to 14). Assess how the narrative is structured and how this serves the narrator's strategic objective. What are the implications for meaning?

Table 3.6 lists the various narrative analysis tasks performed in this study. Task \#1 focuses on themes, process and causality, as well as chronology. It keeps the case intact. Thematic task \#2 points out the relevance of informants' theories (Gubrium \& Holstein, 2006). It recognizes that an informant's theoretical lens may fall outside Giddens' theoretical notions. Tasks \#3 and \#4 look at resident and management views (within and between group differences). Depending on the circumstances, different views may indicate resident resistence to organizational control, whereas similarities may indicate residents' active involvement and cooperation in shaping the organization. Thematic tasks \#5 and \#6 assess whether there is enough similarity in these views to 
refine the communal lifestyle organization typology and the lifestyle notion defined in the literature review. Differences may point to the limits of these notions. Task \#7 looks for gaps: notions mentioned in Giddens' theory that are absent in the data or the opposite situation (i.e., notions that appear in the data that could be better understood if they were addressed in Giddens' theory). Task \#8, the structural analysis, focuses on the research question "Who am I when I live in an organization?" This analysis can uncover unique viewpoints as well as language patterns.

The analytical plan was implemented at various stages of the research: during interview transcription, while coding transcripts, and while writing the thesis document. I began with thematic analysis and analyzed the interview data. Throughout this analysis I was attentive to unusual language patterns or terms that might have implications for selfidentity. As well, I structurally analyzed selected typical, contrasting and discrepant answers relating to the research question "Who am I when I live in an organization?"

Appendix F lists examples of each narrative task and how it was implemented in the research. In addition to this appendix, I make reference to the tasks when discussing the study findings. I indicate how analyses implement a specific analytical task when describing the relevant findings.

\subsection{Case summary}


As part of the data analysis, I wrote a summary of each case. The purpose was to document a respondent's background, document themes or important issues, and to note case similarities and differences. I began the case summary while transcribing the interview. I returned a number of times over the course of the study to review and add to each case summary.

The summary identifies whether or not a case is an exemplar of a particular issue or theoretical notion. As well, it includes an analysis of the agency/structure relationship - how the informant has influenced Lakelands, and how Lakelands has influenced the informant. The case summary also includes a description of the respondent's apartment and furnishings, and documents other personal issues that do not appear in the transcript.

The case summary performed many of the thematic analysis tasks mentioned in the analytical plan. For instance, it documented any sequences, timing, causality and conditions that seemed important in the interview (task \#1); noted themes in the interview plus resident theories (tasks \#1 and \#2); described ways in which a respondent differed from other respondants (task \#3); and noted distinctive language uses (task \#8).

The case summary helps to offset one of the limitations of thematic analysis - an emphasis on cross-case similarities to the detriment of case particularities. The case summary helps to keep individual stories intact and document respondent's particularities.

\subsection{Quantitative analysis}


In addition to using qualitative analysis, the study uses quantitative statistical analysis such as frequencies, cross-tabulations, correlations and odds ratios. Since many of the variables in this study have abnormal distributions, the study uses the non-parametric correlation Spearman's rho for ratio, ordinal and interval data.

Use of non-parametric statistics raises the issue of statistical power. The small number of study cases $(n=30)$ also contributes to this problem. Two ways of improving power include using one-tailed tests and a more generous significance level (Stevens, 2002). To improve power this study uses one-tailed tests, whenever appropriate, and a .10 significance level to test associations. Many exploratory studies and studies with small samples use this figure. Stevens (2002, p. 4-5) notes that even a significance level between .10 and .15 is acceptable for small samples $(n \leq 20)$. To conserve as many cases as possible, this study uses pairwise deletion when calculating associations.

\subsection{Coding}

To facilitate data analysis, I electronically coded the interview transcripts using QDA Miner. The codes are both qualitative and quantitative in nature. The codes, which are described in Appendix G, capture detailed answers to interview protocol questions and the minutia of respondents' narratives including details about the moving decisionmaking process, people's positive and negative experiences at Lakelands, their thoughts on organizational performance; important conditions and factors; and, contextual information (i.e., local environment, relationships with family, language use and social life outside Lakelands). 
In this study, coding followed an inductive process, proceeding from the particular to the general, an approach recommended by Riessman (2008) and congruent with the study's social constructivist approach. Coding was detailed with a word by word and line by line coding of each case. This detailed inductive approach is designed to capture the range of respondents' experiences (Strauss \& Corbin, 1998) and to preserve informants' meanings and language, thereby enhancing validity (Riessman, 2008).

This method operationalizes Lofland and Lofland's (1995, p. 127-145) recommendations for finding data patterns. Coding identifies frequencies; magnitudes (e.g., good, moderate, poor); structures (e.g., organization types); processes; causes and consequences (e.g., positive and negative impacts). Coding performs many tasks outlined in the analytical plan (Table 3.6). Codes document themes, causality and conditions (task $\# 1$ ); informant theories (task \#2); and facilitate within group comparisons (task \#3); and comparisons between residents' and management's descriptions of Lakelands (task \#5).

Given the large amount of information contained in the interview transcripts, and the problem of data overload (Miles and Huberman, 1994), these codes are an effective way to analyze and summarize large amounts of data. They make the data readily accessible. They provide frequency counts. They assist in finding pertinent quotes, and they provide a tool for assessing the range and nature of people's experiences.

Although the codes facilitate many narrative analysis tasks and make the data easily accessible, they also tend to chop up the data. They are cumbersome for describing timing, sequencing, processes and complex reflexive relationships (tasks \#1 and \#8). These gaps are remedied by the case summary and by the structural analysis, which 
provide insights into process, the reflexive relationship between agency and structure, plus emotional and hidden issues.

To summarize, the study uses two types of data analysis: narrative and statistical analysis. Coding is helpful for both types of analysis. Since the study takes a social constructivist approach, and reflexivity is central to this perspective, narrative analysis dominates. None the less, statistical analysis, especially frequency counts and correlations, are used to explore conditions, verify observations and test associations.

\section{The data}

This section describes data collection and data quality. The section begins by describing the process for collecting data and selecting resident cases. Then it discusses the data and its quality - specifically whether or not there is enough variability in the data. Finally, the section looks at coding reliability and validity.

\subsection{Data collection}

The data collection process can influence data quality. This section describes the process for recruiting volunteers and selecting cases. To collect interview and observational data I lived at Lakelands for two and a half months - February 2009 to mid April 2009 - in one of Lakelands' furnished guest suites. To reinforce my independence from management, I paid going rental rates. This two and a half month stay supplements the year I had already spent living at Lakelands as my mother's guest ( 3 weeks to 4 months 
at a time), from the fall of 2002 to the summer of 2006, plus additional visits in 2007 and 2008.

To recruit research participants I sent a letter (Appendix C) inviting every person living at Lakelands to take part in the study. These letters were hand delivered: slipped under each person's door. Almost immediately I began receiving signed consent forms from residents, either slipped under my door or delivered to the front desk. A similar letter went to key management personnel (Appendix C). These letters were distributed through Lakelands' internal mail. Both letters explained the study purpose, intended use, major questions, my affiliations, confidentiality and consent issues.

The day after I arrived at Lakelands, management invited me to the weekly staff meeting to discuss the study. During the meeting, staff suggested I talk to the residents at the Friday coffee party. I did so and the room was full. About 45 residents attended. I spoke and answered questions for about 40 minutes. Afterwards I received another wave of signed consent forms. By the second week of the study I had received 28 signed consent forms plus verbal offers from many residents who said they would sign their consent forms if I needed additional participants. By week three I had received 35 firm offers from residents who wished to participate in the study.

In total, forty-one residents and three managers volunteered for the study. Overall, the rate of participation, or the number of volunteers divided by the number of invitations, was slightly lower for residents $(41 / 188=22 \%)$ than it was for management $(3 / 10=30 \%)$ 
One of the first steps after arriving at Lakelands in the Winter of 2009 was to pilot test the resident interview protocol (Appendix C). There were too few volunteers to test the management interview protocol. I tested the protocol in the first two weeks and made minor revisions. For example, I dropped two questions: one about whether or not residents think Lakelands is a "posh" place, and another that asked: What is it like to live here at Lakelands? How would you describe your experience to someone who knows nothing about Lakelands? People had trouble interpreting the first question and the second question turned out to be repetitious. Since the interview involved long conversations, other questions about life at Lakelands, such as "What is it like living with other people?" and "What is it like eating in the dining room?" produced the same information, but in a more systematic fashion.

After two weeks of data collection (or 7 resident interviews), I wrote the first of five status reports. These working documents outlined progress to date; decisions and inferences made during the research (Riessman, 2008, p. 191); interim findings (e.g., themes, rival narratives, interview results); problems with the research (e.g., changes to the interview protocol, case selection issues, bias problems); and, next steps. The purpose of these reports was to identify and correct analytical problems while in the field, and to begin analysis, interpretation and theory development as soon as possible (Miles \& Huberman, 1994, p. 78). These reports ranged in length from four to ten pages.

In total I conducted 3 interviews with management and 30 with residents. To ensure privacy and a tranquil, relaxed environment, all interviews either took place in the respondent's apartment, or in my apartment. Most people chose their apartments over 
mine. Interviews with management took place in various locales; my apartment, Lakelands' offices and in a restaurant.

Most people (31 out of 33) gave me permission to quote their interview transcripts. All 3 managers who I interviewed approved their transcripts for quotation. Of the 30 residents I interviewed, 28 gave me permission to quote their interview. The 2 residents who did not give permission were willing to allow their transcript to be used in the study, but not for quotation. Two persons, one resident and one manager, were not satisfied with the information they provided during the interview and rewrote their interview transcript. Both approved the revised transcript for quotation. Apart from these two revised transcripts, people either made minor revisions, or no revisions at all before approving the transcripts for quotation. In addition to the 30 resident interviews, I also received permission from a $31^{\text {st }}$ resident to quote two phrases that they used when describing Lakelands in our informal conversations. This person did not volunteer for a full interview, but did speak to me informally about their experiences at Lakelands.

\subsection{Replication logic: The case selection strategy}

Since I received more resident volunteers than needed to conduct the study, a strategy for choosing resident cases became important. Given that this is a multiple case study, the logic of replication guides resident case selection, rather than sampling logic. Each 
resident is a case. To select multiple cases, Yin (2003) recommends using replication logic. The goal is to produce variability:

The logic underlying the use of multiple-case studies is the same [as the replication logic used in multiple experiments]. Each case must be carefully selected so that it either (a) predicts similar results (a literal replication) or (b) predicts contrasting results but for predictable reasons (a theoretical replication)" (Yin, 2003, p. 47).

Like Yin, Miles and Huberman (1994) emphasize the importance of introducing as much variability as possible into a multiple case study. They suggest choosing typical cases as well as contrasting and discrepant cases (Miles \& Huberman, 1994, p. 34):

Three kinds of instances have great payoff. The first is the apparently "typical" or "representative" instance. If you can find it, try to find another one. The second is the "negative" or "disconfirming" instance: it gives you both the limits of your conclusions and the point of greatest variation. The third is the "exceptional" or "discrepant" instance. This instance will allow you to qualify your findings and to specify the variations or contingencies in the main patterns observed. Going deliberately after negative and atypical instances is also healthy in itself; it may force you to clarify your concepts, and may tell you that you indeed have sampled too narrowly (Miles \& Huberman, 1994, p. 34).

Consequently, this study selected resident cases based on the type of narrative they might produce: a typical, contrasting or discrepant narrative (Miles \& Huberman, 1994; Riessman, 2008). A typical narrative is defined as the most common narrative one hears (see Table 3.7). Contrasting narratives, which are less frequent, deviate from the typical case. They may negate or be a contrast to the typical case. Finally, there is the least frequent case, the discrepant case, which represents outliers. 
Table 3.7. Definition of typical, contrasting and discrepant narratives

\begin{tabular}{ll}
\hline Narratives & \multicolumn{1}{c}{ Definition } \\
\hline Typical & The most frequent or common narrative. Common opinion. \\
Contrasting & Less frequent than the typical narrative. Contrasts with, or may \\
& negate the typical narrative. \\
& The least frequent narrative. May negate the typical narrative. \\
\hline
\end{tabular}

The purpose of choosing a wide variety and range of cases is not statistical generalization, but rather analytic generalization: the ability to generalize from the data to the theoretical notions under consideration (Yin, 2003). Miles and Huberman (1994, p. 27-28) argue that in qualitative studies, such as this one, the most useful generalizations are analytic generalizations not "sample-to-population" generalizations.

Since the objective of replication logic is to produce variability in narratives, I identified three conditions that might produce this variability, based on the literature and my observations of Lakelands' life: length of stay, gender, and rebel behaviour. First, Giddens (1991), Goffman (1961) and Townsend (1962) agree that the crisis that is produced by moving may disrupt self-identity. Both Goffman (1961) and Townsend (1962) observe that over time these effects decline. Second, Townsend (1962) observed that men were more likely than women to complain about conditions in residential 
organizations. Some were openly aggressive. Third, I hypothesized based on my observations of life at Lakelands, that a person who is a rebel or eccentric might produce a discrepant narrative. I defined rebels as persons who exhibit behaviour or views that do not conform to social norms. They may flout dress or, eating conventions, have negative views, or complain a great deal.

These three variables - years resident at Lakelands, sex, and rebel behaviour were the three main criteria, or predictor variables, used to select resident cases. Table 3.8, which was developed prior to data collection, sets out predictions for the types of narratives that might be produced by these three variables, using the narrative definitions in Table 3.7. For instance, a typical narrative might come from a widowed woman who is a long time resident of Lakelands. Men who do not exhibit rebel behaviour might produce contrasting narratives, primarily due to their gender. Both men and women who are newcomers to Lakelands might produce narratives that contrast with the typical narrative. Initially, I defined a newcomer as someone who had lived at Lakelands for 6 months or less. During data collection I changed this to one year or less, as newcomers often told me they experienced adaptation problems for 10 months and sometimes more.

Table 3.8. Predicted narratives by case selection criteria

\begin{tabular}{lccc}
\hline \multirow{2}{*}{ Sex } & \multicolumn{2}{c}{ Years resident } & \\
\cline { 2 - 3 } & Less than one year & l year or more & Rebel behaviour \\
\hline Women & Contrasting narrative & Typical narrative & Discrepant \\
\hline & & & narrative
\end{tabular}


Men

Contrasting narrative

Typical or contrasting

narrative

In addition to choosing cases to ensure narrative variability, I also tried to choose a mix of cases that loosely resembled Lakelands' population, as measured by four variables: years resident, gender, marital status and age. Since women outnumber men at Lakelands, I tried to over sample men. The objective was to collect enough male cases to determine whether or not males and females experience life differently at Lakelands.

I established case selection targets for these four variables. Table 3.9 describes these targets and the extent to which the study achieved these targets. Given the large number of volunteers for this study $(n=41)$, most targets were implemented in whole or in part, with the exception of over representing men. Tables $3.10,3.11$ and 3.12 show frequency distributions for years resident, sex, marital status and age. 
Table 3.9. Resident case selection targets and results

\begin{tabular}{ll}
\hline Cases selection targets & Results \\
\hline Years resident & Target mostly achieved. \\
Select cases to resemble characteristics of & Study group case characteristics \\
Lakelands' population: & (See Table 3.10): \\
- mean years resident $=3.3$ years ${ }^{\text {a }}$ & - mean years resident $=3.9$ years \\
- wide flat distribution. & - wide distribution, but not flat. \\
- residency 1 year or less $=20 \%$ & - residency 1 year or less $=16 \%$ \\
\hline Sex & Target not achieved. \\
Over select men compared to percentage & (See Table 3.11): \\
in Lakelands' population: & Men in study group $=33 \%$ \\
- men in Lakelands' population $=29 \%$. & \\
\hline Marital status & Achieved. \\
Select cases to loosely resemble & Study group cases include married, \\
Lakelands' population: specifically, & widowed, divorced persons plus persons \\
- wide variety of marital situations. & in romantic relationships. \\
\hline Marital status by sex & Partially achieved. \\
Select cases to loosely resemble & Achieved for women. Unmarried men \\
Lakelands' population. & under represented and married men over \\
represented. (See Table 3.11).
\end{tabular}

Note.

${ }^{a}$ Statistic provided by Lakelands Retirement Resort. 
Table 3.10. Years resident: Study group ${ }^{a}$

\begin{tabular}{lcc}
\hline Years & Cases & Percent of total \\
\hline$\prec 1$ & 4 & 13 \\
1 & 1 & 3 \\
2 & 3 & 10 \\
3 & 4 & 13 \\
4 & 5 & 17 \\
5 & 8 & 27 \\
$6+$ & 5 & 17 \\
Total & 30 & 100 \\
\hline
\end{tabular}

Note. ${ }^{\mathrm{a}}$ The information in this table is provided by people in the study group.

Table 3.11. Lakelands' population compared to the study group: Marital status by sex

\begin{tabular}{lcccccc}
\hline \multirow{2}{*}{$\begin{array}{l}\text { Marital status } \\
\text { Row\% }\end{array}$} & \multicolumn{3}{c}{ Study group } & \multicolumn{3}{c}{ Population } \\
\cline { 2 - 7 } Column \% & Female & Male & Total & Female & Male & Total \\
\hline Unmarried & 16 & 1 & 17 & 102 & 21 & 123 \\
(Widowed, & $94 \%$ & $6 \%$ & $100 \%$ & $83 \%$ & $17 \%$ & $100 \%$ \\
divorced) & $80 \%$ & $10 \%$ & $57 \%$ & $76 \%$ & $39 \%$ & $65 \%$ \\
Married & 4 & 9 & 13 & 32 & 33 & 65 \\
& $31 \%$ & $69 \%$ & $100 \%$ & $49 \%$ & $51 \%$ & $100 \%$ \\
& $20 \%$ & $90 \%$ & $43 \%$ & $24 \%$ & $61 \%$ & $35 \%$ \\
Total & 20 & 10 & 30 & 134 & 54 & 188 \\
& $67 \%$ & $33 \%$ & $100 \%$ & $71 \%$ & $29 \%$ & $100 \%$ \\
& $100 \%$ & $100 \%$ & $100 \%$ & $100 \%$ & $100 \%$ & $100 \%$ \\
\hline
\end{tabular}


Table 3.12. Age of study group

\begin{tabular}{lcccccc}
\hline Age & Women & $\%$ & Men & $\%$ & Total & $\%$ \\
\hline$\prec 79$ & 3 & 15 & 0 & 0 & 3 & 10 \\
$80-84$ & 2 & 10 & 2 & 20 & 4 & 13 \\
$85-89$ & 8 & 40 & 4 & 40 & 12 & 40 \\
$\succ 90$ & 6 & 30 & 4 & 40 & 10 & 33 \\
Missing data & 1 & 5 & 0 & 0 & 1 & 3 \\
Total & 20 & 100 & 10 & 100 & 30 & 99 \\
\hline
\end{tabular}

Note. Mean $=84.167$ Median $=88$ Mode $=85$ Range $=20$ years.

\subsection{The process: Selecting cases}

This section describes how the case selection strategy was implemented. The process of selecting cases was done in three phases. First, I collected typical narratives, then contrasting narratives, and finally discrepant narratives. This approach conforms with Miles and Huberman's (1994) and Yin's (2003) approach to literal and theoretical replication.

Case selection began with typical narratives. My first interview was with a widowed woman who had lived at Lakelands for many years. Once this interview was complete, I attempted to find a similar case (literal replication) by choosing another woman with similar characteristics who would produce a typical narrative. I interviewed eight women who fell into this category. Then, to strengthen and refine the definition of 
typical and contrasting narratives, I chose a case expected to produce a contrasting narrative; a man who had lived at Lakelands for less than one year (a theoretical replication). This interview did seem to produce a contrasting narrative, as the theory predicted. I then returned to interviewing people with characteristics similar to the first eight interviews (a literal replication) in an effort to deepen and reinforce my understanding of typical narratives. I found similarities and differences in these narratives. For example, crises other than moving, such as health crises, seemed to produce contrasting narratives (Giddens, 1991).

After the eleventh interview I began collecting what I predicted would be typical or contrasting narratives based on Table 3.8. I interviewed all of the men who had volunteered for the study $(n=10)$. I theorized about the reasons why I was hearing typical narratives from some men, and contrasting and discrepant narratives from others. Once again years resident and crises seemed to play a role.

As I was interviewing these men I interviewed their spouses (those who had volunteered). This was an interesting contrast between related men and women. I interviewed spouses separately, usually one after the other, however, I did interview one couple together. I suggested separate interviews but the couple wished to be interviewed together. Thinking this an interesting experience, I agreed. Both produced a typical narrative. Sometimes spouses produced similar narratives and sometimes they did not.

After completing twenty interviews I established targets for the number of typical, contrasting and discrepant cases I hoped to collect: 50-60\% typical cases and a good representation of contrasting and discrepant cases. It was still not clear how many cases 
would be needed, however, I tentatively set the total number at 30 . After the twentieth interview I began interviewing people who had lived at Lakelands for a short period of time. I expected to encounter contrasting narratives. I interviewed all volunteers who had lived at Lakelands for one year or less, with the exception of one. Illness prevented this newcomer from being interviewed. These narratives seemed to contrast with narratives from respondents who had lived at Lakelands for many years. As the theory predicts, adaptation problems were fresh in people's minds. People were able to relate the ways in which self-identity was disrupted as a result of moving to Lakelands.

I interspersed newcomers with people expected to produce discrepant narratives; people who exhibit rebel behaviour. Many of these rebels have lived at Lakelands for a long time. Despite their norm breaking behaviour, most did not produce discrepant narratives. To increase contrasting and discrepant cases I concentrated on people who had lived at Lakelands for more than one year but were relative newcomers in that they had not lived at Lakelands for many years.

At some point I had to decide on the total number of cases to select. There are no statistical rules for this decision. Miles and Huberman (1994) argue that the key in multiple cases studies is to collect enough cases to have confidence in analytic generalizations. They argue that, depending on complexity, a multiple case study with more than 15 cases may be too "unwieldy." Yow (1994) suggests the saturation approach; when one has heard the same narrative many times one probably has enough cases. This makes sense for collecting typical cases, but given limits to my research resources, and given the problem of unwieldy data (Miles \& Huberman, 1994), it was not 
a viable approach for deciding on the number of contrasting and discrepant cases in this study.

In the end I conducted thirty resident interviews. As more residents volunteered to participate than needed, I thanked these people for their generous offer. I explained that I had received enough information to complete the study and needed to begin devoting resources to analysis.

At thirty cases I had enough cases to determine what constitutes a typical narrative. As well, I had a good number of contrasting and discrepant narratives. Additionally, the amount of data appeared formidable. I decided to heed Miles and Huberman's (1994) warning not to exceed research resources by choosing too many cases.

\subsection{The data and narrative classification}

Shortly after I began interviewing residents, I developed a table, or matrix, that summarizes answers to ten major interview questions (Appendix H, Table H.01). The matrix serves a number of purposes. Since it summarizes narrative trends, it guided the resident case selection process. As well, it was helpful in theorizing results and facilitating cross-case analysis over the course of the study.

In addition to summarizing responses, the matrix compares predicted (i.e., column P) and actual narratives (i.e., columns T, C, and D). This points to the effectiveness (or ineffectiveness) of the predictor variables (years resident, sex, rebel behaviour) in 
predicting narrative outcomes. The reader should note that column $\mathrm{P}$ is a case-level measure, whereas columns T, C and D are an answer-level measure (i.e., narratives for interview protocol questions).

Near the end of the data collection process, it became evident that the narrative classification scheme that I had used to predict narratives before the interview took place was not systematic enough to reliably categorize narratives after the interview (see Tables 3.7 and 3.8). To illustrate, a respondent might give typical answers to some interview questions but not to others. Should the case be classified as typical or something else? Therefore, I developed a new method that classifies each answer to an interview protocol question, rather than the entire case, as in the first method.

This new method operationalizes the narrative definitions in Table 3.7 at the level of the interview question, whereas the initial method tried to categorize a respondent's interview transcript as a whole. A contrasting narrative is defined as less frequent than a typical answer, but more frequent than a discrepant answer. A discrepant answer is the least frequent response.

Using interview transcripts, the electronic coding and the data matrix, I determined which responses fell into these three narrative categories. Appendix I, Table I.01 lists the results: typical, contrasting and discrepant answers for 10 interview questions. The matrix indicates that a respondent might have ten typical answers, or any combination of typical, contrasting and discrepant narratives.

This revised method has a many benefits. First, it is systematic and reliable. Another researcher could reproduce the same post-interview narrative measures as this 
study. Second, the method is transparent. It defines what is meant by a typical, contrasting and discrepant narrative for 10 interview questions. Third, since this measure defines what is meant by "narrative variation," it can be used to measure narrative typicality within a case and between cases. Fourth, the measure can be converted to numerical terms, lending itself to statistical analysis. The one caveat is that these three measures are statistically dependent, which limits their use in quantitative analysis. Table H.01 shows how typical, contrasting and discrepant answers are converted to frequencies and percentages.

\subsection{Narrative variability}

In addition to these advantages, this new narrative classification method is useful for determining the extent to which the study achieved its case selection objective - to collect as wide a range of typical, contrasting and discrepant resident narratives as possible (i.e., both literal and theoretical replication). Even though the predictor variables (years resident, sex and rebel behaviour) were not always accurate in predicting narrative outcomes, the study achieved the narrative variability objective that 50 to $60 \%$ of narratives should be typical and there should be a good representation of contrasting and discrepant narratives.

Table 3.13 shows the degree of narrative variability achieved. It calculates the number and percentage of typical, contrasting and discrepant narratives. Typical narratives represent about $70 \%$ of all narratives. This is slightly higher than the target. Although the percentage of typical narratives is higher than the target, there is a good 
percentage of contrasting narratives, with an adequate number of discrepant narratives. Although the number of discrepant narratives is relatively small, given that these types of answers are expected to be infrequent, these numbers seem reasonable.

Table 3.13. Narrative variability

\begin{tabular}{lcc}
\hline Narratives & Frequency of answers & \% of Total \\
\hline Typical & 175 & 71 \\
Contrasting & 53 & 21 \\
Discrepant & 18 & 7 \\
Total & 246 & 100 \\
\hline
\end{tabular}

Note. Cases $=30$. The narrative frequency data come from the data matrix, Appendix H, Table H.01

\subsection{Coding: Reliability and validity}

In addition to assessing narrative variability, there are a number of other criteria for determining the quality of the data. This section examines the reliability and validity of two classification or coding schemes used to analyze this data; the new narrative classification method described above, and interview coding (Appendix G). Determining the reliability and validity of these methods is important since data interpretation relies on these two coding schemes.

First, how reliable and valid is the narrative classification scheme used to classify responses to ten respondent questions? The previous section discusses this approach in 
detail and suggests that the system is reliable. Each narrative category is clearly defined and simple to apply. Another researcher could produce the same results from the same data.

As for validity, do the three narrative categories have construct validity? Is a typical narrative different than a contrasting or discrepant narrative? Babbie and Benaquisto (2002) define construct validity as: "The degree to which a measure relates to other variables as expected within a system of theoretical relationships." The narrative classification scheme meets this requirement. There are clear theoretical distinctions between typical, contrasting and discrepant narratives: distinctions that are based in Miles and Huberman (1994) and Yin (2003) writings on the use of replication logic in multiple case studies, plus the narrative definitions in Table 3.7. Further, as the results show, these classifications are related to other concepts in meaningful ways.

In addition to the narrative classification scheme, this study relies on a thematic coding scheme to code interview transcripts. A list of final 150 codes can be found in Appendix G. The first code book had over 700 codes. To verify the reliability of these qualitative codes, a second researcher coded six interviews ( $20 \%$ of the cases) chosen randomly from the 30 cases. Cases with typical, contrasting and discrepant narratives were randomly selected in the same proportion as they occur in the dataset (Babbie \& Benaquisto, 2002). The sample included three cases that consisted largely of typical narratives, two with primarily contrasting narratives, and one with a primarily discrepant narrative. Since the new narrative classification method does not classify cases, but rather respondent answers to interview questions, I devised a method to aggregate question 
responses to the case level so that I could draw a random sample of cases. Appendix $\mathbf{J}$ describes this method.

To ensure that the second coder understood the code book logic, the second coder attended two training sessions (of two hours each) to learn about the study's theoretical framework, research and interview questions, and to practice coding. After completing half of the first interview with the researcher, using the same code book as the researcher, the coder independently coded the remainder of the training interview as well as the five other interviews. Although the coder saw the code assignments for the training interview, the coder did not see the researcher's code assignments for the five remaining interviews.

Table 3.14 reports two measures of intercoder agreement. The simplest measure, percent agreement, calculates the proportion of coding decisions on which the two coders agreed - indicating $89 \%$ agreement. The second measure, Scott's phi, is a more conservative measure. It takes agreements that happen by chance into account - both the observed proportion of agreements between coders plus the proportion that would be expected by chance (Craig, 1981). These results are within acceptable limits for exploratory research such as this study (Krippendorf, 2004; Lombard, Snyder-Duch \& Bracken, 2002).

Table 3.14. Intercoder agreement statistics

\begin{tabular}{lcc}
\hline Presence or absence in case & $\%$ agreement & Scott's phi \\
\hline The training case & 93.6 & - \\
\hline
\end{tabular}


Five cases

Total $(n=6)$
86.5

88.8
0.703

0.75

\subsection{Rigour of the analysis}

The previous section on data analysis raises the issue of scientific rigour. It discusses the extent to which the study achieved its narrative variability objective, plus the reliability and validity of coding schemes. Although these standards apply to elements of the study, they do not address the study as a whole. What should be the overall standard for scientific rigour in this study?

Riessman (2008) argues that positivist standards for assessing rigour are inappropriate for interpretive narrative research, such as this study. Interpretive research is based on different ontological and epistemological premises than positivist research. Whereas positivism assumes the existence of stable truths, interpretive ontology assumes reflexivity - agents continually recreate social realities. By nature, narratives of the self vary depending on audience, conditions and timing (Atkinson, 1998; Riessman, 2008).

Riessman (2008) also argues that it is inappropriate, in interpretive narrative research, to define validity in positivist terms such as the truthfulness of informant narratives. As Denzin notes:

Narratives do not establish the truth of . . . such events, nor does narrative reflect the truth of experience. Narratives create the very events they reflect upon. In this 
sense, narratives are reflections on - not of - the world as it is known (Denzin, 2000, pp. xii-xiii).

Denzin's idea is consistent with Riessman's notion that narratives are a person's interpretation of reality. Interpretation varies from person to person. These ideas are consistent with Giddens' notion of reflexivity, which argues that people continually revise their narratives of the self, and in doing so, remake their social world.

To identify appropriate standards for interpretive narrative research, Riessman (2008) suggests looking at validity from two perspectives: first, the validity of the respondent's narrative, and second, the validity of the researcher's narrative. In the case of respondents' narratives, validity refers to subjectivity: information that conveys what people mean. Questions to consider include: How well does the research explore informants' explicit and implicit meanings? Do the researcher and the reader come away with an understanding of how informants understand and interpret their lives? Does the researcher adequately explore a plurality of subjective meanings? Are narratives complete? Are sequences, context and conditions preserved?

In the case of the researcher's narrative, validity refers to how well the researcher describes and interprets informant narratives, how transparent and replicable the research is, and whether or not the researcher has used appropriate methods and interpretation: To support theoretical claims, students must demonstrate how they developed and/or used methods appropriate to their research questions, epistemologies, and situated perspectives (Riessman, 2008, p. 188).

This study integrates these validity standards (i.e.,validity of participant and informant accounts, appropriate research design, transparency, replicability) into all 
phases of the research: the research plan, data collection, data analysis, and the thesis document. To improve the validity of informants' narratives, written transcripts include the researcher's and the participant's words. This documents how the informant's account of self-identity is influenced by the researcher and vice versa. The thesis document incorporates lengthy informant quotes. This allows the reader to follow the researcher's analysis and learn from the informant, rather than from the researcher.

To ensure the validity of the researcher's account, I have described and justified the study's epistemological and ontological premises, as well as theoretical and methodological choices such as using Giddens' theory as an interpretive lens; using case study methods; using Riessman's approach to narrative analysis; and supplementing qualitative methods with quantitative analysis.

In addition to using an appropriate research design, the thesis is written in such a way as to make the research process transparent, thereby improving validity. The thesis describes the research plan and assesses the effectiveness of the study design (e.g., case selection, coding reliability). The thesis creates an audit trail showing linkages between the research plan, the data analysis plan, data interpretation and conclusions. As well, the thesis ensures transparency by displaying summary results in Appendices $\mathrm{G}$ and $\mathrm{H}$.

To further ensure research validity, the thesis contains a plurality of narratives supported by evidence. The objective is to ensure that the researcher's narrative does not drown out informants' narratives. To illustrate plurality, I summarize the range of responses and balance this with respondent quotes. I link narrators' stories to theory (Miles \& Huberman, 1994), identify gaps between a priori theory and real life narratives, 
and explore alternative explanations and emerging theories. While writing the thesis I noticed that an over reliance on statistical techniques can suppress informants' voices. To remedy this, I have tried to balance qualitative and quantitative techniques.

A final condition for ensuring validity - replicability - can only be met in part in this study. Publishing the summary results in Appendix H provides a source of raw data for future research. Riessman (2008) also suggests making the raw data available to other researchers. The study's confidentiality provisions do not allow this. Producing a complete transcript might allow persons who are familiar with Lakelands, such as Lakelands' residents or management, to identify an informant. The decision to use narrative analysis remedies this in part, since the thesis reports selected verbatim narratives that researchers may use in future studies. These quotes disguise identities.

\section{Summary}

This section described how the study methods are appropriate given the study objectives, research questions, theory and epistemology. This section discussed how using multiple sources of data and multiple analytical methods helps to triangulate data and analysis thereby increasing confidence in the results. By describing data collection, data quality and data analysis plans, this section discusses how standards for ensuring rigour were integrated into all aspects of the research design.

The intent of this study is to convey, from an informant's point of view, whether one can live the way one likes in a communal lifestyle organization such as Lakelands. 
The findings (chapters 4 to 15), discuss typical and contrasting viewpoints: the joys and the disadvantages of living at Lakelands. These chapters answer the four basic research questions in the following order: Who am I? Am I what I consume? How do I describe the organization? and Who am I when I live in an organization? 


\section{CHAPTER FOUR}

\section{Who am I?}

This chapter begins with the "Who am I?" question. It discusses the characteristics of people who live at Lakelands. This section also discusses residents' moving history. This section is an example of narrative analysis task \#3 - identify similarities and differences between residents.

As Riessman (2008) points out, the question in social constructivist research is not Who am I? which is a functionalist view of self-identity, but rather "When, where and how I am?" (Riessman, 2008 p. 37). In other words, Who am I at a particular point in time under particular conditions? This section focuses on people's experiences before they moved to Lakelands - their background (e.g., demographic characteristics, occupation, family situation, health) - and, why they decided to leave their previous home. From a social constructionist point of view, this section partially answers the "Who am I?" question.

\section{People's characteristics}

A common way to describe self-identity is to discuss a person's background: their gender, marital status, occupation, family characteristics, and health. Men and women in the study group differ widely on marital status. Although over forty percent (43\%) of 
respondents are married, $90 \%$ of men are married whereas only $20 \%$ of women are married. The average age is 85 , with an age range of 20 years. (See Tables $3.5,3.6$ ). Most respondents are white English speaking middle and upper middle class people born in Canada, although $10 \%$ of respondents were born outside Canada. A few speak languages other than English (e.g., French or German).

Most respondents are retired, although I noticed that some people worked for money on a part-time, self-employed basis. Table 4.1 describes people's primary first and second occupations before they retired. To preserve confidentiality, a number of occupational categories were collapsed together. Most primary occupations fall into the professional category where pension benefits are common: management, financial services, health, social services and teaching. Over half of the men I interviewed mentioned their involvement in the Second World War. As veterans, many are entitled to Veteran's benefits. Men's experiences in the war are not included in Table 4.1.

Many women worked outside the home at some point in their lives, either while they were raising their children or afterwards. Women who worked outside the home are entitled to Canada Pension Plan benefits as well as Old Age security. This is a cushion against loss of income when a spouse passes away. The stereotype of the woman who stays at home does not apply to most women I interviewed. Only about $15 \%$ were homemakers their entire lives. [One reason for this may be that homemakers would, ceteris paribus, have lower retirement incomes and be less able to afford Lakelands.] 
Table 4.1. Respondent's primary occupational history

\begin{tabular}{lcccc}
\hline & \multicolumn{4}{c}{ Primary occupations } \\
\cline { 2 - 5 } Type of Occupation & First & $\%$ & Second & $\%$ \\
\hline Management, finance & 4 & 13 & 5 & 17 \\
Health, science, social services, teaching & 8 & 27 & 2 & 7 \\
Trades, farming, sales, administration & 8 & 27 & 2 & 7 \\
Homemaker & 4 & 13 & 4 & 13 \\
Fabrication - textiles, arts and crafts & 3 & 10 & 2 & 7 \\
Transportation and protective services & 3 & 10 & 0 & 0 \\
Not applicable & 0 & 0 & 15 & 50 \\
Total cases & 30 & 100 & 30 & 100 \\
\hline
\end{tabular}

Note. To protect confidentiality, some occupations have been added together.

In addition to occupation, children and immediate family are important when describing self-identity. Especially as one ages, or one's health declines, immediate family can be of great support. Although people who live at Lakelands come from all over Canada, many have moved to the area either because they, and/or their children have retired to the community. Table 4.2 shows that three out of four persons in the study group have one or more immediate family members living nearby (within about a 100 kilometer radius). Table 4.3 shows the importance of grandchildren as well - about one third $(30 \%)$, have grand or great grandchildren living nearby. 
Table 4.2. Family living nearby

\begin{tabular}{lcc}
\hline Answer & Cases & $\%$ \\
\hline No & 8 & 27 \\
Yes, nearby & 22 & 73 \\
Total cases & 30 & 100 \\
\hline
\end{tabular}

Note. Family is defined as children, (great) grandchildren, sons and daughters-in-law.

Table 4.3. (Great) grandchildren living nearby

\begin{tabular}{lcc}
\hline (Great) grandchildren & Cases & $\%$ \\
\hline No & 14 & 47 \\
Yes & 10 & 33 \\
Missing data & & 20 \\
Total cases & 6 & 100 \\
\hline
\end{tabular}

Note.

${ }^{a}$ Six persons did not mention whether have (great) grandchildren.

In addition to family characteristics, health is important to self-identity. As Table 4.4 shows, most people in the study group (over $90 \%$ ) are in good or moderate overall health, based on my observations and respondent's conversations about their health. In Table 4.4, I defined "good overall health" as being visibly in good overall health with no major overall health problems; "moderate health" as visible signs of declining health such as a rapid decline in appearance and physical capabilities, but nothing seemingly life 
threatening; and "poor health" as serious health problems that seem life threatening.

These categories - good, moderate, poor - also apply to memory and hearing. In the case of memory, "poor" was defined to mean a total failure of memory or hearing. Only a few people in the study group have serious hearing problems and none have serious memory problems.

Table 4.4. Study group's health

\begin{tabular}{lcccccccc}
\hline & \multicolumn{1}{c}{ Health } \\
\cline { 2 - 9 } Assessment & Overall & $\%$ & Memory & $\%$ & Hearing & $\%$ & Eyesight & $\%$ \\
\hline Good & 20 & 66 & 29 & 97 & 27 & 90 & 25 & 83 \\
Moderate & 8 & 27 & 1 & 3 & 1 & 7 & 2 & 7 \\
Poor & 2 & 7 & 0 & 0 & 2 & 3 & 3 & 10 \\
Total cases & 30 & 100 & 30 & 100 & 30 & 100 & 30 & 100 \\
\hline
\end{tabular}

Note. This assessment of a person's overall health is based on my observations plus information provided by the respondent.

Eyesight poses more problems than memory or hearing. Eyesight problems are based on my observations and what the resident said during the interview about their eyesight. Some people see well, but having had a stroke, they have difficulties reading. Some people have macular degeneration, a progressive disease that can lead to blindness. The value "good" refers to persons with no difficulties, "moderate" refers to people who say they have difficulty reading or can't read, and "poor" refers to people with macular degeneration, and people who are partially or totally blind. 
Mobility is an even greater problem than eyesight. Forty-three percent of the people I interviewed use walking aids of one kind or another (see Table 4.5).

Table 4.5. Respondents using walking aids

\begin{tabular}{lcc}
\hline Type of aid & Cases & $\%$ \\
\hline None & 17 & 57 \\
Cane & 2 & 7 \\
Walker & 10 & 33 \\
Wheelchair & 1 & 3 \\
Total cases & 30 & 100 \\
\hline
\end{tabular}

Note. This assessment is based on information provided by respondent and on my observations.

Given people's relatively good health, one might assume that people at Lakelands are younger than people who live in assisted living and long-term care. As a Lakelands' manager pointed out, the average age at Lakelands is the same as people in the oompany's former assisted and long-term care facilities:

Manager: I had done some statistics from the company years ago about our population, back when we had long-term care and assisted living as part of our portfolio. Looking at our average client age, and interestingly enough, our average client age at our independent, our assisted living, and in our long-termcare components was almost identical. Like they all fell within one year ... It's not that we get a younger client here at Lakelands, who then ages and goes into assisted living, ages some more and goes into long-term-care. I think it speaks more to about how an individual, who takes care of themselves or their 
own particular medical circumstances, or to their life, as to whether they end up still being healthy well into their $80 \mathrm{~s}$, as opposed to either not living that long or needing more medical care when they get into their $80 \mathrm{~s}$.

In addition to information on people's health problems, I observed people's personalities: whether or not people are introverts or extroverts (see Table 4.6). This assessment is based on my observations. I classified a person as an extrovert if they are involved in many Lakelands' activities, cultivate many friends/acquaintances, and try to adapt the environment to themselves by, for example, sitting on committees or trying to change public opinion. I defined introverts as people who are not involved in many activities, have limited friends/acquaintances, and who adapt to their environment, rather than trying to change it. The following table indicates that there are more extroverts $(67 \%)$ than introverts $(33 \%)$ in the study group.

Table 4.6. Respondents' personalities: Extrovert or introvert

\begin{tabular}{lcccccc}
\hline Personality & Female & $\%$ & Male & $\%$ & Total & $\%$ \\
\hline Extrovert & 14 & 70 & 6 & 60 & 20 & 67 \\
Introvert & 6 & 30 & 4 & 40 & 10 & 33 \\
Total cases & 20 & $100 \%$ & 10 & 100 & 30 & 100 \\
\hline
\end{tabular}

Note. This assessment of a respondent's personality is based on my observations.

One person who I interviewed advanced a theory about extroversion at Lakelands. This relates to narrative analysis task $\# 2$ - document informants' theories. Marlene (a pseudonym, as are all names in this document) theorizes that extroverts are attracted to 
places like Lakelands because it fits their lifestyle; they need to be surrounded by people: Marlene: But I think, to an extroverted type, it [Lakelands] offers much more, you know. I would say I'm an extrovert, but there's a good bit of introvert in my nature. So, it's more suitable for more extroverted people who can't, you know, some people hate to be alone, and they want to have people around them, things happening - music or whatever.

\section{Moving}

In addition to collecting information on people's demographic characteristics and personality, I collected information on their moving history. Most respondents do not leave the family home and come directly to Lakelands (see Table 4.7). People described a series of moves: to an apartment, condominium, or gated community before moving to Lakelands. A large number of respondents either lived in a gated community (43\%) or in a condominium or apartment (27\%) before moving to Lakelands.

Table 4.7. Type of residence prior to Lakelands

\begin{tabular}{lcc}
\hline Type & Cases \# & $\%$ \\
\hline House & 5 & 17 \\
Apartment & 3 & 10 \\
Condominium & 5 & 17 \\
Gated community & 13 & 43 \\
Independent living residence ${ }^{\mathrm{a}}$ & 4 & 13 \\
Total & 30 & 100 \\
\hline Notes. & &
\end{tabular}


Table 4.8 indicates that respondents move for a variety of interrelated reasons. They may be tired of housekeeping, have health problems, or may have to give up their car. This can lead to difficulties in taking care of the house, which in turn increases the need for services such as gardeners, home support, health care, transportation, and security. These services may not be readily available, may be expensive, or may be difficult to manage. As parents age, children may worry about their parent's well being. Parents in turn may be worried about becoming a burden on their children. When parents live in another town they may move to Lakelands to be closer to their children.

Table 4.8. Reasons for moving

\begin{tabular}{lcc}
\hline Reasons & Mentions \# & $\%$ \\
\hline Loneliness, depressed, not happy with home. & 11 & 28 \\
Housekeeping too much work, need & 11 & 28 \\
services. & & \\
Declining health. & 6 & 15 \\
Relieve burden on children. & 4 & 11 \\
Be closer to children/family. & 2 & 5 \\
Live in a better climate. & 1 & 3 \\
Control housing choice, enjoy retirement. & 4 & 10 \\
Total & 39 & 101 \\
\hline
\end{tabular}

Note "Mentions \#" refers to the number of people who mention a particular reason for moving. People may give more than one reason for leaving their former homes. Therefore, the total number of mentions is greater than the total number of cases. 
Collapsing these interrelated codes together - too much work, declining health, relieve burden on children, need services, and to be closer to children - accounts for two thirds $(60 \%)$ of respondents' reasons for moving. These collapsed codes relate to the burden of maintaining a household. This points to the difficulties older people may encounter when trying to manage nuclear family households, even if their home is low maintenance.

Loneliness and depression are important reasons for moving, especially for one out of three women in the group. This relates to narrative analysis task \#1 - identify themes, sequences, timing, causality and conditions. Loneliness can be caused by the death of a spouse or friends, and is exacerbated by living alone and having insufficient contact with people.

Victoria: And then I got depressed. I didn't have anybody to talk to. The people all had their own homes and nobody talked to anybody. We had a tea party, once a week, and hardly anybody came. And they didn't have any activities - nothing to get together with people. And I think that's why I got so depressed because I love people.

Men did not mention loneliness as a reason for moving, perhaps because all of the men in the study group, with the exception of one, are married (Lee \& DeMaris, 2007). Marriage, however, is not a safeguard against loneliness, as one married woman pointed out. Married people can also suffer from loneliness brought on by lack of social contact: Rosemary: I thought, oh, how nice it would be to have a bigger family, but they had their own lives to live and families.

Margot: That's the thing eh.

Rosemary: So I was lonely. And I think I was lonely for the [\#] years I was there. Margot: Oh, [\#] years! Wow! 
Rosemary: I umm . . . Because we had the cars then. Now we don't have any. I was able to get out a bit. I joined an exercise class. But it was monotonous: [personal information]. No, I was lonely.

Margot: Are you lonely here?

Rosemary: No, not a bit!

In sum, Table 4.8 points to a complex set of conditions and interrelationships influencing respondents' moving decisions and housing needs (Folts \& Muir, 2002; Laws, 1996; Trottier et al., 2000). People may move due to loneliness, because they are looking for places that require less work, and/or because their health is deteriorating.

\section{Life-planning}

Some people (11\%) said that they moved because they want to enjoy life, or they want to plan for the future and make their own moving decisions while they can. This points to the relevance of Giddens' notion of life-planning: making strategic decisions about lifestyle options, decisions that consider risk and the projected lifespan (Giddens, 1991, p. 243). Deciding to move to a communal lifestyle sector, rather than staying where one is, hiring help, ordering meals on wheels, or living with one's children, is a strategic decision about lifestyle options. In making these decisions, people consider risks, especially the risk of serious illness.

A number of respondents talked about life-planning (see Table 4.8). Three respondents - Elton, Olivia and Edward - recommend life-planning as a way to manage risks: the risk of having to move due to illness, or of losing decision-making control over one's lifestyle:

Elton: I was saying a lot of people that come in here are not ready for it. They left 
it too long before they found out what they were doing. And then, they come in here, they come in for a couple of months or so. And first thing you know, one of them has passed on, or they're looking after them - then they disappear. We've got quite a bit of that going on here. And if the people coming into places like this should make up their mind early like we did, when we were well able to go around. We had three or four years, we'd go and come as we liked. But we got to the point where we were, that we're getting to, [personal information]. So we said we want to go to the place we like ourselves. And we'll take care of ourselves. We don't want somebody telling us where to go. We made up our, my, mind a little earlier than maybe we should have done, but we felt we'd done it at the right time.

As Elton said, when considering end of lifespan risks, one may move too soon or too late, however, Elton prefers the risks of moving too soon. In waiting too long, one risks being overwhelmed not just by one crisis but by a series of crises: declining health and moving. Olivia argues that if one plans for these risks, one can enjoy life:

Olivia: If they can plan ahead and see what's coming and come while they're still active and able to join in they'll adapt much better than if they wait until they absolutely have to come ... And when they're so old that they, they won't be here very long, then they should come when they're still active, and able to join in and enjoy the place. [Long pause].

Elton and Olivia see life-planning as a strategy to maintain autonomy, to control one's lifestyle options, and to enjoy life for as long as possible.

People who are care givers talked about the benefits of life-planning for themselves and their spouses. One resident mentioned that the move to Lakelands stabilized their spouse's illness. It has given them time to enjoy life:

Margot: You mentioned that you thought that by moving here you'd gotten an extra [\#] years with [spouse] that you wouldn't have had if you had lived ... 
continued living at [the gated community]? What was it here that helped you get that extra time with her?

Resident: Like the meals are provided, cleaning house . . . and so forth were their responsibility. You know, they come in cleaning once a week, changing linen, things that I could do over there. But it was a struggle to maintain all that standard of living, together with my worries about [my spouse]. And to a degree that was somewhat alleviated when we moved over here.

What about people who do not successfully manage risks? Ursula talked about what happened to her, how she was forced to move to Lakelands because of ill health. Decision-making was taken out of her hands. This is what Elton, Edward and Olivia were trying to avoid when they moved to Lakelands. In describing her experience, notice how Ursula used the phrase "on and on," to emphasize how crises piled up:

Ursula: I had, I got a little bit sick and it turned out that I had [type of sickness]. And of course, unfortunately at the same time my regular doctor [gave up their practice]. So she left, and then the clinic ended up having a . . there would be a different person. And that was really bad, bad.

Margot: Bad, bad. Yah.

Ursusla: And these accumulated, and on and on, until I got really sick. And that ended it right there. They had the family [laugh] meeting. And that was the end of that. Mom wasn't living by herself anymore. Of course, mom wasn't to live with [the family] either. [Laughing]. So I looked at places in [city] and on and on. [Discussion]. But then they didn't want me to live in an apartment because I'd have to get groceries. And I didn't know my way around, and on and on it goes. The decision to move is essentially taken away from Ursusla. Ursula loses her autonomy first to ill health, and secondly to her family who are afraid for her well-being. Although the family decided that Ursula could no longer live alone in an apartment, they allowed her to decide where she would move. 
Although the findings suggest that Giddens' notion of life-planning is relevant to this study, Giddens' assumption of an autonomous decision-maker does not always fit older people's experiences, as Ursula's narrative illustrates. This relates to narrative analysis task \#7 - identify gaps in Giddens' theory. The findings indicate that there is a wide autonomy continuum at Lakelands. A parent may make the decision to move to Lakelands and not consult the children, it may be a shared decision, the decision may be precipitated by the family, or a parent may be moved to Lakelands without any consultation, as this resident's experience illustrates:

Resident: I came here, but I didn't know I was coming. Margot: You didn't know you were coming.

Resident: No, because I'd been in the hospital for [a certain amount of time]. [Discussion].

Resident: [Describes illness]. And all of a sudden, we arrived here. And [the family] said: "This is your new home." And I said, "This is my what!" Although this resident's experience is extreme, they are not alone. I have been told over the years by residents that a number of people have had this experience. I was unable to substantiate this information. These people would be in addition to this resident, since they have not told anyone, except myself, about this experience.

This resident's experience illustrates limits to Giddens' notion of life-planning. In addition to limited autonomy, older persons may experience limited lifestyle options. This relates to narrative analysis task \#6 - assess consistency in the lifestyle concept. The reality is that housing options decline if one's health deteriorates. The options that are available do not necessary meet people's lifestyle preferences:

Olivia: And I hope we don't have to go to a nursing home. I guess they're nice too, some of them. But they are more restrictive and more - you're more 
dependent on other people ... [Long pause]. So we don't know what's coming next ...

Living with one's children is usually not an option. Most people I spoke to do not want to live with their children; they consider this to be a burden on their children. Angela echos a common theme: "I don't want to ever live with my children, but I want to be where they are." Since people do not want to live with their children they sometimes must choose lifestyle sectors (living spaces) that are more institutional than they would like. Housing choices may be limited in the locale where they would like to live, or they may not be able to afford to live in a communal lifestyle organization.

Giddens' notion of life-planning can be refined in other ways. Older people often see an end to their lifespan, whereas younger persons do not:

Sonya: I think living in here has made, or living in these places, has made me more aware that there is an end ... and you're coming to it. Maybe before I never thought about it. You just lived your life.

Whereas younger people think they have a long time to live, older people do not have this luxury. This affects life-planning. The risks of crisis - something that disrupts ontological security - are high, as are the risks of loss of control, loss of autonomy and loss of independence. In old age the risks of transformative change are heightened. These changes can include a downgraded lifestyle, a reoccurring theme in the study.

In sum, although the notion of life-planning helps in understanding moving decisions, it needs to be extended to take into consideration three realities facing older persons: potential loss of autonomy, limited lifestyle options, and a limited lifespan. These three risks underpin life-planning for older persons. 


\section{Summary}

This section identifies sequences, timing, causes and conditions that may help explain study outcomes: specifically, study group characteristics, factors that caused people to move and factors that caused people to do life-planning. This is an example of narrative analysis task \#1.

The findings show that the study group is made up of retired white middle class Canadians primarily from double income families. The average person is advanced in age, but in good health. Most men are married whereas most women are widowed. About two thirds of the group are extroverts. Although health prompted some to leave their previous home, there are other considerations: the nature of North American nuclear family living and the paucity of affordable, accessible home support services. North American society does not always support the extra needs that older persons may have: the need for social contact, transportation, and home support services.

This section makes a number of contributions to theory and the literature. It suggests that people's housing needs and moving decisions are complex (Laws, 1996; Folts \& Muir, 2002; Trottier et al., 2000). It describes factors that may cause people to do life-planning: to avoid loss of autonomy, to control lifestyle and to enjoy life.

As well, this section identifies gaps in Giddens' theory, and extends the notion of life-planning to include factors that affect older persons differently than the rest of the population: potential loss of autonomy, limited lifestyle options, and a limited lifespan. This is an example of how the study extends and refines Giddens' theory. 


\section{CHAPTER FIVE}

\section{Am I what I consume?}

Giddens and Laws point to the reflexive relationship between self-identity and social environments - how one shapes the other. Laws (1996) argues that "we are what we consume." We make housing choices based on our view of ourselves, plus these lifestyle sectors shape our self-identity over time:

"Active seniors" are emplaced in the resortlike setting of Sun City, the "frail elderly" in nursing homes, and "poor elderly people" in inner-city section 202 housing. People adopt particular spatial contexts because of their self perceptions of who they are. But their identities are also shaped by those spatial settings (Laws, 1996, p. 175).

Do the study findings support or contradict these arguments? Why did people select Lakelands? Was it because it fit their self-identity? Are people shaped by Lakelands? Also, do residents try to influence Lakelands in ways that have implications for their self-identity? This chapter explores these questions.

\section{Why choose Lakelands?}

The previous section discusses respondents' reasons for moving and how and why they do life-planning. This does not explain why they selected Lakelands. There are numerous housing options in the community where Lakelands is located: gated communities, other 
communal lifestyle organizations similar to Lakelands, continuing care communities, as well as more traditional assisted living and long-term care facilities. So why choose Lakelands?

\subsection{The attractions}

Respondents mentioned a number of things that attracted them to Lakelands: the physical facilities, location of the place, the natural surroundings and the people (see Table 5.1). People said they were attracted to Lakelands by the appearance of the building, and the natural surroundings, especially the gardens. Eleven respondents (37\%) said that Lakelands is beautiful.

Location is a particularly important criteria in choosing Lakelands. Respondents (16 cases) mentioned wanting to live in their neighborhood, or wanting to live in an area with which they are familiar ( 6 cases). These findings support numerous studies on neighbourhoods and identity (Hauge, 2007; Hopkins \& Dixon, 2006; Laws, 1995; Nelson, 2001; Reed, Payton, \& Bond, 1998a; Reed, Payton, \& Bond, 1998b).

Table 5.2 lists typical, contrasting and discrepant answers to the question 'Was the look or the appearance of the place a factor in moving here?' The most common answer - for $81 \%$ of persons who answered this question - was that appearance was an important consideration. This suggests that the image of a place is also an important consideration for many respondents. These findings, Tables 5.1 and 5.2, relate to narrative analysis task $\# 1$ - identify themes, sequences, timing, causality, and conditions. 
Table 5.1. Why choose Lakelands?

\begin{tabular}{lcc}
\hline Attractions & Mentions \# & \% of cases \\
\hline Building, apartment & 19 & $63 \%$ \\
Location & 16 & $53 \%$ \\
Natural surroundings & 13 & $43 \%$ \\
People (management, staff, residents) & 9 & $30 \%$ \\
Familiar with it & 6 & $20 \%$ \\
Price & 4 & $13 \%$ \\
Cruise ship concept & 4 & $13 \%$ \\
Welcoming & 3 & $10 \%$ \\
Food & 1 & $3 \%$ \\
\hline
\end{tabular}

Note. "Mentions" refers to the number of people who mention a particular reason for choosing Lakelands. Since respondents mentioned more one attraction, total mentions are greater than the total number of cases $(n=30)$.

Table 5.2. Typical, contrasting and discrepant narratives: Image or appearance

\begin{tabular}{|c|c|c|c|c|c|}
\hline \multirow{2}{*}{$\begin{array}{l}\text { Question } \\
\quad \& \\
\text { Response }\end{array}$} & \multicolumn{4}{|c|}{ Narratives } & \multirow[b]{2}{*}{$\begin{array}{l}\text { Total } \\
\text { cases }\end{array}$} \\
\hline & Typical & Contrasting & Discrepant & Missing ${ }^{a}$ & \\
\hline $\begin{array}{l}\text { Was the look or the } \\
\text { appearance of the place } \\
\text { a factor in moving here? }\end{array}$ & Yes. & $\begin{array}{l}\text { Atmosphere } \\
\text { important. }\end{array}$ & - & & \\
\hline $\begin{array}{l}\text { Responses } \\
\text {-Total }\end{array}$ & $\begin{array}{c}17 \\
(57 \%)\end{array}$ & $\begin{array}{c}4 \\
(13 \%)\end{array}$ & 0 & $\begin{array}{c}9 \\
(30 \%)\end{array}$ & $\begin{array}{c}30 \\
(100 \%)\end{array}$ \\
\hline $\begin{array}{l}\text {-Minus missing } \\
\text { responses }\end{array}$ & $\begin{array}{c}17 \\
(81 \%)\end{array}$ & $\begin{array}{c}4 \\
(19 \%)\end{array}$ & 0 & - & $\begin{array}{c}21 \\
(100 \%)\end{array}$ \\
\hline
\end{tabular}

Note. ${ }^{\text {a }}$ I did not ask 9 people this question. 


\subsection{My home defines me: Lifestyle fit}

The question "Did people choose Lakelands because it fits their self-identity?" presumes that people are autonomous decision-makers: that they selected Lakelands. This assumption is correct for most respondents (97\%). I spoke to only one person who did not select Lakelands.

Eighty-seven percent of respondents comparison shopped (see Table 5.3), most in the local area, although a few people compared Lakelands to other places in the province, or out of province. Sometimes respondent's family or friends shopped for them. Only one person said that they did not comparison shop because they knew, after the first visit, that Lakelands was right for them. This suggests that there are options in the marketplace and that people are interested in choosing a place that suits them. This relates to narrative analysis task \#3 - identify similarities and differences between residents.

A number of people said that self-identity was an important factor in choosing Lakelands. Jackie talked specifically about self-identity. She gave a detailed account of how she would like her identity to be reflected in her home. (This relates to narrative analysis task \#2 - identify informant theories):

Margot: Why did you choose Lakelands over some other place to live? Because, [your husband] said you weren't too crazy about moving here in the first place. He explained what it was you didn't like . . .

Jackie: I felt that my home defined me, and to give up my home, I was giving up who I was. I had this perception. So I was reluctant.

[Discussion]

It became more and more evident that even the new [independent living residence] couldn't compare with the setting here, and something about the 
ambience when you walked in the front door. It just had a welcoming feeling. And it had a nice look, and an elegant feeling, which was appealing. Maybe I'm a bit of a snob, you know, I don't know. But, it could have been that actually. But it satisfied me. And I said, "so one day it will be, you're right, it will be Lakelands. Jackie recognizes that to be happy, her home must be congruent with her self-identity.

What attracted her to Lakelands was the "setting," "a welcoming feeling," "the ambience when you walked in the front door," the "nice look" and an "elegant feeling."

Table 5.3. Looking for the right place

\begin{tabular}{|c|c|c|}
\hline Shopping & Cases & $\%$ \\
\hline \multicolumn{3}{|l|}{ Comparison shopped } \\
\hline - $\quad$ Resident comparison shopped ${ }^{\mathrm{a}}$ & 23 & 77 \\
\hline - Children/friends comparison shopped for resident ${ }^{b}$ & 3 & 10 \\
\hline Did not comparison shop ${ }^{c}$ & 1 & 3 \\
\hline Missing data & 3 & 10 \\
\hline Total cases & 30 & 100 \\
\hline
\end{tabular}

Note.

Three respondents did not mention whether or not they comparison shopped.

${ }^{\text {a }}$ Resident was aided by friends and/or family.

${ }^{\mathrm{b}}$ Resident did not comparison shop, but others (family, friends) did on their behalf.

${ }^{\mathrm{c}}$ Neither resident, friends nor family comparison shopped.

Jessica talked about self-identity in a slightly different way than Jackie. She stated that before moving to Lakelands, a person should make sure that their lifestyle meshes with Lakelands' lifestyle. This relates to narrative analysis tasks \# 2 and \#3: identity 
informant theories, and assess consistency in the lifestyle concept:

Jessica: I mean, if you wanted to throw a lot of wild parties you wouldn't move into a place like this. You certainly can entertain, and you can certainly have liquor and that sort of thing. But you choose to come here, because you scouted out and you feel that you can manage this kind of a life, or your kind of life in this setting.

Jessica makes a clear distinction between "your kind of life" - your lifestyle - and "this kind of life" or "life in this setting" - Lakelands' lifestyle. She thinks the two must be congruent. There must be lifestyle fit. Therefore, lifestyle fit is a calculation.

Lifestyle fit is related to "my home defines me." It points to the importance of "habits of dress, eating, modes of acting and favoured milieux for encountering others" that fit with one's narrative of the self (Giddens, 1991, p. 81). Both concepts emphasize the importance of sufficient fit between self-identity and what is being offered by the lifestyle sector.

A number of interviews illustrate how people will not move to a place if there is a lack of lifestyle fit - if the gap between their lifestyle and the lifestyle sector is too large. Andy, Rosemary and Hugo talked about not wanting to move to Lakelands after their first visit. They mentioned walkers - often seen as a negative stereotype of aging - and how seeing walkers made them realize that Lakelands did not fit their lifestyle. They decided they did not want move to Lakelands, although eventually, like Jackie, they did move:

Andy: And we were looking around. There was a bunch of walkers here, and so on, and we thought "well, we're not ready for that." [Laughing]. So we stayed home for a while longer in the house.

Similarly, 
Rosemary: Well, we came and had a look. And yes it was very nice, you know the hallway. So there was not an available apartment to even look at. But there was a lady away, and she had given permission for somebody to go in and look at it. So we did. But I wasn't very ... What put me off, I'll tell you, was all the walkers down by the restaurant. And there were not as many as there are now. I thought, "no I'm not ready for that."

Similarly,

Hugo: At first, we were a bit put off with visiting, just touring around with [the former General Manager] and [the Marketing Manager] who was here at the time too. And walking through the main floor and seeing all the walkers lined up there. It looked like a nursing home.

These respondents are talking about lack of lifestyle fit. Andy and Rosemary felt that they "are not ready for that." What "that" is, is implied. Hugo is more specific. He says the place looks like a nursing home, and that's what "put him off." Similarly, Jackie said she did not want to move to Lakelands because her self-identity would change - she would be "old." This relates to Goffman's point that: “. . expected activity in the organization implies a conception of the actor and that an organization can therefore be viewed as a place for generating assumptions about identity" (Goffman, 1961, pp. 186187). Initially, Jackie, Andy, Rosemary and Hugo did not want to participate in a place designed for older people, because it did not fit their view of who they are. In participating, they too would become old.

\subsection{Staying put}

Two interviews describe the importance of self-identity and lifestyle fit from another perspective - the "fateful day" when one must leave Lakelands. As some people refuse to 
move to Lakelands because it does not fit their lifestyle, others refuse to move out because they cannot find another lifestyle sector that fits their self-identity - that measures up to Lakelands' lifestyle. Angela told a story about a resident who considered leaving Lakelands for an assisted living or long-term care organization. Lifestyle fit came to the fore in this story:

Angela: Well, she was telling me the other day - she's having trouble now with [describes problem]. So I guess her [family] thought she should go to a care place - and she said, "we started around" - and of course [name] can afford to go to the best, and that's where they went. And she said, "[Angela] I'm telling you," she says - sometimes she would complain about this place, you know - "Why are they serving apple pie two days in a row?", kind of, you know. And she said "When we, when we find out there's one choice of meals ...," and that's the other place, that's the only difference with the meals. If there was chicken that night, that's it. You didn't get a choice, you know, like here. I don't know how they cook like that ... how they cook ... When I used to do my ... I could never have three choices when my family came home at lunch and dinner. Sit down at the table, "What are you going to have, chicken, beef or whatever?"- whatever you know. And, but anyway, it's expensive cooking. But she said "not only that," she said "They were smelly, they were ..." Some of them, they got as far as the door, and they wouldn't go in! That's how nice this place is compared to ... and I'm talking about the best, you know. So, what they decided to do with [name] is they're going to hire these [name of home care organization] girls and they're going to go [look after her]. She's staying right here. She's not moving. She just loves it. Well, that's how I feel too. I would do the same. Unless I got dopey, you know, and out of my . . . and as long as I'm not senile. I'm staying here until I can't stay on this earth anymore ... [Discussion] . . .You don't hear ... you hear some of them that want to leave but ... like [name], she didn't want to - her [family] said she had to. But "Oh" she said, "No way!" So they decided to stay 
here.

This resident recognizes that moving from Lakelands would require a major shift in her self-identity and lifestyle - one that she is not ready to make. It would entail changes in eating habits and physical surroundings - changes that are "downgrades" in lifestyle. Angela concluded her story by saying that she feels exactly the same way. She will not move, unless she absolutely has to.

Neither Angela nor Angela's friend will be able to move to another residential organization and feel comfortable until their view of themselves shift. A change in health may precipitate a move, however, until they can shift their self-identity to fit their new lifestyle, neither of these women will be comfortable in a nursing home.

\subsection{Shifting self-identities}

Why and how did people change their minds? What are the implications for self-identity? Jackie, Andy, Rosemary and Hugo now live at Lakelands. What precipitated this change?

Did their self-identity shift? Did Lakelands change, or do they feel out of place at

Lakelands? The answer seems to be that their self-identities shifted:

Jackie: But with [husband], he doesn't let it go. He persists, you know. So I finally said "Well what I will do is look around with you and see what there is available and we will go. You know, we'll have it stored in the back of our minds for that fateful day ..." Well, we did look around. Although he had joked every time we passed by here and said, "We'll be in there one day - that's where were going to be." It became more and more evident that even the new [retirement resort] couldn't compare with the setting here, [ . . as quoted previously . . . ]. But it satisfied me. And I said, "so one day it will be, you're right, it will be Lakelands." Well, unfortunately, health things started to crumble. 
Jackie comparison shops and gradually comes to accept that Lakelands has many attributes that she likes. It fits her desire for elegance and friendliness. In the end, declining health radically shifts her self-identity and precipitates her move.

Jackie's comments suggest that Lakelands can shape self-identity even before the move. Jackie was not instantly enamoured with the idea of living at Lakelands. She had to shift her self-perception before she could bring herself to visit, or move there. Rosemary and Hugo illustrate this same point. Both are deterred by the site of walkers on their first visit. Despite this, over time their self-perception changed to the point where they were able to move to Lakelands and accept walkers. Rosemary said:

Rosemary: I know there's people with walkers and wheelchairs, but you get used to that. It's just, thank goodness we're not like that ourselves yet. I hope never. Rosemary can accept that she lives in a place where people use walkers, although she does not want to shift to the point where she uses a walker. Hugo has a similar view: Hugo: So I've got used to it now. If that answers your question. So I accept everything. Because you, one has to. So you have to make up your mind. This is, this what, what it is ... [Discussion] ... Now I'm walking with a [walking aid]. [Laughing].

Hugo's comments suggest it may not be easy to shift self-identity so as to fit into Lakelands' lifestyle. As Hugo said: "one has to." Hugo, like Jackie, also pointed out that one may lose control of one's self-identity due to changes in health; he is now walking with a walking aid. This is a common problem at Lakelands. As moving to Lakelands may shape self-identity, so may changes in health. 
Andy did not explain why or how he changed his mind. His interview suggests that declining health may have been the catalyst, in particular the need for extra housekeeping services. Despite his initial reticence, Andy described himself as being content and happy at Lakelands.

As Lakelands helps shape self-identity before a person moves, Lakelands can shape self-identity over the course of a person's residency. This idea is illustrated in a number of interviews. In Jackie's case, her self-identity shifts before and after the move. After she moved to Lakelands she noticed that people reacted to her differently because she lives at Lakelands. She said this has affected her view of herself:

Jackie: And I remember one of the ladies that she was very chic, just a lovely woman, and I was talking to her about various things. And one of the things she said to me, she said. "When you move in here, [Jackie] you're suddenly old." Margot: Hhh ...

Jackie: And I thought, "How could that be?" But it's true, and it's just another thing that you have to accept. But having accepted that, there are no constraints on you, but ... their perception that, the perception of . . some . . . does change. And you see it with other people, out in the community. When somebody says, "and [name] lives at Lakelands," there's "Oh!" Margot: Okay, so she's part of that . . older group. Jackie: Yah. Margot: Yah. And that's what you didn't want. Is that why you didn't want to move in here; you didn't want to be seen as part of that older group? Jackie: Perhaps, maybe . . . it . . . it, probably, likely was, But I didn't ever . . . think, think that thought. But you know how, it's there. Margot: Yes. Jackie: But it doesn't ruin my happiness. It just means that I'm aware of being perceived differently. And so I perceive myself differently. That's the way it is. 
And in a lot of ways. It's kind of nice, and it's kind of comfortable ... to be in that slot. It's not all that bad.

Jackie decided to embrace "being old." In doing so she achieved peace of mind: her selfidentity and lifestyle became congruent.

Like Jackie, Roger talked about experiencing a shift in self-identity after the move to Lakelands. In contrast to Jackie, Roger did not have to shift his self-identity before moving to Lakelands. Before moving, Roger assessed whether or not Lakelands' lifestyle fit his lifestyle. He considered the location, the landscaping, the decor, the people and the type of accommodation, and concluded that he fit in.

Although Roger concluded that he fit in, after he moved he realized that he might not fit in after all:

Roger: ... although we have spoiled our own association in some regards there, because in moving into an establishment like this, you've got to recognize your own character. One of the first things I said to my wife when I came in, I said. "There a lot of old people in here!" And she said. "Look at the mirror." And look in the mirror, of course it's quite obvious that I am old too. But thanks for saying that; I don't look as old as I really am. But you see all these people with their walkers, and their wheelchairs, and their short steps ... I was a [name of occupation], and I think this is hard to take, because again all my life [in occupation] I tried to have a bearing of a credit to the human race. And to come in here and recognize that the human race has a tremendous amount of failings is something you have to accept - not only physically but mentally.

To fit in Roger had to examine himself and change his self-perception. He related how, in associating with older people, he gradually accepts that he is as old as the people with whom he lives. Roger pointed out that this shift in self-identity can occur both physically and mentally. Physically, Roger has experienced illnesses. These illnesses 
precipitated the move. In addition to accepting the physical changes in his self-identity, Roger described how he has made a painful mental shift - how he has had to change and "recognize his own character." Roger has had to "look in the mirror" and realize that he belongs to this group experiencing physical decline and "a tremendous amount of failings." Roger talks about stigmatization (Goffman, 1963) - how his self-identity is "spoiled" by living in a place where moral and existential issues are concentrated - where his body and other people's bodies are failing.

Roger had to accept these things about himself and others. Getting used to a place, or accepting things signals that self-identity is shifting. It signals that people are changing in order to adapt to their situation. Many of the previous quotes are sprinkled with this idea of "having to accept" which signals that self-identity is shifting:

Jackie: ... and it's just another thing that you have to accept. But having accepted that, there are no constraints on you, Hugo: So I've got used to it now. . . So I accept everything. Because you, one has to.

Rosemary: I know there's people with walkers and wheelchairs, but you get used to that.

In contrast to Jackie, Hugo and Rosemary who decide they "have to accept" a change, Angela and Angela's friend decide that they do not have to accept a change. They refuse to leave Lakelands for a nursing home because they know their selfidentities will be shaped by those places and the people who live there. They will be labeled patients. They will have to live in institutional conditions. They will have to adopt a lifestyle that is less affluent than they are used to, and they will have to live with people experiencing mental and physical decline. This will impact their lifestyle and 
likely stigmatize their self-identity. They will experience a downgraded lifestyle. They will have no food choices, they will not be served gourmet food, they will probably not be able to choose who they sit with at meal times, and they may not be able to find a friend who is mentally able enough to converse with.

In sum, learning to live comfortably at Lakelands requires a fit between one's lifestyle and Lakelands' lifestyle. Sometimes people made a shift in self-identity before the move, and sometimes afterwards. These shifts require acceptance - accepting the self-identity that the lifestyle sector conveys. These shifts can occur in a number of ways. They can be a gradual process, they can be prompted by changes in others' perception, and they can come about as a result of physical decline. Shifting self-identity is part of making lifestyle fit. As well, shifting self-identity illustrates the reflexive relationship between organizations and self-identity.

\section{Organizational reflexivity and self-identity}

Giddens states that agency (i.e., the ability to act) and structure are reflexive and in modernity, organizations are thoroughly reflexive. This is "the routine incorporation of new knowledge or information into environments of action that are thereby reconstituted or reorganised" (Giddens, 1991, p. 243). When one lives in an organization, organizational reflexivity touches the heart of a person's self-identity, as this section illustrates. 


\subsection{We were sold a cruise ship. We weren't sold walkers!}

Jessica suggests that people should assess lifestyle fit before moving to a residential organization. But lifestyle sectors are not stable; they are reflexive. What happens if a person chooses a lifestyle sector, and then the lifestyle changes in ways that clash with a person's self-identity? People take shifts in organizational lifestyle very seriously when they negatively impact self-identity. The walker debate is a case in point.

Forty percent of respondents talked about an increase in the number of people with serious health problems, plus a growth in the number of people using walkers at Lakelands. A long time resident described this problem and its evolution over time:

Margot: If a person were to say to you "it's a nursing home!" What would you say to them?

Marie Josee: Well, I would say to them, "I think it's getting closer to that every day!" I do! You know, Margot, when I first came here, there was one walker, and I think now we have close to 70 down there at meal times between the two servings. And we've got people in motorized wheelchairs in here, and in regular wheelchairs, you know. So, you know, it's getting close.

Whereas Lakelands' marketing brochure and website project positive stereotypes of aging, for many, walkers portray a negative stereotype of aging. Lakelands distinguishes itself from nursing homes and many independent living residences by its hotel and resortlike lifestyle. This lifestyle helps shield residents and visitors from the existential questions related to aging. Cracks in this atmosphere or lifestyle raise troubling questions, as Giddens reminds us: the ontological security which modernity has purchased, on the level of day-today routines, depends on an institutional exclusion of social life from fundamental existential issues which raise central moral dilemmas for human beings (Giddens, 
1991, p. 156).

These troubling questions go to the heart of who we are, our purpose in life, and our mortality. Walkers point to these fundamental existential issues.

A number of people said that Lakelands' lifestyle is slipping. Clara said that the wrong kind of people are moving to Lakelands (McHugh, 2003). She complained that a lot of new people do not fit in because they are too sick. Elton and Olivia make the same comment in the previous section. Some people feel betrayed by this lifestyle shift. Candace and Horace described their feelings of betrayal and disappointment:

Candace: As we were told we were on a cruise ship that never left the shore, we were also told you had to be individually able to look after yourself. And in the last two years, they have been not sticking to that rule and couples - lots of couples that have come in, either one or the other, is incapacitated as you can see by the number of walkers and scooters, or whatever there are. They've multiplied 10,000 fold.

Horace echoed these sentiments and described how disappointed he is in Lakelands: Horace: That's why we chose to live here. And we were quite happy. Except cruise ship living is one thing, but living here is another, really. I had forgotten that we're getting older. The concept as described in the brochures and so forth is one of cruise ship living. And its sort of dress for dinner. You don't see people going around on crutches and wheelchairs and all that sort of thing. This is an old folks home, lets face it. So, I was somewhat disappointed.

Growth in the number of walkers and people who are incapacitated sends out mixed signals: is Lakelands a retirement resort or is it turning into a nursing home?

Sonya described an experience she had living in another residential organization for older people. She described a lifestyle transformation similar to the one at Lakelands, although it went much further than lifestyle changes at Lakelands: 
Sonya: But my [family member] was the first one who started teasing me. When I was going into [independent living residence], she said "When are you going into the nursing home?" I said, "God, it's not a nursing home!" And she said "Oh yes it is." And I said "Oh no it is not. And it never crossed my mind that it could be. So, when, in front of our very eyes it started turning into a nursing home, because they kept bringing these people in ... who could barely walk. Everybody was on walkers; more and more people on walkers ... more and more with head problems, you know. Like there was one, one lady for example ... every night at 7:30 she'd say, "I have to go up to my room and pack" and she'd go and pack because she's leaving in the morning. And then in the morning she'd get up and unpack again.

This continued until Sonya felt that she no longer belonged, or fit in to the lifestyle sector. I asked Sonya how it made her feel to live in a place that was turning into a nursing home. Here is what she said:

Sonya: Oh, I got so, I hated the place!

Margot: Hated it, yes.

Sonya: I really, really hated it. The place had become a nursing home, yet Sonya had not chosen to live in a nursing home, which is one of the reasons she moved. She did not want to be in a nursing home: Sonya: And really there's nothing wrong with a nursing home when you need it. But I certainly don't, wouldn't want to be in a nursing home before I needed it. Like Sonya, people have chosen Lakelands because it is not a nursing home. Growth in the number of walkers at Lakelands signals changes in the organization's lifestyle. Associating with more and more people who use walkers - perhaps even being forced to use a walker oneself - changes a person's self-identity and the lifestyle sector. 


\subsection{Shaping the organization's lifestyle}

Given these concerns over walkers, what effect, if any, do people living at Lakelands have over Lakelands' lifestyle? Do people leave? Do they complain? Does management tailor its policies to take these concerns into account? The findings indicate that some of these things occur.

In addition to moving, new and existing residents shape the walker lifestyle. Not only do new residents use walkers and wheelchairs, long-term residents increasingly use walkers. Horace pointed out that as residents age, they adopt walkers. Olivia thinks that many people use walkers when they really don't need to:

Horace: Can't really blame Lakelands. They had started out with the concept. No walkers, and no wheelchairs and you dressed for dinner and so forth. But the residents themselves sort of dictated, as they were getting older, that they needed walkers. And so once you establish that, as you can see now, about half the people have walkers and wheelchairs, and so forth.

Similarly,

Olivia: Well I guess they're more available and I guess more people need them, although I think some people get them before they need them really. I've avoided them as much as possible.

Not only do new and existing residents shape the walker lifestyle, by using walkers, some residents shape the organization's lifestyle by leaving. In Sonya's case she became so disenchanted with her former residence that she moved to Lakelands.

Although $40 \%$ of the study group mentioned the walker issue, none are considering leaving Lakelands over this issue. In the past, however, people have left over this issue:

Elton: Some people have moved out for that reason. [Laughing].

Margot: Oh really.

Elton: And now they're using walkers! [Laughing]. Yah. The only one was [last 
name of resident].

Only one person in the study group mentioned trying to shape Lakelands' lifestyle by talking to management about this issue. They spoke to a Manager and were told that Lakelands does not have a great deal of choice in the matter:

Resident: I commented to [a Manager] about it about [some time ago] "how come they're letting so many people in that can't look after themselves?" and [they] said, "well I have to take them. If that's . . that's the way they are, if they want to live here."

In my discussions with management, I learned that they are sensitive to this issue. They believe that active retirees want to live in a lifestyle sector that does not remind them of the existential issues raised by disabled seniors:

Manager: We have found that the active senior does not want to be reminded necessarily where it, they're going to be in five or 10 years in terms of health. So they don't always want to be around a client who's midway through a fairly serious health needs. Right, so trying to mix everybody into one environment, we feel isn't the right way to go. Other organizations may be able to make it work. I understand [another retirement resident in town] segments their population groups physically. Right. There is a wing of their building dedicated to more long-term care, and then assisted living, and then independent living residences. And then as your health needs change you move from wing to wing. And certainly you can see how that approach works. We've chosen a different approach for our services. In addition to being aware of the issue, Lakelands' management shapes this issue.

Lakelands can ask people to leave when their health needs become greater than Lakelands' service capabilities. This is written into Lakelands' rental agreement, and from time to time is enforced.

Whereas Lakelands' residents tread lightly around this issue, and seem to have placed little pressure on management, Streib and Metsch (2002) describe conflict that 
arose in a gated community over this type of issue:

An example of conflict involving the residents and the management of a leisureoriented retirement community was observed in an affluent community in Northern California ... A community meeting was called to present the plan for a nursing home, and the turnout was the largest in the history of the community. It was surprising that the residents were overwhelmingly opposed to the idea, for they wanted to maintain the youthful image of an active adult community. The attitude of the residents at the time was that if residents could not live independently in their homes, they should move out of the community and if necessary to a nursing home elsewhere. The thought of having a nursing home on the edge of the community was repulsive to the residents who viewed their community as a place for "youthful" newly retired persons. Some residents probably were denying the realities of aging, and did not wish to face the possibility that they personally might become frail, perhaps dependent in late life. The management quickly decided to abandon any plan for a nursing home (pp. 75-76).

This quote suggests that resident groups can and do shape management policies regarding lifestyles. Although Lakelands' residents are not as militant as the community in Streib and Metsch's (2002) study, perhaps this is because they recognize that they may be using walkers soon, or they may fall seriously ill and be faced with the question of having to move to a nursing home.

\section{Summary}

Am I what I consume? This and the previous chapter lend credence to this argument. The 
findings support Laws' (1996) assertion that people choose specific lifestyle sectors based on their view of who they are. People look for lifestyle fit before they move to a specific lifestyle sector. In assessing lifestyle fit they may look at a number of factors: the appearance of a place, the building, the number of walkers in the lobby, the atmosphere, resident and staff behaviour, and social activities.

The interviews also seem to support Laws' second argument - that people are shaped by the lifestyle sectors where they live. There is a reflexive relationship between self-identity and lifestyle sectors. Sometimes, like Jackie, people are shaped by the lifestyle sector even before they move. Sometimes, like Roger, they change after they move to a lifestyle sector.

The findings indicate that people become unhappy when the organization's lifestyle shifts in ways that reflect negatively on their self-identity. As Horace points out, Lakelands' advertising promises the possibility of reversing, in part, the stigma of being old by living in a Third Age (Blaikie, 1999) organization. Although one cannot hide one's age, and old age is reviled in modernity, a place like Lakelands creates a Third Age space that emphasizes active retirement, empowerment, agency and positive stereotypes of aging (Blaikie, 1999; Cole, 1992; McHugh, 2003). Lakelands' residents underline the point that one may be old, but Lakelands offers the possibility of living in a beautiful place, a place that "even the Queen would be proud of" according to Angela.

Cohabiting with the "wrong kind of people," or too many of the wrong type, stigmatizes a person, as Roger points out. When a previously non-institutional place takes on the trappings of an institution, people feel they are not longer consuming the "right 
kind of goods and services" - or the right self-identity (Giddens, 1991, p. 172; McHugh, 2003).

That people are willing to tolerate a certain amount of stigmatization may be due to their life situation or to an unwillingness to deal with the existential and moral issues that are raised by segregation. Perhaps as the perceived risks of severe disability increase, and as one's friends experience this situation, people are less likely to enforce boundaries between what Blaikie (1999) calls a Third Age, characterized by active retirees, and a Fourth Age, characterized by the very old -- people experiencing disability and senility. If Lakelands' residents were to actively enforce boundaries between Third and Fourth Agers, they would have to address the moral issues that this would raise. It could negatively affect their own lifestyle and well-being, as well as that of their friends.

These findings expand on Giddens' theory by pointing to distinctions within organizational sequestration. This is an example of narrative analysis task \#7 - identify gaps in Giddens' theory. The findings suggest that a Third Age lifestyle sector like Lakelands not only protects society from the moral and existential issues raised by old age, it also performs this service for its residents. Lakelands separates persons in the Third Age from persons in the Fourth Age (Blaikie, 1999). By focusing on active retirement and upscale living, and by limiting the number of severely disabled residents, Lakelands partially hides severe disability, a reality that Blaikie (1999) argues may become increasingly taboo in late modernity due to consumer society's emphasis on preserving youth.

Despite this segregation, Lakelands is unable to completely shield its residents 
from the moral and existential issues related to aging. As will become clear in the next sections of this document, people living at Lakelands come face to face with mortality. The beauty that surrounds people at Lakelands is not sufficient to hide this reality. The inexorable forces of aging are part of Lakelands' lifestyle. 


\section{CHAPTER SIX}

\section{How do I describe Lakelands Retirement Resort?}

When a new organizational model appears, naming and description pose difficulties (Czarniarskwa, 1997; Wallenmac and Sims, 1998). How do people describe a place like Lakelands? Are these descriptions different from descriptions of previous models? Do people talk about Lakelands in the same terms as it is described in advertising? Are there similarities between the way management describes Lakelands and the way residents describe it? This section examines the people's explicit and implicit descriptions of Lakelands. The analysis in this section focuses on analytical task \#5 - assess the possibility of a communal lifestyle organizational typology.

\subsection{Describing Lakelands: Discursive consciousness}

This section explores the ways that people describe Lakelands in explicit terms. These descriptions draw on discursive consciousness or "the conscious reasons that people give to explain their behaviors and motivations" (Tucker, 1998, p. 81). I asked management and residents how they would describe Lakelands to someone who knows nothing about it. Table 6.1 summarizes the findings.

Table 6.1. Descriptions of Lakelands' organizational model 


\begin{tabular}{|c|c|c|c|c|}
\hline Descriptions & $\begin{array}{l}\text { Resident } \\
\text { cases }\end{array}$ & $\begin{array}{c}\% \\
(n=30)\end{array}$ & $\begin{array}{l}\text { Management } \\
\text { cases }\end{array}$ & $\begin{array}{c}\% \\
(n=3)\end{array}$ \\
\hline A cut above ${ }^{a}$ & 14 & 47 & 2 & 67 \\
\hline Age ghetto & 1 & 3 & 0 & 0 \\
\hline All-inclusive, full amenity ${ }^{\mathrm{b}}$ & 17 & 57 & 2 & 67 \\
\hline Apartment-like, condo-like & 6 & 20 & 2 & 67 \\
\hline Apartment (not) & 3 & 10 & 0 & 0 \\
\hline Boarding school & 2 & 7 & 0 & 0 \\
\hline Cruise-ship & 6 & 20 & 2 & 67 \\
\hline Home (not like) & 4 & 13 & 0 & 0 \\
\hline Hotel-like & 6 & 20 & 0 & 0 \\
\hline Hotel (not) (more than) & 1 & 3 & 1 & 33 \\
\hline Independent living & 0 & 0 & 2 & 67 \\
\hline Institutional (not) & 2 & 7 & 0 & 0 \\
\hline $\begin{array}{l}\text { Nursing/old folks home, assisted } \\
\text { living, lodge }\end{array}$ & 10 & 33 & 0 & 0 \\
\hline Nursing home (not) & 4 & 13 & 2 & 67 \\
\hline $\begin{array}{l}\text { Place for last years, speciality } \\
\text { accommodation for older people }\end{array}$ & 4 & 13 & 0 & 0 \\
\hline Residence, seniors residence & 4 & 13 & 3 & 100 \\
\hline Resort, holiday place & 4 & 13 & 1 & 33 \\
\hline Retirement... & 3 & 10 & 1 & 33 \\
\hline $\begin{array}{l}\text { Shelter, structured program place, } \\
\text { village }\end{array}$ & 4 & 13 & 0 & 0 \\
\hline
\end{tabular}

Note. This table counts the number of resident and management cases that use each description.

a Residents said "classy, the best" and management used terms like "premier, upscale."

${ }^{\mathrm{b}}$ Management said "all inclusive," whereas residents used terms like life is "easy, or less work" referring to the fact that Lakelands provides services that reduce or eliminate housekeeping and cooking tasks.

${ }^{c}$ Person uses the word retirement followed by other words to describe Lakelands e.g., retirement residence. 
Residents' most common descriptions of Lakelands' organizational model are that it is: all-inclusive ( $57 \%$ of all resident cases); a cut above the rest ( $47 \%$ of all cases); and an nursing/old folks home, assisted living, lodge (33\% of all cases). The most common descriptors - all inclusive and a cut above the rest - are similar to the description of a communal lifestyle organization. That $33 \%$ of respondents describe Lakelands as similar to a nursing home suggests that respondents may have a negative perception of Lakelands, or they may be referring to the presence walkers, or they may have trouble finding language to distinguish Lakelands from former organizational models.

Table 6.1 shows residents' difficulties describing Lakelands in terms that distinguish it from previous models. Respondents used terms like "apartment/condo-like" ( $20 \%$ of all resident cases); not an apartment ( $10 \%$ of all resident cases); place for last years/speciality accommodation for older people (13\% of all cases); residence/seniors (13\%); and, shelter/structured program place, village (13\% of all cases).

That people liken Lakelands to a communal lifestyle organization, and that some people use the term "cruise ship" - a term used in Lakelands' advertising - partially supports McHugh and Larson-Keagy's (2005) empirical findings that people living in retirement communities integrate marketing messages into their narratives of the self. That people also refer to Lakelands a nursing home may also indicate that some people reject or ignore marketing messages.

Although Lakelands is populated by older persons, only one person talked about its age-segregated nature:

Marlene: But you know, to me it's an unnatural situation. We're in a sort of ghetto of people of our own age. 
Margot: Unnatural.

Marlene: It's unnatural. So when we see a baby or toddler, we just go crazy with excitement! [Laughing].

Margot: [Laughing].

Marlene: So that's not right. The old way of growing old in the village would've been better in many ways with several generations mixing. Yah. This is really unnatural.

Marlene feels that organizational sequestration isolates people from other ages. Older people miss out on the pleasure and excitement that come from mixing with younger generations.

Turning now to management descriptions, there are similarities and differences with resident descriptions, (an example of narrative analysis task \#4 - comparing resident and management responses). Management also describes Lakelands as a communal lifestyle organization: a cut above the rest (67\% of all managers); all inclusive fullamenity (67\% of all managers); and cruise ship (67\%). Management also use terms indicating that they may have difficulty describing Lakelands in terms that distinguish it from other housing types: not a nursing home ( $67 \%$ of all management cases); apartmentlike/condo-like ( $67 \%$ of all cases); more than a hotel ( $33 \%$ of all cases).

The greatest differences between residents and management are negative or technical terms used in the industry to describe seniors housing. Whereas, residents are more likely to describe Lakelands as a nursing home (33\% of residents versus $0 \%$ of managers), managers are more likely to use technical terms like "independent living, residence, seniors residence, and retirement ..." 


\subsection{Talking about Lakelands: Practical consciousness}

Not only do people describe Lakelands in conscious, discursive ways (Giddens, 1991), people also use terms in unconscious, implicit ways. These terms are part of everyday parlance, or practical consciousness: "unarticulated beliefs and knowledges people use to orient themselves to situations and interpret the actions of others" (Tucker, 1998, p. 81). These everyday, uncontrived terms point to social conventions or habits: habitual ways of thinking and talking about Lakelands. Sometimes there is a disconnect between explicit and implicit ways of talking about Lakelands.

Table 6.2 lists everyday implicit terms that residents and management used to talk about Lakelands. These data come from resident and management interview transcripts. The table suggests that management and residents' naming conventions can be similar, but they can also differ. Residents are more likely than management to describe Lakelands in negative or institutional terms, when using implicit language: "the home" ( $13 \%$ of all resident cases versus $0 \%$ of all management cases), and "institution" ( $3 \%$ of all resident cases versus $0 \%$ of all management cases). Managers on the other hand, are more likely to use technical terms such as "facility, building, or community."

"Facility" is a technical term used in the seniors housing and nursing home industry (National Association of Home Builders, 2007) and the academic literature. It is another word for "building" according to the Canadian Oxford Dictionary (Barber, 2004). Management's use of a technical word like "facility" illustrates the influence of these internally referential systems of thought on managers' language. 
Table 6.2. Words used to talk about Lakelands

\begin{tabular}{|c|c|c|c|c|c|c|c|c|}
\hline \multirow[b]{2}{*}{ Word } & \multicolumn{4}{|c|}{ Residents } & \multicolumn{4}{|c|}{ Management } \\
\hline & $\begin{array}{c}\text { Mentions } \\
\#\end{array}$ & $\begin{array}{c}\%^{a} \\
(n=189)\end{array}$ & $\begin{array}{c}\text { Cases } \\
\#\end{array}$ & $\begin{array}{c}\%^{b} \\
(n=30)\end{array}$ & $\begin{array}{c}\text { Mentions } \\
\#\end{array}$ & $\begin{array}{c}\%^{a} \\
(n=69)\end{array}$ & $\begin{array}{c}\text { Cases } \\
\#\end{array}$ & $\begin{array}{c}\%^{b} \\
(n=3)\end{array}$ \\
\hline Place & 92 & 49 & 29 & 97 & 7 & 10 & 3 & 100 \\
\hline Home (my) & 53 & 28 & 15 & 50 & 7 & 10 & 2 & 66 \\
\hline Home (the) & 5 & 3 & 4 & 13 & 0 & 0 & 0 & 0 \\
\hline Facility & 9 & 5 & 4 & 13 & 22 & 32 & 1 & 33 \\
\hline Establishment & 5 & 3 & 4 & 13 & 0 & 0 & 0 & 0 \\
\hline Institution & 1 & 1 & 1 & 3 & 0 & 0 & 0 & 0 \\
\hline Building (the) & 18 & 10 & 13 & 43 & 25 & 36 & 2 & 66 \\
\hline Community & 6 & 3 & 4 & 13 & 8 & 12 & 2 & 66 \\
\hline Total & 189 & $100 \%$ & - & - & 69 & $100 \%$ & - & - \\
\hline
\end{tabular}

Note. "Mentions \#" refers to the number of occurrences of a word in all resident or management transcripts. "Cases \#" refers to the number of resident or management cases that use a particular word.

${ }^{\text {a }}$ Percentage of total mentions.

${ }^{\mathrm{b}}$ Percentage of total resident or management cases.

Since the word "facility" is common in the nursing home industry, it is not necessarily congruent with advertising language describing an "upscale resort." The terms "property" or "community" might be more appropriate to describe a place like Lakelands. This suggests that explicit language used in the housing industry may be congruent with new organizational models (see Table 6.1), but implicit language may lag behind (see Table 6.2).

Although there are similarities in resident and management language use, 
differences suggest that management and residents have different preoccupations and borrow from different language systems (Holstein \& Gubrium, 2000). Whereas management is concerned with managing a "facility/building" and developing a "community," residents are concerned with the "place" they live and making "a home."

\subsection{Is Lakelands my home?}

One might wonder if there is any significance to residents using a seemingly ordinary term like "place" to refer to Lakelands. Most residents - 29 out of 30 - use the word "place" to refer to Lakelands. By itself, this does not seem significant. What else would one call Lakelands? But when one considers the fact that people could use another word - "facility," "home," "the home," "residence," "resort," or "property" - using the word "place" becomes important.

A structural analysis (narrative analysis task \#8) of this transcript uncovers an interesting anomaly. This resident sees a clear distinction between "the place" Lakelands - and their former house or "home." This resident never refers to Lakelands as their home:

Resident: No ... no. I think it's a wonderful place to live. I really do! If you can't be home this is the place to be. I'd rather be home. Of course! Everyone would. But I can't and ... this is fine.

[Discussion]

Margot: So if I were to ask you the question. What do you like least about living here?

Resident: Oh, because I can't be at home.

Margot: Yes okay. Yah, yah.

Resident: I'd rather be home than any place. And of course I can't be. So here I 
am. [Discussion]

Resident: I would say it's a wonderful place to live, if you can't live at home.

This is the best place to be.

The only time this resident uses the word "home" to refer to Lakelands is when they quote the family:

Resident: I had [an illness] and all of a sudden, we arrived here. And [the family] said "this is your new home." And I said, "this is my what!"

Although this is an unusual case, this narrative illustrates how residents use words like "place" and "home" with purpose. This resident does not consider Lakelands to be their real home. This resident is not alone. Whereas most residents (29 out of 30 cases) use the word "place," only half the residents I interviewed (15 out of 30 cases) used the word "home" or "my house" to refer to Lakelands.

This raises the question, why do some people use the word "home" whereas others do not? Are there systematic differences between these two groups? A review of the data identified 2 variables that are associated with use of the word home: "extroversion" and "overall health problems." Neither of these 2 variables are associated with each other. An odds ratio is an appropriate statistical model for measuring the relationship between "home" and "extroversion," whereas Spearman's rho is appropriate for measuring the association between use of the word "home" and "overall health problems."

The first variable - extroversion - refers to my assessment of whether or not a person is an extrovert or an introvert. I classified a person as an extrovert if they are involved in many Lakelands' activities, cultivate many friends, and try to adapt the environment to themselves by, for example, sitting on committees or trying to change 
public opinion. I defined introverts as people who are not involved in many activities, have a limited number of friends, and who adapt rather than change their environment.

Table 6.3. Association between extroversion and use of the word "home"

\begin{tabular}{lccccc}
\hline & \multicolumn{5}{c}{ Extroversion } \\
\cline { 2 - 6 } Word use & Introvert & $\%$ & Extrovert & $\%$ & Total cases \\
\hline No, don't use home & 8 & $80 \%$ & 7 & $35 \%$ & 15 \\
Yes, use home & 2 & $20 \%$ & 13 & $65 \%$ & 15 \\
Total cases & 10 & $100 \%$ & 20 & $100 \%$ & 30 \\
\hline
\end{tabular}

The odds of an extrovert using the word home are 1.8 to1 (i.e., 13/7:1) whereas the odds of an introvert using the word are .25 tol (i.e., $2 / 8: 1$ ). Therefore, the odds of an extrovert using the term home are 7 times greater (1.8/.25) than an introvert. A Fisher exact test ${ }^{6}$ indicates that this is a statistically significant relationship ( $p=.03$ for a twotailed test).

Similarly, there is a significant statistical relationship between overall health problems and calling Lakelands home: Spearman's rho $=-.31 p=.10$, two-tailed test.

6 One disadvantage of the odds ratio is that when one or more cells in a table have small values it can be biased. Fisher's exact test is an alternative statistical significance test useful for categorical data. It is good for small samples but when the assumptions of the test are violated (row and column totals are fixed in advance), as was the case in this study, the test is very conservative. It can result in a Type I error: rejecting the null hypothesis when it is true (Stevens, 2002, p. 4). 
(Since these variables have abnormal distributions I used a non-parametric correlation Spearman's rho). This statistical association suggests that the better a person's overall health the more likely they are to call Lakelands "home." Overall health problems refers to my assessment of a respondent's physical and mental health. This is a much broader category than specific health problems such as eyesight, memory, or physical mobility problems. I defined being in good overall health as being visibly in good health with no major problems; moderate overall health as visible signs of decline in a person's appearance or physical capabilities, but nothing seemingly life threatening; and "poor overall health" as serious health problems that seem life threatening.

What might explain these relationships between extroversion, overall health problems and use of the word "home"? Giddens' (1991) notion of power may shed light on this reflexive relationship between persons and organizations. First, with respect to the statistical relationship with "extroversion," perhaps extroverts are more likely to call Lakelands their "home" because they shape the environment to suit themselves. Perhaps extroverts are more likely to exercise their power - their ability to change things - than introverts. Since introverts interact more passively with their environment, they may be more likely to feel that they must endure things that do not suit them. Consequently, introverts may not have as great a sense of ownership or belonging as extroverts.

As for the explaining why a person in overall good health is more likely to call Lakelands home than a person in poor health, perhaps it is because people in good health are more able to participate in Lakelands' activities. In participating, a person in good health may shape Lakelands and develop a sense of ownership. For example, they may 
manage a particular activity. They may also make more friends. This may contribute to a greater sense of organizational ownership or belonging, which leads to a person calling Lakelands "home."

In sum, characteristics that support personal power or agency vis-à-vis an organization - being in good health or being an extrovert - seem to support use of the word "home." Characteristics that weaken agency - introversion or poor health - seem to reduce the likelihood of a person using the word "home."

\subsection{Is it a suite?}

As words like "home" and "place" reveal social conventions and habits, so do everyday terms people use to describe their private space - their apartment. While structurally analyzing transcripts (narrative analysis task \#8) I noticed that management and residents often use the word "suite" to refer to their apartment. I found this unusual as my habit was to use the word "apartment" or "room" to describe the "guest suite," as it is commonly called, where I resided at Lakelands. This relates to narrative analysis task \#4 - assess similarities, differences between residents and management.

Table 6.4 lists words used by management and residents to describe a resident's apartment. The table indicates that all managers (100\%) use the word "suite" compared to $53 \%$ of residents. This difference may point to the influence of internally referential systems of thought. Management may be trying to convey a message by using the word "suite." "Suite" brings up the image of a "suite of rooms" or a "hotel suite." Hotels use the word "suite" to describe an upscale set of rooms, whereas they use the word "room" 
to describe basic accommodation. Perhaps management is trying to convey the message that Lakelands offers upscale hotel-like accommodation. This difference in word choice suggests that management and residents have different preoccupations. Perhaps management is using this word with purpose, whereas residents are not.

Also, if management introduced the term "suite" to convey that Lakelands is an upscale place, perhaps management's language preferences are gradually shaping residents' preferences. The finding that not all residents use this term, suggests that management language only partially influences residents' habits.

Table 6.4. Words to describe residents' living quarters

\begin{tabular}{lccccccccc}
\hline & \multicolumn{4}{c}{ Residents } \\
\cline { 2 - 9 } Word & $\begin{array}{c}\text { Mentions } \\
\text { N }\end{array}$ & $\%^{a}$ & Cases & $\%^{b}$ & Mentions & $\%^{a}$ & Cases & $\%^{b}$ \\
& $\#$ & $(n=161)$ & $\#$ & $(n=30)$ & $\#$ & $(n=43)$ & $\#$ & $(n=3)$ \\
\hline Apartment & 39 & 24 & 14 & 47 & 2 & 5 & 2 & 66 \\
Suite & 39 & 24 & 16 & 53 & 25 & 58 & 3 & 100 \\
Room & 30 & 19 & 18 & 60 & 9 & 21 & 3 & 100 \\
House or & 53 & 33 & 15 & 50 & 7 & 16 & 2 & 66 \\
home & & & & & & & & \\
Total & 161 & 100 & - & - & 43 & 100 & 3 & 100 \\
\hline
\end{tabular}

Note. "Mentions \#" refers to the number of occurrences of a word in all resident/management transcripts, whereas "cases \#" refers to the number of cases that use a particular word.

${ }^{a}$ Percentage of total mentions.

b Percentage of total cases. 


\subsection{Language of sequestration}

In addition to terms that describe residents' apartments, some residents and management used language that harks back to former institutional settings (Williams \& Guendouzi, 2000). I call these language habits a language of sequestration - language that describes a sequestered or boundaried experience. In the past people were "placed," "admitted," "committed," "incarcerated" and "initiated" into institutions. The term "in" is important. It points to physical boundaries that separate, or sequester "inmates" from the world.

I uncovered this language convention while structurally analyzing a respondent's narrative (narrative analysis task \#8). I then found similar patterns in other narratives. Williams and Guendouzi's (2000) research notes a similar pattern. They found that people in a U.S. West Coast retirement community frequently use phrases like "in here" and "on the outside." Williams and Guendouzi's (2000) describe this pattern:

She notes her brother and other friends had initially teased her about moving into the retirement community, invoking negative images by using the word "the home." Notice too her own use of the phrases "when I came in" and "friends on the outside," indicating a boundaried place referred to in terms similar to those used to refer to other institutions - for example prisons. Thus although Buena is a community with a very positive image that residents (and others) praise, residents own talk shows ambivalence about their identity as residents of such a place (Williams \& Guendouzi, 2000, p. 71).

In studying the above narrative, I noticed that the authors - Williams and Guendouzi - also use the term "in": "teased her about moving into [italics added] the retirement community." This prompted me to structurally analyze my own narrative, as well as all management and resident narratives. I found that this is a common language habit at Lakelands. 
This raises the question, Why use this word? The phrase "in here" is a subtle, circuitous way of talking about reflexive relationships with residential organizations. It employs a passive rather than an active phrasing structure. Dropping the word "in" would be simpler and more direct. This suggests that language of sequestration is purposeful.

Table 6.5 shows specific uses of the term "in here" or its variations: "bring in," "put in," or "forced in." Overall, two out of three managers (66\%) use the term "in here" or its variations, whereas 21 out of 30 residents $(70 \%)$ use "in here" or its variations. Four out of 30 residents use the term "outside" (e.g., on the outside), whereas I did not find any instances of management using this term. These numbers suggests little difference between management and residents' use of language of sequestration.

Although management and residents seem to have similar habits, there are differences between residents. Not all residents use these terms - "in here," "on the outside" or variations on these terms. Whereas twenty-three cases (77\%) use one or more of the terms in Table 6.5, seven (23\%) cases do not.

This raises the question, Why do some respondents use this language of sequestration whereas others do not? Are there conditions that affect these two groups differently? This question relates to narrative analysis tasks \#1 and \#3-identify themes, sequence, timing, causality, conditions and identify similarities and differences between residents. 
Table 6.5. Language of sequestration versus the alternatives

\begin{tabular}{lcccc}
\hline & \multicolumn{2}{c}{ Residents } & \multicolumn{2}{c}{ Management } \\
\cline { 2 - 5 } & Mantions \# & $\begin{array}{c}\text { Cases \# } \\
(n=30)\end{array}$ & Mentions \# & $\begin{array}{c}\text { Cases } \\
(n=3)\end{array}$ \\
\hline $\begin{array}{c}\text { "Move in here." } \\
\text { Alternative: "Move/come here." }\end{array}$ & 7 & 4 & 2 & 2 \\
"Come in here." \\
$\begin{array}{c}\text { Alternative: "Come here." } \\
\begin{array}{c}\text { "Landed in/went in here." } \\
\text { Alternative: "Land here." }\end{array}\end{array}$ & 6 & 4 & 1 & 1 \\
$\begin{array}{c}\text { "Bring/put/force, in here." } \\
\text { Alternative: "Bringing them here." }\end{array}$ & 3 & 2 & 0 & 0 \\
$\begin{array}{c}\text { "Bring in" (help). } \\
\text { Alternative: "Gethire help." }\end{array}$ & 3 & 2 & 1 & 1 \\
$\begin{array}{c}\text { People "in here." } \\
\text { Alternative: "People here." }\end{array}$ & 5 & 4 & 0 & 0 \\
$\begin{array}{c}\text { "Living/being in here." } \\
\text { Alternative: "Living/being here." }\end{array}$ & 7 & 4 & 0 & 0 \\
$\begin{array}{c}\text { "In, Lakelands/this place/here." } \\
\text { Alternative: "At Lakelands." "Here." }\end{array}$ & 13 & 11 & 1 & 1 \\
"Inside" (e.g., Bring it inside) \\
$\begin{array}{c}\text { Alternative: "here" } \\
\text { "Outside" (e.g., on the outside) } \\
\text { Alternative: "in town" }\end{array}$
\end{tabular}

Note. "Mentions \#" is the number of occurrences in transcripts, whereas "case \#" is the number of resident or management cases using the phrase. Often people use more than one phrase. 
To identify reasons, I examined statistical relationships between the variable "in here/outside" (i.e. use or absence of "in here" and "outside") and other variables in the data set. I found that 3 variables are related to "in here/outside": marital status, years resident, and number of previous residential organization experiences. None of these variables are interrelated. Due to differences in the measurement levels of these variables, I tested the strength of these relationships using different statistical models (see Tables 6.6 and 6.7). The first variable - marital status - is a nominal level variable that can be tested using the odds ratio and Fisher's exact test. The other 2 variables - years resident and previous residential organization experience - are ratio level variables amenable to correlation. Since distributions are abnormal, I used a non-parametric correlation Spearman's rho.

Tables 6.6 and 6.7 indicate that people who are unmarried (widowed or divorced) are more likely to use the term "in here/outside" than married persons. The odds of an unmarried person using "in here/outside" are 7 times greater than a married person. A Fisher exact test suggests this relationship is statistically significant $(p=.05$ for a twotailed test). Table 6.7 indicates that the longer a respondent has lived at Lakelands, or the greater the number of times a respondent has lived or worked in a residential organization, such as a boarding school, the more likely they are to use the term "in here/outside." 
Table 6.6. Association between marital status and use of the word "in here/outside"

\begin{tabular}{lccc}
\hline \multirow{2}{*}{ Word use } & \multicolumn{3}{c}{ Marital status } \\
\cline { 2 - 4 } & $\begin{array}{c}\text { Unmarried } \\
\text { (widowed/divorced) }\end{array}$ & Married & Total cases \\
Don't use "in here/outside" & 2 & 6 & 8 \\
Use "in here/outside" & 15 & 7 & 22 \\
Total cases & 17 & 13 & 30 \\
\hline
\end{tabular}

Table 6.7. Associations with "in here/outside"

\begin{tabular}{lc}
\hline Variables & In here/outside \\
\hline Years resident & $\begin{array}{c}.36^{*} \\
(\mathrm{n}=30)\end{array}$ \\
Number of previous residential & $.37^{*}$ \\
organization experiences & $(\mathrm{n}=30)$
\end{tabular}

Note. ${ }^{\prime} p \prec .10 .{ }^{*} p<.05$. Two-tailed test. Since these variables have abnormal distributions, I used the non-parametric correlation coefficient Spearman's rho.

What might explain these variations in residents' use of language of sequestration? Perhaps these differences can be explained using Giddens' notion of power and empowerment. First, there appears to be a relationship between being unmarried and use of "in here/outside." Perhaps being widowed or divorced lessens a resident's sense of empowerment vis-à-vis the organization. In losing a partner one may lose ties to the "outside world." This loss may increase a person's sense of isolation or 
sense of being separated from friends and society and contribute to the feeling that one is "shut in," or has been "put away." As well, perhaps being single may lessen one's involvement or participation in society. Similarly, perhaps being married supports one sense of empowerment vis-à-vis organizations and society in general. This may lessen the likelihood of feeling "shut in."

Second, there appears to be a relationship between length of exposure to residential organizations and use of "in here/outside." Perhaps, if a person has lived or worked in residential organizations in the past, a person may expect, and accept, a loss of personal power vis-à-vis management. One may consider sequestration, or being separated from "the outside," as a given. Alternatively, perhaps in living in organizations, one learns to reify the notion of organization, especially the notion of boundaries, and this assumption is then reflected in day-to-day language. The longer one has lived at Lakelands, the more likely one is to use the term "in here/outside." This suggests that frequency and length of exposure to residential organizations may influence the reflexive relationship between people and organizations to the point where people begin employing language of sequestration.

This suggests that Giddens' (1991) notions of power may be useful in explaining whether or not a resident uses the terms "in here/outside." Persons who find themselves alone, without a spouse, and persons who have had lengthy or numerous experiences living in residential organizations are more likely to use the term "in here/outside." These persons may have experienced loss of power in a number of ways: in status, in social relationships, in society, and vis-à-vis organizations. These losses may in turn lead them 
to use terminology that describes being "shut in" as a reflection of their perceived powerlessness.

These language habits illustrate that sequestered organizations can shape selfidentity in varying ways, depending on one's life situation (i.e., marital status, experience living in organizations). Since self-identity is reflected in narrative, unique language patterns such as "in here/outside" are signs of self-identity change. These habits suggest that people feel shut in; they have lost power vis-à-vis organizations and the "outside" world.

\section{Summary}

This section makes a number of contributions to the literature. It lends support to Czarniawska's (1997) and Wallenmac and Sims' (1998) argument that people have difficulty describing new organizational arrangements. Residents and management struggle, at times, to find explicit descriptions for Lakelands. This section also supports McHugh and Larson-Keagy's (2005) argument that clients of communal lifestyle organizations absorb and use marketing language. Management and residents use marketing language like "cruise ship" and "suite" to distinguish Lakelands from other forms of housing.

This section also illustrates the relevance of studying explicit and implicit language use (Giddens, 1991). It highlights how internally referential systems of thought, like advertising can shape day-to-day language. People who work with these systems, like managers, seem to have different language conventions than residents who do not 
work with these systems (Holstein \& Gubrium, 2000).

This section also highlights how structural analysis combined with statistical analysis, can produce important findings. Seemingly innocuous language habits are statistically associated with people's characteristics, such as marital status or experience living in a sequestered organization. Giddens' (1991) notions of power and empowerment proved relevant in explaining these associations. These language habits may reflect ways in which people experience, or perceive, a loss (or lack) of power in their relationships with organizations. As well, these language habits signal how sequestration can shape narrative, and in doing so shape self-identity (Holstein \& Gubrium, 2000). 


\section{CHAPTER SEVEN}

\section{Who am I when I live in an organization? Adaptation}

This chapter explores the difficulties people may have in adapting to their new life. Both Goffman (1961) and Townsend (1962) mention that people experience a period of adaptation when they move to a residential organization. Goffman notes that adaption influences self-identity. To explore this, I asked respondents whether they had to change or adapt to life at Lakelands.

Table 7.1 shows considerable variability between typical, contrasting and discrepant answers. Of those who answered this question $(n=28)$, sixty-four percent $(18$ cases) said that they either did not need to adapt (11 cases) or needed to adapt a little ( 7 cases). The remainder found adaptation somewhat difficult (18\%) or very difficult $(18 \%)$. This relates to analytical task \#3 - identify similarities and differences between residents.

Newer residents reported more severe problems than long-term residents. This raises the possibility that the figures in Table 7.1 are affected by the number of years a person has lived at Lakelands. Statistical analysis supports this observation. There is a significant correlation between "years resident" and "adaptation required": Spearman's rho $=-.43 p=.02$ (cases $=28$, two-tailed test). The longer a person lives at Lakelands, the less likely they are to report a large amount of adaptation required. 
Table 7.1. Typical, contrasting and discrepant narratives: Adaptation

\begin{tabular}{|c|c|c|c|c|c|}
\hline \multirow{2}{*}{$\begin{array}{l}\text { Question } \\
\quad \& \\
\text { Response }\end{array}$} & \multicolumn{4}{|c|}{ Narratives } & \multirow[b]{2}{*}{ Total cases } \\
\hline & Typical & Contrasting & Discrepant & Missing ${ }^{d}$ & \\
\hline $\begin{array}{l}\text { Have you had to } \\
\text { change or adapt? }\end{array}$ & $\begin{array}{l}\text { No. Or yes } \\
\text { a small } \\
\text { amount }^{\mathrm{a}}\end{array}$ & $\begin{array}{l}\text { Yes, } \\
\text { moderate } \\
\text { amount }^{b}\end{array}$ & $\begin{array}{l}\text { Yes, large } \\
\text { amount }^{\mathfrak{c}}\end{array}$ & & \\
\hline $\begin{array}{l}\text { Responses } \\
\text { - Total cases }\end{array}$ & $\begin{array}{c}18 \\
(60 \%)\end{array}$ & $\begin{array}{c}5 \\
(17 \%)\end{array}$ & $\begin{array}{c}5 \\
(17 \%)\end{array}$ & $\begin{array}{c}2 \\
(6 \%)\end{array}$ & $\begin{array}{c}30 \\
(100 \%)\end{array}$ \\
\hline $\begin{array}{l}\text { - Minus missing } \\
\text { cases }\end{array}$ & $\begin{array}{c}18 \\
(64 \%) \\
\end{array}$ & $\begin{array}{c}5 \\
(18 \% \\
\end{array}$ & $\begin{array}{c}5 \\
(18 \%)\end{array}$ & - & $\begin{array}{c}28 \\
(100 \%)\end{array}$ \\
\hline \multicolumn{6}{|c|}{$\begin{array}{l}\text { Note. } \\
\text { a Eleven people answered no, and seven "yes/a small amount." }\end{array}$} \\
\hline \multicolumn{6}{|c|}{$\begin{array}{l}{ }^{\mathrm{c}} \text { Resident said they found it hard or difficult to adapt to life at Lakelands. They said things like: it is taking } \\
\text { (or took) a long time to adapt; they are still having trouble adapting; they cannot remember the period of } \\
\text { time after the move; they would like to leave Lakelands, or they are thinking about leaving. }\end{array}$} \\
\hline
\end{tabular}

\subsection{Factors that help and hinder adaptation}

The correlation between "years resident" and "adaptation required" suggests that time is an important condition. Over time, people adapt. Townsend (1962) and Goffman (1961) found similar results; initial adaptation problems diminish over time. This study found that adaptation can take a long time. Some people continue to experience difficulties after having lived at Lakelands for ten months, and some, like Hugo, needs even more time to adapt. Hugo talked about his two year struggle, and how he places the blame on himself: Hugo: I still find it difficult, though. I should tell you that it took me 10 months to 
settle down here.

Margot: 10 months.

Hugo: took me a long time. [Discussion]

Hugo: It took some time to get used to. But I was very reluctant to come here. In fact, if it hadn't been this place, I don't know what I would have done. I don't think I would've stayed here. It's the surroundings and the walk we could do that attracted me - the creek and the area. If it had been downtown I wouldn't have liked it at all. I'm sure. Yah, I am. I'm settled in now. Still, things I find difficult to get used to. [Discussion]

Hugo: No, honestly now I'm getting used to the place and I do enjoy it now. [Discussion]

Margot: Anyway getting back to this. You said that you had trouble adapting to life here and you mentioned...

Hugo: Well, it took me 10 months.

Margot: 10 months, 10 months ...

Hugo: Well, I think it was my own fault. I should've tried a little harder to settle down. But being [\# of] years in [place] with my family not too far away and friends too. I missed them for a long time.

Hugo's struggle with adaptation is illustrated in the structural analysis of his shifting narrative (narrative analysis task \#8). He began his story by saying that he "still finds it difficult." Then he said it took him ten months to adjust, suggesting that he has adjusted. Next he said, "I'm settled in now" followed by the statement, "Still, things I find difficult to get used to," which suggests he has yet to fully adapt. Further on in the discussion Hugo said he is still adjusting, "No, honestly now I'm getting used to the place and I do enjoy it now." This shifting narrative suggests Hugo is still adapting. Hugo's narrative raises the question, Are there factors, apart from time, that affect adaption? Hugo thinks that there are a number of conditions that have hindered his 
adaptation - he misses his family, and he blames himself that he has not adapted more quickly. He also thinks that Lakelands - its gardens, and walking trails - have helped his adaption. In contrast to Townsend (1962) and Goffman's (1961) research, which emphasizes the ways repressive organizations hinder adaptation, Hugo emphasizes that Lakelands has helped him to adapt. This analysis relates to narrative analysis task \#5assess possible communal lifestyle organization typology by identifying differences between total institutions and communal lifestyle organizations.

Hugo, and many other people who live at Lakelands, talked about factors that help or hinder adaptation. Table 7.2 lists four key factors: Lakelands itself, individual self-control, fate, and situational factors. This analysis relates to narrative analysis task $\# 1$ - identity themes, sequence, timing, causality, conditions.

\section{A. Lakelands' effect on adaptation}

This study did not find any evidence that Lakelands - its management or residents initiate new residents by stripping identity. (Note how use of "in" in the word "initiate" is an example of language of sequestration). Instead, a Lakelands' manager told me that Lakelands accepts residents "as they are." (Note how, in the following quote, this Manager used the word "inside," which is another example of language of sequestration): Manager: They can be who they are. And that is also something I tell them, I said "You be whoever you are. You don't have to be something for us. You take your personality, who you were there, and you bring it inside. 
Table 7.2. Factors that help and hinder residents' adaptation

\begin{tabular}{|c|c|c|c|}
\hline Helps & $\begin{array}{l}\text { Cases } \\
(n=30)\end{array}$ & Hinders & $\begin{array}{l}\text { Cases } \\
(n=30)\end{array}$ \\
\hline \multicolumn{4}{|c|}{ Lakelands' effect on adaptation } \\
\hline Enjoy dining room & 5 & $\begin{array}{l}\text { No "buddy system" for } \\
\text { newcomers }\end{array}$ & 2 \\
\hline Know Lakelands' social norms & 5 & Gossip & 2 \\
\hline Have transportation & 5 & & \\
\hline $\begin{array}{l}\text { Lakelands' services, people (e.g., } \\
\text { kindness) }\end{array}$ & 3 & & \\
\hline Have choices (e.g., food) & 1 & & \\
\hline \multicolumn{4}{|c|}{ Individual self-control and adaptation } \\
\hline $\begin{array}{l}\text { Changing attitudes/behaviour: } \\
\text { - } \quad \text { Acceptance } \\
\text { - } \quad \text { A good attitude } \\
\text { - } \quad \text { Humour }\end{array}$ & $\begin{array}{c}11 \\
7 \\
2\end{array}$ & $\begin{array}{l}\text { Lack of social contact: } \\
\text { Not used to } \\
\text { people, no friends, } \\
\text { unsociable }\end{array}$ & 11 \\
\hline $\begin{array}{l}\text { Dealing with homesickness: } \\
\text { - } \quad \text { Fantasize being elsewhere } \\
\text { - } \quad \text { Return to one's former home } \\
\text { - } \quad \text { Walk in nature } \\
\text { Grieve the move }\end{array}$ & $\begin{array}{l}2 \\
2 \\
2 \\
1\end{array}$ & $\begin{array}{l}\text { Homesick } \\
\text { One's eating schedule } \\
\text { differs from Lakelands' } \\
\text { schedule }\end{array}$ & 2 \\
\hline \multicolumn{4}{|c|}{ Fate and adaptation } \\
\hline & & Crises (e.g., death) & 7 \\
\hline & & $\begin{array}{l}\text { Forced to move to } \\
\text { Lakelands }\end{array}$ & 2 \\
\hline \multicolumn{4}{|c|}{ Situational factors and adaptation } \\
\hline $\begin{array}{l}\text { Came from similar accommodation, } \\
\text { topography, climate }\end{array}$ & 5 & Gender or marital status & 3 \\
\hline Time & 4 & & \\
\hline
\end{tabular}


Van Maanen (1987) argues that organizational socialization can "confirm or to dismantle the incoming identity of a newcomer" (p. 33). Lakelands' welcoming processes "ratify and establish the viability and the usefulness of the characteristics the person already possesses" (Van Maanen (1987, p. 33). This relates to narrative analysis task \#5 assess possible communal lifestyle organizational typology by finding differences between communal lifestyle organizations and total institutions.

In addition to accepting people as they are, Lakelands' services can help adaptation. For instance, Hugo mentioned that the bus service helps adaptation:

Hugo: We missed it [the car] a lot when we arrived. But then we found a way of getting our independence back. By using the shuttle, of course, and also using the city bus too, to take us downtown. So that gave us some relief. We were on our own again, not relying on everybody.

"Going out" and freedom of movement is a theme in this study. This relates to narrative analysis task $\# 1$ - identify themes, sequence, timing, causality, conditions. Giving up one's car is a very difficult step and is mentioned by many people (17 cases or $57 \%$ of respondents). The people I interviewed value freedom of movement: the ability to go where they wish, when they wish, without being dependent on others for transportation (Rudman, Friedland, Chipman \& Sciortino, 2006).

Apart from Lakelands' bus service, people often mentioned how the dining room can help or hinder adaptation. The dining room is the centre of Lakelands' social life where people spend a large portion of their day. Being able to fit in - quickly learning social norms and being accepted by others - is crucial. Sonya, a new resident, has experienced multiple problems. Some residents have made her adjustment difficult:

Sonya: And I sort of come in with great enthusiasm, and I'm just . . not . . . 
settling in as well as I should. For one thing I have found, and it's no good saying to me, "you should do things differently," I found the dinnertime was very, very difficult, because you would come in, and stand there like a fool and not know where to sit. And I would look around, and you'd end up at a table and I had at least three unfortunate experiences which, if I talk about them afterwards, people say "Oh, nonsense, you know, they're not allowed to save seats," but they would say "Oh, somebody else always sits there."

Margot: Awww ...

Sonya: And I should, I shouldn't have let it bother me but it did bother me! In addition to seating difficulties, Sonya has born the brunt of gossip, another condition that hinders adaptation:

Sonya: . . . there's a group of [people] that sits [personal information] in the dining room, and they have the unfortunate habit of talking loudly and think they can't be heard. And I've got this horribly, horribly good hearing. And I heard her say one day, this was probably the third occasion that I thought, I thought I'd heard something, and each time I thought, "let it, let it go, let it go, let it go." This third time I heard her say " [person talks about Sonya]," "she's . . [person talks about Sonya]." And I sort of looked over there, and I thought, "let it go, let it go. There's no point in going back and saying anything."

[Discussion]

Sonya: [Laughing]. No, but I felt, I really felt very badly about that comment that I overheard in the dining room. Now I just absolutely ignore her altogether. But I don't want to start off by, I didn't want to start off by getting into fights with people you know, and getting into bad feelings and not talking to this one or that one, because most of them are really, really, really nice.

As a new resident, Sonya feels, and is, vulnerable. She has experienced repeated rejection, aggression and humiliation in the dining room, and in a variety of ways. A structural analysis (narrative analysis task \#8) of Sonya's transcript shows how she uses 
emphasis and repetition to convey the seriousness of the problem: "I'm just . . not ... settling in as well as I should"; “dinner time was very, very difficult"; "three unfortunate experiences"; "I've got this horribly, horribly good hearing"; "let it, let it go, let it go, let it go"; "let it go, let it go"; "felt very badly," "most of them are really, really, really nice."

Sonya decided that she has little to no control over other people's behaviour. The only thing that she can do is to "let go" and not fight - to control her own behaviour and to not let the situation bother her. In recounting these experiences to other residents she does not feel supported. She feels, however, that these bad experiences are mitigated by the nice people that she meets.

Sonya's narrative illustrates how a number of factors can work together to help and hinder adjustment to Lakelands; nice people help, a buddy system would help, accepting difficult situations helps, gossip hinders, and not enjoying the dining room hinders. Sonya's experience is not unique. I spoke to another relative newcomer, Frances, who in her first week at Lakelands, was treated badly by a number of female residents. Like Sonya, gossip was used as a form of aggression. It seems that newcomers, especially women, may experience difficulties with female residents: experiences that are designed to exclude the newcomer from Lakelands' social life.

\section{B. Self-control and adaptation}

Table 7.2 shows that respondents are more likely to mention how they can change themselves rather than how Lakelands' management or residents need changing. The notion of self-control, or being responsible for one's life, is central to Giddens' theory. 
This notion implies that people are active, knowledgeable and competent, and that they shape circumstances, particularly their immediate social surroundings. This points to how, in modernity, people work on the reflexive project of the self.

This suggests that working on the self is widely accepted by Lakelands' residents. It is reflected in the lack of support that Sonya receives from fellow residents. They discount her experience by suggesting "she should do things differently." Sonya's narrative suggests that the people she has spoken to about her problem see adaptation as an individual rather than a systemic issue.

As shown in Table 7.2, respondents mentioned four key factors over which they believe they have control: their attitudes/behaviour, social contacts, homesickness and eating schedule. Sonya mentioned the importance of having friends, and how this is invaluable in adapting: "And actually, I think, you know, if you've got, if you make one good friend you're usually okay. That, and I haven't made that one good friend yet."

Combating homesickness is another adaptation problem. People mentioned a number of strategies they use: going back home, "fantasizing being elsewhere" and grieving the move. Fantasy is a creative approach to adaptation (Rowles, 1978):

Ursula: Well, to me, it's like I am in Italy. So to me, I'm pretending I'm in Tuscany.

Margot: You're pretending you're in Tuscany.

Ursula: Yes, I look out and see the [bushes] and the trees. Because, otherwise it would drive me insane looking out at these [landscape], and or whatever they call them everywhere. Because I like open prairie. Standing out in the prairie - I just love it.

Marlene also uses fantasy as an way to adapt:

Marlene: Well, I just disliked everything about moving into a communal living 
situation. But so did he! [Laughing] We used to spend a lot of time talking about how we could escape!

Margot: [Laughing]

Marlene: Move to Tahiti or something. Live in a tent ...

Fantasy is an amusing way to deal with homesickness, however, grieving is less

pleasant. Sonya talked about the importance of grieving:

Sonya: You learned ... you shed a few tears maybe when you left some places, but you learned never to look back and say "Oh, that was better than being here." You learned to be able to take the next place in stride. And I remember once we had a psychologist, [personal information] . . and one of the things they were telling all of us - [personal information] - you should allow yourself to grieve every time you move because you are grieving for whatever you left behind. Even if it's your garden or your plants or, whatever. You have to go through that - the grieving.

Whereas most respondents emphasize the importance of changing oneself in order to adapt to Lakelands, Edward and Yann take another perspective. They suggest that others must adapt to them:

Edward: I've probably insulted a lot of people in [town], and probably insulted a lot of people here. But they're getting used to me. There's the odd person that will make a remark or kind of look sideways. But most of the people that know me real well, they poke me in the ribs or something.

Similarly,

Yann: And I've probably contributed, you know, on an equal basis. I mean, I'll probably be a pain to some other people sometimes.

Sonya, Edward and Yann's narratives raise a number of points. First, adaptation is not just about self-control, it points to systemic issues. Some factors may be within a person's control, such as grieving, while others may be outside a person's control, such as gossip and difficulties in the dining room. Second, adaptation operates in a reflexive 
way. As newcomers learn to adjust to Lakelands, so Lakelands and its long-term residents adapt to newcomers. Adaptation is reflexive, depending on the self, others and the social situation. Third, multiple factors are at work - some hinder and others help adaptation.

\section{Fateful moments in the context of adaptation}

In addition to factors that people think they can control, which affect adaptation, respondents mentioned a number of factors that could be described as fateful - things they cannot control. Respondents mentioned being forced to move to Lakelands (2 cases), and various other crises ( 7 cases) such as death (Table 7.2).

Respondents experienced many crises that could be described as fateful. Table 7.3 shows the number of respondents that experienced crises before and after the move. Table 7.4 describes these crises and frequency of occurrence. Crises include: illness (spouse, friends, self); moving; death (spouse, family, friends); care giver stress; serious fights with family; loss of possessions; financial crisis; and loss of volunteer work. A number of factors may influence the accuracy of the figures in Table 7.3 and 7.4. First, these tables are based on my conversations with respondents and knowledge of their situation. I did not directly ask respondents how often they experienced crises. Instead, I counted the number of crises mentioned in the transcripts, plus any crises of which I was aware, given my knowledge of the interviewees' situation. Consequently, these two tables may underestimate the total number of crises experienced. 
Table 7.3. Number of crises respondents experienced: Before and after the move

\begin{tabular}{lcccc}
\hline \# crises & $\begin{array}{c}\text { Before } \\
\text { move }^{a}\end{array}$ & $\begin{array}{c}\% \\
(n=30)\end{array}$ & $\begin{array}{c}\text { After } \\
\text { move }^{b}\end{array}$ & $\begin{array}{c}\% \\
(n=30)\end{array}$ \\
\hline 0 & - & & 5 & 17 \\
1 & 8 & 27 & 13 & 43 \\
2 & 17 & 56 & 9 & 30 \\
3 & 1 & 3 & 2 & 7 \\
4 & 3 & 10 & 0 & 0 \\
5 & 0 & 0 & 1 & 3 \\
6 & 0 & 0 & 0 & 0 \\
7 & 1 & 3 & 0 & 0 \\
8 & 0 & 0 & 0 & 0 \\
9 & 0 & 0 & 0 & 0 \\
Total cases & 30 & $100 \%$ & 30 & $100 \%$ \\
\hline
\end{tabular}

Note.

${ }^{a}$ Two years before the move, including the move to Lakelands.

b After the move to Lakelands.

A second factor that may underestimate the number of reported crises is the length of time a person has lived at Lakelands. Over time, people forget past crises. Table 7.5 indicates that "years resident at Lakelands" is associated with "crises that occurred before the move," but not with "crises that occurred after the move." The greater the number of years a person has lived at Lakelands, the fewer the number of crises that they report before the move. 
Table 7.4. Type of crises: Before and after the move

\begin{tabular}{lcccc|cccc}
\hline $\begin{array}{l}\text { Type of } \\
\text { crisis }\end{array}$ & \multicolumn{5}{c|}{ Before the move $^{a}$} & \multicolumn{5}{c}{ After the move $^{b}$} \\
\hline & $\begin{array}{c}\text { Mentions } \\
\#\end{array}$ & $\begin{array}{c}\% \\
(n=64)\end{array}$ & $\begin{array}{c}\text { Cases } \\
\text { \# }\end{array}$ & $\begin{array}{c}\% \\
(n=30)\end{array}$ & $\begin{array}{c}\text { Mentions } \\
\#\end{array}$ & $\begin{array}{c}\% \\
(n=42)\end{array}$ & $\begin{array}{c}\text { Cases } \\
\#\end{array}$ & $\begin{array}{c}\% \\
(n=30)\end{array}$ \\
\hline Illness $^{\mathrm{c}}$ & 15 & 23 & 13 & 43 & 29 & 69 & 22 & 73 \\
Moved $^{\text {d }}$ & 33 & 51 & 30 & 100 & 3 & 7 & 3 & 10 \\
$\begin{array}{l}\text { Death } \\
\text { e }\end{array}$ & 10 & 16 & 9 & 30 & 4 & 10 & 3 & 10 \\
$\begin{array}{l}\text { Care giver } \\
\text { stress }\end{array}$ & 3 & 5 & 3 & 10 & 1 & 2 & 1 & 3 \\
$\begin{array}{l}\text { Fights with } \\
\text { family }\end{array}$ & 1 & 2 & 1 & 3 & 2 & 5 & 2 & 7 \\
$\begin{array}{l}\text { Financial } \\
\text { crisis }\end{array}$ & 1 & 2 & 1 & 3 & 1 & 2 & 1 & 3 \\
$\begin{array}{l}\text { Other } \\
\text { losses }\end{array}$ & 1 & 2 & 1 & 3 & 2 & 5 & 2 & 7 \\
$\begin{array}{l}\text { Total } \\
\text { Tote This }\end{array}$ & 64 & 101 & - & - & 42 & 100 & - & - \\
\hline
\end{tabular}

Note. This table lists the number of mentions and cases. By including mentions, this table conveys the fact that some residents experienced a serious crises (e.g., illness) more than once. For example, 13 residents experienced serious illness before the move (their own illness or someone else that is close to them), but some resident experienced illness multiple times, which brings the number of mentions to 15 . ${ }^{\text {a }}$ Two years before the move, including the move to Lakelands.

${ }^{\mathrm{b}}$ After the move to Lakelands.

${ }^{c}$ This refers to serious illness experienced by the respondent or significant others. Includes severe homesickness.

${ }^{\mathrm{d}}$ This category counts the move to Lakelands as a serious crisis. Some people moved more than once in the two years prior to the move to Lakelands.

${ }^{\mathrm{e}}$ This category includes death of spouse, family and/or close friends.

${ }^{\mathrm{f}}$ Includes severe reaction to loss of volunteer work, or loss of pet. 
Although the figures in Tables 7.3 and 7.4 may not be completely reliable, they partially support respondents' theory that crises can hinder adaption. Table 7.5 indicates that the greater than the number of crises respondents experienced before the move, the more severe the adaption problems they reported. In contrast, crises after the move are not associated with reported adaption problems.

Table 7.5. Associations with "adaptation required"

\begin{tabular}{lcc}
\hline Variables & Adaptation required & Years resident \\
Years resident & $-.43^{*}$ & - \\
& $(\mathrm{n}=28)$ & \\
Crises before the move $^{\mathrm{a}}$ & $.40^{*}$ & $-.46^{*}$ \\
& $(\mathrm{n}=28)$ & $(\mathrm{n}=30)$ \\
Crises after the move $^{\mathrm{b}}$ & -.20 & .23 \\
& $(\mathrm{n}=28)$ & $(\mathrm{n}=30)$ \\
\hline
\end{tabular}

Note. ${ }^{t} p<.10 .{ }^{*} p<.05$. Two-tailed test. Since these variables have abnormal distributions, I used the non-parametric correlation coefficient Spearman's rho.

${ }^{a}$ Before the move, including the move to Lakelands.

${ }^{\mathrm{b}}$ After the move to Lakelands.

My observations of life at Lakelands combined with the interview data and Tables 7.3 and 7.4, suggest that the stereotype of the older person living a peaceful life does not fit people at Lakelands. Fifty-six percent (56\%) of respondents experienced two crises and $10 \%$ experienced four or more crises before, and including the move, to Lakelands. In addition to these crises, $74 \%$ experienced one or two crises after the move. The most common crises mentioned are illness, moving and death of significant others.

These findings are supported by the literature (Katz, 2005; Townsend, 1962) and 
by my experience living at Lakelands. During the two month study period, three residents died (one of whom was a respondent in this study). Another person died who was a long time resident. This person left Lakelands a few months prior to my arrival. In addition, over five people moved, either to be closer to family or because they needed extra care. This raises the question, What is the impact of these crises on people? Giddens says that existential issues must be addressed psychologically:

Existential questions and doubts raise some of the most basic anxieties human beings can face. By and large, under conditions of modernity, such questions do not have to be confronted directly; they are institutionally 'put aside' rather than handled within the personality of the individual (Giddens, 1991, p. 184-5). Since Lakelands institutionally sequesters death and illness, these questions cannot be "put aside." Also, since Lakelands concentrates death and illness, residents must psychologically process a greater burden of existential issues than persons living in ageintegrated communities or organizations.

Ursula supports this. Ursula is a relative newcomer and she said that she finds frequent death and illness at Lakelands difficult, even more troubling than deaths in her family:

Ursula: Because I know I'm talking about my neighbours and my family dying. That's different, because you're in a different environment and situation. Here you meet someone and then you seem to get along - they're interesting to talk to. And then all of a sudden "pop" they're dead! Or they're gone somewhere else because they can't be cared for here. That's very difficult. There's too much of that, all, constantly. But then I guess that would have to be the way. And it's not something that you can explain to people really. [Discussion] Ursula: And so I think it's, it's kind of daunted me that it couldn't . . . being it the same if I were in [my home town] - my [relatives died], and it didn't matter. 
Although the fact that I was . . I don't know, it's just different somehow. I don't know how to explain it to you, but it's different ... And they die. I mean, I was sorry that they died. But here it seems to be more . . . personal or closer. It's because you see them every day, I don't know.

A structural analysis of this quote (narrative analysis task \#8) explores Ursula's difficulty in facing and psychologically processing concentrated death and illness at Lakelands. Normally, Ursula is articulate, but here she becomes incoherent: "And so I think it's, it's kind of daunted me that it couldn't . . being it the same if I were in [my home town]." Ursula summed up her narrative difficulties by saying "it's not something that you can explain to people really." Even though Ursula is a new resident she has formed attachments. Losing fellow residents troubles her more than losing her relatives. She said that this is the one thing that she likes the least about Lakelands.

Are there other psychological consequences of processing this unusual burden of existential issues? Giddens argues that fateful moments, (like death and illness), can disrupt our routines, disturb adaptation processes and can produce psychological crisis:

Fateful moments necessarily disturb routines, often in a radical way. An individual is thereby forced to rethink fundamental aspects of her existence and future projects (Giddens, 1991, p. 202-203).

Giddens argues that psychological crises can seriously disrupt people's sense of time, space, continuity and self-identity (Giddens, 1991 p. 37). This is supported by Violet's experience. Violet experienced a large number of crises prior to her move to Lakelands: Margot: Was there anything about Lakelands, about living here, that you found you had to adapt to?

Violet: You know, you're asking me a question that I'm honestly not sure of 
because the first year I was here I can't remember.

Margot: Okay!

Violet: It was only [\#] months from the time my husband died. And we had been,

I think from the time I was [\#] years old, and we were always together.

In Violet's case a combination of crises - the death of her husband, financial crises, the move, and loss of many possessions (Belk, 1988) - seriously disrupted her ontological security, to the point that it affected her memory, her sense of time and her sense of self continuity. Although Violet is an extreme case, my conversations with residents indicate that, at Lakelands, crisis takes centre stage. Respondents experience a tumultuous, complex life. These are not minor crises, they represent serious disruptions to well-being. How do people cope with these fateful moments? How do they process the psychological burden? Jackie described the process of adapting to fateful moments:

Jackie: That's one thing about living, and I suppose that would be in any facility for the elderly, but it definitely is something that is front and foremost - not just in the elevator ${ }^{7}$. I think, you spoke about ... when we reach this age we're kind of honed and certain things just flow by and we get to know our values, and what's important. And I think maybe that, that is one of the things that does the honing. Margot: is the?

Jackie: You experience death, you experience loss.

Margot: And a lot of it here.

Jackie: Yah. And you have to ... accept that and you have to sort of internalize it to some degree so that it's not "gloom and doom."

\footnotetext{
7 When a Lakelands' resident passes away, management posts a notice in the elevators.
} 
Margot: That's one thing that strikes me here, that people mention, that people are happy here. You don't see people walking around with sad faces or ... Jackie: Yup.

Jackie suggests that psychologically processing fateful moments begins with a loss, moves to acceptance, then internalization ("to some extent"), and learning to be happy in the face of loss. Internalization involves learning over time "to let certain things just flow by," "to know your values," and to learn "what is important." This process, which Lakelands' residents experience over and over again, "hones," or shapes selfidentity. It teaches a person how to accept and internalize more rapidly, and it teaches a person how to experience happiness in the face of grief. Jackie calls the outcome of this honing process a type of wisdom.

Jackie's narrative supports Giddens' theory. Giddens predicts that being exposed to death and illness provides opportunities for self-development (Tucker, 1998, p. 205; Giddens, 1991, pp. 9-10). Although the trajectory of the self becomes a series of crises when one lives at Lakelands, crises that must be psychologically processed, residents learn to adapt. This process, however, may be less difficult for long-term residents than for newer residents like Ursula.

To take this reality into account, Giddens' notion of organizational sequestration needs to be extended; organizational sequestration not only protects society from ontological insecurity (Giddens, 1991), but it also concentrates death and illness in age sequestered organizations like Lakelands. The people living and working in these organizations face an unusual number of existential issues: a greater number than people 
living and working in age-integrated lifestyle sectors. They must psychologically process these issues. In doing so they may acquire a type of wisdom.

\section{Situational factors and adaptation}

In addition to factors that relate to fateful moments, people mentioned a number of situational factors that can help and hinder adaptation. Respondents talked about spatial and geographic issues (5 cases), and gender and marital status (3 cases), as helping or hindering adaptation.

The literature suggests that spatial issues are important to people (Hauge, 2007; Hopkins \& Dixon, 2006; Laws, 1995; Nelson, 2001; Reed, Payton, \& Bondet, 1998a). Not only do respondents favour places that are in their neighborhood, that they are familiar with (see Table 5.1), and that they consider attractive (see Table 5.2), some respondents believe that physical space, topography and climate can help or hinder adaptation (see Table 7.2). A few people ( 3 cases) talked about how it is easier to adapt if one comes from accommodation that is similar to Lakelands. This relates to narrative analysis task \#2 - identify informant theories. Townsend (1962) makes a similar point in his study. Townsend found people's self-identity was less challenged when living conditions resembled previous living arrangements.

In addition to spatial issues, new residents ( 2 cases), talked about how climate and topography affect their ability to adjust. Climate is related to freedom to go out, which is a theme in this study. People want to go outside when it pleases them. If the weather is inclement, it can affect their ability to adjust if they have just moved to Lakelands. 
Marlene and Ursula made this point. Marlene noted that although she loves to walk

outside, she was unable to do so when she first moved to Lakelands. The summer was too hot. The weather was temperate when Ursula first moved to Lakelands. She was able to spent a lot of time outside, which she feels helped her to adapt:

Ursula: It was . . . well I was thinking, good God, what am I doing here!

So it was a good thing it was [Spring] because I was able to go outside. I spent a lot of time outside at the pond.

Margot: Okay, so that's how you dealt with it.

Ursula: Yes, I just went outside and went for a walk by myself. And then I came back in. So it gradually got better and better. But how it would have been in the middle of winter, I don't know. It would have been very hard.

In addition to climate, topography may be a factor affecting some people's ability to adapt to Lakelands. Ursula complained about the topography around Lakelands - the hills make her feel trapped. One of the things that she likes about Lakelands is its interior open-concept design, which mitigates the "hemmed-in feeling" she gets when she goes outside. Elton, who also comes from the same region as Ursula, made a similar comment: Margot: And what do you like most about the place [Elton]?

Elton: I like the openness of the place all around here.

In addition to the ways that accommodation, climate and topography may help or hinder adaptation, respondents talked about the way they think that one's marital status or gender affects adaptation. Townsend's (1962) study suggests that men may have more difficulty adapting to a residential organization than women; they are more likely to complain than women about living conditions. People in this study have contrasting views on the subject. Some think it is harder for men to adapt than women, whereas 
others believe that it is easier for men to adapt. Some think it is harder to adapt if one is married and others think it is easier. Statistical analysis supports these conflicting comments. I did not find a significant statistical relationship between "adaptation required" and "gender" (Spearman's rho $=-.03 p=.88$, two-tailed test, $\mathrm{n}=28$ ) or "adaptation required" and "marital status" (Spearman's rho $=-.17 p=.38$, two-tailed test, $\mathrm{n}=28$ ). Since these variables have abnormal distributions, I used the non-parametric correlation Spearman's rho.

\subsection{Adaptation: An ongoing process}

The interview question "Have you had to change to adapt?" was intended to capture information about adaption after the move, however, people also talked about an ongoing need to adapt. Although the literature tends to focus on initial adaptation (Goffman, 1961; Townsend, 1962), my observations and conversations with residents suggest that adaptation is an ongoing process in a place like Lakelands. One of the things that I have noticed over the years, when I return to Lakelands, is that when people I know see me, they often warn me by saying: "There have been a lot of changes since you left. It's not the same. You'll see a lot of new faces." This points to an important phenomena at Lakelands - resident and staff turnover.

Resident and staff turnover necessitates ongoing adaptation for all residents: both long-term and new residents. Since about 200 people live at Lakelands, with an annual turnover of about $25 \%{ }^{8}$, adapting to new people, and saying goodbye to old friends and

\footnotetext{
8 Statistic provided by Lakelands' management.
} 
acquaintances, is an ongoing challenge. As well, staff leave. The year proceeding this research (2008) Lakelands' residents witnessed a large staff turnover.

Relationships between residents and staff can be very close, and a staff departure can be as important, or even more important than resident departures as Frances explains: Margot: So if I were to ask you, what is it that you like the most about Lakelands, what would you say?

Frances: I would probably think that the best thing, that if everything else was gone, I would want to keep the staff. Isn't that funny? But the [Marketing Director, the Activity Coordinator and the Receptionist] and even the servers and the girls that clean my room. They are strong for me. Yah. Other people can change ... they doze off somewhere.

People may take employee departures in their stride, or they may react as if it is a

death. Rennie talked about falling into a depression when an employee left:

Margot: You said also you experienced a kind of a depression ...

Rennie: Yah. I didn't want to go out. I didn't want to do [laugh] anything. I wanted to stay ...

Margot: Oh really.

Rennie: I wanted to stay home. And I'd go down and have my supper, come back and I just didn't feel like going anyplace. This lasted for about ... a little over a week. And then, [my husband said] "we're going to live here." I wanted to get out and move! And I found a place where I would've gone to [a new upscale independent living residence].

Margot: [Discussion] So well, at least your depression didn't last too long.

Rennie: No it didn't. That's all know. I don't know, if that's the way the depression was. I just didn't feel like doing anything at all. I didn't even feel like eating, or making a meal. But I'm okay now. I don't care. You know the ... So, I know, now I know how people feel because I thought like I'd lost a lot, because it was a big move ... and we could've stayed at home. [Discussion] 
Rennie: Oh, it was just shortly after [they] left. They just, it just, it just . . felt like ... a bomb was dropped you know! It just squashed everything ... [Long pause] . . . But it didn't affect a lot of people because they just never cared! They just come down and eat and go home ... you know. They didn't participate in anything. So ... [long pause].

Rennie described the various phases she went through to adapt to this departure - shock, anger, depression and apathy. She talked about "not caring now." Her tone suggests that she has grudgingly given up, but still cares very much about what has happened. In the end, this experience seems to give Rennie new insight into loss. She has greater sympathy for others: "So, I know, now I know how people feel because I thought like I'd lost a lot.”

These narratives illustrate how residents may react to departures: to staff as well as resident departures. The grieving process can be similar to a death: shock, anger, sadness, and depression (Jeon \& Dunkle, 2009). At Lakelands, departures are repeated over and over again. These departures have the potential to continuously disrupt routines. Adaptation becomes an ongoing affair in a segregated organization like Lakelands. Residents must continuously face crises of all sorts including illnesses, departures and deaths of fellow residents and staff. The risk of loss is great at Lakelands.

\subsection{Adaptation and self-identity}

Given the need to continually adapt at Lakelands, how does this affect self-identity? Giddens' notion of self-identity suggests that self-identity is reflected in narrative: "the self as reflexively understood by the individual in terms of his or her biography." 
Therefore, changes in narrative signal changes in self-identity. Where adaptation occurs it is accompanied by changes in self-identity.

Adaptation and changes in self-identity can occur slowly over time, or quickly. The walker issue discussed in the previous chapter is an example of changes in the reflexive project of the self that occurred gradually. In contrast, some employees leave suddenly. Illness, which is common, can also happen suddenly. Jackie described the way illnesses can suddenly, and radically change the self:

Jackie: So, only you don't let go gradually in that situation. You let go. [Personal discussion]

Margot: Yah, yah.

Jackie: So all of a sudden I was a totally different person, and had to be. And [my husband] was right here. You know the time was right and everything. The good Lord was planning ahead, and we were following the steps. [Discussion] Jackie: Well, there had to be a major change in my life anyway. There had been. And once you're on that, that [treatment] and various things like that, you kind of step onto this treadmill and you just follow it because you've made that choice. Well, that's how my life became. I was on that, that route. And Lakelands was part of it. So, the adapting was one big crash course at the beginning ... Jackie's change in self-identity occurs rapidly. She "lets go" and suddenly becomes a "totally different person." Jackie lets go of her past life and her responsibilities at home and accepts her new situation. She accepts that she has no control over her household, her illness, or its treatment.

The narratives in this section illustrate how people adapt in various ways that change self-identity. These narratives describe the process of adaptation, or the reflexive project of the self. For example, Sonya described a number of highly emotional changes 
to the self: "coming in with great enthusiasm," "not settling in as she should," "feeling like a fool," "being bothered by the situation," "feeling very badly," "trying to let go" and "grieving." Jackie talked about the speed at which self-identity can change as well as steps in the adaptation process: suddenly letting go, submitting, internalizing, wisdom and learning to be happy. Both Sonya and Jackie talked about the process of self-identity change. This process constitutes the reflexive project of the self.

\section{Summary}

The findings in this section makes a number of contributions to the literature. A person's self-identity is confirmed when they move to Lakelands, rather than being disconfirmed or stripped as is the case in a total institution (Goffman, 1961; Townsend, 1962; Van Maanen, 1987). As well, many of Lakelands' services are designed to help people maintain or enhance their previous lifestyle, in contrast to total institutions, which strive to downgrade a person's lifestyle.

People do have to adapt when they move to Lakelands, however, time heals these wounds. The longer a person lives at Lakelands, the less they remember severe adaptation problems. This supports Townsend (1962) and Goffman's (1961) findings.

Residents mentioned a number of factors that help and hinder adaptation. As Giddens' theory predicts, people's adaptation strategies emphasize changing the self rather than the place in order to adapt. This suggests that respondents believe in the importance and necessity of reflexive self-control.

The interview question focused on initial adaptation, however, respondents also 
talked about an ongoing adaptation process with implications for the reflexive project of the self. Both new and long-term residents must continually adapt. Whereas new residents must adapt to the move, long-term residents must adapt to new people and to the departure, illness or death of long-term residents, to staff departures, or to their own illnesses. Concentrated and repeated exposure to existential issues may shape the self. There is limited evidence that people learn to accept and internalize crises (Grant, 2007), and that this can produce meaningful self-actualization (Giddens, 1991).

In sum, the findings suggest that living in a place like Lakelands has profound implications for self-identity. Because Lakelands is a residential organization, and because it is age-segregated, residents must constantly adapt to new people, to sickness and to death. They face a greater number of existential issues, which must be psychologically processed within the self, than people living in age-integrated environments. Although the reflexive project of the self is under constant revision, these crises may provide opportunities for self-development, or a type of wisdom. 


\section{CHAPTER EIGHT}

\section{Who am I when I live in an organization? My self-identity}

A number of researchers talk about retirement communities creating opportunities for remaking aging identities through consumer lifestyles, active retirement, and by dislocating home from local space and family (Blaikie,1999; McHugh, 2003; Katz, 1999). To explore respondents' conscious perceptions about self-identity change, I asked respondents if living at Lakelands has affected the way they see themselves. Responses vary a great deal. Of those who answered this question $(n=25)$, twelve people $(48 \%)$ said they haven't changed, eleven (44\%) said they have, and two (8\%) said they have, but as a result of health changes, rather than as a result of living at Lakelands (see Table 8.1). About one half of respondents feel that their self-identity remains unchanged.

Some people like Jessica and Marlene attribute this to having a strong ego:

Margot: So does living ... has living ... does living here affect the way you see yourself?

Jessica: . . . I don't think so ...

Margot: That might be a hard question.

Jessica: . . . Well ... I don't even think about it. I have enough self-confidence to know I'm me ... and so I don't think it affects me ... it may sound superior or something, but I just mean I have enough self-confidence that I don't worry about that sort of thing... 
Similarly,

Marlene: I don't think either [residential organization] has made a great change.

Because I'm a person with a strong ego. So, I'm still myself, you know. Yeah.

[Laugh].

Margot: Okay. Okay.

Marlene: I mean, I wasn't a person who was absorbed by my husband's

personality either. You know, I've maintained my individuality all my life.

Table 8.1. Typical, contrasting and discrepant narratives: Self-identity change

\begin{tabular}{lccccc}
\hline $\begin{array}{l}\text { Question } \\
\&\end{array}$ \\
\begin{tabular}{l} 
Response \\
\cline { 2 - 5 }
\end{tabular} & Typical & Contrasting & Discrepant & Missinga & $\begin{array}{c}\text { Total } \\
\text { cases }\end{array}$ \\
\hline $\begin{array}{l}\text { Does living here } \\
\text { affect the way you }\end{array}$ & No. & $\begin{array}{c}\text { Yes (e.g., } \\
\text { old, } \\
\text { see yourself? }\end{array}$ & $\begin{array}{c}\text { Poor health } \\
\text { changes }\end{array}$ \\
$\begin{array}{l}\text { Responses } \\
\text {-Total }\end{array}$ & 12 & 11 & identity. & & \\
-Minus missing & $(40 \%)$ & $(36 \%)$ & $(7 \%)$ & $(17 \%)$ & $(100 \%)$ \\
responses & 12 & 11 & 2 & - & 25 \\
\hline $\begin{array}{l}\text { Note. } \\
\text { a Five persons did not answer this question. }\end{array}$ & $(48 \%)$ & $(44 \%)$ & $(8 \%)$ & & $(100 \%)$ \\
\hline
\end{tabular}

While Jessica and Marlene attribute a lack of change to a strong ego, Charlotte attributes a lack of change to being able to maintain her independence:

Margot: Here ah, does living here affect the way you see yourself?

Charlotte: ... [long pause] How do you mean? I mean

Margot: OK.

Charlotte: I'm $m e$ [italics added]. 
Margot: OK.

Charlotte: [Laughing] Does that answer your question?

Margot: That does! Thank you very much. That's it. You're me! Yah!

Charlotte: Yah

Margot: Yah.

Charlotte: I'm still, I'm still [Charlotte]. I still live my own life and do my own things. So there is nothing to top that.

Charlotte feels that she is living as she always has. Perhaps if Charlotte had lost her independence, she might have experienced a change in self-identity.

These narratives suggests that a lack of change in self-identity may be due to a number of factors: a strong ego, continuity in lifestyle, or perhaps a functional view of the self (Erikson, 1959) - the view that self-identity is stable and unchanging. While about half of respondents reported no change in self-identity, the other half talks about changes.

What accounts for reported changes in self-identity? The study discovered two factors that may lead to a reported change in self-identity. Table 8.2 lists two variables that are statistically associated with self-identity change: crises before the move, and previous residential organization experiences. (These two variables are also interrelated Spearman's rho $=.30 p=.10 \mathrm{n}=30$, two-tailed test). The more crises a person experiences before the move, including the move, the more likely they are to report a change in self-identity. Crises include events that disrupt routines, that can produce psychological crises, or that can lead a person to ask fundamental questions about life. Crises include the death of a loved one, illness, fights with family, loss of possessions, and loss of volunteer work. 
A second factor that is associated with self-identity change is residential organization experience. The greater the number of residential organizations in which a person has lived or worked, the more likely they are to report a change in self-identity. Residential organizational experience includes: living in condominiums, gated communities and other retirement residences; living in boarding school; and working or living in residential organizations such as the armed forces, hospitals, nursing homes and correctional facilities. Table 8.3 indicates that most respondents have had one or two previous experiences living or working in residential organizations. These data came from responses to open-ended questions about occupational and moving history. As a result, these numbers may be under-reported.

Table 8.2. Associations with self-identity change

\section{Variables}

Crises before the move ${ }^{\mathrm{a}}$

\begin{tabular}{lc} 
Crises before the move & $.52^{*}$ \\
$(\mathrm{n}=25)$ \\
Number of previous residential & $.38^{\dagger}$ \\
organization experiences & $(\mathrm{n}=25)$ \\
\hline
\end{tabular}

\section{Self-identity change}

\section{$.52 *$}

Note. ${ }^{\dagger} p \prec .10 .{ }^{*} p<.05$. Two-tailed test. Since these variables have abnormal distributions, I used the non-parametric correlation coefficient Spearman's rho.

${ }^{\text {a }}$ The number of crises in the two years before the move, including the move to Lakelands.

What might be the explanation for these two associations with self-identity change? Perhaps Giddens' theory can explain these relationships. First, in the case of 
"crises before the move," Giddens predicts that serious crises, like death, illness and moving, challenge ontological security. As a result, the reflexive project of the self is revised, sometimes in fundamental ways (Giddens, 1991). Townsend (1962) and Goffman's (1961) research also supports this theory. They observe that a move to a total institution-like residential organization disrupts self-identity. The data seem to support this interpretation. The more crises that occur before the move, the more opportunities for revising self-identity.

Table 8.3. Number of previous residential organization experiences

\begin{tabular}{lcc}
\hline $\begin{array}{l}\text { Number of previous } \\
\text { residential organizations }\end{array}$ & Cases \# & Percent \\
\hline 0 & 6 & 20 \\
1 & 12 & 40 \\
2 & 11 & 37 \\
3 & 1 & 3 \\
Total & 30 & 100 \\
\hline
\end{tabular}

Note. "Number of organizations" refers to the total number of residential organizations in which a respondent has lived or worked over the course of their life. This includes living in a condominium, gated community, retirement residence, working in a hospital/nursing home, working in a prison, living in a boarding school, being in the army.

As the number of crises before moving increases the likelihood of self-identity change, so does the number of previous residential organization experiences. Perhaps each experience in a residential organization disrupts and changes self-identity. Also perhaps there is an incremental effect since the greater the number of prior experiences, 
the more likely a person is to report a self-identity change at Lakelands. Some of these experiences occurred a long time ago: in childhood (i.e., living in a boarding school); or 60 years ago while serving in the armed forces during World War II. Some experiences may have occurred only a few years ago, for example living in a gated community or living in a place like Lakelands.

Another explanation for this relationship is that perhaps people report a selfidentity change at Lakelands as a result of comparing their current situation - living in a luxury residential environment with a wealth of leisure opportunities - to previous experiences where they did not have these amenities, or where they experienced deprivation. People may notice a change in self-identity because their current experience is so different from previous experiences. For instance, there are great differences between total institution-like organizations and Lakelands. As well, there are great differences between residential organizations where one is a worker, and Lakelands where there are no work demands. Even persons who moved from a condominium or gated community where residents are retired, would experience differences. These organizations do not have the housekeeping services, social opportunities, and the gourmet dining experience that Lakelands offers. Perhaps it is the act of comparing past and present, combined with the extent of the difference, that changes self-identity.

These two statistical associations with self-identity change (i.e., crises before the move and previous residential organization experience) point to the power of crises disruptive circumstances - and to the power of residential organizations, both past and present. The self-identity changes that occur in association with these experiences are 
large enough for people to notice a difference in themselves.

In addition to these two factors that produce self-identity change, respondents described the ways in which their self-identity has changed. For instance, respondents said they "feel old," "feel good or happier," or feel they have become "less selfish." Some changes may reflect a loss of status, such as no longer being a property owner or feeling less important. Sometimes people mentioned more than one change (see Table 8.4).

Table 8.4. Self-identity changes

\begin{tabular}{|c|c|}
\hline Due to living at Lakelands & Mentions \# \\
\hline Feel old & 6 \\
\hline Feel good/proud, happier & 5 \\
\hline Less selfish, more tolerant of infirmity & 3 \\
\hline No longer a property owner & 2 \\
\hline Feel less important, more humble & 1 \\
\hline Subtotal & 17 \\
\hline \multicolumn{2}{|l|}{ Due to illnesses } \\
\hline Less confident, worry more, change activities & 4 \\
\hline Total mentions & 21 \\
\hline
\end{tabular}

Note. Cases $=13$. A number of people mentioned more than one of the above categories. 


\subsection{Feeling old}

"Feeling old" is the most frequent response to the question "Does living here affect the way you see yourself?" People mention that by living at Lakelands, one becomes old, since one is living with other older people. Respondents in all age groups - the 70s, $80 \mathrm{~s}$ and $90 \mathrm{~s}$ - reported feeling old. Jackie talked about how one suddenly becomes old when one moves to Lakelands. The following repeats sections quoted earlier:

Margot: Does living here affect the way you see yourself?

Jackie: Oh yah. Oh yah. [Laughs]. It was the main thing of the kicking and screaming that "I'm not going" type of thing and ... I used to go with [husband] and we had [church] services at [place]. And I remember one of the ladies, that she was very chic - just a lovely woman. And I was talking to her about various things. And one of the things she said to me, she said. "When you move in here, [Jackie] you're suddenly old."

Margot: Hhh ...

Jackie: And I thought, "How could that be?" But it's true, and it's just another thing that you have to accept. But having accepted that, there are no constraints on you, but ... their perception that, the perception of . . some ... does change. And you see it with other people, out in the community. When somebody says, "and [Jackie] lives at Lakelands," there's "Oh!" Margot: Okay, so she's part of that ... older group.

Jackie: Yah.

Margot: Yah. And that's what you didn't want. Is that why you didn't want to move in here? You didn't want to be seen as part of that older group? Jackie: Perhaps, maybe . . . it . . it, probably, likely was, But I didn't ever . . . think, think that thought. But you know how, it's there.

Margot: Yes.

Jackie: But it doesn't ruin my happiness. It just means that I'm aware of being perceived differently. And so I perceive myself differently. That's the way it is. 
And in a lot of ways. It's kind of nice, and it's kind of comfortable ... to be in that slot. It's not all that bad.

Margot: Yah, yah.

Jackie: But you do recognize ...

Jackie explained that she did not want to move to Lakelands because, at an unconscious level, she knew it would change her self-identity - that she would become old by associating with older people. Her suspicions are confirmed by a woman who said that she had this experience. Since moving, Jackie believes that others react to her differently - they see her as old - which in turn affects how she sees herself. This points to a reflexive relationship between others' perceptions and self-identity.

Ursula's narrative supports Jackie's story. Ursula said that she too feels old, now that she lives at Lakelands:

Margot: Living here at Lakelands, does it affect the way you see yourself? Ursula: Yes. Now I'm old. I hadn't really thought about being old before. [Very long pause] Yah.

\subsection{Feeling proud, blossoming and love}

In addition to feeling old, a number of people said they feel happier, or better about themselves. Some have experienced a radical positive transformation. Henrietta is proud to be living in a place like Lakelands. It makes her feel "good." Like Jackie, she likes the sophisticated appearance of Lakelands' building and grounds:

Margot: Does living here affect the way you see yourself?

Henrietta: Yes.

Margot: In what way?

Henrietta: Well Lakelands is . . How do they? . . It's shown a sophisticated building - the whole thing. You're living in the best place of all the buildings. 
Yes, they all said "this was the most . . " because of this park. Everybody just loves it, they move in. That's what. It is the best!

Margot: So how does that make you feel?

Henrietta: Good!

Margot: Good!

Henrietta: "You can live in a cheaper one." I says, "where in the basement"?

Forget it!

Living in a basement apartment would not make Henrietta feel good about herself.

As living at Lakelands can improve one's self-image, it can also allow people to "socially blossom." Rosemary talked about how she was lonely in her home, and how she is happier living at Lakelands now that she has people to talk to:

Margot: Are you lonely here?

Rosemary: No not a bit!

Margot: Oh big difference!

Rosemary: Oh, you can't stop me talking, perhaps you gathered that!

Margot: And you have how many family here?

[Discussion]

Margot: So it's the people here [at Lakelands], that . . .

Rosemary: And that's the difference.

Margot: Make the difference? Okay, yah, what a difference eh!

Rosemary: Yes. I talk much more. Well, I had nobody to talk to . .

Lakelands allows Rosemary to escape the social isolation that can come from nuclear family living and to blossom by having contact with others (Folts \& Streib, 1994).

Andy made a similar comment. He has noticed a significant change in his wife's personality since moving to Lakelands. She has become a social being:

Andy: You see [my wife] is a very quiet person. Doesn't like to talk to anybody. In fact, I wondered about bringing her here. But it took about [\#] months, and she would talk to all sorts of people! [Laughing]. See we never had any close friends 
other than [personal discussion].[Laughing]. Well, she talks to people now. She didn't when we first came here.

Andy's perception is supported by his wife. When I asked her how she felt about living at Lakelands she said: "I felt like I'd died and gone to heaven!" For her, moving to Lakelands was a wonderful transformation.

Both Henrietta and Victoria experienced loneliness and depression before coming to Lakelands. They talked about how the love that they give and receive at Lakelands has transformed their lives:

Henrietta: ... And that's, and those people [people at Lakelands], they just love me. And I love them. We are so close together. I'm telling you, and they help me [background information]. And that was so much better. I did, I did, and so the Lord was good to me and that's the way it's going... Still going like that. Similarly,

Victoria: Anyway. I'm really glad I came here. It's been a real wonderful thing for me. It changed my whole feelings about people and about life, and I love people. And now I can love them! You know, and I do. They like it. They like me - they love me back.

Loving relationships bring purpose and meaning to Henrietta and Victoria's lives. They receive and return this love to others.

Although Lakelands' upscale appearance and active retirement policy can remake self-identity in positive ways, being age-segregated, it can also shape self-identity in negative ways (e.g., feeling old). Overall, Tables 8.1 and 8.2 indicate that positive (or no impact) on self-identity outweighs negative impacts.

\subsection{Meaningful self-actualization}


In addition to supporting arguments that communal lifestyle organizations remake aging identity (Blaikie,1999; McHugh, 2003; Katz, 1999), there is support for Giddens' argument that being exposed to existential questions expands the self in meaningful ways (Giddens, 1991, p. 201-203). Giddens argues that internally referential systems of modernity, including consumerism, can isolate people from moral and existential issues, thereby morally stunting the self:

Personal meaninglessness - the feeling that life has nothing worthwhile to offer becomes a fundamental psychic problem in circumstances of late modernity. We should understand this phenomenon in terms of a repression of moral questions which day-to-day life poses, but which are denied answers. 'Existential isolation' is not so much a separation of individuals from others as a separation from the moral resources necessary to live a full and satisfying existence. The reflexive project of the self generates programmes of actualisation and mastery. But as long as these possibilities are understood largely as a matter of the extension of the control systems of modernity to the self, they lack moral meaning [italic added]. 'Authenticity' becomes both a pre-eminent value and a framework for self-actualisation, but represents a morally stunted process (Giddens, 1991, p. 9). Based on Giddens' analysis, one would expect that Lakelands would provide opportunities for meaningful self-actualization, since moral and existential issues are not repressed, but rather are concentrated at Lakelands. Some respondents support this argument. As noted in section 7.01C, Jackie said that being constantly exposed to death "hones" a person, creating a kind of wisdom. As well, a number of other people (Clara, Leo and Frances) talked about becoming more humane or accepting of others:

Leo: But no, then you learn to be accepting of a lot of things that people do. Similarly,

Margot: Okay. Yah ... Has living here changed the way you see yourself? 
Frances: Yah, maybe. Yah. It does. Probably made me not quite so selfish in my thought . . . in the way, you know, if I used to see somebody who was, this is really mean, a little crippled or something, "I don't know what's wrong with her." And here, I think, "she's suffering, she would love to be like the rest of us, but she can't." So, that has made me probably more mellow.

Frances attributes changes in her attitude to being exposed to other people's difficulties. In living at Lakelands, people are exposed to a host of social, moral and existential issues. Most respondents did not talk about wisdom, but they did talk about being more accepting of their fellow human beings. This suggests that these experiences can expand the self in a meaningful way.

\section{Summary}

This section makes a number of contributions to the literature. It identifies factors that are associated with a change, or a lack of reported change in self-identity since moving to Lakelands. Persons with a strong ego, an unchanged lifestyle, or a functional view of the self seem less likely to report changes in self-identity. In contrast, the greater the number of crises a person experienced before the move, and/or the greater the number of previous experiences in residential organizations, the more likely a person reported changes in self-identity.

The findings illustrate and expand on the argument that self-identity is remade in retirement communities (Blaikie,1999; McHugh, 2003; Katz, 1999). At Lakelands, selfidentity is remade in negative and positive ways. Although living in an age-restricted community can negatively influence self-identity - make one feel old - Lakelands' can 
make people feel better about themselves, sometimes producing a radical positive transformation of the self. As well, Lakelands can banish social isolation, and offer opportunities for meaningful self-actualization - especially greater humanity. In sum, positive effects on self-identity seem to outweigh negative effects. Self-identity is either maintained or enhanced at Lakelands. 


\section{CHAPTER NINE}

\section{Who am I when I live in an organization? Naming conventions}

The previous sections looked at the ways in which people adapt to Lakelands as well as self-identity changes. This section looks at language conventions - specifically naming conventions - and the implications for self-identity. Organizations influence individual narratives in subtle ways, providing preferred ways of viewing the world or conceptualizing problems (Gubrium \& Holstein, 2008). Townsend (1962) and Davies (2001) argue that organizations use names to convey something about people's organizational status and identity.

I explored this issue by asking residents what they think about being called by their first name by everyone - residents, staff, and young servers included. This relates to analytical task \#1 - identify themes, sequence, timing, causality and conditions. As Table 9.1 indicates, residents are overwhelming in favour of being called by their first name. Marlene mentioned that she likes being called by her first name by residents and management, since they are her peers, but she does not like being called by her first name by the young servers. 
Table 9.1. Typical, contrasting and discrepant narratives: Naming conventions

\begin{tabular}{|c|c|c|c|c|c|}
\hline \multirow{2}{*}{$\begin{array}{l}\text { Question } \\
\& \\
\text { Response }\end{array}$} & \multicolumn{4}{|c|}{ Narratives } & \multirow[b]{2}{*}{$\begin{array}{l}\text { Total } \\
\text { cases }\end{array}$} \\
\hline & Typical & Contrasting & Discrepant & Missing & \\
\hline $\begin{array}{l}\text { What do you think } \\
\text { about people } \\
\text { calling each other } \\
\text { by their first } \\
\text { name? }\end{array}$ & Fine. & $\begin{array}{l}\text { Fine, but some } \\
\text { other naming } \\
\text { habits are funny } \\
\text { (e.g., "you } \\
\text { guys"). }\end{array}$ & Not fine. & & \\
\hline $\begin{array}{l}\text { Responses } \\
\text { - Total } \\
\text { - Minus missing } \\
\text { responses } \\
\end{array}$ & $\begin{array}{c}18 \\
(60 \%) \\
18 \\
(90 \%) \\
\end{array}$ & $\begin{array}{c}1 \\
(3 \%) \\
1 \\
(5 \%) \\
\end{array}$ & $\begin{array}{c}1 \\
(3 \%) \\
1 \\
(5 \%) \\
\end{array}$ & $\begin{array}{c}10 \\
(30 \%) \\
- \\
- \\
\end{array}$ & $\begin{array}{c}30 \\
(100 \%) \\
20 \\
(100 \%) \\
\end{array}$ \\
\hline $\begin{array}{l}\text { What do you think } \\
\text { about use of the } \\
\text { word "residents"? }\end{array}$ & Fine. & $\begin{array}{c}\text { Fine. Makes } \\
\text { suggestions for } \\
\text { alternative names }\end{array}$ & Not fine. & & \\
\hline $\begin{array}{l}\text { Responses } \\
\text { - Total } \\
\text { - Minus missing } \\
\text { responses }\end{array}$ & $\begin{array}{c}10 \\
(33 \%) \\
10 \\
(53 \%)\end{array}$ & $\begin{array}{c}8 \\
(27 \%) \\
8 \\
(42 \%)\end{array}$ & $\begin{array}{c}1 \\
(3 \%) \\
1 \\
(5 \%)\end{array}$ & $\begin{array}{c}11 \\
(37 \%) \\
- \\
-\end{array}$ & $\begin{array}{c}30 \\
(100 \%) \\
19 \\
(100 \%)\end{array}$ \\
\hline
\end{tabular}

Most people like the social closeness that first names imply. Olivia and Angela said that they like being called by their first name because it is less formal:

Angela: Now I don't know, I think I kind ... the ones that I like ... I kind of like to be called [by my first name] rather than [my last name]. It sounds so old and formal. [Laughing]. It's nice. I enjoy it now. You know.

Olivia said that it adds to the friendliness of the place.

Olivia: No, I think it's nice to call everybody by their first name. It's much 
friendlier than being very polite.

Apart from making the place feel friendly, quite a few people ( 5 cases) said that using first names is practical - it is easier to remember than first and last names. As well, a number of people pointed out that it is common today to call people by their first names, and that Lakelands is no different from the rest of society.

In addition to being modern and practical, Elton said he likes the practice because it makes him feel young:

Elton: Oh, I've no trouble with it. And I get kind of surprised when somebody calls me Mister. I didn't realize that I'm that old!

Elton's point is that old age is a state of mind. The physical body may be old, but inside we may not feel old (Biggs, 1999; Featherstone \& Hepworth,1991). Not only does calling a person Mr. or Mrs. create social distance, for Elton it harks back to a time when one always used these terms for one's elders.

Although people like being called by their first names, Elton and Olivia pointed out that Lakelands' naming practices have changed over time. In the past, people were called Mr. and Mrs. but, since the introduction of first names on people's name tags, the practice has changed. Knowing first names has led to using first names.

In addition to asking people whether they like to be called by their first name, I asked residents what they thought about calling people who live at Lakelands "residents." Once again the response was overwhelmingly in favour of the practice. Only one person, Pieter, objects. He does not see himself as a resident. Lakelands is his home. Being called a resident implies impermanence in his mind. 
Some people explained why they think the term "resident" is appropriate, and why other names are inappropriate. They talked about how calling people at Lakelands "members of a club," "patients," "tenants," "live ins," "inmates," “customers" or "clients" is inappropriate. People mentioned that the word "residents" is not only appropriate for someone who lives in a residence, as they do, but also for someone who lives in an apartment or a home. Jackie summed this up by saying that the term is appropriate and dignified at the same time:

Jackie: What would be the option? Tenants? Clients? You know, I think residents covers it. It's what residents means to you, and I guess to me. There's a dignity to that.

In exploring this naming practice, I asked management where it had originated, and whether or not it was a conscious choice:

Manager: That's ... something that comes from our family's background in longterm care. But clients in long-term care are being called residents for ages. And so when we got into this industry, we just called clients residents as well and that, so that's more like a historical artifact of our operations that developed than any conscious ...

Margot: By the way I noticed that Hyatt Classic, which has the Hyatt, is part of Hyatt, they have this type of service and they call the people who live in their organizations residents.

Manager: Yes, we think it's a more friendly term than customer or client. It doesn't necessarily have any negative connotations. It recognizes that it's people that live here.

This conversation makes the point that the term resident crosses boundaries. It is used in both nursing homes and communal lifestyle organizations like Classic Residence by Hyatt, Del Webb, Leisure Care, and Chartwell, as illustrated by their websites: We like to say that living at a Del Webb resort-style community is like being on 
vacation every day. And much the way a resort caters to its guests' needs in every way, Del Webb caters to our residents [italics added] to make sure you can live life to the fullest (Del Webb, 2010).

Similarly,

For more than 20 years, Classic Residence by Hyatt retirement communities have helped residents [italics added] worry less and live more (Hyatt Corporation, 2010).

Similarly,

Leisure Care communities are abuzz in 2010 with fun, creative, purpose-driven programming that will enhance lives and allow residents [italics added] and employees to get involved and express their individuality (Leisure Care, 2010). Similarly,

At Chartwell, we are people caring for people. Our greatest responsibility is the care and service we provide to our residents [italics added] (Chartwell Seniors Housing REIT, 2010).

Although many leading communal lifestyle organizations use the term "residents," some may shun the word, as I discovered in a visit to a communal lifestyle organization in another city. The "Community Relations Coordinator" explained that they consider themselves to be an independent living community, not a "facility" or "a home." She said they don't use the word residents because it suggests a facility or a home. Instead, they call people "members" to signify that they are "members of a club." Management and staff in this organization use explicit and implicit language in a purposeful way. They are signaling that the organization's identity, and the self-identity of its inhabitants, are distinct from institutional settings. 


\section{Summary}

Respondents agree with the identity, organizational status (Davies, 2001; Townsend, 1962) and ways of thinking conveyed by Lakelands' naming conventions (Gubrium \& Holstein, 2008). Residents are in favour of the friendliness and social equality that first names imply. As well, they are in favour of the notion that they "reside" at Lakelands. They do not see themselves as temporary guests, but rather as permanent residents. Most have never questioned, nor thought about Lakelands' naming conventions suggesting that these routines fit the lifestyle. 


\section{CHAPTER TEN}

\section{Who am I when I live in an organization? Living with others}

What is it like to live in a communal setting where people who are not related socialize and eat together every day? In North America we live in nuclear families. Even people living in close proximity, such as condominiums and apartments, do not eat or socialize together everyday. For most, living in such a situation is novel. Living with others raises the question of "Where is the 'me' among the "we'?" and "Who does the organization (management and residents) want me to be?"

This section covers a number of topics related to living with others: privacy, eating with others, conflict and friendships. I explored these issues by asking respondents the question "What is it like to live with other people?" The general response was that respondents like living with others. No one said that they dislike living with other people. Olivia noted that it would be very difficult to live at Lakelands, if one disliked people:

Olivia: If you're the kind of person that just can't stand other people around you, then you're in trouble. You just stay in your room and vegetate I guess.

Some people, when asked what it is like to live with other people, pointed out that you can't like everyone. You pick and choose your friends:

Angela: The people $-98 \frac{1}{2} \%$ of them are perfect. Just great. Just lovely people men and women ... 
Rosemary made the unusual comment that living with others at Lakelands is similar to being on holiday:

Rosemary: Oh. It's like ... you're on holiday and you're at a hotel and you see them daily.

Margot and Rosemary: [Laughing].

Rosemary: But here it goes on ... for a long time, I hope. [Laughing]. Margot: Yah. Yah.

Rosemary: You say good morning to them and good night. Yah ... but that's ... I feel I've got a smile on my face more often.

This is an interesting point, and may help to explain Lakelands' name - a retirement resort. Rosemary said that unless we are on holiday we rarely socialize daily with other people, however, this is what happens at Lakelands every day.

"Being on holiday" points to the idea that Lakelands is creating a leisure selfidentity. Folts and Streib (1994) emphasize this point by calling communal lifestyle organizations "leisure-oriented communities." As Goffman (1961) points out, by participating in an organization's activities, one adopts the self-identity this implies. Consequently, a organization focused on leisure creates a leisure self-identity.

Although most people said that they like living with others, seven persons $(23 \%)$ said that they don't really live with other people. They have their own private apartments where they retreat, when need be. When they are in their apartments, people respect their privacy - they do not come knocking on their door:

Jessica: Well, you're not really living with other people. You can go in and close your door and never see another soul until you go to dinner the next day. So you don't have to be in anyone's pocket, and no one comes knocking at your door. It 
wouldn't, it just wouldn't happen or rarely. You know, they don't do that.

This suggests that residents have a private and public life, with a balance between the two. If people have enough private space, they do not feel like they are living with others.

\subsection{Privacy}

Privacy is an important theme in the literature on residential organizations. Townsend (1962) observes that having enough private space helps preserve self-identity. Goffman (1961) makes a similar observation. One of the strategies that total institutions use to strip self-identity is to eliminate private space and personal possessions.

When I asked people at Lakelands if they have enough privacy, $76 \%$ of those who answered the question said, without any reservations, that they do (see Table 10.1). Some people said they have enough privacy, but then mention problems. Edward, who shares an apartment with his wife, said he has enough privacy, but also said that he does not have enough private space. He feels he is never alone at Lakelands:

Edward: What is it like to live with other people here? Well, you can't go off and be by yourself. Of course, I can go out and sit on the bench, but I'm not used to going out and sitting on a bench. The way I would put it, you haven't got the privacy. Not that it's that important. But sometimes you want to have privacy, even from [wife]. Or she from me. I think that's, I hope that's normal? I could compare living here, like being in a shopping centre. There's people all around you. People around, don't hurt you. It shouldn't bother you.

Like Edward, Ursula mentioned that the number of people at Lakelands can be overwhelming:

Ursula: And, but coming here was a shock because all of a sudden there was 
people everywhere.

Table 10.1. Typical, contrasting and discrepant narratives: Privacy

\begin{tabular}{|c|c|c|c|c|c|}
\hline \multirow{2}{*}{$\begin{array}{l}\text { Question } \\
\quad \& \\
\text { Response }\end{array}$} & \multicolumn{4}{|c|}{ Narratives } & \multirow[b]{2}{*}{$\begin{array}{l}\text { Total } \\
\text { cases }\end{array}$} \\
\hline & Typical & Contrasting & Discrepant & Missing ${ }^{a}$ & \\
\hline $\begin{array}{l}\text { Do you have } \\
\text { enough privacy? }\end{array}$ & Yes & $\begin{array}{c}\text { Problems: } \\
\text { gossip; want more } \\
\text { time alone. }\end{array}$ & $\begin{array}{l}\text { Problems: } \\
\text { theft. }\end{array}$ & & \\
\hline Responses & 19 & 4 & 2 & 5 & 30 \\
\hline - Total & $(63 \%)$ & $(13 \%)$ & $(7 \%)$ & $(17 \%)$ & $(100 \%)$ \\
\hline $\begin{array}{l}\text { - Minus missing } \\
\text { responses }\end{array}$ & $\begin{array}{c}19 \\
(76 \%)\end{array}$ & $\begin{array}{c}4 \\
(16 \%)\end{array}$ & $\begin{array}{c}2 \\
(8 \%)\end{array}$ & - & $\begin{array}{c}25 \\
(100 \%)\end{array}$ \\
\hline
\end{tabular}

Note.

${ }^{a}$ Either I did not ask the resident this question, or they did not directly answer the question.

As Edward and Ursula suggest, not only is control over physical space important for privacy and self-identity, but having adequate emotional space is important (Goffman, 1961; Townsend, 1962). One of the ways that total institutions strip selfidentity is by invading emotional space. In contrast, Elton talked about how it is possible to have private emotional space, even when in public at Lakelands:

Margot: Do you have enough privacy [Elton]?

Elton: Oh yes. No problem at all there. Nobody bothers me when I go out. I go down and talk to them and I sit. If I'm tired I get up and walk away. Put their cup 
away and my cup away.

Being left in peace when in public is an important element of having enough privacy.

One of the ways that people invade emotional space at Lakelands is with gossip. When talk harms, it becomes gossip. Of the thirty persons I interviewed, three $(10 \%)$ complained of gossip. Sonya and Frances, both fairly new residents, complained about female gossips. Horace who has lived at Lakelands for some time, complained about resident talk, which he said spreads like "a whirlwind." As well, Horace complained about management gossip. I asked him to explain what happened:

Horace: Well, when I'm dealing with [person A] I'm walking by past the manager's desk, or one of the offices there, someone will come in and bring up the fact that I've been talking to [person A]. Or [person A] has said something to them. I guess she's entitled to do that. But . . . and then, even down there, they ... although they all claim they don't say anything to anybody ... they have to. Because then I hear something from somebody who's been talking to somebody else on that ... It's quite a ... I find that a disappointment.

Margot: A disappointment, yah.

Horace: I like to think I'm a very private person. I am . . . an interesting topic for everybody. I think it's not just me, it's everybody.

This story describes resident and management gossip. Management has strict policies about their employees talking about residents. All employees sign a confidentiality agreement. Nonetheless, it appears that problems occur.

In addition to problems with the office, Horace complained about housekeeping staff. He talked about how upset and disappointed he was when housekeeping talked about his private life to management. Even if one has private space, Horace's experience points to limits on privacy when housekeepers or care givers enter residents' apartments. 
If an organization provides these services, these employees can keep an eye on residents, provide information to management, and management can then use the information to supervise or manage residents' lives (Powell \& Biggs, 2000).

Apart from Horace, no one questioned this practice. People do not complain that housekeeping's weekly visits invade their privacy. Marie Josee talked about how Lakelands housekeeping service helps to ensure residents' safety. She feels that it serves as a check, if someone is hurt or worse:

Marie Josee: [\#] days that [person] had been passed away before [they were] found when the housekeepers, it was their day to come and clean [the] suite! A number of people mentioned how they appreciate and welcome the security and protection that this service provides. Nonetheless, Horace's experience underlines the trade-off that occurs between protection and privacy in a communal lifestyle organization.

Another implication of Lakelands' housekeeping service is the potential for theft. Two people (6\%) mentioned incidents of petty theft; in one case the loss of dish cloths, and in another the loss of money. This is rare, however, as one resident pointed out, there are many staff who could have access to a resident's apartment.

Not only does housekeepings' weekly visit to resident apartments have the potential to compromise privacy, it opens the door - both figuratively and literally - to other residents compromising a person's privacy. When housekeeping cleans an apartment, they prop the door open. This is an accepted routine. I was never given the option, and never thought about, or questioned this practice while at Lakelands. I have 
since asked a resident about this routine, and was told that some people ask housekeeping to close their door. If people allow their doors to be left open, it can be a source of entertainment for curious people. It can also serve as a weekly reminder of management's proprietary privileges as owners.

This illustrates how management routines, like housekeeping practices, can obscure moral issues. When these practices become routine or standardized, the moral issues they raise may be obscured, or difficult to question and oppose. To the extent that these routines are not discussed or negotiated with residents, they may erode self-identity. This illustrates how internally referential systems, like management practices, can be guided by intrinsic criteria that are unique to the system of thought rather than external criteria like moral issues (Giddens, 1991).

These narratives, especially Horace's narrative, raise the issue of institutional surveillance - the visible or invisible "supervisory control of subject populations," or "the use of information to coordinate social activities" (Giddens, 1991, p. 15). Management's responsibility for maintaining Lakelands' lifestyle may necessitate this to a certain extent. As well, residents and family may wish this type of surveillance in order to protect against falls and injury. Nonetheless, these practices may also invade privacy.

This is a complex issue, as these narratives illustrate. Lakelands takes many steps to try to ensure residents' privacy, from providing large spacious apartments to asking employees to sign a privacy agreement that specifically states that employees are not to talk about residents' private lives. In addition, Lakelands does not allow soliciting. No person or company can come into the building and knock on people's doors. As well, 
protecting a person's physical privacy, Lakelands' encourages conventions that protect emotional space. For instance, people do not talk about sensitive topics such as politics and religion in the dining room, unless they are with close friends. Trying to convert a person to one's religion is also not permitted, unless the person expresses an interest.

Despite these protections, this section points to the tensions that can exist. When people live in common with others, and when they do not own their space - when they rent like at Lakelands - tensions can arise between one's home and living in an organization. Boundaries between home and the organization can become blurred and lines transgressed.

\subsection{Eating in the dining room}

In addition to privacy, another issue in living with other people relates to dining arrangements at Lakelands. Although Lakelands' residents do not live with other people in the strict sense of the term, they usually eat every day with people who are not family. Most dining room tables seat four, with a few tables seating two persons. Time spent in the dining room can represent a significant portion of the day. Meals tend to be leisurely: taking from one, to one and a half hours. The speed of the meal is controlled by the servers, who take food orders and serve the food. People eat anywhere from one to three meals a day in the dining room, depending on their meal plan. Table 10.2 is an example of analytical task \#3 - to identify similarities and differences between residents. 
Table 10.2. Respondents' meal plans

\begin{tabular}{lcc}
\hline Meals & Cases & \% of total cases \\
\hline Basic plan ${ }^{\mathrm{a}}$ & 15 & $50 \%$ \\
Basic plan plus lunch & 6 & $20 \%$ \\
Basic plan plus lunch and all breakfasts & 9 & $30 \%$ \\
Total cases & 30 & $100 \%$ \\
\hline Note. & \\
${ }^{a}$ The basic plan is included in the monthly rent and consists of the evening meal and 3 continental \\
breakfasts a week.
\end{tabular}

Since dining arrangements force people to socialize, I asked people what they thought about eating in the dining room. Would they prefer to eat in their apartments? To my surprise, people like to eat in the dining room (see Table 10.3). Although there are times when respondents order a tray, such as when they are sick, most people prefer to eat in the dining room. People said that they enjoy the company. They said it is good for them: it forces them, and others, to socialize.

The number of people who refuse to eat in the dining room is small, given the total number of people at Lakelands:

Manager: Out of about 185 residents at the present time I would say four have their dinner meal nightly in their room and about two to three others, on any given night, would order a tray due to a medical procedure or illness. During a period of colds or flu this would of course jump for the duration of the episode. One or two rarely come down for dinner... 
Table 10.3. Typical, contrasting and discrepant narratives: Dining

\begin{tabular}{|c|c|c|c|c|c|}
\hline \multirow{2}{*}{$\begin{array}{l}\text { Question } \\
\& \\
\text { Response }\end{array}$} & \multicolumn{4}{|c|}{ Responses } & \multirow[b]{2}{*}{$\begin{array}{l}\text { Total } \\
\text { cases }\end{array}$} \\
\hline & Typical & Contrasting & Discrepant & Missing & \\
\hline $\begin{array}{l}\text { Would you } \\
\text { prefer to eat in } \\
\text { your apartment } \\
\text { rather than the } \\
\text { dining room? }\end{array}$ & No. & $\begin{array}{l}\text { Yes and No. } \\
\text { Sometimes like } \\
\text { eating in } \\
\text { apartment. }\end{array}$ & $\begin{array}{l}\text { Yes or No. } \\
\text { Changed } \\
\text { personal eating } \\
\text { schedule. }\end{array}$ & & \\
\hline $\begin{array}{l}\text { Responses } \\
\text { - Total } \\
\text { - Minus missing } \\
\text { responses }\end{array}$ & $\begin{array}{c}22 \\
(73 \%) \\
22 \\
(82 \%) \\
\end{array}$ & $\begin{array}{c}3 \\
(10 \%) \\
3 \\
(11 \%)\end{array}$ & $\begin{array}{c}2 \\
(7 \%) \\
2 \\
(7 \%) \\
\end{array}$ & $\begin{array}{c}3 \\
(10 \%) \\
- \\
-\end{array}$ & $\begin{array}{c}30 \\
(100 \%) \\
27 \\
(100 \%)\end{array}$ \\
\hline
\end{tabular}

${ }^{\text {a }}$ Either I did not ask the resident this question, or they did not directly answer the question.

Apart from eating with strangers, I expected body control issues to be a reason for not wanting to eat in the dining room. Ursula mentioned that many people worry about being able to keep control of their body:

Ursula: And a lot of them I find are very leery about being sick in the dining room or falling over in the dining room, you know, fainting or whatever. But then again, you don't want to make a spectacle of yourself in public and that kind of thing. A lot of them worry about that.

Yann talked about how he lost control in the dining room and how the servers adroitly defused the problem:

Yann: One of the things I would say about the dining room staff is that there are bound to be some problems with people dropping things, or spilling things and so on. And I've frequently been, occasionally I've been the cause of it - [personal discussion]. And within minutes, seconds, the dining room staff had moved us to a different table. 
Margot: My goodness!

Yann: And everything new and clean. And they just left this mess I made, and they cleared it up. So it wasn't even not ...

Margot: That's clever.

Yann: To me that's a ... a sign of good staff.

Although body control issues may be a concern, it does not deter people from eating in the dining room. Lakelands trains it servers to handle these issues so they do not become an embarrassment.

Eating in the dining room may be difficult for other reasons. Two respondents ( $7 \%$ ) had to make major adjustments to conform to Lakelands' meal schedule. This points to the way in which organizations can shape bodily regimes like eating schedules. Even though the timing is not right for their internal body clocks, these two people still like to eat in the dining room. In total institutions, eating schedules are highly regimented (Goffman, 1961), whereas at Lakelands, one has about a two hour window for a meal.

Eating in the dining room can be particularly difficult for newcomers. Newcomers must negotiate a complex set of norms or social conventions. They must learn that at lunch they seat themselves, while at dinner they must wait in line to be seated by the Maître d'. Although the Maitre d' is responsible for seating people, Hugo found seating at the evening meals confusing when he first arrived. He would have liked to see a sign that says "wait to be seated." As well, people must learn what to wear when they go to the dining room. They must wear appropriate attire and footwear (e.g., no slippers). Newcomers must make their way socially, eating every meal initially with total strangers. Additionally, there are a great many people at Lakelands. Ursula talked about "mobs of people" in the dining room: 
Ursula: And coming here, that was quite a shock. That was the hardest part. Going to the dining room or meeting all these people or they kept saying "good morning." And you know, I have no idea who they were! But they looked very nice, you know. [Laughing]. It wasn't a threat, you know. It was just mindboggling. All of a sudden there were so many people.

In addition to difficulties with social norms, people, whether they are newcomers or long-time residents, often talked about another issue: how difficult it is to converse with some people at the dining table:

Ricardo: I know that there are one or two or three people, who . . . are maybe a little bit ... hard to converse with ... and they soon become avoided. And it's too bad, because some of those people are - nothing wrong with them. They're just simply may be quiet when they're eating dinner. [Discussion]. I have one or two or three people that I would just as soon not sit with because they talk too much. They talk all the time in fact.

Over time, as newcomers learn the ropes, they learn to avoid the pitfalls. They learn who to sit with and who not to sit with, however, the learning process can be difficult.

This section illustrates that despite the difficulties that people may encounter in the dining room, with body control issues, and with their fellow diners, people who live at Lakelands much prefer to eat in the dining room than in their apartments. They believe that mixing and socializing is fun, and is good for everyone.

\subsection{War and Peace}

Another issue in living with others is the question of social harmony (Williams \& Guendouzi, 2000). Although people do not always get along, conflict is not the norm at Lakelands. Twenty-three percent of respondents ( 7 persons out of 30 cases) have 
experienced conflict - gossip (cases $=3$ ), fights $($ cases $=2)$ and falling out with people (cases $=2)$.

Conflict seems to be short lived. For the most part, peace reigns at Lakelands. A number of long time residents said that people get along at Lakelands:

Andy: No, it's, what I like about it is there's never a disagreeable word with anybody - residents or staff. And why does a person, why would a person have to live in a place where it wasn't comfortable?

Similarly,

Candace: I've never seen a personality clash here, but maybe there are some, I don't know.

Despite this, I learned of isolated problems, and the patterns seem different for men and women. I learned of open conflict between men: harsh words, bullying, and conflicts that almost degenerated into fist fights. Ricardo talked about how he was bullied by another resident in the dining room. Ricardo had taken "his" chair. All of these fights were between men who have resided at Lakelands for some time. In contrast, fights between women are quieter and seem to involve long-term residents gossiping about new residents. Whereas men engage in harsh word, women tend to engage in less confrontational behaviour.

Respondents usually described their fellow residents in positive or glowing terms, even those who have experienced conflict, as Table 10.4 indicates. Seventy-five percent of mentions are positive, describing people as nice, friendly, wonderful or happy.

\section{Table 10.4. Respondents' assessment of people at Lakelands}




\begin{tabular}{lcc}
\hline Descriptor & Mentions \# & $\%$ \\
\hline Nice, friendly, wonderful & 41 & 55 \\
Not nice, snob & 12 & 16 \\
Happy & 15 & 20 \\
Not happy, lonely & 6 & 8 \\
Total mentions & 74 & 100 \\
\hline
\end{tabular}

\subsection{Pure relationships}

In living with others there is the possibility of conflict, however, there is also the possibility of making good friends. The social atmosphere or lifestyle at Lakelands does not resemble the homes that Townsend (1962) studied, where organizational routines and lack of privacy disrupted pure relationships. Pure relationships consist of "a social relation which is internally referential, that is, depends fundamentally on satisfactions or rewards generic to that relation itself" (Giddens, 1991, p. 244). Based on internally referential criteria such as romantic love, choice, freedom, and commitment, pure relationships are "good until further notice" (Giddens, 1991, p. 187).

All of the conditions that Giddens identifies as being necessary for creating and maintaining pure relationships - privacy, mutual trust, reciprocity, common lifestyles and shared histories - exist and are promoted at Lakelands. Most people feel they have enough privacy. As well, although conflict and betrayal exist, they seem to be temporary sporadic incidents for most people. Even respondents who experienced difficulties with a particular resident, described their fellow residents in glowing terms. This suggests that 
Lakelands sets the stage for mutual trust.

In addition to privacy and trust, Lakelands' services help people reciprocate, another condition of pure relationships. Reciprocity requires a lot of work, but Lakelands helps people entertain and socialize, by providing food and a social space:

Yann: And if you want to arrange something special, like I put on a [party] one day in the other dining room and we had [\#] people, and I just talked to the chef about what we'd have served up.

People talked about how easy it is to entertain family and friends, even when these friends live outside the local area:

Mandy: I still have the same friends, you know, and I phone them up, and they come and stay, or come and visit, I should say. So, I haven't missed out in that way.

In addition to helping residents reciprocate, people at Lakelands have a common lifestyle. Every day, by dining together and participating in the same activities, they are participating in a common lifestyle and building a shared history, two additional conditions for pure relationships. People at Lakelands come from a similar age group. Although the age range is wide, about 30 years, they all have experienced two traumatic events - The Depression and World War II.

Consequently, Lakelands creates and promotes the five conditions that Giddens (1991) argues are necessary for pure relationships: privacy, mutual trust, reciprocity, common lifestyles, and shared histories. Making a friend at Lakelands is easy:

Charlotte: Because everybody seems to make a friend after they get in. So, you 
know I think that's the best part about it.

Pure relationships are not only possible with residents, but also with staff. A number of residents pointed out how fond they are of staff. The cultural divide between staff and residents that Goffman (1961) observed in total institutions does not exist at Lakelands. Sonya talked about her experience in another residence where management discouraged staff/resident relationships and compared it to Lakelands:

Sonya: The staff felt like - that's the other thing - the staff felt like they were the head mistress and the teachers rather than ... these people, these feel more like friends. You can poke your nose around [Marketing Director's] door and make a comment. They [the Receptionists] always make a point of greeting you by name. And they're always friendly and helpful.

For some, pure relationships at Lakelands become like family relationships. This points to the limits of Giddens' notion of pure relationships. It is an example of narrative analysis task \#7 - identify gaps in Giddens' theory. Edward and Ursula talked about the lines blurring between traditional kinship and pure relationships:

Edward: That's the way I talk about it. We live in the same house, so I think we have to treat each other and consider the set up as a home - it's not our home it's their home, but it's the same building. So that's where I get the family part of it.

Similarly,

Ursula: I think because it's so close knitted, it's like a family after a while. Edward and Ursula point to a number of factors that may create that feeling of family: living and dining under the same roof; creating shared histories; and rules or social conventions that promote sharing and cooperation. This suggests, that if conditions are right, distinctions between friends and family may diminish. Sometimes pure relationships at Lakelands turn into family relationships. Some people become involved 
in romantic relationships that end in marriage.

Although Lakelands creates and promotes the five conditions that Giddens (1991) argues are necessary for pure relationships, Lakelands age-sequestered nature also disrupts pure relationships. This is another example of analytical task $\# 7$ - to identify gaps in Giddens' theory. Respondents talked about how people "disappear" at Lakelands. One moment they are there and the next they are gone:

Ursula: Here you meet someone and then you seem to get along - they're interesting to talk to. And then all of a sudden "pop" they're dead! Or they're gone somewhere else because they can't be cared for here. That's very difficult. Lakelands' age-sequestered nature, which leads to the disappearance of one's friends, may shape friendships:

Jackie: There is a component to it, which you can't change, and that is that we're all in the end stages of our lives and ... if you're out living in the community, depending on your circle of friends, there are deaths. In here ... you are facing it ... many more times. So you have to face your own. We try, or I tried to avoid that most of my life. But you don't anymore when you're in here. And that shapes you too. It shapes your relationships.

Margot: In what way does it shape them? Jackie: Well, for some ... you're living with constant fear. You're constantly reminded that ... we don't live forever. And although we may seem hale and hearty, that can change very quickly. But you're reminded of that, because there are these deaths. I mean, this is the end of our lives. We're very fortunate that we're as comfortable as we are, and for how long we don't know. That's one thing about living, and I suppose that would be in any facility for the elderly, but it definitely is something that is front and foremost - not just in the elevator. Jackie mentioned that some people live in fear - fear of their own death. This may also be extended to fear of friends dying. A fear of losing friends may shape the 
development of pure relationships for some. Alternatively, it might encourage some people to embrace new friendships. Although I did not meet anyone who talked about this problem, the potential exists.

Although illness and death can disrupt pure relationships, it is also the source of new friendships and emotional support. People support each other at Lakelands, especially when a loss occurs:

Charlotte: You know, except that there's a lot of support here if you've been left on your own, and you know that you've got friends. They don't sit on top of you, but you know that you can call if you need them which is a good sign. Similarly,

Frances: Along the way there is always somebody there to help you. And I think that's what's so wonderful. You think, "oh darn. That's happened," but then somebody's there and says, you know, "everything is going to be okay." This suggests that friendships thrive at Lakelands, even in the face of death and illness.

\section{Summary}

This section explores a complex, multi-faceted issue - living with others. In discussing issues like privacy and eating with others, this section makes a number of contributions to the literature. It highlights similarities and differences between Lakelands and the institutions that Goffman (1961) and Townsend (1962) studied. Overall, differences are much greater than similarities. Living at Lakelands is like being "on holiday," rather than being "in prison." This analysis of differences and similarities relates to narrative analysis task \#5 - assess the possibility of a communal lifestyle organizational typology.

In contrast to total institutions, people have privacy. This privacy, along with 
Lakelands' services and social climate help maintain existing friendships and promote new friendships (Giddens, 1991) especially between residents, but also between staff and residents. At times, lines between friends and family become blurred to the point where friends become family (Giddens, 1991).

This section argues that some management practices have their roots in total organizations (Goffman, 1961; Townsend, 1962). At Lakelands one's home is controlled, in part, by management. The difference between Lakelands and the total institution is the degree and purpose of control. Whereas the intent of the total institution is warehousing, punishment and reflexive self-control, the purpose of the communal lifestyle organization is to provide housekeeping services, leisure and protection.

Although management recognizes the line between owner's rights and residents' proprietary rights, remnants of the supervisory gaze exist (Foucault, 1975; Powell \& Biggs, 2000). Management routines can create situations where this line is transgressed. When the demarcation between private and public space is blurred, this can raise emancipatory and life-political issues such as the right to privacy and self-determination (Giddens, 1991). 


\section{CHAPTER ELEVEN}

\section{Who am I when I live in an organization? Rules and conventions}

Rules and social conventions are part of living in an organization. They not only describe how an organization wants a person to behave, they also reflect assumptions about a person's self-identity (Goffman, 1961). They provide clues to the question "Who does the organization want me to be?" Townsend (1962) and Goffman (1961) talk about a loss of autonomy associated with authoritative rules in total institutions. Rules and conventions may limit the scope of individual decision-making. As well, Giddens' theory (1991) would predict that rules and social conventions can encourage self-reform. This supports the literature, which suggests that an emphasis on active retirement in communal lifestyle organizations shapes the aging self (Katz, 2005, McHugh, 2003; McHugh and Larson-Keagy, 2005).

To explore these issues, I asked people whether or not they feel there are a lot of rules at Lakelands. Of those who answered this question (cases $=26$ ), $96 \%$ said they do not feel there are too many rules (see Table 11.1). People support the rules, and some people think there should be more rules. The one person who provided a contrasting answer complained that the rules are changeable - they change with each new General Manager. 
Table 11.1. Typical, contrasting and discrepant narratives: Rules

\begin{tabular}{lccccc}
\hline $\begin{array}{l}\text { Question } \\
\&\end{array}$ \\
\begin{tabular}{c} 
Response \\
\cline { 2 - 5 }
\end{tabular} & Typical & Contrasting & Discrepant & Missing & $\begin{array}{c}\text { Total } \\
\text { cases }\end{array}$ \\
\hline $\begin{array}{l}\text { Do you feel there } \\
\text { are a lot of rules? }\end{array}$ & No & $\begin{array}{c}\text { No. Rules change, } \\
\text { not definite. }\end{array}$ & Yes & & \\
$\begin{array}{l}\text { Responses } \\
\text { Total }\end{array}$ & 25 & 1 & 0 & 4 & 30 \\
- Minus missing & $(83 \%)$ & $(3 \%)$ & & $(13 \%)$ & $(100 \%)$ \\
responses & 25 & 1 & - & 26 \\
\hline Note & $(96 \%)$ & $(4 \%)$ & & & $(100 \%)$ \\
\hline
\end{tabular}

${ }^{a}$ Either I did not ask the resident this question, or they did not directly answer the question.

Two people had difficulty thinking of a single rule at Lakelands. Nonetheless, rules do exist and some are posted. I took a walk around the property and photographed signs - about 65 in total. Examples include "no smoking," "no parking," "don't prop the door open," what to do in case of fire, and meal service times. Although I found many signs, they are not conspicuous or offensive, as Frances pointed out:

Frances: No . . . No ... I have heard of different places or visited people, where there's signs beside every door. You know, "Do this" "You can't do that" and "Go do this first place before you get to the third place" and that kind of stuff. No I don't think there's too many rules ...

In addition to posted rules, there are unwritten rules, policies and social conventions, such as no unsolicited proselytizing. These norms regulate life and provide clues as to how Lakelands shapes self-identity. Whereas rules and policies come from management, social conventions may come from management, residents or a 
combination of both. Like rules, the purpose of social conventions is to control, influence or shape behaviour. The next section discusses some of Lakelands' important norms and policies: the active retirement policy, the open seating policy, being friendly and appropriate dress.

\subsection{Active retirement}

Lakelands' active retirement policy informs many management practices and social conventions at Lakelands. Active retirement conveys certain assumptions about older people: that older people should be active, that activity has benefits, and that inactivity and isolation are less desirable. A Lakelands' manager described Lakelands' active retirement policy, its benefits and the role of the Activity Coordinator:

Manager: We want to provide an experience, which is above and beyond what most people, most seniors, could get living by themselves. We want to provide that sense of community that they have in living in close proximity with 200 other people. We want to encourage an active lifestyle. It has health benefits. It has, you know, mental benefits. One of the largest problems in seniors is depression. And, you know, our research says that that's caused in large part by isolation.

Margot: Okay.

Manager: So by bringing people out of their suites and getting them, encouraging them to get involved in groups, you know, according to their interests, you know, coming out for the fun events that are put on, encouraging volunteerism, that's all part of enrichment. Enhancing the life. They always have a choice, but we want to make it easy for them to make that choice to get out of their suite and get involved. [Discussion]

Margot: What is the role of the Social Director, and social activities? What purpose does that fulfill in your objectives and mission? 
Manager: Well that speaks to the enrichment part. I mean that's really what that person does on an all day, every day basis. They're here to make the residents lives better and more enriched. That's planning and coordinating activities, outings, something as simple as, you know, a St. Pats day meal: you know, getting green decorations. That's fairly obvious, but fairly basic. And that just kind of enhances the atmosphere. Then there's things like coordinating outings, say to the theater, or a bus tour to see the Christmas lights around town, that kind of thing. They also coordinate various special-interest groups say, you know, the bridge club, the pool tournament, that kind of thing. Those are, you know . . . in a lot of cases the residents will take an active role in planning and managing those activities, but the Activity Coordinator kind of makes sure that that happens: provides the encouragement, provides some support where support is needed, provides materials or supplies if they are needed, that sort of thing. We don't expect them to do everything. We expect them to encourage residents to do as much of it for themselves as possible. So in that kind of role they are cheerleaders and a resource for support, as opposed to being front line in getting those activities happening.

This quote suggests that active retirement is linked to two other management tasks: providing "an experience" and providing "a sense of community." All three tasks are intended to achieve Lakelands' goal: "To maximize the enjoyment and enrichment of life for our Residents" (Table 3.1). These notions - "enjoyment" and "enrichment" relate to self-actualization. Giddens distinguishes between this type of general selfactualization and meaningful self-actualization, which relates to being exposed to existential and moral issues. The following repeats portions of an earlier quote:

The reflexive project of the self generates programmes of actualisation and mastery. But as long as these possibilities are understood largely as a matter of the extension of the control systems of modernity to the self, they lack moral meaning (Giddens, 1991, p. 9). 
This self-actualization is not painful and does not involve deprivation. It is enjoyable and "enriches" the individual. Active retirement is described as being integral to achieving Lakelands' goal - making life enjoyable and enriched. Active retirement assumes that people should be active, that these activities should take place in a vibrant "enriched" social environment, and that these activities should allow people to exercise their competencies. Active retirement is a means to achieve a lifestyle objective - an enjoyable enhanced life. (This analysis relates to narrative analysis task \#6 - assess consistency in the lifestyle concept, specifically, whether Giddens' notion of lifestyle fits the data.)

The benefits of active retirement seem to be supported by the study findings. A number of people, especially widowed women (cases $=5$ ), reported social isolation, loneliness and depression before moving to Lakelands, while only two persons reported depression after moving to Lakelands. In this latter group, one's person's depression was provoked by a staff departure and lasted a week, whereas the second person's depression seems related to their recent move to Lakelands.

At Lakelands, being active is defined in a number of ways: being part of a community, participating in activities, eating in the dining room, and volunteering. That Lakelands has an Activity Coordinator - a person dedicated to implementing the active retirement policy - and that the word "activity" is embedded in this person's title, indicates the policy's importance. This policy is not unique to Lakelands. The literature and advertising suggest that active retirement, and the presence of Activity Coordinators, are common in communal lifestyle organizations (Folts \& Streib, 1994; Hyatt Corporation, 2008; Katz, 2000, 2005; McHugh \& Larson-Keagy, 2005). 
Goffman (1961) argues that an organization's activities convey assumptions about self-identity. By promoting active retirement, Lakelands is creating an "active selfidentity." When a person participates in these activities they accept organizational assumptions about their identity. Most people I spoke to at Lakelands support Lakelands' active retirement policy. Some have moved to Lakelands because of it. Many respondents said that people should mix and socialize. They should eat in the dining room and they should take part in activities because it is good for them:

Marlene: It's not healthy to live a hermit-like existence. [Laugh]. So that's a good aspect.

I spoke to only one person who questions the existence of the active retirement policy, and the assumptions it conveys about resident self-identity:

Ricardo: I didn't come here to have Lakelands show me things to do with my time, at all. And all my life since I was a little kid ... Now, you find children, young children looking for somebody to hold their hands, to play a game or whatever. Well, we made our own fun when we were kids.

Ricardo said that Lakelands assumes that people are children, that they need to be entertained. He feels he is an adult and can make his own fun.

Assumptions about residents' self-identity are also embedded in the way the active retirement policy is implemented. Over the years, I have noticed variations in the nature, quantity and sophistication of Lakelands' activities. A number of residents complained about a current lack of sophistication in Lakelands' activities. Rennie and Roger complained that some activities are for children: 
Rennie: We had, now they do little games like if we were little kids.

Margot: Yah, okay.

Rennie: You know. And we ... we don't want that. And they said, "Oh you're getting out." We have a bus, you can go out and eat, but you're going out with the same people as you eat with here. You want to be with somebody else. Why should I go out and pay and go out with all these people that I eat with down here?

Margot: Now you say these games, they're like kids, games for little kids. Can you give me an example of what you consider to be, you know what those things are?

Rennie: I haven't gone too much. But I heard that they, one day, they had a Lady's Breakfast, or Men's Breakfast, and they had a "bean toss."

Margot: Oh, "bean toss" yah ...

Rennie: Things like that. And well you saw those pictures in the Country Kitchen? We had, had the Olympics and that was wonderful. That was [former Activity Coordinator's] doing.

Margot: That was quite something. That was, that was spectacular.

Rennie: And then she had another one. She had another one planned - a big one till she left.

Margot: and that fell by the wayside ...

Rennie: And she had one that we ... oh, what was it now ... oh, it was different countries. We had to represent each. We all got dressed and we made, we all made up a song and we were from Hawaii. So we had downstairs, we decorated, Hawaiian - Hawaiian clothes and Hawaiian food. And then we had a great big dinner and she had tables all decked out and everything. It was wonderful! People were looking forward to things like that! But now there isn't anything to look forward to.

Similarly,

Roger: And this is the suggestion I'm going to make: that the kind of games we 
play here are games for children. Well, cards is very . . is an adult game. But not too much association or challenge. Not too much challenge. Once you learn to play the game, not much challenging.

In addition to complaining that some activities are childish, Rennie and Roger complained that they are not challenging. Rennie and Roger prefer unique, diverse, and sophisticated activities that are challenging and entertaining. This suggests, that to achieve Lakelands' objectives - enjoyment and enrichment - Lakelands' activities should be challenging and interesting. Activity, for the sake of activity, is insufficient.

This raises the question 'What happens if one does not participate? What are the consequences? A Lakelands' manager pointed out that Lakelands does not impose participation on residents. This is supported by fourteen residents (47\%) who specifically mentioned that they feel free to participate, or not, as they wish. On the other hand, three residents $(10 \%)$ stated that they have been encouraged to participate in program activities, or eat more frequently in the dining room. These three residents interpret Lakelands' actions in a variety of ways: as ranging from polite interest in their welfare to controlling behaviour. Jackie mentioned that her husband felt pressured to participate in one particular activity:

Jackie: It was at that time that they were doing the special Olympics things here And [former Activity Coordinator], in her enthusiasm, wanted to involve [my husband] and he couldn't be involved because of the health issues. She was very persistent.

Margot: Yah, okay.

Jackie: And it was difficult. It was a difficult time for [husband] to let [former Activity Coordinator] know that he wasn't one of the group that could be controlled, you know. Okay, we did bump into that. That, that is not so with [the 
current Activity Coordinator]. Things are available, but there's no ... [long pause] ... there is no control exerted on that. In other words, you have control. Jackie said that, with the exception of this one instance, they have not felt pressured.

In another case, a resident complained that Lakelands spoke to their family, asking why they did not participate in activities. This was done without the resident's approval. After talking about feeling betrayed, the resident said: "So, but you should be allowed to be all those things and still ... be part of that community I think." This resident is arguing for agency - free choice - and diverse lifestyles. (To protect this person's confidentiality, I do not provide the full quote).

This type of unsolicited management of residents' lives seems at odds with management's previous description of the active retirement policy: "They always have a choice, but we want to make it easy for them to make that choice..." As well, Lakelands' actions seem at odds with the following management narrative about the importance of treating residents as responsible, competent adults:

Manager: ... this one lady and I had a really good rapport and she was an [profession]. So she was pretty bright, and she'd come in and she challenged me a couple of times too. But she'd say "when did we become invisible?" Margot: Ahhhh Manager: What do you mean, [name of resident]? She says "I've got a great pair of glasses. I go shopping at [the grocery store], and it's like people don't even see me." She says "I'm standing in the lineup and the cashier will address someone. And even though I have said something they'll address someone else who doesn't have grey hair and glasses, somebody who's younger, or if I'm with my daughter, they'll speak to my daughter, even though I might have asked the question." Margot: Yes. Manager: So she says "when did I become invisible?" When did we as a senior 
become invisible? Well, since then I've really watched that and noticed it. And it's true. People will ignore, almost thinking that you're already senile, or that you don't have the thought process, or you can't take care of yourself. And it's not true. Well, nobody in Lakelands feels that way. They might find out that they have senility or Alzheimer's or dementia of some kind. But they give them the dignity of their years, and also that they assume that we can treat them like adults and not like children.

This manager pointed out how age stereotyping operates in our society. The older we are, the more incompetent people assume we are. People unthinkingly hand power over to younger people. Older people become invisible. When residential organizations treat family as surrogate decision-makers without the resident's consent, it disrupts selfidentity by undermining the resident's sense of competency and autonomy. Townsend (1962) and Goffman (1961) note that when institutions "manage" people behind their backs, residents feel betrayed.

This incident - encouraging a resident to participate in Lakelands' community life by talking to a resident's family - is unusual. In all fairness to management, perhaps they were worried about this person's well-being. Nonetheless, the story suggests that management can, at times, behave in paternalistic ways - management can "manage" people's lives, thereby limiting agency. The resident's narrative indicates that management assumed that the resident was the problem, rather than considering that Lakelands' activity might not appeal to the resident. Lakelands was asking the resident to "self-reform." By not participating, the resident rejected management's assumptions about 'who they should be' (Goffman, 1961).

In sum, this points to a life-political issue. Life politics argues that older people 
should have the opportunity and freedom to form a self-identity of their own choosing. The way that Lakelands implements its active retirement policy impacts self-identity. The policy is intended to be implemented so that it enriches life enjoyment and preserves agency. Service standardization, and undue interference in residents' lives can hamper life enjoyment and agency.

\subsection{The seating debate}

Another important Lakelands' policy that has implications for self-identity is Lakelands' open seating policy. There is a debate among residents over this policy. The debate revolves around whether or not people should be allowed to save tables and seats for their friends. Should people be able to turn away people who ask to sit at their table? This debate focuses mainly on evening dining room seating, but also includes seating at the Sports Bar and the card tables in the Country Kitchen. One of Lakelands' managers explained Lakelands' open seating policy:

Manager: A great rule we have is no saving of seats though at times this is difficult. All of us tend to be creatures of habit and change is a challenge for us all. People who have lived here for a while get used to eating with the same people, at the same time, and when a new person appears in their midst it is difficult for them not to say: "Oh, that seat belongs to so and so, or I'm saving that seat for someone." [Discussion]. If they wish to sit together they will need to come in together.

The open seating policy seems to reflect Lakelands' active retirement policy. The intent is to encourage people to mingle, and to ensure that newcomers are welcomed. At the lunch meal people seat themselves, however, at the evening meal, the Maître d' seats 
people. The Maître d' accommodates people's seating preferences, and manages traffic jams when the dining room becomes crowded. An experienced Maître d' knows who sits with whom, and where they prefer to sit.

The seating policy seems to mainly affect persons who do not have seating preferences, especially newcomers. People who are part of a group are usually not disturbed, although this has disadvantages. Four long-term residents who usually sit with the same people complained about the social convention that they have established for themselves. Of the four, one person moved to another table while the other three remainat the same table for fear of insulting their friends. Marie Josee explained her situation:

Marie Josee: I . . well, for one thing, you go to the dining room and the same people sit at the same tables - nearly all the time. And I would dearly love to make the move from the table I'm on. And I don't want to hurt the [people's] feelings that I sit with. So here I sit.

Many people (15 cases) mentioned the seating debate. Most think open seating is a good thing, but some disagree, and others argue both sides of the debate. Those in favour of open seating talked about the importance of meeting new people, making newcomers feel welcome, and having variety in one's life:

Marlene: The advantage of this other is that you meet a lot of people and you learn a lot of things that you'd never know. I was sitting with a man the other day. Somebody else at the table got him going, and he was a chap who lived in [town] in the Depression years and he [personal discussion]. But that was all fascinating to me because it was totally outside my own experience, you know. Heard a lot of wartime stories, because I'm of the age group, and my [family and friends] were in the armed forces. But this was different. So things like that liven up the situation, you know, when you're moved around.

As Marlene explained, being "moved around" - note the passive turn of phrase - is good 
for one. This linguistic insight relates to structural analysis - narrative analysis task \#8.

In arguing for open seating, people often talked about the disadvantages of fixed seating, and how it is common in nursing homes:

Edward: And some people would prefer to eat with a certain couple all the time. Well, that's what happens in a lot of institutions. You're booked to a table. You have what's on the menu today, which is usually one item, you know - one main course. And you sit with Mr. Smith and Mrs. Jones and Mr. So-and-so and soand-so, at that table - number 12 - for every meal. And suppose I don't like Mr. Smith? I have to go to management and say I don't want to eat with that guy. Well, I don't want him to find out about it either. He's a nice guy, but I don't want to eat with him. And I like the idea that we can go and we can sit with those two, or those two, or if we prefer we can sit by ourselves. And if we sit at a table for four, and somebody joins us - great. You're welcome. And it's, it makes it more social. I think they never - I hope they always keep it at that level.

One of the implications of this argument is that if people are allowed to continue to save seats and tables, Lakelands could degenerate into a place with fixed seating like in nursing homes.

Henrietta, who is in favour of fixed seating, talked about how she likes to sit with her friends, how they like to sit at a particular table, and how management should not interfere with their choices. Henrietta explained this position:

Henrietta: ... we had trouble here for a while, with our tables, you know. We like to sit together with the ones that we sat from beginning on. We like to sit together all at once. It came about . . everything is changeable. You can sit by any table or, or anyplace you want, you know. And that part, I didn't like. I didn't like that, that part. I was together with [names of people]. We sat together at that, at that table for years. Together, you know. Now, [they] left. Now that space was empty, and anybody would come and sit there, you know ... and even take my place, or 
take [name's] place ... And that part, I don't like. I don't.

So that part ... should be people like to sit all the time where they sit and leave them alone, you know. But no, they change, and now you can sit anywhere ... and they sure do! Anybody comes and sits in my place and ... I don't like that. Margot: Yes ... yeah.

Henrietta: And we can't sort of stop it somehow . . . but I don't know. . . Henrietta emphasizes that she cannot seem to change this management convention. Her narrative suggests that the situation has stabilized somewhat, but that she is still unhappy, since anyone can take her seat or her table. This highlights the role of the Maitre d' who controls seating, and can limit residents' choices. (See Appendix K for a detailed structural analysis of this story).

Marlene argues against open seating from a similar perspective. The Maître d' not only chooses where one sits - at what table - but also with whom. This can limit resident's choices:

Marlene: Well, actually, as [my family] points out to me quite often, I'll complain about say the dining arrangements. You have no control over who you sit with normally. The answer to that is get your own group together and go in together. Only one person told me that they have contested Lakelands' dinner seating conventions. They and a friend sat themselves, rather than waiting to be seated by the Maître d'. It is not clear from the conversation whether or not they do this on a regular basis. Based on my observations, I suspect not. At the evening meal, people sit in the dining room anteroom where they wait their turn to be seated by the Maître d'. By ignoring this procedure, residents risk "being spoken to" by the Maître d' or by management. Based on my observations over the years, very few people would ever knowingly challenge this social norm. 
This debate illustrates how routines and internally referential systems, such as Lakelands' open seating policy, can override other policies such as customer service. An emphasis on customer service would satisfy Henrietta and Marlene's wishes. Henrietta's story suggests that her wishes were respected in the past, however, something has changed. There appear to be two changes: a new Maître d', plus a new emphasis on enforcing the open seating policy. Henrietta and Marlene question the seating policy's internally referential criteria (i.e., it is important to mix with others) by raising moral issues such as: Should seating choices be a matter of resident choice? Is strict application of a policy like open or fixed seating controlling? Is this a form of control that limits resident autonomy?

This is an example of life politics in action. Residents are using external criteria moral criteria - to question an internally referential management practice. The issue is complex, since most people who question the fixed seating policy are also in favour of the active retirement policy. Most residents support management's efforts to manage or control the social environment - to encourage people to mix. As well, they believe that rules and norms are necessary in organizations. The crux of the moral issue seems to revolve around limiting choice. People want to have choice. They do not want someone making decisions for them, especially when those decisions do not reflect their wishes.

\subsection{Friendliness}

Another important social convention at Lakelands that has implications for self-identity is being nice and being friendly. This is closely related to active retirement. Being 
friendly contributes to a sense of community. Olivia described this social convention:

Olivia: You have to get along with people: be sure that you don't offend people or don't get too bossy with other people or be nasty to them. You've got to fit in and be friendly with everybody.

Note the two imperative phrases - "You have to" "You've got to" - "get along with people," "fit in" and "be friendly with everybody." This phrasing emphasizes the importance and inflexibility of this social norm. This is an example of structural analysis, narrative analysis task \#8.

What happens if one does not conform to Lakelands' friendliness norm? Goffman (1961) argues that people learn which behaviours conform to social conventions and which behaviours undermine these conventions. In rejecting social conventions people reject the organization's assumptions about their self-identity. Being nasty, bossing people around, and not talking sends out signals that one does not fit in, that one is not part of the community. Not surprisingly, the typical response to someone who breaks this social norm is to avoid them:

Marie Josee: If they don't want to speak to me - too bad. I'll know next time, and I won't bother speaking... Similarly,

Ricardo: I know that there are one or two or three people, who ... are maybe a little bit ... hard to converse with ... and they soon become avoided. And it's too bad, because some of those people are - nothing wrong with them. They're just simply may be quiet when they're eating dinner.

Everyone quickly learns who is unfriendly because these people stand out. They are different from the rest:

Angela: You just kind of fall into a pattern, and everybody, well I guess anybody 
that's doing something wrong would standout like, like a - you've broken some kind of a rule.

Angela pointed out that social norms are easily enforced when everyone is supposed to be doing the same thing (Goffman, 1961). Although social conventions are not rules per se, they are powerful social controls. They are an unquestioned pattern of behaviour. People do not even have to think about them, they "just kind of fall into a pattern" (Angela).

The self-identity pattern at Lakelands is to be a friendly and nice person. If one is not, one will be ignored. This type of norm breaking behaviour is fairly rare at Lakelands, although people talked a great deal about unfriendly people in the interviews (cases $=8$ ). Residents feel very strongly about this norm, and any resident who rejects this faces strong opposition. This demonstrates how social norms can be established and enforced by residents as well as by management.

\subsection{Dress regimes and identity switching}

Another important social norm at Lakelands is dressing well. Smart casual is the norm. Some people are more formal, wearing suits. When I lived with my mother, I realized after a period of time, that my dress was too casual. What I normally wear around the house, or to the grocery store, is inappropriate for Lakelands' public areas. As a result, I spruced up my wardrobe.

Dress codes are subtle, and newcomers, or people from another generation, may not be aware of these conventions. A number of people talked about their dissatisfaction with some young staff members' dress. 
Roger: Would you believe [they are] coming in wearing jeans! Next thing we know we have a contest up there - not a contest - a Friday, jeans Friday. Anybody wearing jeans they donate a dollar for a prize and the money goes of course to the bursary in here. I don't have jeans. I wore jeans for some 30 years. [Laughing] Anyway. Damned if I'm going to wear jeans and I resent being served in them. Even in restaurants. The waiters wear jeans. [Long pause] Again my [profession] came in, I suppose. I think they understand I'm usually dressed cleanly with dress pants on. And I resent these people who come in without being properly dressed. But they do! They have been dressing properly here, but I'm afraid that this jean thing is going to come on too strong and people will start "I can wear jeans, or I can wear an old pair of work clothes." I hope they don't let that happen. Okay?

These findings indicate that dress is integral to self-identity and to Lakelands' lifestyle (Beck, 2003; Giddens, 1991). This relates to narrative analysis task \#6 - assess consistency in the lifestyle concept. Management can try to influence the dress code, but this does not mean that a new social convention like wearing jeans will be adopted by residents. For the most part, the convention is to wear smart casual wear in Lakelands' common areas. I have never seen people wearing house coats or bedroom slippers. Upscale dress - "smart casual" wear - is key to Lakelands' lifestyle, and the self-identity constructed by that lifestyle. Roger's dress signals that he is a professional, and that he is still in control of his body. Changing dress codes would change Lakelands' lifestyle and influence residents' self-identity. Roger sees wearing jeans as the "thin edge of the 
wedge" - the beginning of a possible lifestyle change that he does not condone.

At Lakelands, breaking dress codes in an outrageous way, is a source of entertainment (See Figure 11.1). Identity switching, or changing one's appearances in outrageous ways, breaks up self-identity. This can be liberating as well as fun. The former General Manager did this often:

Mandy: I'll never forget the Easter, at Easter he was dressed like a chicken [laughing]. Do you know, [name], who drives the bus? [name]? And he was a yah, what was he now? He was a bunny!

Mandy and Margot: [Laughing].

Mandy: He was sweating! But [Manager] was the chicken and he would go from one table to the other and start cackling. And then, all of a sudden, he would take an egg out of his pocket, or some where or other, and show that he'd, he'd laid an egg!

Margot: [Laughing]

Mandy: So he was good fun. So that's something that they should have ... Margot: Fun ... more fun.

Whereas smart dress signals that one is in control of the aging body and that one lives in an upscale place, identity switching signals that Lakelands is a party place, a place where people have fun and can escape their day-to-day self-identity. 
Figure 11.1 Identity switching

Examples of identity switching from Lakelands' fund raising calendars 2005 and 2006.

These calendars were sold to the public.
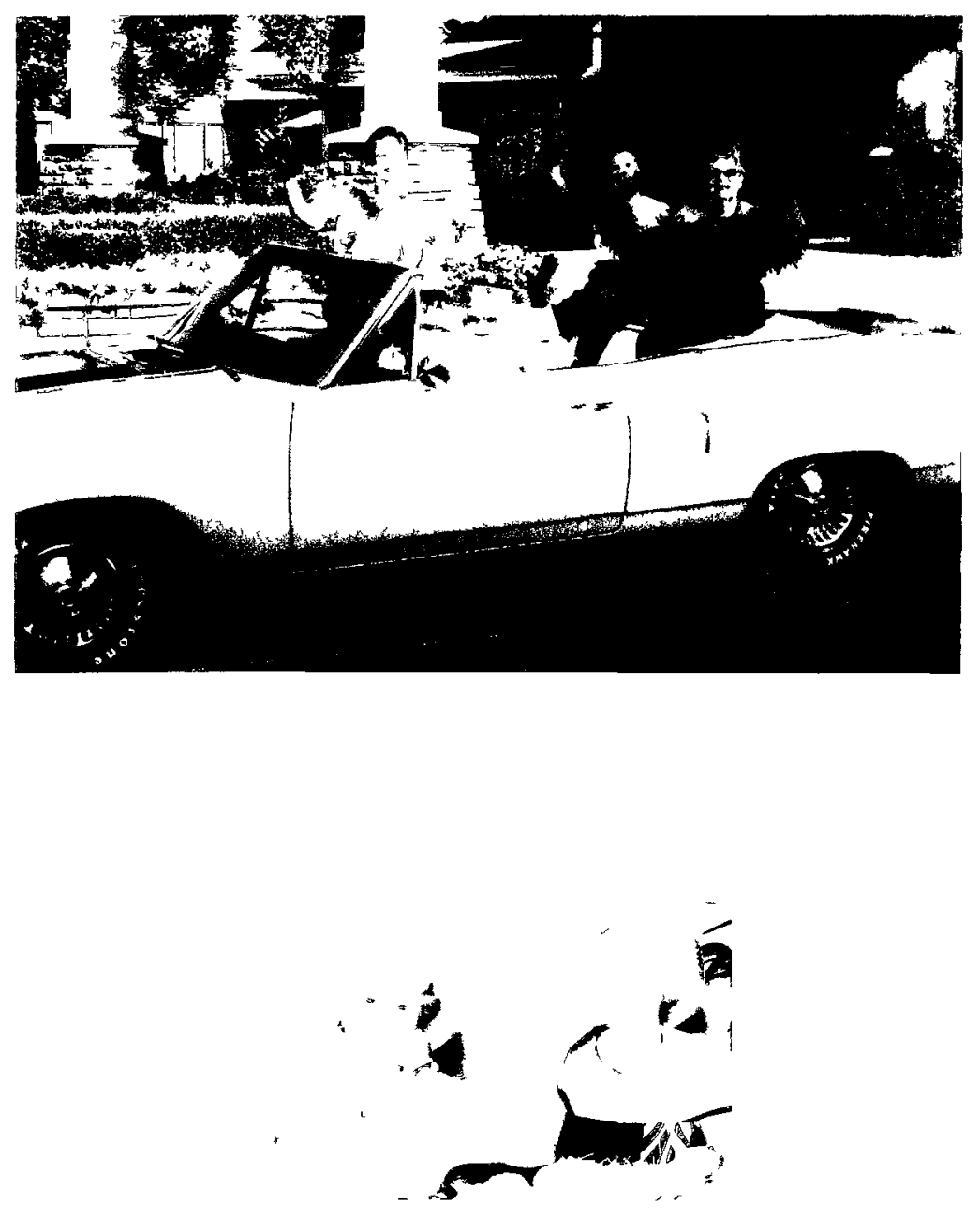


\section{Summary}

This section helps to answer the question "Who does the organization wants me to be?" Although Townsend (1962) and Goffman (1961) talk about a loss of autonomy associated with authoritative rules in total institutions, residents do not complain about Lakelands' rules. Instead, respondents talk about the importance of conforming to Lakelands' social conventions. At Lakelands, people are encouraged to look smart, be active and be friendly and social.

These findings make a number of contributions to the literature. They point to a link between active retirement and self-actualization - creating an enjoyable enriched life. Like many retirement communities, Lakelands emphasizes active retirement as part of its overall social objectives (Blaikie, 1999; Ekerdt, 1986; Katz, 2000; Kelly, Steinkamp \& Kelly, 1987; Streib, 2002).

That most people support Lakelands' active retirement policy suggests that they agree with an active self-identity (Blaikie,1999; McHugh, 2003; Katz, 1999), as well as with the idea of an enriched enjoyable life - after all, people have chosen this lifestyle sector. People emphasize that active retirement is optional - there is room for variation. Most respondents (47\%) said that they feel free to participate or not. Three respondents $(10 \%)$ said they have felt pressured to participate. That this pressure was short lived suggests that Lakelands limits its efforts to impose conformity.

Although Lakelands' residents do not lose autonomy associated with authoritative rules, as in a total institution (Townsend, 1962; Goffman, 1961), they may lose autonomy associated with social conventions or management routines. Henrietta and Marlene's 
narrative, illustrate how difficult it can be to oppose, or change, management routines. People who break management routines or social norms, risk being noticed. Depending on the extent and nature of norm breaking, one can be "spoken to" by management or by other residents, excluded by one's peers, or have the feeling that one does not fit in. In some cases family will be asked to intervene, as in the case of one resident who did not wish to participate in Lakelands' activities. Since groups and families can enforce social norms, management intervention may not be required. This points to the ways that organizations and families can limit agency and shape self-identity.

The open seating debate is an example of a contested social norm. The debate illustrates life politics in action. The debate questions the moral premises of an abstract system - Lakelands' seating policy and the way that it conflicts with Lakelands' customer service philosophy - "Understanding our residents and anticipating their needs" (Table 3.1). The debate raises questions such as: To what extent is it morally justifiable to limit seating choices? and What should be the limits of organizational practices that limit a customer's way of life?

These findings also make a contribution to the literature by highlighting the theme of perfect communities (Jacobs, 1974; McHugh, 2003; McHugh \& Larson-Keagy, 2005; Katz, 2005). When Lakelands' management and residents support active retirement when they encourage people to be active, dress smartly and be friendly - they may be striving to create a perfect community. The empirical literature suggests that idyllic spaces and perfect communities are a trait of communal lifestyle organizations (Jacobs, 1975; McHugh, 2003; McHugh \& Larson-Keagy, 2005; Laws, 1995, 1997; Katz, 2005). 
Creating utopian or perfect communities is a long standing tradition in North America (Peterson, 2005; Sutton, 2004). Designed to overcome societal ills, utopian communities are places where people of like mind come together to further social, and sometimes spiritual objectives. Lakelands' vision that 'Lakelands' residents are able to enjoy significantly more stimulating, interesting and enriching lives than they could experience anywhere else" suggests that management is trying to create a perfect community; a community that is an improvement over the status quo.

Perfect communities often promote homogeneity and harmony and thus have the potential for ignoring individual wishes. They also have the potential for being totalitarian (Peterson, 2005). Focusing on a social objective like active retirement can be a detriment to self-actualization, especially if service standardization conflicts with the notion of customer, or personal service. The seating debate illustrates the conflict that can arise between a social objective - creating a perfect community - and individual aspirations. 


\section{CHAPTER TWELVE}

\section{Who am I when I live in an organization? Living as I like}

Lakelands' rules and social conventions raise the question of whether or not a person can live as they like, unfettered by management or by other residents. To explore this issue, I asked respondents this question. Twenty-five people (83\%) said that they can live as they like, four (13\%) said that they could "pretty much live as they like" and one person (3\%) said that they could not live as they like, due to restrictions at Lakelands (see Table 12.1). This last person is unsatisfied with the cooking facilities and food at Lakelands.

The four respondents who said that they can "pretty much live as they like" mentioned a number of things about Lakelands that limit their ability to live as they like. Olivia mentioned having to conform to social norms: having to fit in. She also mentioned that what she likes least about Lakelands is that it is not like her own home:

Margot: What kind of restrictions do you experience now? You mentioned, when you first came in, what kind of restrictions you experienced.

Olivia: Well, it's not quite the same as your own home, you know. It's just, you feel a little as if you're kind of visiting.

[Discussion]

Olivia: Yah. You have to get along with people: be sure that you don't offend people or don't get too bossy with other people or be nasty to them. You've got to fit in and be friendly with everybody. 
Olivia is a long time resident. That she feels like she is "just visiting" speaks to the difficulties that one can have making an organization one's home.

Table 12.1. Typical, contrasting and discrepant narratives: Living as one likes

\begin{tabular}{|c|c|c|c|c|}
\hline \multirow{2}{*}{$\begin{array}{l}\text { Question } \\
\quad \& \\
\text { Response }\end{array}$} & \multicolumn{4}{|c|}{ Narratives } \\
\hline & Typical & Contrasting & Discrepant & $\begin{array}{l}\text { Total } \\
\text { cases }\end{array}$ \\
\hline $\begin{array}{l}\text { Can you live the } \\
\text { way you want, free } \\
\text { of restrictions from } \\
\text { Lakelands? }\end{array}$ & $\begin{array}{l}\text { Yes, no restrictions from } \\
\text { Lakelands. Other } \\
\text { restrictions may exist } \\
\text { e.g., health. }\end{array}$ & $\begin{array}{l}\text { Pretty much } \\
\text { (a few } \\
\text { limits from } \\
\text { Lakelands). }\end{array}$ & No. & \\
\hline Response & $\begin{array}{c}25 \\
(83 \%)\end{array}$ & $\begin{array}{c}4 \\
(13 \%)\end{array}$ & $\begin{array}{c}1 \\
(3 \%)\end{array}$ & $\begin{array}{c}30 \\
(100 \%)\end{array}$ \\
\hline
\end{tabular}

Rennie raised another difficulty. She mentioned not being able to invite the former Activity Coordinator to her apartment. Other than that, Rennie said that she is living the way she would like. This restriction speaks to ways management can limit residents' proprietary rights. The following management narrative outlines Lakelands' views on home and participatory management:

Manager: Home is something that we've always recognized for our clients. This is their home. The day they move in here this is where they live and ... and the whole building, not just their suite, but the whole building is their home. And we respect that. Then it becomes, even though we own the building, they have some proprietary right to have a say in how things happen: what happens even. So with the recognition that we have to manage the building and provide the services that we're committed to doing that - we have to listen to our residents, because 
we are operating in their home. And, you know, that's something that we've always recognized or believed, and always talked about with our staff.

This statement acknowledges the importance of participatory management, but also notes that there is a balance between management's and residents' proprietary rights. In this instance, Lakelands' staff relations policy trumps residents' proprietary rights. This restriction limits Rennie's ability to maintain her friendship with a former staff member.

Another important restriction relates to the number of people living at Lakelands. Four persons mentioned that there are too many people. Clara mentioned that she would prefer a smaller group, although she acknowledged that at Lakelands she has choices in friends. This notion emerged in other interviews, although people did not say, as Clara does, that it limits their ability to live as they wish. Marie Josee mentioned she would like to live in a place with fewer people. She finds that as more couples move to Lakelands, the total number of people has increased. Ursula talked about having been overwhelmed by a "mob" of people when she first arrived, and Edward talked about Lakelands being like a "shopping mall" with people everywhere.

When residents mentioned things that restrict their ability to live as they wish, they were more likely to mention restrictions outside Lakelands' control (see Table 12.2) than restrictions within Lakelands' control (see Table 12.1). Table 12.2 indicates that the most frequently mentioned limitations outside Lakelands' control are health related (16 cases). The second most frequently mentioned restriction is loss of the family car, not going out as much, or not traveling (12 cases). 
Table 12.2. Living as I like: Restrictions outside Lakelands' control

\begin{tabular}{lc|lc}
\hline & Cases \# & Limited by & Cases \# \\
& $(n=30)$ & & $(n=30)$ \\
\hline Car, travel, going places & 12 & Health, age & 16 \\
Family, friends, spouse & 5 & Finances & 1 \\
Cooking, housekeeping & 5 & & \\
Home town & 4 & & \\
Possessions & 3 & & \\
Land, bigger space & 3 & & \\
Hobbies & 2 & & \\
\hline
\end{tabular}

This raises the question, if $83 \%$ of people feel they can live as they like, what is it about Lakelands that produces this outcome? This relates to narrative analysis task \#1 identify themes, sequence, timing, causality and conditions. People mentioned a number of factors that contribute to a positive experience (see Table 12.3). Lakelands relieves people of householder burdens, which allows people to be comfortable, enjoy life and not worry. It provides bus transportation, which allows people to be autonomous and have freedom of movement. It offers activities and companionship so that residents can have fun and no longer feel alone. It offers choices, so that respondents can choose among various lifestyle options. Finally, Lakelands provides protection and security, which gives residents' and their families peace of mind. 
Table 12.3. Positive experiences at Lakelands

\begin{tabular}{lcc}
\hline Positive & $\begin{array}{c}\text { Cases \# } \\
(n=30)\end{array}$ & $\begin{array}{c}\% \\
(n=30)\end{array}$ \\
\hline Comfortable, happy & 24 & $80 \%$ \\
Easy, less work & 16 & $53 \%$ \\
No worry, not bothered & 14 & $47 \%$ \\
Autonomous, independent, choices & 10 & $33 \%$ \\
Fun & 8 & $27 \%$ \\
Healing, life giving & 8 & $27 \%$ \\
Supported, protected & 8 & $27 \%$ \\
Not lonely & 3 & $10 \%$ \\
\hline
\end{tabular}

In addition to the factors mentioned in Table 12.3, I found five additional factors that are associated with people living as they wish at Lakelands (see Table 12.4). Specifically, if people agree with Lakelands' naming practices (i.e., using the term resident, calling people by their first names) they are more likely to say they can live as they wish at Lakelands than if they do not agree with this naming practice. Also, the better a respondent's eyesight and memory, the more likely they are to say that they can live as they wish. And finally, respondents having family living nearby are more likely to say that they can live as they like, than are respondents who do not have family nearby. These correlations are consistent with the notion that experiencing stronger personal agency facilitates adjustment. 
Table 12.4. Relationships with "can live as I like"

\begin{tabular}{lc}
\hline & \\
\hline Variables & Spearman's rho \\
"Resident" is fine & $.47^{*}$ \\
& $(\mathrm{n}=19)$ \\
First name is fine & $.42^{\dagger}$ \\
& $(\mathrm{n}=20)$ \\
Eyesight problems & $-.35^{\dagger}$ \\
& $(\mathrm{n}=30)$ \\
Memory problems & $-.38^{*}$ \\
Family nearby & $(\mathrm{n}=30)$ \\
& $.39^{*}$ \\
\end{tabular}

Note. ${ }^{t} p \prec .10 .{ }^{*} p<.05$. Two-tailed test. Since these variables have abnormal distributions, I used the non-parametric correlation coefficient Spearman's rho.

What might be the explanation for the associations in Table 12.4? Perhaps these associations, like others identified in this research, can be explained by Giddens' notion of power. The first two associations relate to management assumptions about resident identity. The more respondents agree with these naming conventions, the more likely they are to say that they can live as they like. Perhaps in agreeing with Lakelands' naming conventions, respondents are affirming that they belong, that they fit into the community. Perhaps this agreement suggests that management has, in large measure, been able to meet respondents' self-identity aspirations. Both of these conventions are within Lakelands control and point to a way that management can ensure that people live as they wish - by promoting self-identities that residents agree with or aspire to. 
This finding supports Ferrells' observation that customers are happiest with a product or firm when they can positively identity with the firm:

Research has demonstrated that consumers identify with organizations and may perceive an overlap between organizational attributes and their individual attributes. The concept of organizational identification is important because consumers often seek organizational images that are congruent with their selfidentity. Organizational disidentification may occur when individuals perceive a conflict between their defining attributes and the attributes defining the organization. This disidentification represents a separation of a person's selfconcept from that of the organization and translates into negative perceptions of the organization (Ferrell, 2004, pp. 127-128).

In contrast with factors over which Lakelands' management has control, health problems are outside their control. The better a respondent's eyesight or memory, the more likely they are to say they can live as they wish. This supports the findings in Table 12.2 that indicate that poor health limits respondents' ability to live as they wish. Perhaps these findings can also be explained by a loss of personal power. Perhaps eyesight and memory problems reduce a person's sense of control over the environment. Both eyesight and memory problems, if they become severe enough, can jeopardize a person's ability to continue living at Lakelands. To live at Lakelands one must be able to look after oneself. In other words, having these problems can limit agency - limit housing options, and ultimately lifestyle choices.

As good eyesight and memory help to preserve agency, having family nearby may also support agency. It may reduce risks arising from fateful moments like serious illnesses. For example, if a person falls ill and is transported to the hospital, family members can visit the person and comfort them. As well, family can liaise with the 
hospital and Lakelands to work out any difficulties arising from the situation. Residents with family nearby may not have to depend on others, or depend on Lakelands. Having family nearby may be a source of physical, emotional and moral support which may increase one's sense of control, security, and the capacity to manage risk.

\section{Summary}

In summary, the data indicate that health problems limit people's ability to live as they wish. In contrast, adequate transportation (Rudman, Friedland, Chipman \& Sciortino, 2006), having family nearby, and being in agreement with organizational conventions such as naming - support being able to live as one wishes at Lakelands.

This section helps to put any negative comments about living at Lakelands in perspective. Despite criticisms, most people (83\%) unequivocally said that they can live the way they want, free of restrictions from Lakelands. This suggests that although people may not always be happy with some aspects of Lakelands' operations, it does not diminish their overall ability to live as they wish. These problems do not diminish their pleasure in life or their personal plans.

These findings suggest that Lakelands allows most people to be themselves - to live as they wish. Although organizational sequestration is largely a source of disempowerment in total institutions, it is a source of empowerment at Lakelands. Lakelands empowers older people by providing services that help in managing risks that arise from aging - problems such as lack of transportation, managing a household, and social isolation. Respondents reported positive experiences at Lakelands such as being 
comfortable and happy, having less work, having less worry, feeling protected and supported, having fun, having choices, and being autonomous and independent (see Table 12.3). 


\section{CHAPTER THIRTEEN}

\section{Who am I when I live in an organization? Suggesting changes}

In addition to exploring how organizations shape self-identity, the study examines how respondents influence Lakelands. Giddens' theory would predict that it is a reflexive relationship. Relevant questions include: What do residents want the organization to be? How do they shape the organization? What are the implications for resident self-identity? Previous sections touched upon this topic. The walker and seating debate illustrate how residents may contest management practices that negatively affect self-identity, or that affect their rights or lifestyle. Residents may complain to management, to fellow residents, and they may push back or break norms in an effort to recover a preferred lifestyle or to create organizational practices that they find acceptable.

This section examines how residents shape the organization by making suggestions to management, plus resident perceptions of management's responses. In addition, it looks at factors that limit resident criticism. This topic is useful in assessing the degree to which residents are active or passive consumers, and the degree to which management is responsive to resident complaints.

I asked respondents whether or not they have made suggestions to management (see Table 13.1). Of the 26 persons who answered this question, $17(65 \%)$ said they have in the past (typical plus discrepant answers). People gave various reasons for not making 
suggestions to management (35\%). Some have no suggestions or complaints. They see things as working well at Lakelands. Other residents - the discrepant answer - feel that management does not listen, or will not change things, therefore they no longer bother to make suggestions. Four persons, or $15 \%$ of the persons who answered this question, have this perspective. All of these persons are long time residents:

Mandy: I do think sometimes you would like something to be different. And you might speak about it at their, at their Residents' Meeting. But it doesn't change much. [Laugh]. Not that I have much to change. But you can hear other people saying "Oh, we should do this or we shouldn't do this." But it goes on pretty well, you know. You don't have a choice ... to ... change much, you know. And, which ... I don't know if that's a good idea or not. They should listen to ... people that are here, because after all, we pay our rent, you know. So, that's one thing that I ... I think they should listen to a bit more.

Table 13.1. Typical, contrasting and discrepant narratives: Suggestions for change

\begin{tabular}{lccccc}
\hline \multirow{2}{*}{$\begin{array}{c}\text { Question } \\
\text { \& } \\
\text { Response }\end{array}$} & Typical & Contrasting & Discrepant & Missing $^{a}$ & $\begin{array}{c}\text { Total } \\
\text { cases }\end{array}$ \\
\cline { 2 - 6 } & Yes & No. & $\begin{array}{c}\text { Yes, but no } \\
\text { longer, mgt } \\
\text { doesn't listen. }\end{array}$ & \\
\hline $\begin{array}{l}\text { Have you made } \\
\text { suggestions for } \\
\text { change? }\end{array}$ & & & 4 & 4 & 30 \\
$\begin{array}{l}\text { Responses } \\
\text {-Total }\end{array}$ & 13 & 9 & $(13 \%)$ & $(13 \%)$ & $(100 \%)$ \\
- Minus missing & $(43 \%)$ & $(30 \%)$ & 4 & - & 26 \\
responses & 13 & 9 & $(15 \%)$ & - & $(100 \%)$ \\
\hline
\end{tabular}

Note.

${ }^{a}$ Either I did not ask the resident this question, or they did not directly answer the question. 
Residents can make complaints and suggestions in a number of ways. They can attend the monthly Residents' Meeting; sit on the Culinary Committee; fill out a comments form; talk to the owners, management or staff; or write a letter to management. On one occasion, residents circulated a petition and gave it to management. This was on the subject of reinstating the former Activity Coordinator. In contrast to some communal lifestyle organizations (Streib, Folts \& La Greca,1985; Streib \& Metsch, 2002; Williams \& Guendouzi, 2000), residents at Lakelands do not have a Board, or an Advisory Board.

Over the years I have attended a number of residents' meetings. The level of resident participation varies. Usually, the meetings are well attended. Some General Managers are open, encouraging complaints and suggestions, whereas others are less so. During the study period, I attended a Residents' Meeting where the Chef stood up and asked for complaints and suggestions about the food. He received a few suggestions and then there was total silence. In response he said. "You're letting me off the hook." This was greeted by laughter. In addition to the Chef trying to ferret out suggestions, the Souschefs periodically circulate in the dining room asking people for their comments. This suggests that management may want input, but residents are not always willing to provide that input. Some residents may be passive consumers.

\section{1 “I don't want to complain”}

Gubrium and Holstein (2008) talk about the importance, when doing narrative analysis, of considering the reflexive relationship between the environment and people's stories: "what meanings, understandings, and contingencies are storytellers up against in the 
circumstances" (Gubrium and Holstein, 2008, p.27). They argue that the environment shapes people's stories, for example what stories can and cannot be told.

This is an important consideration when analyzing resident's stories about suggestions to management. Apart from perhaps under reporting suggestions to management (Table 13.1) - perhaps respondents do not want me to think they are complainers (Goodwin \& Spiggle, 1989) - respondents mentioned a number of reasons why they do not make suggestions: not wanting to be a complainer, feeling life is so good that one does not have the right to complain, feeling one lacks influence with management, peer pressure, and not wanting to risk being evicted. This relates to narrative analysis task \#1 - identify themes, sequence, timing, causality, conditions.

A number of narratives illustrate reasons for not complaining. Sonya is reluctant to complain for a number of reasons. When living in another residential organization she learned that being a complainer is undesirable. She became frustrated with an unresponsive organization and with fellow residents who did not lend support:

Sonya: So, and I would go to the meetings, and I would protest and, and and I was the only one who would open my mouth and stand up and complain. So a lot of the older people thought I was nothing but a complainer, you know. But none of them would dare stand up and say what they thought. So this is one of the reasons why I sort of kept quiet and backwards and kept my mouth shut here, because I didn't want to land myself in the same situation. So I've got a lot inside here. Whereas Sonya does not want to be labeled a complainer, given her previous experience in another organization, Marlene feels she does not have the right to complain about life in a luxurious place like Lakelands:

Marlene: Well, we all have to acknowledge that I . . criticize myself often for bitching about anything, either at [previous residence] or here. I mean, we're 
living luxuriously. And my [family] would come to visit us at [previous independent living residence] and I'd be complaining about something. So [they] got the habit where [they] came in and [they'd] say "another rotten day in Paradise eh!" Margot \& Marlene: [Laughing].

Marlene: We're very fortunate but we don't feel as fortunate as we are. Margot: Well.

Margot \& Marlene: [Laughing]

Marlene: I have to kind of pinch myself to remind myself of it. Maybe $1 \%$ of the human race, at age $[\#]$ has this pleasant a living accommodation. Especially having been to [poor country] a couple of times, you know. [Discussion] It's a good reality check when you go to a place like that.

Marlene feels she does not have the right to complain because she sees herself as being so fortunate to live at Lakelands. Many people feel this way.

In addition to feeling that one has no cause to complain, there is peer pressure against complaining. Residents say they should not complain, or they say others should not complain:

Henrietta: I told that to the whole gang there one time. They were starting to grumble on a Friday morning at the country kitchen. I got up, and I told them. I says: "you had a chance to go look at five or six other buildings" I says, "Why did you come here? Why?" I says, "Because you liked it. It was the best!" In addition to peer pressure, some people may be reluctant to complain because they are afraid of drawing attention to themselves and risking eviction, especially people whose health is failing. Two people mentioned this to me over the course of the study. Rennie, was actually threatened with eviction by the former manager. She did not take this threat seriously since the former manager was very ill at the time. She attributes his aggressive behaviour to his illness: 
Rennie: [Rennie describes the situation]. And he jumped: "You're not supposed to do that!" He really was mad! He said "That's against the law!" And, and I said [Rennie describes how a staff member helped her.] He said, "You can give me the money!" And I said "Oh no, I won't." He said "I can put that towards something." He said,"You know, if you do that, I can evict you!" And so I just let that go. I thought "What can I do?" I went and bought a nice [gift] with the money. And I gave it to [the staff member].

Margot: So you're not supposed to give money?

Rennie: No.

Margot: But you can give [gifts]?

Rennie: Yah. You can give gifts.

The former Manager's actions are reminiscent of the ways that total institution administrators use space to control behaviour - downgrading unruly patients to poorer living conditions and rewarding good patients by improving their living conditions (Goffman, 1961; Townsend, 1962). In this case, the former Manager threatens a long time resident, who is in good health, with eviction.

Rennie believes that threat of eviction is present in most people's minds. She talked about how people attending Residents' Meetings hesitate to complain to management. She also discussed the petition that was circulated among residents to reinstate the former Activity Coordinator, and how some people refused to sign it because they said they are afraid of displeasing management and being evicted:

Rennie: But at the meeting, you can bring up anything you want. [Fellow resident], gets up and talks. But nobody defends him. They all keep quiet because they're afraid they might be evicted or, or something.

Margot: So people are afraid that they might be evicted?

Rennie: Yah.

Margot: Yah. 
Rennie: I think this is it because ... When we were having the papers [petition] signed for [former Activity Coordinator] some of them said no, we're afraid we might be ...

Margot: Evicted. Yah.

Rennie: Because this is a private place.

In addition to the fear of being evicted, this reluctance to complain may be due to generational values. A manager explained that Lakelands' clients accept the status quo: Manager: The generation that we have now was born in the Depression or grew up in the Depression. They've seem a lot of change in their lifetime. Where a good number of them would have grown up in a one room cabin, settled on the prairies, and had a horse-drawn wagon for transportation now you've got cell phones and computers, and that kind of thing. So, huge changes in their lifetimes. And they tend to be accepting of the status quo.

There is support for this idea in the literature. Lyons, Higgins and Duxbury (2007) say that the Mature Generation, who were born before 1945, and experienced the Depression, are hardworking, save for the future, and conform to traditional values.

About $40 \%$ of respondents spoke about complaining. Either they said they should not complain, and/or they said others should not complain. This suggests that reluctance to complain is a narrative reality at Lakelands (Gubrium and Holstein, 2008). This is supported by the data. If a person says that they, or someone else, should not complain, the odds of them not having made suggestions to management are 5:1 (Fisher exact test $p$ $=.05$, two-tailed test). 
Table 13.2. Not complaining and "making suggestions to management"

\begin{tabular}{lccc}
\hline $\begin{array}{l}\text { Suggestions } \\
\text { to management }\end{array}$ & Not complaining & Total \\
& 4 & $\begin{array}{c}\text { I/they should not } \\
\text { complain }\end{array}$ & \\
\hline No suggestions & 11 & 8 & 12 \\
Have made suggestions & 15 & 3 & 14 \\
Total & & 11 & 26 \\
\hline Note. Missing cases $=4$. & & &
\end{tabular}

\subsection{Institutional reflexivity}

Although there are numerous reasons why people do not make suggestions to management, there is some evidence that residents can successfully shape Lakelands' operations, especially when the bottom line is threatened. While I was at Lakelands, management reversed a marketing policy that favoured new clients over existing ones. Four respondents talked about this policy:

Margot: Free rent for three months ...

Marie Josee: That's a lot of money!

Margot: That's a lot of money.

Marie Josee: That's a lot of money.

Margot: That might be, depending on the suite, that might be $\$ 2000$ to $\$ 3000$ a month right?

Marie Josee: Could be I suppose - whether it's a couple or one person or whatever. But that is not fair to the rest of us! When I came here, I got a housecoat and it was too big for me!

Margot: [Laughing].

Marie Josee: I am not kidding you. But Margot I'm not kidding you. I could've 
put two people in it. And the girls all talk about those things.

Marie Josee's comments reflect resident complaints about the policy. As Lakelands' vacancy rates climbed during the sub-prime crisis and the recession that followed. Management tried to attract new clients by offering three months free rent and free meal packages to people who moved to Lakelands before the end of March 2009. This produced a wave of discontent among existing residents. At the February 2010 Residents' Meeting, the Interim Manager talked about the policy, explained how it worked, and then said that management had made a mistake and apologized for the policy. He asked for resident comments and said that he would take these comments to his Management Committee, which would consider ways that Lakelands could offer more benefits to current residents.

One month later, at the March Residents' Meeting, management announced a rent rollback to 2008 levels. This represents savings of $\$ 100$ per month or more for many residents. In addition, management announced Lakelands would pay $\$ 500$ to any resident who attracts a new resident to Lakelands. These changes reward existing customers for their loyalty and helped to calm resident complaints about the marketing policy.

These changes illustrate how resident discontent, combined with an economic downturn and increasing vacancy rates, can sensitize management to resident concerns. At these times, when demand is low and supply high, even the most passive consumers can flex their muscles and be heard. 


\section{Summary}

Although people do make suggestions to management, the narrative reality at Lakelands (Gubrium and Holstein, 2008) is that many residents are reluctant to complain. They limit suggestions to management. Respondents gave a number of reasons for not complaining: peer pressure, not wanting to be a complainer, feeling they do not have the right to complain since they are living in luxurious conditions, and fear of eviction. When people decide not to complain, they are engaged in self-reform; they are shaping their narrative to fit the status quo and limiting agency. This tendency toward self-reform is characteristic of modernity and of residential organizations (Giddens, 1991).

Although about half the people at Lakelands tend to be passive consumers, (at the time of the study), the results indicate that tough economic times can increase residents' power vis-à-vis management. Like many industries, the seniors housing industry experienced a reversal of fortunes during the 2009 recession. The situation was no different at Lakelands, and resident complaints were rewarded with a quick and generous response. 


\section{CHAPTER FOURTEEN}

\section{Who does the organization want me to be? Assimilation}

The previous sections focused on answers to ten interview questions. Most of these questions are related to the question 'Who am I when I live in an organization?' In analyzing these ten questions, I noticed a pattern (see Table H.01, Appendix H). Some long-term residents have very high scores for typical narratives. Sometimes $100 \%$ of the answers to the ten interview questions are typical narratives. Newer residents tend to favour contrasting narratives. Based on Townsend (1962) and Goffman's (1961) findings, I anticipated narrative differences between newcomers and long-term residents.

To explore this observation, I looked at the statistical associations between a person's narratives (percent of each type of narrative) and the number of years they have lived at Lakelands, as well as other variables that might influence this relationship (see Table 14.1). This relates to narrative analysis task \#1 - identify themes, sequence, timing, causality and conditions.

Since typical, contrasting and discrepant answers are mathematically dependent, I only tested relationships with typical and discrepant narratives. Typical answers are the common responses to ten interview questions, contrasting answers are the next most common response, and discrepant answers are the least common response (Appendix I). I report relationships with contrasting answers in Appendix L, but do not interpret the 
results. Also, I did not find associations with discrepant narratives. This may be due to the small number of discrepant narratives $-7 \%$ of all narratives were discrepant narratives (Table 3.13).

Table 14.1. Associations with narrative

\begin{tabular}{lcc}
\hline & \multicolumn{2}{c}{ Narrative } \\
\cline { 2 - 3 } Variables & Typical & Discrepant \\
Years resident & $.48^{*}$ & -.12 \\
& $(\mathrm{n}=30)$ & $(\mathrm{n}=30)$ \\
Age & $.33^{\prime}$ & -.24 \\
& $(\mathrm{n}=29)$ & $(\mathrm{n}=29)$ \\
Hearing problems & $.30^{\dagger}$ & -.28 \\
& $(\mathrm{n}=30)$ & $(\mathrm{n}=30)$ \\
\hline
\end{tabular}

Note. ${ }^{t} p<.10 .{ }^{*} p<.05$. Two-tailed test. Since these variables have abnormal distributions, I used the non-parametric correlation coefficient Spearman's rho.

Table 14.1 indicates that three variables are related to typical narratives: years resident, age and hearing problems. The longer a person lives at Lakelands, the older they are, or the worse their hearing, the greater the number of typical answers to the ten interview questions. Additionally, the longer a person lives at Lakelands the older they are likely to be (Spearman's rho $=.48 p=.01 \mathrm{n}=29$ ).

What might be the explanation for the three statistical relationships in Table 14.1? Can they be explained using Giddens' notion of power? First, the association between 
years resident and typical narratives seems to relate to the power of organizations: "Who does the organization want me to be?" and "Where is the 'me' among the 'we'?" The data suggest that over time, the "me" and the "we" tend to converge at Lakelands. There may be an assimilation or socialization effect at Lakelands. Although Lakelands does not strip self-identity and accepts people as they are, over time, self-identity seems to shift to resemble that of the group. Residents, as well as management policies, may influence the culture. Perhaps Lakelands' social norms (e.g., active retirement), peer pressure and wanting to fit in contribute to this trend. As Angela pointed out, over time one "falls into a pattern." Anyone who does not fall into this pattern "stands out" (Goffman, 1961). Perhaps over time, newcomers try to fit into this pattern - adopt typical narratives - in order to blend in and be accepted. Power in this case is the power of routine, social conventions, seniority and social status. As people are gradually assimilated into a Lakelands' culture, the power of the individual viewpoint declines.

The second association - the greater a person's age the more likely they are to have typical narratives - also indicates an assimilation effect. This relationship may have a number of explanations. Perhaps as one ages, one comes to realize that it is very difficult to change the world, including life at Lakelands. Therefore, one accepts the status quo, rather than trying to change public opinion. Consequently, one becomes more like others and assimilates. A second explanation for increasingly typical narratives as one ages, is perhaps wanting to be accepted. Blaikie (1999) argues that old age, especially deep old age, is becoming increasingly taboo in Western society. Perhaps, as one ages, one encounters more and more ageism in society at large. Perhaps this rejection 
makes it increasingly important to be accepted at Lakelands - to find a refuge where one is accepted. A person may increasingly adopt typical narratives at Lakelands in an effort to increase the chance of fitting in.

In addition to age and years resident, having poor hearing increases the likelihood of typical narratives. Perhaps a decline in hearing contributes to a sense of isolation - a feeling of being cut off from others, and a sense of increasing powerlessness. Having contrasting or discrepant narratives may increase the risk of experiencing even greater isolation. To guard against this risk, a person with poor hearing may increasingly adopt common viewpoints as a way to build relationships.

\section{Summary}

These results suggest that, over time, there is an assimilation effect at Lakelands. The older a person, the longer they live at Lakelands, and the poorer their hearing, the more likely they are to give typical answers to the ten major interview questions. Since selfidentity is reflected in narrative, increasingly typical narratives suggest that self-identity converges towards the group. When living in an organization, the "me" increasingly resembles the "we."

These findings make a number of contributions to the literature. First, they support empirical research which indicates that conservatism increases with age - a relationship that seems to hold into the 70 s and 80 s age group (Truett, 1993). This may have implications for persons managing residential organizations: for example, marketing campaigns and day-to-day management. 
Second, the findings may indicate that increased exposure, or experience living in organizations, weakens agency. Increasingly typical narratives may be an indicator of weakening agency, suggesting that residents' ability to exercise power vis-à-vis other residents or management may decline over time. This may influence residents' ability to effect change in residential organizations. The relationship between agency and power, can, however, be complex. Although individual agency may decline, group power may increase. Persons holding increasingly similar views may be inclined to form groups, or join existing groups, as a means for effecting organizational change. 


\section{CHAPTER FIFTEEN}

\section{Towards a typology: Communal lifestyle organizations}

The findings highlight some key features of communal lifestyle organizations and can be used to help build a typology of a communal lifestyle organization. For the purpose of this study, the working definition of a communal lifestyle organization was:

A planned age-restricted community with a resort-like upscale appearance and leisure lifestyle. The organization may be non-profit or profit generating. Often owned and managed by corporations, communal lifestyle organizations may also be resident owned and managed.

This section refines and extends this working definition. Table 15.1 summarizes the main characteristics of a communal lifestyle organization. As well, it compares these characteristics to a total institution. There are two reasons for making this comparison. First, the total institution has received a great deal of attention in previous research. Second, this comparison sheds light on the use of management power to limit or promote client self-actualization.

Table 15.1 refers to pure or ideal types. In the case of the total institution, the table utilizes Goffman's (1961) archetype, which is a prison-like organization. 
Table 15.1. Communal lifestyle organizations and total institutions

\begin{tabular}{|c|c|c|}
\hline Elements & Communal lifestyle organization & Total institution \\
\hline $\begin{array}{l}\text { Target } \\
\text { population }\end{array}$ & $\begin{array}{l}\text { Clients pay to live in the } \\
\text { organization. Middle to upper } \\
\text { middle class. Competent agents: } \\
\text { mentally competent, autonomous. } \\
\text { Commonly, but not necessarily } \\
\text { restricted to retired persons. }\end{array}$ & $\begin{array}{l}\text { Clients obliged to live in the } \\
\text { organization. Primarily lower classes, } \\
\text { minorities. Houses "deviant" persons: } \\
\text { criminals, mental patients. }\end{array}$ \\
\hline $\begin{array}{l}\text { Objectives, } \\
\text { rationale }\end{array}$ & $\begin{array}{l}\text { Life enjoyment, enhancement, } \\
\text { pampering. "You deserve rewards } \\
\text { now." }\end{array}$ & $\begin{array}{l}\text { Warehousing, reforming deviance, } \\
\text { punishment. }\end{array}$ \\
\hline $\begin{array}{l}\text { Self- } \\
\text { identity }\end{array}$ & $\begin{array}{l}\text { Accept, enhance self-identity. } \\
\text { Create a leisure identity. }\end{array}$ & $\begin{array}{l}\text { Disconfirm, strip, stigmatize self- } \\
\text { identity. }\end{array}$ \\
\hline $\begin{array}{l}\text { Appearance } \\
\text { boundaries }\end{array}$ & $\begin{array}{l}\text { Upscale, non-institutional } \\
\text { professionally designed, } \\
\text { welcoming. Visitors, residents free } \\
\text { to come and go. }\end{array}$ & $\begin{array}{l}\text { Institutional, drab, not welcoming. } \\
\text { Boundaries restrict entry and exit. }\end{array}$ \\
\hline $\begin{array}{l}\text { Services, } \\
\text { delivery }\end{array}$ & $\begin{array}{l}\text { Create leisure, consumer culture, } \\
\text { customer service, satisfaction, } \\
\text { choice, personal service. }\end{array}$ & $\begin{array}{l}\text { Obligatory treatment/custodial model. } \\
\text { No choice, standardization. No way to } \\
\text { exit. }\end{array}$ \\
\hline Lifestyle & $\begin{array}{l}\text { Commodified upgraded lifestyle. } \\
\text { Like being on holiday. Active fun, } \\
\text { leisure activities (optional). }\end{array}$ & $\begin{array}{l}\text { Downgraded, impoverished lifestyle. } \\
\text { Uncomfortable, boring. Menial, hard } \\
\text { work. Obligatory activities. }\end{array}$ \\
\hline $\begin{array}{l}\text { Privacy, } \\
\text { security }\end{array}$ & $\begin{array}{l}\text { Private living space. Protection } \\
\text { from harm. }\end{array}$ & $\begin{array}{l}\text { Little to no private living space or } \\
\text { privacy. Subject to harm, fear, anxiety. }\end{array}$ \\
\hline Governance & $\begin{array}{l}\text { Ranges from resident managed to } \\
\text { owner managed. Changes with } \\
\text { customer desires, market forces. }\end{array}$ & $\begin{array}{l}\text { Total hierarchical power. Total } \\
\text { management control. Usually instrument } \\
\text { of the state. Subject to laws, regulations, } \\
\text { political influence. }\end{array}$ \\
\hline $\begin{array}{l}\text { Norms } \\
\text { autonomy }\end{array}$ & $\begin{array}{l}\text { No authoritative rules. Deviance } \\
\text { tolerated. Autonomy expected. }\end{array}$ & $\begin{array}{l}\text { Authoritarian, arbitrary control. Loss of } \\
\text { autonomy. }\end{array}$ \\
\hline Community & $\begin{array}{l}\text { Perfect community: neigbourly. } \\
\text { Pure relationships. Community and } \\
\text { self co-exist. }\end{array}$ & $\begin{array}{l}\text { Promotes social isolation, severs } \\
\text { relationships. Community trumps self. }\end{array}$ \\
\hline $\begin{array}{l}\text { Staff } \\
\text { resident }\end{array}$ & $\begin{array}{l}\text { Mutual respect, cooperation, } \\
\text { teamwork, friendship, equality. }\end{array}$ & $\begin{array}{l}\text { Mutual suspicion. Cultural divide. } \\
\text { Antagonism. Favouritism. }\end{array}$ \\
\hline
\end{tabular}

Note. This table describes ideal types. Implementation may fall short of ideals. 
Table 15.1 indicates that communal lifestyle organizations are non-institutional in philosophy and appearance, and strive for an upscale, sophisticated image. Professionally designed, the exterior and interior reflect a style that is in keeping with the organization's leisure objectives. The building and grounds are typically show pieces: they are welcoming, have unique design touches, and indicate that residents are financially at ease (Blaikie, 1999; Del Webb, 2010; Golant, 2001; Harrington, 1994).

A communal lifestyle organization's objective is to promote life enjoyment and life enhancement (Estes, 1991; Folts \& Streib, 1994). This is exemplified by Lakelands' goal statement: "To maximize the enjoyment and enrichment of life for our Residents" (Figure 3.1). Life is not to be endured or suffered. The intent is to create a place where people are happy, lead an exciting life, have fun, and are pampered. Services and accommodation are upscale - three to four star and up - and are more plentiful than at home (McHugh \& Larson-Keagy, 2005).

Communal lifestyle organizations emphasize enjoying life "now" rather than deferring spending. The credo "You deserve it!," which is part of Lakelands' advertising message, argues that it is socially acceptable to spend on oneself, to upgrade one's lifestyle, and to do so now, rather than saving for future generations (McHugh \& LarsonKeagy, 2005).

In keeping with these objectives, communal lifestyle organizations create leisure (Folts \& Streib, 1994). Lakelands creates free time. Although people in a communal lifestyle organization are usually retired, householder tasks remain. Communal lifestyle organizations can eliminate or assist in these tasks. By reducing householder tasks, they 
create more time and energy to enjoy leisure or address health problems.

In addition to creating leisure, communal lifestyle organizations create a leisure self-identity - something that only the wealthy could afford to do in the past. This relates to analytical task \#6 - assess consistency in the lifestyle concept. This leisure lifestyle is created by relieving people of household tasks, and by providing leisure activities that are meaningful, exciting and fun. By participating in an active or leisure-oriented lifestyle (Folts \& Streib, 1994) people accept the active or leisure self-identity that this lifestyle implies (Goffman, 1961).

In creating a leisure self-identity, communal lifestyle organizations strive to enhance customers' self-identity. Ideal communal lifestyle organizations accept people as they are (McHugh, 2003) and treat people equally and with respect. As well, they increase social status by providing attractive accommodation and a holiday-like milieu. In contrast, total institutions strip and stigmatize identity, and downgrade social status.

In maintaining or enhancing self-identity, communal lifestyle organizations permit, or encourage, self-actualization (McHugh, 2003). This goes beyond customer satisfaction (Bitner, Booms \& Tetreault, 1990) or preserving a customers' autonomy and independence. Although customer satisfaction, independence and autonomy are necessary for living as one wishes in a residential organization, they are not necessarily sufficient. This distinction is important since customer satisfaction (Canada Mortgage and Housing Corporation, 2001; Kleinsorge \& Koenig, 1991), independence and autonomy (Ball, Perkins \& Whittington, 2004; Baltes, 1996; Golant, 2001; Streib, Folts \& La Greca, 1985) are cited as important goals to strive for in residential organizations for 
older persons. In contrast, research into life satisfaction or well-being in residential organizations (Hong \& Duff, 1994; Hong \& Duff, 1997; Kelly, Steinkamp \& Kelly, 1987; McQuillen, Licht \& Licht, 2001; Mitchell \& Kemp, 2000; Sherman \& Cooper, 1988 ) is more closely related to the notion of self-identity or self-actualization.

Giddens' theory - the notion of self-identity - suggests a higher standard. Being able to live as one wishes - preserving or enhancing self-identity - relates to Giddens' notions of power, emancipatory politics and life politics. Giddens defines power as "the ability to get things done, and the ability to achieve one's wishes, even against the desires of others (Tucker, 1998 p. 82). Emancipatory politics argues that people's rights should be respected. Life politics points to the potential power of organizations and industries to control self-identity, life chances (Blazer, Sachs-Ericsson \& Hybels, 2005) and selfactualization. Life politics argues that people should have the opportunity and freedom to form a self-identity of their own choosing. Therefore, in maintaining or enhancing selfidentity, the ideal communal lifestyle organization goes beyond promoting customer satisfaction, independence and autonomy. It strives to achieve the standards of both emancipatory and life politics.

In addition to permitting people to form a self-identity of their own choosing, communal lifestyle organizations preserve privacy (Golant, 2001). In contrast, people in total institutions lose control of their private space, body, activities, and self-identity (Goffman, 1961; Townsend, 1962). Whereas people in total institutions are not safe from staff or neighbours (Goffman, 1961), communal lifestyle organizations advertise privacy, security and protection from crime (McHugh, 2000; McHugh \& Larson-Keagy, 2005). 
Communal lifestyle organizations are often owned and managed by corporations, but they may be resident-owned and managed. Therefore, there is a potential for democracy (Hunt, Feldt, Marans, Pastalan \& Vakalo, 1984; Osgood, 1984; Peconic Landing, 2010; Streib, Folts \& La Greca, 1985). When organizations are not resident owned, owners often invite limited resident participation in management decisions. Resident advisory committees, volunteerism, and suggestions are usually encouraged (Hunt, Feldt, Marans, Pastalan \& Vakalo, 1984; Streib \& Metsch, 2002).

Whether communal lifestyle organizations are resident-owned or not, customer service and choice are fundamental to their operation (Hunt, Feldt, Marans, Pastalan \& Vakalo, 1984; Streib \& Metsch, 2002). As competitive enterprises, they are subject to market forces and consumer desires.

In contrast to total institutions, where power can be arbitrary (Goffman, 1961) and residents are not free to exit the organization, in a communal lifestyle organization authority is negotiated and contractual, and residents are free to leave (ALCA, 2010; Del Webb, 2010; Hunt, Feldt, Marans, Pastalan \& Vakalo, 1984; Streib \& Metsch, 2002). Managers provide a service and customers pay a fee for the service. Typically, management and customers agree to a contract that lists mutual obligations and organizational rules (Streib \& Metsch, 2002). This occurs at Lakelands. Although management could arbitrarily break this contract or make unpopular rules, customers can hold management accountable, or move to another organization (Streib \& Metsch, 2002).

People living in total institutions lose autonomy to authoritative rules (Goffman 1961; Townsend, 1962). In contrast, customer autonomy is preserved in communal 
lifestyle organizations to the extent that management and staff do not lose sight of customer service philosophy. The prevailing credos are freedom and choice (Del Webb, 2010; Hunt, Feldt, Marans, Pastalan \& Vakalo, 1984; McHugh, 2003). Apart from basic rules, management and residents cooperate in maintaining social norms such as active retirement and friendliness (Jacobs, 1974). Deviance is tolerated to the extent that it does not impair residents' safety or enjoyment, or break organizational rules (Streib \& Metsch, 2002). The relationship between management, staff and customers is cooperative and respectful with management and staff focusing on good customer service (see Table 3.1).

This suggests that clients in communal lifestyle organizations have more power vis-à-vis management than residents in total institutions. To exercise such power, however, clients must know their rights, and be capable and willing to exercise them. If not, the balance of power may shift in favour of management, and the organization may begin to slip away from the communal lifestyle model.

In addition to emphasizing lifestyle choice and consumer power, communal lifestyle organizations are in the business of creating perfect communities: kind, supportive, harmonious and safe communities (Laws, 1996, 1997; Katz, 2005; Jacobs, 1974; McHugh 2003; McHugh \& Larson-Keagy, 2005). This can be an antidote to dysfunctional aspects of North American urban life (Lucas, 2002; McHugh \& LarsonKeagy, 2005): crime, isolation, anomie, individualism, and ageism (i.e., discrimination against older people). This social objective - creating perfect communities - builds on a long North American tradition (McHugh, 2003; Peterson, 2005; Sutton, 2004).

The preceding discussion describes the basic category - an ideal communal 
lifestyle organization. This raises the question, what types of organizations fall into this category? Table 15.2, which describes the beginnings of a typology, describes four types and divides these types into typical and atypical communal lifestyle organizations.

Table 15.2. Types and conditions of communal lifestyle organizations

\begin{tabular}{|c|c|c|c|c|}
\hline & Atypical & Typic & & Atypical \\
\hline Type & $\begin{array}{l}\text { Assisted } \\
\text { living }\end{array}$ & $\begin{array}{l}\text { Independent living } \\
\text { residences }\end{array}$ & $\begin{array}{l}\text { Gated } \\
\text { community }\end{array}$ & $\begin{array}{l}\text { Luxury apartment, } \\
\text { condominium, } \\
\text { hotel, cruise ship }\end{array}$ \\
\hline $\begin{array}{l}\text { Necessary } \\
\text { conditions }\end{array}$ & \multicolumn{4}{|c|}{$\begin{array}{l}\text { Some services (e.g., recreation) are in common. Clients live in an upscale } \\
\text { non-institutional environment (e.g., three to five star). Clients have } \\
\text { agency. They are able to exercise power, and are mentally competent and } \\
\text { autonomous. The organization creates leisure and a leisure self-identity. } \\
\text { Governance ranges from resident managed to owner managed. Service } \\
\text { delivery is based on a customer service philosophy. }\end{array}$} \\
\hline
\end{tabular}

Note. Continuing care communities are communal lifestyle organizations. They do not appear as a specific category in these tables since they are a combination of the above categories. The information in this table is based on a number of sources including: Care Planning Partners Inc. (2010); Del Webb (2010); Giddens (1991); Golant (2001); Hunt, Feldt, Marans, Pastalan \& Vakalo (1984); Jacobs (1974); McHugh (2005); Lindquist \& Golub (2004); Residential Ocean Liners (2010).

Table 15.2 sets out a number of conditions that must be met for an organization to be considered a communal lifestyle organization. One of these is mental competence. The rationale for including mental competence as a defining condition is that if a person is not mentally competent, they may have difficulty exercising their rights. This specification is based on Giddens' theory of agency, which is premised on the idea that people are active, knowledgeable and competent, and that people shape circumstances, particularly their immediate social surroundings. Giddens argues that power and agency break down as bodily discipline declines: "bodily discipline is intrinsic to the competent social agent; it 
is transcultural rather than specifically connected with modernity" (Giddens, 1991, p. 57). As an older person's bodily control declines, they tend to be viewed as incompetent in Western society, or less competent agents than younger persons (Baltes, 1996): "A competent agent is one routinely seen to be so by other agents. He or she must avoid lapses of bodily control, or signal to others by gestures or exclamations that there is nothing 'wrong' if such events should occur" (Giddens, 1991, p. 56). Declining bodily control places limits on older person's ability to influence others. Since one of the distinguishing features of a communal lifestyle organization is consumer power, agency is critical. It requires the ability to be a competent agent and have the power and resources to take action that may influence management practices.

Table 15.3 builds on the previous table. It describes the characteristics of four organizational types: assisted living, independent living residences, gated communities and luxury apartments, condominiums, hotels and cruise ships. The typology is loosely organized along a continuum: degree of communal living and state of a clients' health. Independent living residences and assisted living tend to have the most services in common - dining and recreation services - whereas luxury apartments, or condominiums tend to have the least services in common - usually only recreation services.

Although continuing care communities are communal lifestyle organizations, they do not appear as a specific category in these tables since they are a combination of most the above categories; typically apartments or condominiums, independent living and assisted living (Golant, 2001; Timmermann, 2006). People in continuing care communities move from one type of accommodation to another as their health dictates. 
This and the following tables, are based on the study findings, the research literature and a review of organizational websites.

\subsection{Typical communal lifestyle organizations}

Table 15.3 describes two typical communal lifestyle organizations: independent living residences and gated communities. Independent living residences come in many shapes and sizes. In Canada and the United States they may be stand-alone buildings for older seniors - a place where people have their own apartments, complete with kitchenette and bathroom, and share communal dining and recreation facilities. Services include housing, all inclusive home management services, dining and social activities (Care Planning Partners Inc., 2010; Rotary International, 2010). Lakelands is an example of an independent living residence. In Canada they are often called "retirement residences."

The second type of typical communal lifestyle organization - a gated community - is often a large housing development with communal recreational facilities. They may even be small towns (Hunt, Feldt, Marans, Pastalan, \& Vakalo, 1984). Although they are not always gated, they are master planned age-segregated communities, typically for young active seniors. The objective is to provide low maintenance housing, social activities, friendship networks and community (Lucas, 2000; McHugh, 2003). Residents may purchase and manage their own houses, condominiums or apartments. Sometimes these communities are co-located with independent living residences, assisted living and nursing homes (Jacobs, 1974; Hunt, Feldt, Marans, Pastalan, \& Vakalo, 1984). 
Table 15.3. Characteristics of communal lifestyle organizations

\begin{tabular}{|c|c|c|c|c|}
\hline & \multirow{2}{*}{$\frac{\text { Atypical }}{\text { Assisted living }}$} & \multicolumn{2}{|c|}{ Typical } & \multirow{2}{*}{$\begin{array}{c}\text { Atypical } \\
\text { Luxury, } \\
\text { apartment, } \\
\text { condo, hotel, } \\
\text { cruise ship. }\end{array}$} \\
\hline & & $\begin{array}{l}\text { Independent living } \\
\text { residences } \\
\text { (e.g., Lakelands) }\end{array}$ & Gated community & \\
\hline $\begin{array}{l}\text { Generic } \\
\text { description }\end{array}$ & $\begin{array}{l}\text { Assisted living, } \\
\text { congregate, } \\
\text { supportive, } \\
\text { sheltered } \\
\text { housing. }\end{array}$ & $\begin{array}{l}\text { Retirement } \\
\text { residence or } \\
\text { community; } \\
\text { congregate or } \\
\text { sheltered or } \\
\text { supportive } \\
\text { housing. }\end{array}$ & $\begin{array}{l}\text { Independent } \\
\text { living, retirement } \\
\text { community. }\end{array}$ & $\begin{array}{l}\text { As described } \\
\text { above. }\end{array}$ \\
\hline $\begin{array}{l}\text { Objective, } \\
\text { services, } \\
\text { delivery }\end{array}$ & $\begin{array}{l}\text { Create a perfect } \\
\text { community, all } \\
\text { inclusive } \\
\text { housekeeping } \\
\text { services, health } \\
\text { care, recreation. }\end{array}$ & $\begin{array}{l}\text { Create a perfect } \\
\text { community, all } \\
\text { inclusive } \\
\text { housekeeping } \\
\text { services, } \\
\text { recreation. }\end{array}$ & $\begin{array}{l}\text { Create a perfect } \\
\text { community. } \\
\text { Housing, activity } \\
\text { centre, possibly } \\
\text { pool, golf, } \\
\text { shopping mall. }\end{array}$ & $\begin{array}{l}\text { Upscale } \\
\text { accommodation } \\
\text { with recreational } \\
\text { facilities. May } \\
\text { include dining. }\end{array}$ \\
\hline $\begin{array}{l}\text { Target } \\
\text { population, } \\
\text { size }\end{array}$ & $\begin{array}{l}\text { Older seniors } \\
75+. \text { Often } 50- \\
200 \text { residents. } \\
\text { Nursing care. }\end{array}$ & $\begin{array}{l}\text { Older seniors. } \\
\text { Typically 50-200 } \\
\text { residents. }\end{array}$ & $\begin{array}{l}\text { Young seniors } \\
50-75 . \text { Small to } \\
\text { mid-size } \\
\text { population } \\
(5000+) .\end{array}$ & $\begin{array}{l}\text { All ages. May } \\
\text { also be restricted } \\
\text { to retirees. Can } \\
\text { have larger } \\
\text { population than } \\
\text { independent or } \\
\text { assisted living. }\end{array}$ \\
\hline $\begin{array}{l}\text { Activity, } \\
\text { health }\end{array}$ & $\begin{array}{l}\text { Low activity. } \\
\text { Poor health. May } \\
\text { be cognitively } \\
\text { impaired. }\end{array}$ & $\begin{array}{l}\text { Moderately active. } \\
\text { Good to moderate } \\
\text { health. }\end{array}$ & $\begin{array}{l}\text { Moderate to high } \\
\text { activity. Good } \\
\text { health. }\end{array}$ & $\begin{array}{l}\text { Moderate to high } \\
\text { activity. Good to } \\
\text { moderate health. }\end{array}$ \\
\hline
\end{tabular}




\begin{tabular}{|c|c|c|c|c|}
\hline & Assisted living & $\begin{array}{c}\text { Independent living } \\
\text { residences } \\
\text { (e.g., Lakelands) }\end{array}$ & Gated community & $\begin{array}{l}\text { Luxury, } \\
\text { apartment, } \\
\text { condo, hotel, } \\
\text { cruise ship. }\end{array}$ \\
\hline Governance & $\begin{array}{l}\text { Primarily owner } \\
\text { managed. }\end{array}$ & $\begin{array}{l}\text { Primarily owner } \\
\text { managed. }\end{array}$ & $\begin{array}{l}\text { Resident to } \\
\text { owner managed. }\end{array}$ & $\begin{array}{l}\text { Resident to } \\
\text { owner managed. }\end{array}$ \\
\hline Land & $\begin{array}{l}\text { Minimal land } \\
\text { unless part of a } \\
\text { larger seniors' } \\
\text { community. }\end{array}$ & $\begin{array}{l}\text { Minimal land } \\
\text { unless part of a } \\
\text { larger seniors' } \\
\text { community. }\end{array}$ & $\begin{array}{l}\text { Large land } \\
\text { holdings. }\end{array}$ & $\begin{array}{l}\text { Varies. Large } \\
\text { land holdings to } \\
\text { minimal or no } \\
\text { land (e.g. cruise } \\
\text { ship). }\end{array}$ \\
\hline $\begin{array}{l}\text { Living } \\
\text { space }\end{array}$ & $\begin{array}{l}\text { Spacious. Rental } \\
\text { apartment with } \\
\text { bathroom, } \\
\text { kitchenette. }\end{array}$ & $\begin{array}{l}\text { Spacious. Rental } \\
\text { apartment with } \\
\text { bathroom, } \\
\text { kitchenette. }\end{array}$ & $\begin{array}{l}\text { Spacious. Owner } \\
\text { occupied house, } \\
\text { condo or } \\
\text { apartment. }\end{array}$ & $\begin{array}{l}\text { Owner occupied, } \\
\text { rental (short and } \\
\text { long term stay). }\end{array}$ \\
\hline $\begin{array}{l}\text { Degree of } \\
\text { communal } \\
\text { living }\end{array}$ & $\begin{array}{l}\text { Common social } \\
\text { activities, dining. }\end{array}$ & $\begin{array}{l}\text { Common social } \\
\text { activities, dining. }\end{array}$ & $\begin{array}{l}\text { Common social } \\
\text { activities. }\end{array}$ & $\begin{array}{l}\text { Apartment, } \\
\text { condo: social } \\
\text { activities. Hotel: } \\
\text { dining. Cruise } \\
\text { ship: recreation, } \\
\text { dining. }\end{array}$ \\
\hline Boundaries & $\begin{array}{l}\text { Boundaries may } \\
\text { restrict entry, } \\
\text { exit. }\end{array}$ & $\begin{array}{l}\text { Visitors, residents } \\
\text { come and go. }\end{array}$ & $\begin{array}{l}\text { Visitors, } \\
\text { residents come } \\
\text { and go. }\end{array}$ & $\begin{array}{l}\text { Visitors, } \\
\text { residents come } \\
\text { and go. }\end{array}$ \\
\hline Privacy & Total privacy. & Total privacy. & Total privacy. & Total privacy. \\
\hline
\end{tabular}

Note. Although continuing care communities are communal lifestyle organizations, they do not appear in these tables since they are a combination of the above types. The information in this table comes from a number of sources including: Beesley (1989); Canadian Gated Communities Research Project (2006); Care Planning Partners Inc. (2010); Del Webb (2010); Golant (2001); Hunt, Feldt, Marans, Pastalan \& Vakalo (1984); Jacobs (1974); McHugh (2005); Lindquist \& Golub (2004); Residential Ocean Liners (2010). 


\subsection{Atypical communal lifestyle organizations}

Table 15.3 also describes two types of atypical communal lifestyle organizations: luxury apartments, condominiums, hotels, cruise ships and assisted living. The first category luxury apartments, condominiums, hotels and cruise ships - may include owner occupied or rental accommodation with a range of services in common: from leisure amenities such as pools, exercise rooms and gardens to restaurants and concierge services. Not all organizations that fall into this category are necessarily communal lifestyle organizations, only those that are upscale, have common services and create a leisure lifestyle.

I classify luxury apartments, condominiums, hotels and cruise ships as atypical primarily because they may attract people from a wide age range, in contrast to the other three types of communal lifestyle organizations, which tend to attract retired persons. Also, although it is possible to live on a permanent basis in hotels and cruise ships (Lindquist \& Golub, 2004; Residential Ocean Liners, 2010), this is an uncommon living situation.

The second type of atypical communal lifestyle organization - assisted living - is similar to an independent living residence except it provides nursing or medical services. Assisted living has a hotel-like appearance (Assisted Living Concepts, 2010; Bali et al., 2004; Golant, 2001) and provides similar services to a nursing home, although the operating philosophy differs. (See Table 15.4 for a description of a typical nursing home). Golant (2001), who is an expert in assisted living, argues that people in assisted living avoid the loss of privacy and autonomy that occurs in typical nursing homes:

They [residents] have more say [than in a typical nursing home] about how they conduct everyday activities, such as when they eat or recreate, and they play a 
more active role in deciding what services they receive and when they receive them. Proponents of this alternative argue that a nursing home or institutional setting is often unnecessary to address the everyday needs and behaviors of even the most physically and cognitively frail older population (Golant, 2001, p. 14). Although assisted living clients may have more power than in a typical nursing home, they may also have less power than in independent living residences, where people may be more able to exercise their rights because they are in better health.

The above quote by Golant (2001) suggests that some clients in assisted living may be mentally incompetent. Consequently, not all assisted living residences meet one of the basic conditions of a communal lifestyle organization (i.e., that clients be mentally competent). Therefore, I argue, based on Golant's (2001) work, that assisted living organizations are probably, at best, atypical communal lifestyle organizations.

Table 15.4 illustrates that in contrast to assisted living, typical nursing homes cannot be classified as communal lifestyle organizations as they do not meet the necessary conditions: they are not upscale, they have an institutional approach, they use a medical service rather than a customer service model, they do not offer as many choices, and they lack privacy and freedom of movement. People living in nursing homes may have much less personal space and privacy than people in communal lifestyle organizations. In some nursing homes, people share rooms and bathrooms and cannot lock their doors (Golant, 2001). This has implications for pure relationships and selfidentity, especially the ability to live as one wishes. 
Table 15.4. Characteristics of typical nursing homes

\begin{tabular}{ll}
\hline & Typical nursing home \\
\hline $\begin{array}{l}\text { Generic description } \\
\text { Objective, services, } \\
\text { delivery }\end{array}$ & $\begin{array}{l}\text { Long-term care. } \\
\text { Nursing care, limited activities. Institutional. Medical needs } \\
\text { trump customer service. }\end{array}$ \\
Target population, size & $\begin{array}{l}\text { Often larger population than independent or assisted living. } \\
\text { Private or government subsidized. }\end{array}$ \\
Activity, health & $\begin{array}{l}\text { Low activity, poor health. May be cognitively impaired. } \\
\text { Governance }\end{array}$ \\
$\begin{array}{l}\text { Public or private sector managed. Clients have less say over } \\
\text { services than independent or assisted living. }\end{array}$ \\
Living space & $\begin{array}{l}\text { Minimal land unless part of larger development. } \\
\text { Sitchenette. Limited personal possessions. Institutional. }\end{array}$ \\
$\begin{array}{l}\text { Degree of communal } \\
\text { living }\end{array}$ & $\begin{array}{l}\text { Social activities, dining in common. } \\
\text { Boundaries }\end{array}$ \\
Privacy & $\begin{array}{l}\text { Boundaries may restrict entry, exit. } \\
\text { Limited, no privacy. May be unable to lock door. }\end{array}$
\end{tabular}

Notes. From Baltes (1996), Golant (2001), Nelson (2000).

Up to this point, I have discussed communal lifestyle organizations and total institutions. This represents only a small portion of all residential organizations. What about other types of residential organizations? Where do they fit? Table 15.5 lists various types of residential organizations and classifies them into three categories: communal lifestyle organizations, other residential organizations, and total institutions. Some organizations, like nursing homes and boarding schools, may appear in more than one of these categories. That there are so many different organizations in the other residential 
category, points to the need for more research and theory about residential organizations and their impact on resident self-identity, power and agency.

Table 15.5. Comparing all types of residential organizations

\begin{tabular}{lll}
\hline \multicolumn{1}{c}{ Communal lifestyle } & Other residential organizations & \multicolumn{1}{c}{ Total institutions } \\
\hline $\begin{array}{l}\text { Luxury apartment, } \\
\text { condo, hotel, cruise }\end{array}$ & $\begin{array}{l}\text { Farms, ships, educational } \\
\text { residences (university }\end{array}$ & $\begin{array}{l}\text { Concentration camps, } \\
\text { prisons, mental hospitals, } \\
\text { ship, gated }\end{array}$ \\
$\begin{array}{l}\text { community, } \\
\text { independent living } \\
\text { residences, assisted } \\
\text { living, continuing } \\
\text { care communities. }\end{array}$ & $\begin{array}{l}\text { camps, migrant worker } \\
\text { dormitories, research stations, },\end{array}$ & $\begin{array}{l}\text { certain nursing homes, } \\
\text { certain education-related } \\
\text { residences (boarding }\end{array}$ \\
\hline
\end{tabular}

\section{Summary}

In accomplishing narrative analytical task \#5 (to assess the possibility of a communal lifestyle organization typolology) this section makes a unique contribution to the literature. It begins to develop an alternate theory to Goffman's (1961) total institution. The typology indicates that there are three differences between total institutions and communal lifestyle organizations: the extent of management power; the type of boundaries between public and private life; and, the consequences for resident selfidentity. First, in total institutions, there are few limits on management power (Goffman, 1961). In contrast, in communal lifestyle organizations, management power is limited by the power of the consumer and the power of the market place (Hunt, Feldt, Marans, 
Pastalan \& Vakalo, 1984; Streib \& Metsch, 2002). Also, democracy is possible in communal lifestyle organizations (Streib \& Metsch, 2002), whereas it is not in total institutions (Goffman, 1961).

A second difference between communal lifestyle organizations and total institutions relates to boundaries. There are differences in the nature of boundaries. Inside the total institution there are few boundaries between private and public life. Any boundaries that exist to protect private life can be violated, including the integrity of residents' bodies. As well, a boundary exists between the total institution and society as a whole. This boundary is difficult to cross and hides the inside of the total institution from public view (Goffman, 1961; Townsend, 1962). In contrast, in communal lifestyle organizations, clear boundaries exist between a person's private home and public life. The private is hidden from the public. Boundaries between the organization and society are permeable. People can see inside the organization, with the exception of residents' private space.

A third difference between communal lifestyle organizations and total institutions relates to self-identity. Managers of total institutions have a great deal of power to negatively influence resident self-identity - to strip and stigmatize self-identity (Giddens, 1991; Goffman, 1961; Townsend, 1962). Total institutions focus on warehousing protecting society from residents' deviant self-identity - and/or self-reform - forcing residents to conform to social roles. Residents have little power to shape the organization.

In contrast, communal lifestyle organizations strive to enhance self-identity. In the case of older persons they attempt to reduce stigmatization arising from ageism 
(McHugh, 2003). They promote self-actualization and life enjoyment (McHugh, 2003; Streib \& Metsch, 1997). The result is that in an ideal communal lifestyle organizations people can largely live as they wish (Lonnecker, 1995). Additionally, residents have power to shape the organization, either through day-to-day management of the organization, through advising management, through volunteer work, through leaving the organization, or through group pressure. Also, as a consumer group, resident values and preferences can shape the communal lifestyle industry.

In sum, this section makes a unique contribution to the literature: it works towards developing an alternate theory to Goffman's (1961) total institution theory. An important task in this endeavour is determining whether or not Giddens' theory can be generalized to other organizational contexts. The next section address this issue. 


\section{CHAPTER SIXTEEN}

\section{Analytic generalization}

In addition to developing a communal lifestyle typology, one of the objectives of this study is to assess the analytic generalizability of Giddens' theory. Rather than attempting to statistically generalize to a larger population, the objective is theoretical. If Giddens' notions can be successfully applied to the 30 cases in this study, then that provides evidence that they can be generalized beyond Giddens' original context (Yin, 1994), to people who live in other well-run communal lifestyle organizations like Lakelands, or perhaps people and employees in other residential and work settings.

This study relies heavily on Giddens' theory. The findings suggest that some theoretical notions can be refined or extended to better fit the Lakelands' data. This section discusses theoretical generalizability and refinements to nine of Giddens' notions, specifically, self-identity and the reflexive project of the self, lifestyle, bodily appearance, organizational sequestration, life-planning, fateful moments, pure relationships, power, and emancipatory and life politics. As well, this section examines gaps in the theory. Table 16.1 summarizes the results, which are discussed in more detail in the following sections. 
Table 16.1. Giddens' notions: Generalizability and theoretical refinements

\begin{tabular}{ll}
\hline Giddens' notion & Contributions of this study \\
\hline Self-identity & Four methods to analyze self-identity: 1) five interview \\
Generalizable to persons in all & questions assessed perceived changes in self-identity; 2) \\
organizational settings - & narrative analysis analyzed self-identity changes over time; \\
residential and work. & 3) typical, contrasting and discrepant narrative categories \\
& measured variability in self-identity narratives; 4) statistical \\
& correlation between years resident at Lakelands and typical \\
& narratives measured self-identity change. Generalizable to all \\
& organizational settings.
\end{tabular}

Lifestyle

Lifestyle is generalizable to all residential and work settings, although the ability to consume may be curtailed in some settings, like total institutions.

Lifestyle fit: a calculation to determine whether one's lifestyle "fits" the organization's lifestyle. Generalizable to persons in all residential and work settings with the possible exception of places, like total institutions, where freedom of choice is limited.

Leisure self-identity: self-identity that revolves around a leisure lifestyle. Generalizable to communal lifestyle organizations and other organizations that create leisure lifestyles.

\section{Bodily appearance}

Generalizable to persons in all residential and work settings.

Organizational sequestration

Generalizable to sequestered residential and work settings.
Identity switching: changing one's appearance, often in outrageous ways, breaks up self-identity. This can be liberating and fun. Generalizable to all persons/settings.

Concentration of existential issues: abnormal frequency of existential issues arising from aging, illness and death. Generalizable to organizational settings that sequester moral and existential issues like aging, death and illness.

Third versus Fourth Age organizations: describes the organizational segregation of active older persons in relatively good health (i.e., Third Agers) from older persons experiencing decrepitude and senility (i.e., Fourth Agers). Generalizable to residential settings for older persons.

Enhanced and stigmatized self-identity: in moving to an age restricted communal lifestyle organization, self-identity can be enhanced and/or stigmatized. Generalizable to age restricted communal lifestyle organizations. 


\begin{tabular}{ll}
\hline Giddens' notion & $\begin{array}{l}\text { Contributions of this study } \\
\text { Language of sequestration: terms like "in here" or "on the } \\
\text { outside" describe psychological and physical boundaries } \\
\text { between organizations and society. Generalizable to persons } \\
\text { in boundaried residential and work settings. }\end{array}$ \\
\hline $\begin{array}{l}\text { Life-planning } \\
\text { Generalizable to persons in all } \\
\text { organizational settings with }\end{array}$ & $\begin{array}{l}\text { Recognition that age, ill health, lack of lifestyle choices } \\
\text { persons. }\end{array}$ \\
$\begin{array}{l}\text { the exception of total } \\
\text { institutions, where freedom to }\end{array}$ &
\end{tabular}

\section{Fateful moments}

Generalizable to persons in all organizational settings.
Crises: fateful moments or extended experiences that produce psychological crisis. Examples include caregiver stress, death, illness, moving, fights with family.

Generalizable to persons in all organizational settings.

\section{Pure relationships}

Generalizable to persons in all organizational settings, with the possible exception of total institutions where freedom is limited.
Friendship and family may blur: friends may feel like family, or friends may marry. May have limited generalizability in settings like total institutions.

Death may shape friendships: fear of losing friends to death and illness may limit some persons from forming pure relationships or alternatively encourage people to embrace new or more friendships. Generalizable to any setting.

Conditions shaping power: statistical analysis indicates that individual characteristics such as age, marital status, extroversion, health, family location, crises before the move, and organizational experience can shape power relationships between residents and organizations. Generalizable to any setting.

\section{Emancipatory politics}

Generalizable to all settings.

\section{Life politics}

Generalizable to residential and work settings, with the exception of total institutions where freedom is limited. 


\subsection{Self-identity and the reflexive project of the self}

The notion of self-identity is employed a great deal in this study. Although the study maintains Giddens' notion, it also develops four ways to analyze self-identity. These operationalizations may be useful to other researchers.

The first of these four methods assesses self-perceived changes in self-identity. It asks respondents five questions: Have you had to change or adapt? Does living here affect the way you see yourself? What do you think about the use of the word "residents"? What do you think about everyone calling each other by their first name? Can you live the way you want? The intent of these questions is to tap respondents' perceptions and theories about self-identity (narrative analysis task \#2), and to ask them to describe self-identity changes, such as the adaptation process. These questions focus on respondents' explicit (conscious) understanding of the reflexive project of the self, including conditions, causes and sequencing.

There is considerable variability in typical answers, suggesting that these five questions tap various elements of self-identity: for example, $64 \%$ said they had to adapt a small amount; $48 \%$ said they notice no change in how they see themselves; $95 \%$ agree with calling people residents and using first names; and $83 \%$ feel they can live as they like with no restrictions from Lakelands. Given this variability, the final question, "Can you live as you wish?" asks people to sum up their situation. This method could also be adapted to other settings such as workplace and residential organizations.

In addition to these questions, the study uses a second method to assess selfidentity and the reflexive project of the self. This method uses narrative analysis 
(thematic and structural analysis) to determine how self-identity changes over time. Since Giddens defines narrative as biography, changes in people's stories point to the ways self-identity changes. This approach describes respondents' explicit and implicit (subconscious) understanding of the reflexive project of the self. As well, it identifies conditions, causes, sequencing and processes: how and why various conditions affect self-identity, including people's reflexive relationship with the organization (narrative analysis task \#1).

In addition to narrative analysis, the study uses a third method, one that assesses variability in self-identity narratives: typical, contrasting or discrepant narratives. This method is useful in a number of ways: one resident's narratives can be compared to another resident's narratives (narrative analysis task \#3); narratives can be described qualitatively and quantitatively; and, contrasting and discrepant narratives can point to the limits of Giddens' notions. Although this method is applied to 10 interview questions, it could be applied to any number of interview questions.

In addition to measuring narrative variability, the study uses a fourth method - a quantitative measure of self-identity change - specifically, the correlation between years resident (number of years living at Lakelands) and typical narratives. This assesses the extent to which an average individual's narratives come to resemble group narratives representing assimilation into Lakelands' community and its values.

Since Giddens' notion of self-identity is complex, these four methods help to ground the notion in an empirical reality. They triangulate information from one measure or method to another, thereby increasing validity (Yin, 2003). They tap explicit and 
implicit views; case level processes; comparative views; and, the reflexive relationship between self and organization. They complement each other and provide a wealth of information about a complex concept. This helps to ensure that the study captures the full meaning of self-identity and the reflexive project of the self. As well, these four methods are transferable. Not only can they be used to study self-identity in other residential settings (Conlon, Van Dyne, Milner \& Ng, 2004; Wilcox \& Holahan, 1976), they can also be used in work settings (Ashforth, 2000; Kreiner, Hollensbe \& Sheep, 2006; Leonard, Beauvais \& Scholl, 1999; Sluss \& 2007).

Although the study uses these four methods for exploring self-identity, the notions themselves - self-identity and the reflexive project of the self - remain unchanged. They are amenable to this research setting and seem to be amenable to most research settings. The key to their successful use is an analytical method, like narrative analysis, that is ontologically congruent with Giddens' notion of reflexivity (Miles \& Huberman, 1994; Riessman, 2008).

\subsection{Lifestyle}

In addition to operationalizing Giddens' notion of self-identity, this study examines the consistency of the lifestyle concept (narrative analysis task \#6), plus it extends the notion to include lifestyle fit and a leisure self-identity. The findings indicate that this notion is consistent with the data. Specifically, the notion is broad enough to incorporate two compatible ideas: lifestyle as a routinized set of practices, and lifestyle as consumption that defines self-identity (Giddens, 1991; Belk, 2003). When people move to Lakelands 
they are choosing a routinized set of life practices plus they are purchasing a commodity (Folts \& Streib, 1994) that defines self-identity (Laws, 1995) - a leisure self-identity. Communal lifestyle organizations often explicitly seek to create a leisure self-identity for residents. Although this notion of leisure self-identity is generalizable to communal lifestyle organizations it may also be generalizable to other types of organizations that attempt to create leisure lifestyles and self-identities for their members such as clubs.

In addition to creating the notion of a leisure self-identity, the findings extend Giddens' notion of lifestyle to include the idea of "lifestyle fit." This is an example of how informants' theories can refine Giddens' notions. Jessica talked about how people determine whether or not they fit Lakelands' lifestyle. Lifestyle fit is a calculation. People calculate whether the organization's lifestyle fits their lifestyle. People usually make this calculation before they move, however, they may also make it after they move. At any point in time, either side of the equation may change: the organization's lifestyle or the person's lifestyle. Lifestyle fit is a useful extension of Giddens' theory. It helps to explain how people choose lifestyle sectors, plus it considers the reflexive relationship between self-identity and organizations (Laws, 1995).

The notions of lifestyle, a leisure self-identity and lifestyle fit are generalizable to most residential (Biggs, Bernard, Kingston \& Nettleton, 2000; Laws, 1995) and work situations (Waring, 2008; Ferrell, 2004), with the possible exception of total institutions. Although people living in total institutions experience a lifestyle - a routinized set of practices - the underlying premise of choice is compromised in prison-like total institutions where people typically do not choose their lifestyle sector. They may be 
forced to move to a total institution, and they may not be able to leave when they wish.

\subsection{Bodily appearance}

One of the ways that people define self-identity is through their dress regimes or bodily appearance. At Lakelands people use dress to convey an upscale lifestyle and they resist dress regimes that reflect negatively on self-identity. At times, however, people wear outrageous costumes as a source of entertainment. To extend Giddens' notion of bodily appearance to fit this behaviour I developed the notion of identity switching - adopting new identities as a source of entertainment. Identity switching tests the boundaries of convention, albeit in ways that are socially acceptable.

The notions of bodily appearance and identity switching are generalizable to all organizational settings (Brewis, Hampton \& Stephen, 1997; Nencel, 2010; West, 1982), including total institutions where Goffman observed identity switching: instances where people in prison theatre productions wore costumes (Goffman, 1961, p. 99).

\subsection{Organizational sequestration}

The notion of organizational sequestration proved useful in this study. This study noted four extensions to Giddens' theory: concentration of existential issues; Third versus Fourth Age organizations; enhanced and stigmatized self-identity; and a language of sequestration.

First, the findings extend the notion of organizational sequestration to include the concentration of existential issues. This recognizes that sequestration has ramifications 
for the people living in these organizations. Specifically, sequestration concentrates existential issues. People experience death and illness in concentrated form. This produces a more thoroughly reflexive project of the self and provides opportunities for meaningful self-actualization (Scherwitz, Pullman, McHenry, Gao \& Ostaseski, 2006; Ward, 2009). This notion is generalizable to organizations that sequester moral and existential issues such as death and illness.

Second, the findings extend sequestration to include divisions between Third versus Fourth Age organizations. Not all age-segregated residential organizations concentrate death and illness to the same degree. The burden differs in independent living residences, assisted living, and nursing homes. Blaikie (1999) argues that a new distinction between a Third Age marked by active retirement and Fourth Age marked by severe bodily decline, intensifies the taboo of death and illness. This intensification is reflected in organizational segregation of sequestered groups (Shippee, 2008). This notion is generalizable to residential settings for older persons.

Third, the study extends the notion of organizational sequestration to recognize that it can enhance and stigmatize self-identity (Goffman, 1963). Moving to Lakelands can influence self-identity in both negative and positive ways. Living at Lakelands can simultaneously diminish and enhance social status. Moving to Lakelands can make one feel old. It signals that one is now part of the "very old" group. On the other hand, Lakelands' upscale atmosphere signals that one is deserving of special attention, of being pampered. One is an affluent Third Ager, rather than a maligned Fourth Ager (Blaikie, 1999). This refinement is generalizable to persons living in age restricted communal 
lifestyle organizations. It may not be generalizable to other residential settings for older persons, such as nursing homes, since these organizations generally do not try to enhance self-identity in the way that communal lifestyle organizations do.

Fourth, this study extends the notion of organizational sequestration to include a language of sequestration. Organizational sequestration can influence language use (Williams \& Guendouzi, 2000). People's use (or non use) of certain terms may signal their awareness of sequestration, or the degree to which they feel free to move "in" and "out" of the organization. Perhaps the greater the perception of boundaries, the greater the likelihood a person may use language of sequestration. One might expect to see more frequent use of this language in reference to prison-like organizations, or to remote or isolated organizations like oil rigs, ships, or remote work camps. Therefore, this notion is likely generalizable to any boundaried residential or work setting, not just settings that sequester moral and existential issues.

\subsection{Life-planning}

The findings suggest that life-planning needs to be refined to take into consideration older persons' realities: age, ill health and a lack of lifestyle choices. Giddens defines life-planning as "the strategic adoption of lifestyle options, organised in terms of the individual's projected lifespan, and normally focused through the notion of risk" (Giddens, 1991, p. 243). Although this notion helps in understanding how older people make lifestyle decisions, it does not consider three realities common to older persons: potential loss of autonomy, limited lifestyle options, and a limited lifespan (Baltes, 1996; 
Bonnet, Gobillon \& Laferrère, 2010; Golant \& Salmon, 2004; Trottier, Martel, Houle \& Berthelot, 2000). As a result, older people may experience life-planning differently than younger people since they experience a different set of risks, and since they may be more aware that they are reaching the end of their life span. This notion is generalizable to older persons, irrespective of the setting.

\subsection{Fateful moments}

The findings extend the notion of fateful moments to create a wider notion called "crises." Giddens defines fateful moments as: "moments at which consequential decisions have to be taken or courses of action initiated" (Giddens, 1991, p. 243). Fateful moments disrupt routines and involve decisions that affect the future. They may raise existential questions and influence self-identity (Giddens, 1991, p. 131).

Informants mentioned a number of events that were psychologically disruptive, however, they do not correspond fully to the definition of fateful moments since they do not require decisions about the future. For instance, loss of possessions can be psychologically disruptive (Belk, 1988), however, this loss does not necessarily require a decision about the future. This notion is an example of how informants can help develop theory (narrative analysis task $\# 2$ - to identify informant theories).

In this study, experiences that are defined as crises, include fateful moments like death, severe illnesses, and moving, as well as disruptive events or experiences that create psychological distress such as care giver stress, financial crises, fights with family, loss of possessions including pets, and loss of volunteer work. The definition of crises 
could be further expanded to include experiences such being the target of gossip and bullying. The notion of crises includes fateful moments as well as other disruptive experiences that create significant or severe psychological distress. This study did not try to assess the degree of psychological discomfort associated with these crises, however, this could be refined in future research. Like fateful moments, the notion of crisis can be generalized to any organizational setting.

\subsection{Pure relationships}

In addition to creating a notion called crises, this study extends Giddens' notion of pure relationships in two ways: friendship and family may blur and death may shape friendships. First, at Lakelands, pure relationships can turn into family relationships. The line between friend and family becomes blurred - people who are friends can become like family. As well, some people become involved in romantic relationships that end in marriage. This notion is generalizable to most settings, however, there may be some limits in total institutions where the five conditions for forming pure relationships (Giddens, 1991) are not always present - privacy being one example.

Second, sequestered organizations can increase the risk that friends will be parted, due to illness and death. Fear of future loss may dissuade some people from forming friendships or alternatively encourage people to embrace new, or more friendships. When this occurs, the specter of death shapes friendships. I did not talk to anyone experiencing this problem at Lakelands, but the potential exists. This notion is generalizable to any organizational setting - residential or work related. 


\subsection{Power}

In addition to using Giddens' notion of power, the study identifies conditions shaping power - individual characteristics that can support and weaken agency vis-à-vis organizations. Power is defined as "the ability to get things done, and the ability to achieve one's wishes, even against the desires of others (Tucker, 1998 p. 82). The notion of power is used throughout this document to explain a series of statistical relationships that represent the reflexive relationship between residents and the organization. Although the notion of power is generalizable to all contexts, the evidence suggests that some residents experience organizational life differently than others (narrative analysis task \#3 - to identify similarities and differences between residents). Some characteristics seem to support agency and others seem to weaken agency. These characteristics include age, marital status, extroversion, health, family location, crises, and experience living in organizations. This is discussed in further detail in the next chapter (see Table 17.3). The notion of power is generalizable to other organizational settings.

\subsection{Emancipatory politics and life politics}

The notions of emancipatory and life politics were useful in this study. Neither concept was refined or extended. The notion of emancipatory politics comes from radical, liberal and conservative theory on how to "release underprivileged groups from their unhappy condition, or to eliminate the relative differences between them" (Giddens, 1991, p. 211). Emancipatory politics assumes power is hierarchical. In organizational settings, emancipatory politics relates to rights and fairness, such as the right to independence, 
autonomy and fair treatment. This notion is generalizable to all types of organizational settings. In democratic societies, even total institutions are obliged to guarantee certain basic domestic and international rights and freedoms to organizational members (Correctional Services of Canada, 1997).

Life politics assumes that power is generative, reflexive and transformative rather than hierarchical and causal, as in emancipatory politics. It focuses on personal decisions with moral or existential overtones: "It is a politics of self-actualisation in a reflexively ordered environment, where the reflexivity links self and body to systems of global scope" (Giddens, 1991, p. 214). To exist, life politics requires basic social, political and economic emancipation, however, emancipation does not necessarily lead to life politics.

The radical transformation that has occurred in seniors housing since the $1960 \mathrm{~s}-$ the creation of communal lifestyle organizations for example - constitutes life politics in action. These organizations promote principles of life politics - the opportunity and freedom to form a self-identity of one's own choosing.

Communal lifestyle organizations also raise life political issues, especially the issue of organizational sequestration and segregation. Gated communities are often criticized for being exclusionary (Canadian Gated Communities Research Project, 2006) or even racist (McHugh \& Larson-Keagy, 2005; Low, 2001):

This retreat to secured enclaves with walls, gates, and guards materially and symbolically contradicts American ethos and values, threatens public access to open space, and creates yet another barrier to social interaction, building of social networks, as well as increased tolerance of diverse cultural/racial/social groups 
(Low, 2001, p. 45).

There are arguments for and against this point of view (Manzi, 2005).

Organizational sequestration also raises the life political issue of segregating Third Agers from Fourth Agers. This issue is not discussed in the literature, however, it can be inferred from Blaikie's (1999) work. As segregation intensifies within communal lifestyle organizations, or between communal lifestyle organizations and nursing homes, Fourth Agers' lifestyle choices are increasingly limited. Fourth Agers are being encouraged to move to assisted living and nursing homes. This has emancipatory and life political implications for Fourth Agers, and can affect life chances. For instance, nursing homes, in Ontario and British Columbia, have been criticized for becoming sites of increasing fear and violence because people with violent dementia or other illnesses are being placed in nursing rather than in more expensive psychiatric beds, and because facilities are understaffed and staff do not receive sufficient training (Canadian Broadcasting Corporation Marketplace, 2007a, 2007b).

That communal lifestyle organizations promote as well as raise life-political issues points to the flexibility of this notion. As with emancipatory politics, the notion of

life politics is generalizable to most organizational settings. Its application, however, may be somewhat limited in total institutions, where choice and self-actualization are limited.

\subsection{Gaps in the theory}

One of the tasks in determining analytic generalizability is to identify gaps in Giddens' theory (narrative analysis task \#7) - both notions that are not useful and areas where 
additional theory is required. Of the theoretical notions discussed in this study, all were useful. Some such as the life span, authenticity, rites of passage, and the trajectory of the self, do not appear in this document, however, they were used as background to the analysis. This suggests that other researchers may find these notions useful.

The study identifies two gaps in the theoretical framework - areas where additional theory would be useful. First, the discussion of a communal lifestyle organization typology points to the need for a theory of purposeful communities, especially utopian-like communities designed to achieve social objectives (McHugh, 2003). Although Giddens' micro-macro focus helps to fill the gap, it would be helpful to have a more refined theory: for example, information on the history of utopian organizations, how they relate to capitalism, plus examples of organizational strategies could be informative (Peterson, 2005; Sutton, 2004). Such a theoretical extension would help to explain the relationship between social goals, the self, others, the family, community and society, and be congruent with Giddens' theory.

The discussion of the communal lifestyle organization typology also points to a second gap in the study's theoretical framework - a theory of customer service. Although the study relies on popular theories of customer service, a more sophisticated approach would be useful (Bitner, Booms \& Tetreault, 1990; Conlon, Van Dyne, Milner, \& Ng, 2004; Mohr \& Bitner, 1991). An example would be a theory, or theories of customer service that define customer service; discuss issues of power; link micro and macro-level issues like customer service, self-identity and organizational success (Ferrell, 2004); and consider space and time, such as the history of customer service and consumer culture 
(Belk, 1995) in North America.

\section{Summary}

This study builds on a small body of work that attempts to apply Giddens' theory of modernity and self-identity to aging (Everingham, 2003; Mellor \& Shilling, 1993; Powell \& Wahidin, 2005), to discourse analysis (Heracleous \& Hendry, 2000), to consumer research (Jafari, 2008; Wattanasuwan \& Elliott, 1999), to organizations in general (Webb, 2004), and to other empirical settings (Askegaard, Gertsen \& Langer, 2002; Barrett \& Walsham, 1999; Gross \& Simmons, 2002; Plumridge \& Thomson, 2003). In building on this work, this study makes a number of new contributions to the literature. This study proposes eleven extensions or refinements to Giddens' theory. This includes four methods for measuring and analyzing self-identity, plus a number of new concepts such as lifestyle fit and identity switching. In contrast to Plumridge and Hendry (2000) who conclude that their qualitative longitudinal data sets quickly outstripped Giddens' selfidentity theory, this study found Giddens' theory to be useful, especially when contrasted with Goffman's total institution theory, and when combined with the literature on aging.

This section suggests that Giddens' theory is generalizable to people living and working in most organizational settings. Giddens' work has all of Miles and Huberman's hallmarks of good theory (1994, p. 144). It is relevant to communal lifestyle organizations; it is useful for explaining, predicting, and interpreting what is going on; it fits or can be fitted to the data; and, it can be modified. 


\section{CHAPTER SEVENTEEN}

\section{Discussion of the findings}

This section summarizes and discusses the study findings related to the research questions, the communal lifestyle organization typology, and the analytical generalizability of Giddens' theory.

This section highlights nine key findings: 1) knowing respondent characteristics helps in predicting agency vis-à-vis organizations; 2) communal lifestyle organizations like Lakelands organizationally sequester Third Agers from Fourth Agers; 3) organizational sequestration produces a language of sequestration that is symptomatic of a sequestered self-identity and weakening agency; 4) organizational sequestration concentrates existential issues; 5) communal lifestyle organizations can negatively affect self-identity and also produce positive transformations of the self; 6) people can live as they like in at least some communal lifestyle organizations; 7) over time, people living in communal lifestyle organizations can experience an assimilation effect; 8) democracy is possible in communal lifestyle organizations; and, 9) Giddens' modernity and selfidentity theory is generalizable to all residential settings. This section interprets these key findings, explains how they build on the existing literature, and discusses this study's unique contributions to the literature. The chapter begins with a discussion of the findings related to each of the four research questions: Who am I? Am I what I consume? How do 
I describe the organization? and Who am I when I live in an organization?

\section{Who am I?}

This section summarizes and discusses findings related to the "Who am I?" question. As Riessman (2008) points out, the question in social constructivist research is not 'Who am I?', which is a functionalist view of self-identity, but rather "when, where and how I am?" (Riessman, 2008 p. 37). Therefore, I asked respondents about their background as well as conditions prior to the move, and at the time of the study. These conditions include reasons for moving and the decision-making process (i.e., life-planning). A summary of key findings is shown in Table 17.1.

\section{Table 17.1. Key findings related to the question: Who am I?}

Lakelands is inhabited by "older seniors" in good to moderate health wanting help with household tasks.

Most have family nearby but do not want to be a burden on their families.

Most men are married whereas most women are widowed.

Most people move from gated communities, condominiums and apartments.

Knowing a person's characteristics helps in predicting agency vis-à-vis residential organizations (management and other residents).

The findings indicate that respondents are mainly retired white middle class Canadians. Two thirds are women. Most men are married (90\%) whereas most women $(80 \%)$ are widowed or divorced (Table 3.11). The average age is 85 (Table 3.12). Most respondents are in good to moderate health (Table 4.4). Two thirds are extroverts. 
People's reasons for moving are similar to findings reported in the empirical literature (Erickson, Krout, Ewen \& Robison, 2006; Gibler, Moschis \& Lee, 1998; Groger \& Kinney, 2006; Krout, Moen, Holmes, Oggins \& Bowen, 2002; Nelson, 2001; Stimson \& McCrea, 2004). Factors that led to the move to Lakelands included: loneliness, need for housekeeping support and transportation, and worry about becoming a burden on the children (Table 4.8). Most respondents (73\%) have family living nearby (Tables 4.2 and 4.3 ). The majority moved from a gated community (43\%) or a condominium/apartment (27\%). Seventeen percent came from the family home (Table 4.7). People's planning and decision-making styles vary (Lovegreen, 2007) from proactive to reactive. A proactive style involves moving to avoid loss of autonomy, to control lifestyle, and to enjoy life while a reactive style relates to being obliged to move due to a health crisis (Lovegreen, 2007). Respondent's characteristics seemed to be related to agency as discussed below.

\subsection{Respondent characteristics and agency}

This study identified a number of significant statistical correlations between respondent characteristics and agency. Chapters 6 to 14 present these findings. This section groups these associations by individual characteristics: age, marital status, extroversion, health, family location and experience living in organizations. The objective is to illustrate how personal characteristics are associated with organizational experiences. Appendix M lists all statistical relationships identified Chapters 6 to 14 grouped in by respondent characteristics. 
Table 17.2 provides a summary of key associations and an interpretation of the meaning of the statistical relationships. Most of these relationships can be explained by Giddens' (1991) theory, or by theory and findings from the literature. As described in Chapters 6 to 14, multiple interpretations may be hypothesized for most relationships, however, Table 17.2 includes the most consistent and parsimonious interpretation of these findings.

Although Table 17.2 describes a complex network of relationships, patterns emerge. Many of these patterns appear to related to agency vis-à-vis organizations. For instance, Table 17.2 indicates that advancing age produces typical narratives. Since typical narratives may be an indicator of declining individuality, this would suggest that advancing age predicts weakening agency.

As advancing age seems to predict weakening agency, so does being unmarried. If a person is married they are less likely to use a language of sequestration, such as "in here/outside," than if they are unmarried. Language of sequestration may be an indicator of weakening agency since it suggests that a person is sequestered or separated by boundaries from the "outside" world - boundaries that limit participation in society. Since using this language seems to indicate weakening agency, being married may enhance agency.

Extroversion also seems to predict agency. Extroverts are more likely than introverts to call Lakelands "home". Using the word "home" suggests a sense of ownership or having private space. This sense of ownership, or having private space may be related to agency. If so, then extroversion seems to predict agency. 
Table 17.2. Correlations with respondent characteristics

$A G E$

The older a person is, the more their narratives (and self-identity) resemble group views. Conformity increases. There is an assimilation effect (See Table 14.1).

MARITAL STATUS

Being married reduces the likelihood of a person using a language of sequestration ("in here/outside"). (See Table 6.6).

EXTROVERSION

Extroversion increases a sense of ownership - having private space (i.e., calling Lakelands "home"). (See Table 6.3).

HEALTH

The better a person's overall health the more likely they are to have a sense of ownership - having private space (i.e., calling Lakelands "home"). (See Chapter 6). Good eyesight and memory contribute to self-actualization (i.e., respondents are more likely to say they can live as they like). (See Table 12.4).

Poor hearing increases the likelihood of narratives (and a self-identity) that resemble the group. There is an assimilation effect. (See Table 14.1).

FAMILY NEARBY

Having family nearby increases self-actualization (i.e., respondents are more likely to say they can live as they like). (See Table 12.4).

ORGANIZATIONAL EXPERIENCE

The more residential organizations where a person has lived or worked:

- $\quad$ the more likely they are to use a language of sequestration (i.e., "in here/outside"). (See Table 6.7).

- $\quad$ the more likely they are to say their self-identity has changed (See Table 8.2).

The greater the number of years a person has lived at Lakelands:

- $\quad$ the more likely they are to use a language of sequestration (i.e., "in here/outside"). (See Table 6.7)

- the more likely they are to have narratives that resemble group narratives. This is an assimilation effect. (See Table 14.1). 
In addition to extroversion, good health (i.e., overall good health, good eyesight, memory and hearing) seems to predict agency. The better a person's "overall health" the more likely they are to call Lakelands "home" which may indicate a sense of agency. Similarly, good eyesight and memory increase the likelihood that a person will say they can live as they like at Lakelands. Living as one likes seems to indicate agency. The poorer a person's hearing the more their narratives resemble group narratives. Typical narratives seem to be an indicator of weakening agency. Therefore, good health (i.e., overall good health, good eyesight, memory and hearing) seems to predict agency and poor health seems to predict weakening agency.

As good health seems to predict agency, so does having family nearby. Having family nearby increases the likelihood that a person will say that they can live as they like. "Living as one likes" seems to indicate that a person has agency. Therefore, having family nearby seems to enhance agency.

As family nearby seems to be related to agency, increasing experience in residential organizations - prior residential organization experience and years resident seem to predict weakening agency. The greater the number of residential organizations in which a person has lived or worked, the more likely they are to use a language of sequestration (i.e., use the terms "in here/outside"), and the more likely they are to say their self-identity has changed. Using a language of sequestration, and feeling that selfidentity has changed seem to indicate weakening agency. Also, the longer a person has lived at Lakelands, the more likely they are to use a language of sequestration (i.e., "in here/outside"), and the more likely they are to have typical narratives - another indicator 
of weakening agency. Consequently, these relationships seem to suggest that increasing experience in residential organizations weakens agency.

To summarize, Table 17.2 indicates how personal characteristics are associated with certain organizational experiences. It helps in understanding how some personal characteristics seem to predict agency whereas others predict weakening agency. Ceteris paribus, these factors appear to operate in the following ways: advancing age and increasing experience in residential organizations weaken agency, whereas extroversion, family nearby and good health support agency. Table 17.3 summarizes these relationships.

These findings have a number of implications. First, the findings seem to indicate that living in a residential organization weakens agency. This applies to past or present experiences. The effect seems cumulative. This supports arguments in the literature than communal lifestyle organization shape and reform self-identity (Blaikie, 1999; McHugh, 2003; Katz, 2005). Also, the relationships in Table 17.2 indicate that the greater the experience living or working in residential organizations, the greater the likelihood that self-identity shifts: one notices identity, personality or attitude changes; one increasingly adopts common viewpoints - the "me" converges towards the "we" - and one tends to uses a language of sequestration. 
Table 17.3. Who am I and agency

\begin{tabular}{ll}
\hline \multicolumn{1}{c}{ Support Agency* } & \multicolumn{1}{c}{ Weaken Agency* } \\
\hline Married & Not married \\
Extroversion & Introversion \\
Relative youth & Advancing age \\
Family nearby & Family not nearby \\
Good health & Poor health \\
Minimal experience in residential & More experience in residential \\
organizations & organizations \\
\hline
\end{tabular}
Note. ${ }^{*}$ Ceteris paribus.

A second implication of these findings relates to combinations of variables. What happens when these characteristics are combined? When people experience clusters of variables that weaken agency - advanced age combined with widowhood and poor health - agency may be significantly weakened vis-à-vis the residential organization. This suggests that widows or widowers living in assisted living or nursing homes are likely to experience weakened agency. At Lakelands, some people have characteristics that tend to weaken agency, however, most possess at least some factors that support agency. Most residents are extroverts in good to moderate health with family living nearby.

A third implication of these findings is that if family nearby supports agency then Snowbirds may experience weakening agency since they usually leave their families for the winter. Van den Hoonaard's (2002) empirical study of a Florida Retirement Community seems to support this interpretation. She found that Snowbirds, widows and newcomers tend to be marginalized in Florida retirement communities. 
In sum, the study builds on the literature and makes a number of original contributions: it identifies significant statistical relationships and it points out the implications of a person experiencing clusters of variables that support or weaken agency.

\section{Am I what I consume?}

This section summarizes and discusses findings related to the question "Am I what I consume?" A summary of key findings is shown in Table 17.4.

\section{Table 17.4. Key findings related to the question: Am I what I consume?}

Lakelands shapes people's lifestyle and self-identity before and after the move.

Respondents continuously assess lifestyle fit.

Communal lifestyle organizations like Lakelands organizationally sequester Third Agers from Fourth Agers.

Giddens (1991) and Laws (1996) argue that there is a reflexive relationship between self-identity and social environments, and that consumption choices define selfidentity. People make housing choices based on their lifestyles and these lifestyle sectors shape self-identity (Laws, 1996). This study finds support for Giddens' (1991) and Laws' (1996) theories.

The findings indicate that respondents select Lakelands based on their selfidentity and that Lakelands shapes their lifestyle and self-identity before and after the 
move (Laws, 1996). Before moving, people take steps to assure themselves that Lakelands' lifestyle "fits" their lifestyle. They compare places. To assess lifestyle fit they evaluate things like the physical appearance of the building and gardens, social activities, the number of walkers, and types of residents, staff and social activities. When asked if appearance was a factor, $81 \%$ said yes and $19 \%$ said atmosphere was important. Some said they did not want to move to Lakelands because of the number of walkers they saw. To make the move, and to accept walkers, they had to shift their self-identity.

Not only do some people have to shift their self-identity before the move, some must shift self-identity after a move. For instance, some people complained that Lakelands has changed, that it is starting to resemble an institution. This suggests they no longer feel they are consuming the "right lifestyle" or self-identity (McHugh, 2003). If the disconnect becomes too great, people may move (Ferrell, 2004).

The notion of consuming the "right lifestyle" has implications for consumer choice and segregation. Although I did not ask people what they thought about walkers, $40 \%$ of respondents either mentioned an increase in walkers, or an increase in the number of disabled people living at Lakelands, or both. This suggests respondents are concerned about the presence of Fourth Agers in a Third Age organization like Lakelands. This preoccupation is supported by a Lakelands' manager who said that people living at Lakelands do not want to be reminded of where they may be in a few years time: Manager: We have found that the active senior does not want to be reminded necessarily where it, they're going to be in five or ten years in terms of health. So they don't always want to be around a client who's midway through a fairly serious health needs. Right, so trying to mix everybody into one environment, we feel isn't the right way to go. 
This concern for consuming the right self-identity supports increasing segregation amongst sequestered organizations based on health status. This finding is supported by a number of empirical studies in retirement communities. Not only do residents favour segregation based on health status (Jones, 1994; Shippee, 2008; Streib \& Metsch, 2002), 1994), they may also voluntarily conform to these norms by frequently leaving the organization when their health no longer fits the organizational lifestyle:

The residents of Sun City Center appear to be willing to move, when the environment no longer meets their needs, rather than using the services or modifying the physical environment to achieve congruence between the demands of the activities-of-daily-living and the capabilities of the residents. These selfimposed norms preserve the community's "healthy, active life style" image (Jones, 1994, p. abstract).

This points to an important conclusion. Just as Lakelands organizationally protects society from the moral and existential issues raised by old age (Giddens, 1991), it performs a similar service for its residents. Designed for persons in the Third Age persons in good health - Lakelands organizationally sequesters Third Agers from Fourth Agers - people experiencing severe disability and illness (Blaikie, 1999).

Consumer preferences and societal taboos like death, illness and aging (Blaikie, 1991; Giddens, 1991) help explain segregation by health status within communal lifestyle organizations. These finding have implications for continuing care communities, which co-locate Third and Fourth Agers (Shippee, 2008). The organizational types in the communal lifestyle organization typology are often co-located, and people move from one type of housing to another depending on their health. Shippee's (2008) study of a continuing care retirement community found that boundaries between levels of care can 
be stigmatizing for Third Agers, who have higher status in these communities and may not like living close to Fourth Agers.

As well, these findings have implications for the idea of aging in place. Residents may have difficulty aging in place - difficulty staying in a communal lifestyle organization of their choice (Frank, 2002). If their health problems outstrip the services that are offered, and if they cannot purchase these services, they will probably be asked to leave.

In sum, the research question "Am I what I consume?" can be answered in the affirmative. The findings suggest that people's consumption choices at Lakelands are designed to define self-identity (Belk, 1988) and continuously shape self-identity.

\section{How do I describe the organization?}

This section summarizes and discusses findings related to the question "How do I describe the organization?" When new organizational models appear, people may find it difficult to describe these organizations (Czarniarskwa, 1997; Wallenmac and Sims, 1998). To determine whether or not respondents make distinctions between Lakelands and former institutional models, I asked respondents to describe Lakelands. A summary of key findings is shown in Table 17.5. 
Table 17.5. Key findings related to the question: How do I describe the organization?

Management and residents describe Lakelands as a communal lifestyle organization.

Explicit and implicit language habits are not always congruent with Lakelands' noninstitutional upscale lifestyle model.

Organizational sequestration produces a language of sequestration that is symptomatic of a "sequestered" self-identity and weakening agency.

The findings indicate that when employing explicit language (i.e., making a conscious effort to describe Lakelands) residents and management described Lakelands as a communal lifestyle organization, although some residents said it is beginning to resemble a nursing home. At times, explicit and implicit language are at odds. Management's use of the word "facility," which is a common term for nursing homes, is not in keeping with Lakelands' upscale non-institutional character. This suggests that in the seniors' housing industry, implicit language may lag behind explicit conventions.

In addition to the word "facility," there are other gaps between implicit and explicit language. In analyzing resident transcripts I found that some respondents call Lakelands "home" whereas others do not. Also, some residents and management use what I call a "language of sequestration" - implicit language conventions historically used to describe life in institutions (Williams \& Guendouzi, 2000). This language uses terms like "in here" and "on the outside" to convey the experience of being sequestered "in" an organization, or being separated by boundaries from the "outside" world.

Since Giddens says that self-identity is reflected in our narratives, these language conventions have implications for self-identity. Use of the word "home" conveys the 
message that "one belongs" - or that one has private space at Lakelands that is distinct from Lakelands' public or common spaces. In contrast, people who call Lakelands “a place" may perceive that they are living in an organization or institution - a public place. Similarly when people use the terms "in here" or "on the outside" they are describing Lakelands as a sequestered place. Perhaps they perceive they are being separated from the "outside" world by boundaries - boundaries that limit their participation in society. These findings suggest that organizational sequestration - even in communal lifestyle organizations - produces a language of sequestration. Although terms like "in here," "inmate," "incarcerated," "on the outside" are often used in reference to prisons, these terms, albeit fewer in number, are in use at Lakelands and probably other communal lifestyle organizations, as Williams and Guendouzi's (2000) empirical research also suggests.

This raises the question, why does a language of sequestration employed in prisons seem more rich and varied than the terms used at Lakelands? Even naming conventions like "inmate" reflect a sequestered identity. Is it because prisoners, having less freedom to cross boundaries than at Lakelands, perceive themselves as being more cut off from society than people at Lakelands? At Lakelands, only certain persons use this language, suggesting that it is something about their situation that contributes to this boundaried conceptualization. As Tables 17.2 and 17.3 indicate, people who use the word "home" tend to have characteristics that support agency - they are extroverts and/or have good overall health - whereas residents who use a language of sequestration tend to have characteristics that weaken agency - they are unmarried and have more experience living 
or working in residential organizations than other residents. These findings build on Gould (2009) and Williams and Guendouzi's (2000) work. They make an original contribution to the literature by observing that these implicit language habits vary with residents' characteristics, plus these characteristics are related to agency.

In sum, this study found that there are differences in explicit and implicit language used to describe Lakelands. In exploring these differences, the study found that some implicit terms reflect Lakelands' sequestered nature - they convey a "sequestered identity." These findings also shed light on why this language may rarely be found in some communities, or why some people use this language whereas others do not. The findings also suggest that it will take time for new language habits to be created around communal lifestyle organizations.

\section{Who am I when I live in an organization?}

This section summarizes and discusses findings to the question "Who am I when I live in an organization?" This focuses on the central issue in this study - Can people develop a self-identity of their own choosing when they live in an organization? Who does the organization want them to be? Do people become submerged in a group identity? This section is divided into eight subsections: adaptation, self-identity change, naming conventions, living with others, rules and conventions, living as one likes, suggestions for change and assimilation. These subsections correspond to ten major interview questions. 


\subsection{Adaptation}

This section summarizes and discusses findings for the interview question "Have you had to change or adapt to Lakelands?" Table 17.6 show a summary of key findings.

\section{Table 17.6. Key findings regarding adaptation}

\section{Interview question: Have you had to change or adapt?}

Organizational sequestration concentrates existential issues.

Adaptation is an ongoing project.

Concentrated exposure to death and illness can shape the self, producing meaningful self-actualization and provide an opportunity for the growth of wisdom.

Both Goffman (1961) and Townsend (1962) note that people experience a period of adaptation when they move to a residential organization. Goffman notes that adaption influences self-identity. The present findings indicate this. Lakelands seems to confirm a new resident's self-identity (Van Maanen, 1987) rather than stripping self-identity, as in total institutions (Goffman, 1961; Townsend, 1962). Despite this, some people reported having to make changes to adapt: none or small changes $(64 \%)$, moderate changes $(18 \%)$ or large changes $(18 \%)$. Newcomers reported more severe problems than long-term residents. This suggests that time solves initial adaptation problems (see Table 7.5). Respondents mentioned four factors that affect adaptation: Lakelands' services and people, individual self-control, fateful moments and situational factors (MacNeill, 1991). Of these four factors people tend to emphasize self-reform (Giddens, 1991). Residents consider being active, competent, and working on the self as important 
(Begovic, 2005; MacNeill, 1991). Respondents also emphasize that Lakelands - its transportation services, gardens and friendly people - help newcomers adapt.

Although there is an initial adaptation period, adaptation never ends at Lakelands. The reflexive project of the self is an ongoing project. While new residents adapt to the move, long-term residents adapt to new people, the departure, illness or death of longterm residents, or their own illness. Although Lakelands is a Third Age organization (Blaikie, 1999), residents face a greater number of existential issues than people living in age-integrated environments. Age sequestration concentrates illness and death - events which must be psychologically processed within the self.

These findings build on the literature and make an original contribution to our understanding of life in residential organizations. Previous empirical research calls attention to high death and illness rates in residential organizations (Katz, 2005; Townsend, 1962). What is new in this study is the extension of Giddens' notion of sequestration to include the psychological consequences for residents.

Specifically, Giddens (1991) argues that the institutional sequestration of experience protects society from moral and existential issues. This study explores the consequences of this situation - concentrated death and illness in sequestered organizations and the need to process existential issues "within the psychological field of the self" (Giddens, 1991, pp. 167-168). In being continually exposed to death and illness, a resident's ontological security is frequently challenged. The reflexive project of the self must be continually revised, and sometimes in fundamental ways (Giddens, 1991).

Concentrating existential issues may have other consequences. It may discourage 
friendships, or it may encourage people to embrace new, or more friends. Although I did not meet anyone who talked about this phenomenon, Jackie did mention that death shapes relationships, although she did not expand on this point.

In addition to shaping relationships, concentrated death and illness may create a greater zest and joy for life. Although death can produce depression, as a number of residents pointed out (Henrietta, Rennie), Lakelands is not all "doom and gloom" (Jackie). At Lakelands people appear happy. Perhaps regularly facing death makes one more aware of one's limited life span, as well as the need to make the most of one's life to focus on what is important, as Jackie says.

In addition to creating a zest for life, experiencing concentrated existential issues may explain why some people said they have become more accepting and supportive of others. A number of respondents said that since moving to Lakelands they have become less selfish and more tolerant of others (see Table 8.4). A number of residents also talked about the care and support that they give, and receive when someone has experienced a loss (e.g., Charlotte, Marlene, Henrietta, Jackie, Victoria, Frances). Perhaps having experienced loss, one recognizes the need to comfort others. Perhaps one feels more able to provide support. Having shared the experience of loss, perhaps one becomes more aware of what a person in grief might need.

All of these consequences point to a burden that is being placed on "the psychological field of the self" (Giddens, 1991, pp. 167-168). People must process more grief than if they lived in an age-integrated community. These consequences also point to the positive effects of being exposed to a higher than normal number of existential issues. 
There are opportunities for meaningful self-actualization (Giddens, 1991) and the growth of wisdom (Nielsen, 1992), opportunities that might not exist to the same degree in an age-integrated community.

\subsection{Self-identity change}

This section summarizes and discusses findings for the interview question "Does living here affect the way you see yourself?" A summary of key findings is shown in Table 17.7.

Table 17.7. Key findings regarding self-identity change

Interview question: Does living here affect the way you see yourself?

Communal lifestyle organizations like Lakelands can negatively affect self-identity and also produce positive transformation in the self (e.g., blossoming and love).

Positive changes outweigh negative changes.

Lakelands strives to maintain or enhance self-identity.

A number of researchers (Blaikie,1999; McHugh, 2003; Katz, 1999) talk about retirement communities creating opportunities for remaking aging identity through the adoption of consumer lifestyles, active retirement, and by dislocating home from local space and family. This study found evidence that self-identity is remade in both positive and negative ways at Lakelands. When I asked respondents if living at Lakelands had affected the way they see themselves, about half reported no change, whereas the other half reported changes. Those who reported changes talked about feeling old, feeling good 
or proud, and feeling happier or less selfish.

The study identifies factors that are associated with a lack of reported change, and with a reported change in self-identity. Persons with a strong ego, an unchanged lifestyle, or a functionalist view of the self seem less likely to report changes in self-identity. In contrast, the greater the number of crises a person experienced before the move, and the greater the number of previous experiences in residential organizations, the more likely a respondent reported changes in self-identity. These factors point to the power of crises and residential organizations to produce noticeable changes in self-identity.

Respondents who notice changes, talk about the ways in which they have changed - feeling old now, for example. Although living in an age-restricted community can negatively influence self-identity - make one feel old - Lakelands can also make people feel better about themselves. This builds on a number of empirical studies that suggest a move to a communal lifestyle organization can bring happiness and new purpose to life (Begovic, 2005; Grant, 2007). These results also support Giddens' (1991) prediction that although society's less powerful tend to be subject to sequestration, organizational sequestration does not necessarily result in disempowerment:

... it would be wrong to understand the sequestration of experience as allenveloping and homogeneous, which it is not. It is internally complicated, throws up contradictions, and also generates possibilities of reappropriation (Giddens, 1991, p. 167).

At Lakelands some people reported a radical positive transformation in selfidentity - a blossoming of sorts. Examples include: becoming social (Andy's wife); finding friendships that bring happiness (Rosemary); learning to love people (Victoria); 
finding support and love from residents and staff (Henrietta, Victoria); and being emotionally healed from the effects of grief:

Charlotte: Because you'll notice some people that'll move in here that have lost their partner. And it's hard. It's hard both ways, and then they move into something like this, but eventually, after a while, you notice such a change in them, because of the, I guess it's the fellowship or the friendship that they find in here.

These findings regarding positive, and sometimes radical transformations in the self raise the question "why has this come about?" Could structural change be a contributor? Communal living, as it exists in communal lifestyle organizations, represents a significant structural change from nuclear family living. Communal lifestyle organizations create a setting where positive relationships between people can developrelationships that can be an antidote to the isolation and anomie that can come from nuclear family living (as Rosemary's case illustrates). Perhaps this structural shift is at the root of many positive transformations in self-identity reported by respondents.

Communal living by itself is not, however, sufficient for positive, and sometimes radical transformations in the self. People live communally in total institutions. Therefore, a communal living structure explains only part of the puzzle. This suggests that other factors may be equally important such as humane, caring relationships between people, or perhaps a relatively equal power relationship between management and residents. This last factor - equal power relationships - is supported by Giddens' theory, which would predict that equality in personal relationships is essential for self- 
determination:

Powerlessness experienced in a personal relationship may be psychologically more damaging and consequential than powerlessness felt in relation to more encompassing social systems. Of course these may feed into each other in various ways (Giddens, 1991, p. 193).

These findings also support the literature on aging identities in retirement communities. This study's micro-level data on negative and positive changes to selfidentity complement the literature, which tends to emphasize the implications of macrolevel concerns such as consumerism, active retirement policies, and the growing disembeddedness of home from local spaces (Blaikie,1999; Grant, 2007; McHugh, 2003; Katz, 1999; Laws, 1996; Phillipson, 2007).

In sum, while some respondents reported no change in self-identity, others reported noticeable changes, some of which are positive and some of which are negative. Overall, self-identity at Lakelands is either generally maintained or enhanced.

\subsection{Naming conventions}

This section summarizes and discusses findings for two interview questions "What do you think about everyone calling each other by their first name?" and "What do you think about the use of the word residents?" A summary of key findings is shown in Table 17.8. 
Table 17.8. Key findings regarding naming conventions

Interview questions: What do you think about everyone calling each other by their first name? What do you think about use of the word "residents"?

Residents agree with these conventions and the identity, organizational status and ways of thinking they convey.

Naming conventions are statistically associated with self-actualization:

- A respondent who said the term "resident" is fine is more likely to say they can live as they like at Lakelands (Table 12.4).

- $\quad$ A respondent who said that first names are fine is also more likely to say they can live as I like at Lakelands (Table 12.4).

Townsend (1962) and Davies (2001) argue that residential organizations use names to convey something about people's organizational status and identity. Organizations influence self-identity in subtle ways - offering preferred ways of viewing the world or conceptualizing problems (Gubrium \& Holstein, 2008).

To explore this issue I asked respondents what they thought about these two naming conventions. Respondents (95\%) said they like being called "residents" and they like being called by their first name. They like the friendliness and social equality that first names imply. As well, from a practical point of view, they cannot suggest a better word to use than "residents" to describe persons living at Lakelands. These findings suggest that respondents agree with the identity, organizational status and ways of thinking these naming conventions convey.

In addition to building on the literature (Davies, 2001; Gubrium \& Holstein, 2008; Townsend, 1962) these findings make an original contribution by uncovering a relationship between Lakelands' naming conventions and self-actualization, or agency. 
There is a statistical correlation between being in agreement with Lakelands' naming conventions and being able to live as one likes. If a resident agrees with Lakelands' naming conventions, either the term "resident" or calling people by their first names, they are more likely to say that they can live as they like at Lakelands (see Table 12.4).

These findings have a number of implications. First, the finding that most respondents have never thought about Lakelands' naming conventions suggests that routines may be difficult to recognize or oppose (Gubrium \& Holstein, 2008). Further, they can have a subtle influence on organizational life and self-identity (Davies, 2001).

Second, this relationship may indicate that successful naming practices practices that people agree with and use - are an indicator of a cooperative relationship between management and residents. The findings may indicate that management has successfully interpreted and operationalized residents' preferred self-identities and lifestyles.

Third, it is possible that when companies successfully operationalize residents' preferred self-identities and lifestyles, this may contribute to commercial success. Ferrell (2004) argues that customers reward companies that confirm preferred self-identities: Research has demonstrated that consumers identify with organizations and may perceive an overlap between organizational attributes and their individual attributes. The concept of organizational identification is important because consumers often seek organizational images that are congruent with their selfidentity. Organizational disidentification may occur when individuals perceive a conflict between their defining attributes and the attributes defining the organization. This disidentification represents a separation of a person's selfconcept from that of the organization and translates into negative perceptions of the organization (Ferrell, 2004, pp. 127-128). 
In sum, naming conventions have implications for residents and management. These conventions may be associated with resident agency and self-actualization as well as the commercial success of a communal lifestyle organization.

\subsection{Living with others}

This section summarizes and discusses findings for two interview questions: "Would you prefer to eat in your apartment rather than eat in the dining room?" and "Do you have enough privacy at Lakelands?" Table 17.9 shows a summary of key findings.

\section{Table 17.9. Key findings regarding living with others}

Interview questions: Would you prefer to eat in your apartment rather than eat in the dining room? Do you have enough privacy?

Respondents like living with others.

People maintain existing friendships and develop new pure relationships.

People prefer to eat in the dining room.

Most people have sufficient privacy.

Management or staff occasionally transgress resident boundaries.

In North America, where nuclear family living is the norm, most people do not eat or socialize with non-family every day. Given this social norm, it is perhaps surprising that all respondents said they like living with others. People maintain existing friendships and develop new pure relationships (Giddens, 1991) with staff and residents. All of the conditions that Giddens identifies as being necessary for creating and 
maintaining pure relationships - privacy, mutual trust, reciprocity, common lifestyles and shared histories - exist and are promoted at Lakelands. As well, a number of people talked about how Lakelands feels like family. In other words, lines between pure relationships and kinship can blur at Lakelands.

Respondents described their fellow residents in positive terms. Although people do not always get along, conflict is not the norm at Lakelands. Twenty-three percent of respondents ( 7 persons out of 30 cases) have experienced conflict - gossip (cases $=3$ ), fights (cases $=2$ ) or falling out with people (cases $=2$ ). Although they reported conflict, most instances are minor and of short duration.

This climate of sociability is reflected in dining arrangements. Most people like eating in the dining room (82\%), except when sick (11\%). Of the 188 residents who lived at Lakelands at the time of the study, only two to three regularly ate in their apartments.

In communal living situations, privacy is important. Townsend (1962) and Goffman (1961) found that privacy is essential for maintaining self-identity. At Lakelands, most respondents said they have sufficient privacy (76\%). Although most people said they have enough privacy, both physical and emotional privacy can be transgressed at Lakelands. Some people reported instances of theft and gossip. Management routines such as housekeeping practices can also transgress residents' proprietary rights.

These findings point to the issue of boundaries between private and public spaces. Ideal communal lifestyle organizations establish clear boundaries between private and public space (see Table 15.1). Declining health has implications for these boundaries. 
The communal lifestyle organization typology (see Table 15.3) indicates that as resident health declines, reliance on management and staff services may increase (Lucas, 2002). This may lead to boundary transgressions. Perhaps the greater the frequency of boundary crossings by management and staff, as they deliver more services to residents, the greater the possibility of boundary erosion. Staff may forget to knock, they may leave doors open, or they may talk about residents' personal lives to others. Given that communal lifestyle organizations emphasize privacy, this represents a threat to the ideal model.

In sum, the findings build on the literature by providing micro-level data on what it is like to live with others. This contributes to a body of research that adopts an in-depth or ethnographic approach to the study of communal lifestyle organizations (Frank, 2002; Gould, 2009; Jacobs, 1974; Kontos, 1998; Williams \& Ylänne-McEwen, 2000).

\subsection{Rules and conventions}

This section summarizes and discusses findings for the interview question "Do you feel there are a lot of rules at Lakelands?" Table 17.10 shows key findings.

\section{Table 17.10. Key findings regarding rules and conventions}

Interview question: Do you feel there are a lot of rules?

Lakelands does not have too many rules.

Residents support active retirement.

Most people say they feel free to participate or not in Lakelands' activities.

When routines and social conventions become disconnected from Lakelands' customer service philosophy, or when staff and management become controlling, resident's selfidentity may be negatively influenced. 
Rules and social conventions provide clues to the question "Who does the organization want me to be?" They encourage desired behaviours and reflect organizational assumptions about self-identity (Goffman, 1961). In answer to this interview question, the majority of respondents said they support Lakelands' rules and social conventions. Ninety-six percent indicated that there are not too many rules.

Respondents also support important social conventions such as active retirement, which informs many of Lakelands' social norms such as being active, friendly, integrating newcomers, eating in the dining room and dinner time seating by the Maître $d$ '. Although active retirement is an important social norm, $47 \%$ percent of respondents emphasized that they feel free to participate or not in Lakelands' activities. Ten percent said they have felt pressured at some time in the past. That this pressure was short-lived suggests that people are largely free to choose to participate.

Although respondents emphasized that they have a choice in whether or not to participate, when organizational routines become disconnected from Lakelands' customer service philosophy, or if staff and management become controlling, resident agency may be compromised. This can negatively influence self-identity and compromise autonomy. The study found a number of examples of this: limits on dining room seating choices stemming from hosted dining room seating; staff speaking to family in an effort to encourage a resident to participate in activities; and housekeeping leaving apartment doors open, without negotiating this practice with residents.

The results also indicate that, for the most part, management and staff try to steer a course between the "rules" and resident preferences. Nonetheless, problems occur. A 
number of resident narratives, illustrate how difficult it can be to oppose, or change, management routines. When people do oppose, or try to break accepted management routines or social norms, they may risk being noticed.

Lakelands' rules and social conventions - like active retirement - are designed in an attempt to create a perfect community. The goal is to maximize life enjoyment and enrichment (Table 3.1) - to provide a setting conducive to a type of individual selfactualization. These findings support a body of empirical literature that argues that communal lifestyle organizations, strive for perfection. They "engineer" physical spaces and social life (Fitzgerald, 1986; Jacobs, 1974; Laws, 1995; Katz, 2005; McHugh \& Larson-Keagy, 2005). Jacobs (1974) observes that there is an social convention around "being nice" and "being friendly" in Fun City. People are reluctant to offend by talking about controversial topics such as religion and race politics. In a more recent study McHugh and Larson-Keagy (2005) note that retirement communities are characterized by perfectly manicured physical spaces and residents with uniform characteristics - for example uniformity in dress, occupation and political affiliations. This literature also relates how residents extol the benefits of these communities: their civility, friendliness, low cost, safety and beautiful landscapes. These positive virtues and benefits are repeated in numerous studies (Grant, 2007; Fitzgerald, 1986; Jacobs, 1974; Katz, 2005; Marans, Hunt \& Vakalo, 1984; McHugh, 2003). These research findings suggest that residents believe that these communities are an improvement over the alternatives - an objective that perfect communities strive to achieve. 


\subsection{Live as I like}

This section summarizes and discusses findings for the interview question "Can you live the way you want, free of restrictions form Lakelands?" A summary of key findings is shown in Table 17.11.

Table 17.11. Key findings regarding living as I like

Interview question: Can you live the way you want, free of restrictions from Lakelands?

People can live as they like at Lakelands.

Respondents suggest that poor health and limited transportation are key factors in not living as one wishes.

The study found a number of statistically significant correlations. A respondent is more likely to say they can live as they like:

- $\quad$ if they like being called a "resident" or by their first name (Table 12.4).

- $\quad$ the better their eyesight or memory (Table 12.4).

- $\quad$ if they have family living nearby (Table 12.4).

In answer to this question, most people said that either they can (83\%), or pretty much can (13\%) live as they like free of restrictions from Lakelands. Respondents reported positive experiences living at Lakelands: being comfortable and happy; having less work; having less worry; feeling protected and supported; having fun; having choices; and being autonomous and independent.

The study found five factors that are associated with being able to live as one likes. Only two of these factors are within Lakelands' control - Lakelands' naming 
conventions and Lakelands' transportation services. When respondents agreed with Lakelands' naming conventions (i.e., use of first names and calling people "residents") they were more likely to say they can live as they like (see Table 12.4). Respondents also mentioned that having transportation helps in being able to live as one likes (see Table 12.2). In particular, many respondents lamented the fact that they can no longer drive a car. A number of informants said that Lakelands' bus service helps fill this gap. Three factors outside Lakelands' control can increase people's ability to live as they like: having family nearby, having good eyesight and having a good memory (see Table 12.4). These are statistically significant correlations.

The findings point to the importance of physical freedom as a condition for being able to live as one wishes (see Table 12.2). Respondents said that good health and freedom of movement - the ability to travel when and where one wishes (Rudman, Friedland, Chipman \& Sciortino, 2006) are key to living as one wishes (see Table 12.2). This suggests that as people's health and physical mobility decline, residents of communal lifestyle organizations may be more likely to say they cannot live as they wish, irrespective of the organizational environment in which they find themselves. These findings suggest that, after factoring out the health and mobility issue, Lakelands seems to be effectively responding to consumer desires. In responding to consumer desires, well-run communal lifestyle organizations like Lakelands can promote resident self-actualization - the ability to pursue a life of one's choosing. Given that selfactualization is a fundamental principle of life politics (Giddens, 1991), this suggests that a well-run communal lifestyle organizations can promote life-political ideals. 
This study builds on the literature on satisfaction and well-being in residential organizations (Begovic, 2005; Gardner, Browning \& Kendig, 2005; Hong, \& Duff, 1994; Hong \& Duff, 1997; Karn, 1980; Kontos, 1998; Lee, 2003; MacNeill, 1991; SikorskaSimmons, 2001). As well, it makes an original contribution by going beyond the issue of customer satisfaction, independence and autonomy and examines a more fundamental issue - self-identity, or the ability to live as one wishes in an organization. These findings make an important contribution to the literature by showing that it is possible to live as one wishes in an organization, and by identifying conditions that help and hinder selfactualization.

\subsection{Suggestions for change}

Giddens' theory would predict that there is a reflexive relationship between residents and organizations - organizations shape resident self-identity and residents shape organizations. Previous sections support this prediction. Lakelands' management and residents shape resident self-identity, for example through the active retirement policy and residents shape Lakelands. The walker and seating debate (chapters 5, 11) illustrate how residents may contest management practices that negatively affect self-identity, thereby influencing management practices. In addition, Chapter 5 discusses how consumer preferences may shape Lakelands as well as the seniors housing industry.

This section summarizes and discusses findings for the interview question "Have you made suggestions for change?" A summary of key findings is shown in Table 17.12. 
Table 17.12. Key findings regarding suggestions for change

Interview question: Have you made suggestions for change?

Many people do not want to be "complainers."

People who say they or others should not complain are less likely to make suggestions to management.

Half of respondents are passive consumers. Either they do not made suggestions $(35 \%)$, or they no longer make suggestions $(15 \%)$.

The findings indicate that $65 \%$ of respondents have made suggestions to management, although 15\% no longer make suggestions because they feel management does not listen (see Table 13.1). This implies that those who have not made suggestions (35\%), plus those who no longer make suggestions (15\%) are passive consumers: people who do not demand, or have given up demanding better goods and services.

The findings indicate that a number of factors limit or encourage resident suggestions to management. First, reluctance to complain limits suggestions to management. About $40 \%$ of respondents either said they do not want to complain, and/or that people have no cause to complain about life at Lakelands. The study found a significant correlation between these two variables - people who say they or others should not complain are less likely to make suggestions to management.

In addition to not wanting to be a complainer there are a number of other factors that limit suggestions to management: believing that management does not respond to complaints, feeling that because one lives in luxurious circumstances one has no right to 
complain, and fear of eviction.

Aside from factors that limit suggestions to management, the study found evidence that economic conditions may influence the outcome of resident suggestions. Tough economic times can increase residents' power vis-à-vis communal lifestyle organizations. After the subprime crisis, resident complaints to management about rent levels were rewarded with a quick and generous response.

These findings contribute to the literature on governance in communal lifestyle organizations (Hunt, Feldt, Marans, Pastalan \& Vakalo, 1984), and to empirical research on participation in management decisions, and conflict between residents and management (Borawski-Clark, 1992; Kontos, 1998; MacNeill, 1991; Streib \& Metsch, 2002). The findings identify conditions that support and weaken resident agency vis-à-vis the organization (e.g., a reluctance to complain). These findings raise a number of questions: What are the implications of serving a passive client group? Does management lose an important source of information on how to improve performance? Does failure to complain influence customer self-identity and loyalty? ( Ekinci, Dawes \& Massey, 2008; Ferrell, 2004; Szymanski \& Henard, 2001).

\subsection{Assimilation}

This section summarizes and discusses findings related to resident assimilation. A summary of key findings is shown in Table 17.13. 
Table 17.13. Key findings regarding assimilation

Over time, people experience an assimilation effect living at Lakelands.

The study found that the longer a person lives at Lakelands the more likely it is that their narratives will become increasingly typical. This effect appears in answers to ten major interview questions. These finding have implications for self-identity and agency. Since self-identity is reflected in narratives, converging narratives suggest that the "me" is increasingly being submerged by the "we." These findings suggest an assimilation effect - perhaps shared values and a sense of community that develop over time, rather than solely through self-selection (i.e., people moving to communities that they believe fit their values).

The existence of an assimilation effect seems to support or explain findings from other empirical studies of retirement communities, which often report a strong sense of community and a seemingly homogeneous population with similar values (Fitzgerald, 1986; Grant, 2007; Katz, 2005; Gardner, Browning \& Kendig, 2005; Jacobs, 1975). This study makes a unique contribution to the literature by developing a method for assessing narrative homogeneity (typical narratives) and protest narratives (discrepant narratives). In addition, this study identifies a number of conditions - years resident, age, being married, poor hearing, not having family nearby and increased organizational experience - that seem to increase narrative homogeneity. This builds on empirical studies that explore factors affecting social cohesion (Shippee, 2008) and social integration (Borawski-Clark, 1992; Van den Hoonaard, 1992) in retirement communities. 
In addition to making theoretical and methodological contributions to the study of community formation in communal lifestyle organizations, these findings may point to the importance of management in creating a sense of community. Given the large turnover in some communities due to the high concentration of death and illness, preserving community may be a task requiring constant work, especially on the part of management. The higher the turnover the more difficult this task may be (Shippee, 2008).

This management task becomes particularly important if communal lifestyle organizations are in the business of trying to create a perfect community, as I argue above. The assimilation effect may constitute an outcome or performance measure of this effort. Evidence of an assimilation effect may suggest that management is achieving one of the objectives of perfect communities - the creation of an harmonious community where people can maximize life enjoyment. On the other hand, evidence of assimilation, or creation of an harmonious community, may also indicate declining agency and increasing conformity. As a person's views increasingly resemble others, individuality, and hence agency may decline.

Assimilation, either by accretion (i.e., increased time spent living in residential organizations) or by management design, has implications for resident power. Although individual agency may decline over time in residential organizations, group power may increase. It may be easier to mobilize groups of like-minded individuals than it would be with groups holding disparate views. Residents wishing to effect organizational change may choose groups as the vehicle for promoting change when individual efforts fail. 


\section{A communal lifestyle organization typology}

This section summarizes and discusses findings related to the communal lifestyle organization typology. A summary of key findings is shown in Table 17.14.

Table 17.14. Key findings regarding a communal lifestyle organization typology

Democracy is possible in communal lifestyle organizations.

Communal lifestyle organizations create leisure and a leisure self-identity.

Clients have agency, and are able to exercise power.

Service delivery is based on a customer service philosophy

The study identifies the major characteristics of a communal lifestyle organization, how these characteristics differ from a total institution, plus it identifies the various types of communal lifestyle organizations. The study proposes that for an organization to be classified as a communal lifestyle organization it must meet a number of conditions: some services must be in common; the lifestyle is usually upscale; clients have agency; the organization creates leisure and a leisure self-identity; governance is either resident managed or owner managed; and service delivery is based on a customer service philosophy.

In addition to these conditions, there are three main differences between total institutions and communal lifestyle organizations: the extent of management power, the nature of boundaries between public and private life, and, the consequences for resident self-identity. Managers in communal lifestyle organizations have less power than in total 
institutions. Democracy is possible in communal lifestyle organizations. Communal lifestyle organizations establish clear boundaries between private and public life, whereas there is little to no privacy in total institutions. Communal lifestyle organizations have permeable boundaries whereas total institutions have rigid boundaries between the organization and society. Communal lifestyle organizations strive to maintain or enhance self-identity whereas total institutions strive to stigmatize deviant self-identities.

The typology describes four types of communal lifestyle organizations: the luxury apartment, condominium, hotel or cruise ship; gated communities; independent living residences; and, assisted living. They vary in a number of ways: degree of communal living, state of a clients' health and possibly also degree of resident agency. Luxury apartments, and condominiums tend to have the least amount of services in common, clients tend to be in the best state of health, and the model tends to support the greatest amount of client agency. In contrast, assisted living tends to have the most services in common, clients are in the poorest state of health and the model tends to support the lowest levels of client agency (see Table 15.3).

These findings build on empirical studies and descriptions of retirement communities (Hunt, Feldt, Marans, Pastalan \& Vakalo, 1984; Laws, 1996; Katz, 2005; McHugh \& Larson-Keagy 2005; Streib, 2002) by identifying the defining characteristics of various types of communal lifestyle organizations, including their governance structures. As well, these findings make an original contribution to the literature by highlighting the implications of organizational arrangements for agency and self-identity (Streib, Folts \& La Greca, 1985). 
In addition to identifying implications for agency and self-identity, the typology raises emancipatory and life political issues related to lifestyle sector options for older persons. On the one hand, communal lifestyle organizations have the potential to be democratic. This is a positive step, especially given the repressive reputation of total institutions. On the other hand, organizational sequestration within communal lifestyle organizations for older persons, and between these organization and nursing homes, suggests that Fourth Agers have diminishing lifestyle options. The typology seems to suggest limits on aging in place (Frank, 2002) - modifying physical environments or using products and services that permit persons to stay in their homes and communities despite health changes. Reports that Canadian nursing homes in some jurisdictions are becoming increasingly violent and dangerous (Canadian Broadcasting Corporation Marketplace, 2007a, 2007b) suggest that the increasing segregation of physically and mentally disabled seniors, combined with cuts in government spending, are producing dire conditions for older persons and the people who live or work in these institutions.

\section{Analytic generalization}

This section summarizes and discusses findings related to the analytic generalizability of Giddens' theoretical framework. A summary of key findings is shown in Table 17.15. 
Table 17.15. Key findings regarding analytic generalization

Giddens' modernity and self-identity theory is generalizable to any residential context, with some limitations.

The theory may be limited in its application to older persons and to total institutions. The study suggests eleven refinements to the theory, a number of new concepts, and four methods for a measuring and analyzing self-identity.

This study found Giddens' theory useful for studying Lakelands, especially when compared to Goffman's total institution theory, and when combined with the literature on aging. The study found that Giddens' theory is generalizable to people living and working in most residential settings. The study refines some notions to take into consideration the realities of aging (e.g., limits on bodily control, diminishing agency, diminishing lifestyle options) and the realities of total institutions (i.e., limits on freedom and lifestyle options).

This study builds on a small body of literature that applies Giddens' modernity and self-identity theory to aging (Everingham, 2003; Mellor \& Shilling, 1993; Powell \& Wahidin, 2005), to discourse analysis (Heracleous \& Hendry, 2000), to consumer research (Jafari, 2008; Wattanasuwan \& Elliott, 1999), to organizations in general (Webb, 2004), and to other empirical settings (Askegaard, Gertsen \& Langer, 2002; Barrett \& Walsham, 1999; Gross \& Simmons, 2002; Plumridge \& Thomson, 2003).

The study makes a number of original theoretical and methodological contributions to the literature. Demonstrating that Giddens' theory can be successfully applied to an empirical setting, and that it is analytically generalizable, creates new 
options for researchers. As well, four methods for measuring and analyzing self-identity, which are generalizable to any setting, may be helpful in self-identity studies.

\section{Summary}

This study had two major objectives: to explore how people construct self-identity in a communal lifestyle organization, and to assess the usefulness and generalizablity of using Giddens' modernity and self-identity theory for this task. This section summarized the results of this effort. This section highlighted nine key findings: 1) knowing respondent characteristics helps in predicting agency vis-à-vis organizations; 2) communal lifestyle organizations like Lakelands organizationally sequester Third Agers from Fourth Agers; 3) organizational sequestration produces a language of sequestration that is symptomatic of a sequestered self-identity and weakening agency; 4) organizational sequestration concentrates existential issues; 5) communal lifestyle organizations can negatively affect self-identity and also produce positive transformations of the self; 6) people can live as they like in at least some communal lifestyle organizations; 7) over time, people living in communal lifestyle organizations can experience an assimilation effect; 8) democracy is possible in communal lifestyle organizations; and, 9) Giddens' modernity and selfidentity theory is generalizable to all residential settings.

In addition to these key findings, the study uncovered a number of associations and possible causal relationships. Effect sizes tend to be small to medium in size. For example, odds ratios range from 5 to 7 . Spearman's rho coefficients range in size from .31 to .52 . This roughly translates into an $\mathrm{r}^{2}$ of between .10 and .29 according to Gilpin's 
(1993) conversion tables. Since Gilpin's tables are based on medium to large samples, these conversions are estimates only. These effect sizes may serve as starting points which will help future researchers to determine which relationships may be worth investigating further (Vacha-Haas and Thompson, 2004).

These findings provide qualitative and quantitative evidence that suggest it is possible to live as one wishes in a communal lifestyle organization. The data also imply that organizations may change self-identity over time. They may weaken agency. People may perceive changes in self-identity such as feeling old, or the "me" may increasingly be submerged in the "we." Alternatively, communal lifestyle organizations may support agency. They may produce positive transformations in the self such as feeling proud, happier, or becoming less selfish. These changes suggest that communal lifestyle organizations may provide opportunities for moral self-actualization and the growth of wisdom.

Apart from organizations shaping residents, residents also have an effect on communal lifestyle organizations. They shape specific organizations such as Lakelands by managing these organizations (where the governance structure permits), by providing suggestions to management and by volunteering in activities. Residents are also shaping the industry through their consumer preferences. This has produced organizations that are physically beautiful, offer a wealth of lifestyle options and amenities, and create the potential for pure relationships and community. The dark side is that consumer preferences - preferences that are not unique to older persons - are increasingly sequestering physically and mentally disabled older persons in ways that limit their 
lifestyle options. Persons with the financial resources can avoid the worst lifestyle sectors that are reserved for poor Fourth Agers (Canadian Broadcasting Corporation Marketplace, 2007a, 2007b). 


\section{CHAPTER EIGHTEEN}

\section{Conclusions}

\section{Conclusions and contributions of the research}

This study focuses on what happens when private family space is located in a public space. If the notion of home is being dislocated from traditional family space, and people are becoming more nomadic, it may become more common for people to live and work in organizations. This study helps us to understand some of the issues that arise when home is an organization.

The study makes six key contributions to organization theory and research: 1) it demonstrates that Giddens' theory is a good lens for exploring self-identity in residential organizations; 2) it responds to Clegg's (2006) criticism that organization theory ignores the totalitarian and inhumane aspects of some residential organizations; 3 ) it underlines the importance of concepts such as self-identity, emancipatory and life politics for people living in organizations; 4) it uncovers characteristics that may predict agency vis-à-vis residential organizations; 5) it privileges the diverse views and voices of older people living in organizations - a group that is hidden from society and not well understood; and, 6) it discusses the affordability of communal lifestyle organizations.

First, the study makes an important contribution to organization theory by 
demonstrating that Giddens' theory is a good lens for exploring self-identity in residential organizations. By grounding this theory in an empirical context - something that has rarely been done - the study demonstrates that this theory is analytically generalizable to residential settings. By describing context, conditions, and experiences in great detail, future researchers may understand the limits of applying Giddens' theory to other organizational contexts. For instance, the study indicates that Giddens' theory does not always consider the risks and implications of end of lifespan issues, which are salient in residential settings serving older persons.

This work also illustrates the advantages of using a sophisticated theoretical framework in empirical research. As Van De Ven (1989, p. 486) remarks "nothing is quite as practical as a good theory." Compared to the alternatives, especially functionalist theories popular in the management literature, the depth and breadth of Giddens' work, and its explanatory power, become evident.

In addition to demonstrating the usefulness of Giddens' theory in an empirical context, this study makes an important contribution by responding to Clegg's (2006) criticism that organization theory ignores the totalitarian and inhumane aspects of some residential organizations such as total institutions:

Bauman's work is not entirely without discussion in the organizations literature (see Clegg, 2002; Grey, 2005, p. 25), but much of the discussion misses the mark. If a central aspect of the Holocaust concerned its organizational possibility, wouldn't one think that this might be a central theme of contemporary organization studies? Wouldn't organization studies want to focus on this case as an exemplification of how what was good in organization could produce what was evil in human action? (Clegg, 2006, p. 427). 
This study addresses Clegg's concerns by looking at the characteristics of a new organization model - one that is a theoretical contrast to the total institution. In doing so, this study documents how and why "bureaucratic rationality" (Clegg, 2006) in the communal lifestyle organization can maintain or enhance self-identity and how democracy is possible in residential organizations (Follett, 1973; Tonn, 2003).

In addressing Clegg's concerns, this study underlines the importance of selfidentity to organizations and organization theory. Self-identity goes beyond traditional concerns such as customer satisfaction, human rights issues in dormitory settings (Martin, 1984; Smith, 2003), or preserving older persons' independence and autonomy in residential settings (Baltes, 1996; Ball, Perkins \& Whittington, 2004; Collopy, 1988). It points to the ways in which the exercise of management power over individuals can hinder or assist individual self-actualization or freedom to live as one wishes.

The study also makes a contribution to organizations and organization research by identifying a number of factors - individual characteristics - that may predict agency visà-vis residential organizations. Although the study cases come from a specific population, the factors in question - marital status, extroversion, age, family nearby, health, and experience in residential organizations (see Table 17.3) - are broad enough to be worth exploring in research focusing on other populations living or working in organizational settings. By identifying conditions that may weaken or strengthen agency, this study assists organizations in monitoring human rights and self-identity issues.

The study also makes a contribution to organizational and marketing research by communicating the voices and viewpoints of older people living in organizations - a 
group that is often the subject of discrimination, hidden from society and not well understood. This fills a gap in the organizational, gerontological and marketing literature with detailed case-based information about organizational life as lived by a segment of older Canadians.

This work also contributes to organizational research, public policy, and organizations by discussing affordability. This study indicates that this lifestyle is within the reach of many middle class Canadians, if providers match Lakelands' prices (Tables $3.8,3.9)$. The study demonstrates that the cost of living in a communal lifestyle organization, if priced like Lakelands, is similar to public sector nursing home costs and less expensive than private sector nursing home costs (Table 3.2 and 3.4). By lowering prices, organizations could benefit from a significant growth in the market.

\section{Limitations of the study}

The study has several limitations which warrant consideration. Although findings can be generalized to white middle class seniors living in North American communal lifestyle organizations, all findings may not be empirically generalizable to other age groups, cultures, or to people living in other types of residential organizations. The findings may not be empirically generalizable to organizations that do not have a leisure objective: such as schools or places where people live and work. Bernard, Bartlam, Sim and Biggs (2007, p. 557) point out that retirement communities in North America and Australia which emphasize leisure, may not resemble communities in Britain and Europe. Also, older persons living in societies that value age rather than youth, such as North American 
Aboriginal communities, may have different experiences.

Although the generalizability of the findings may be limited, this study which focuses on a seemingly privileged group of people - middle and upper middle-class Canadians - underlines the importance of issues such as management power and selfidentity for a broad spectrum of persons, irrespective of their age, class, financial situation or culture.

In addition to limitations on empirical generalizability, this study may also be limited by the number of male cases in the study group. The case selection objective was to over sample male cases (Table 3.9) so as to explore experiences that might be unique to men. This limitation is somewhat mitigated by the fact that the study included men in the same proportion as in the Lakelands' population. Also, the qualitative and quantitative data found no evidence that males experience self-identity differently than females at Lakelands. For instance, the gender variable was not statistically associated with any of the variables derived from the 10 major interview questions (e.g., adaptation required, self-identity change, naming conventions, live as I like etc.). Since the absence of a relationship may be related to the small number of cases in this study this issue should be explored in future research.

\section{Suggestions for future research}

Very little past research has been done on self-identity in residential organizations, especially by organizational researchers. Consequently there are numerous research questions that warrant further attention. 
First, apart from replicating this study in other independent living residences, this study could be replicated in an assisted living facility. The objective would be to explore the moral implications of bodily decline, especially mental decline, for self-identity and power vis-à-vis management and other residents. Researchers could also replicate this study in other residential organizations to see if the findings are reproduced in different cultures, contexts and age groups.

Second, future research could explore the assimilation effect - the relationship between years resident and type of narrative. Researchers could examine what conditions influence assimilation in residential organizations. Is there an assimilation effect irrespective of the type of resident (i.e., young, old, worker, retired)? Is the assimilation effect stronger in homogeneous or heterogeneous populations? What effect do contrasting or discrepant narratives have, if any, on an assimilation effect? What effect does the assimilation effect have on people's ability to organize as a group and to effect organizational change? What relationship, if any, is there between the assimilation effect and living as one likes?

Third, in addition to exploring the assimilation effect, future studies could explore how the language of sequestration in used in other residential settings. Issues to explore include: Is this language more or less complex than the terms discovered at Lakelands and in Williams and Guendouzi's (2000) study? Can structural narrative analysis uncover other vocabulary and grammatical styles reflecting this identity such as the use of the passive voice? What conditions detract or contribute to its use? What is the relationship of the language of sequestration to individual characteristics and self-identity? 
Finally, self-identity in university residences would be a fruitful research topic for university students, since they are either living in residence or have had experience doing so. An autoethnography, or multiple case study could shed light on this under-researched topic. Although people have studied university residences (Hays \& Oxley, 1986; Wilcox \& Holahan, 1976), they have not studied how students construct self-identity in these residential organizations.

\section{Implications for entrepreneurs, marketers and managers}

This study has numerous implications for entrepreneurs, marketers and managers of residential organizations. Six key implications are: the study sets out an organizational typology; there is a large potential market for communal lifestyle organizations; choice of language is important in advertising and day-to-day communications; negative stereotypes of aging or the trappings of institutional life may deter persons from moving to communal lifestyle organizations; organizational routines influence agency in residential settings of all types; and, the Baby Boomer generation may bring about change in North American residential organizations.

The study develops a typology that can be used by entrepreneurs and managers to design or monitor the organizational philosophy of a communal lifestyle organization. The typology describes the characteristics of typical and atypical communal lifestyle organizations and contrasts these characteristics to total institutions and to nursing homes.

Another implication of this study is that there is a large potential market for 
communal lifestyle organizations in Canada (Tables 3.2 to 3.4) and worldwide, as populations age (The Economist, 2008) and family structures change (The Hindu India's Online Newspaper, 2003). People would be much more willing to give up their homes if residential organizations were affordable, appealing to people's self-identity aspirations, and were managed appropriately. This could translate into a tremendous growth in the industry.

In addition to the potential growth of this market, another implication of this study for entrepreneurs, marketers and managers relates to the importance of language in advertising and day-to-day organizational practices - specifically, language used to describe communal lifestyle organizations and client naming conventions. The findings indicate that the terms used to describe a communal lifestyle organization should be congruent with the model - both for implicit and explicit terms. In making clear linguistic distinctions between communal lifestyle organizations and other residential organizational models, entrepreneurs, marketers and managers help customers understand how this new lifestyle option differs from other options.

In addition to clear organizational descriptions, the findings suggest that client naming conventions are important. Well chosen terms describing client self-identity may help clients live as they like in residential organizations (Table 12.4). The empirical research suggests that this may in turn promote customer satisfaction and loyalty (Belk, 1988; Ekinci, Dawes \& Massey, 2008; Ferrell, 2004). In other words, appropriate naming conventions may help to attract and retain customers.

A final point with respect to language is that these language conventions should 
be congruent - terms used to describe the communal lifestyle organization and terms used to describe customers. Ferrell (2004) argues that "organizational disidentification may occur when individuals perceive a conflict between their defining attributes and the attributes defining the organization." This observation is consistent with Giddens' (1991) theoretical framework which points to the reflexive relationship between selfidentity and social environments. When people observe a disconnect between their selfidentity and the social environment - if they perceive they are not consuming the "right goods and services" (Belk, 1988) - they may go elsewhere.

In addition to the importance of implicit and explicit language, the study suggests that negative stereotypes of aging or the trappings of institutional life may deter persons from moving to communal lifestyle organizations, or may prompt existing customers to leave an organization if the lifestyle changes. The literature and the findings suggest that "younger" active seniors may be more sensitive to this issue than "older" seniors approaching the Fourth Age. This has implications for entrepreneurs, marketers and managers of residential organizations. Advertising, organizational design and day-to-day management activities need to carefully distinguish between Third Age and Fourth Age lifestyles and self-identities.

In addition to the importance of translating self-identity into organizational symbols and day-to-day life, the study suggests that entrepreneurs and managers should be attentive to day-to-day routines if they wish to promote client agency and self-identity, and retain customers. For instance, in communal lifestyle organizations, day-to-day routines can emphasize good customer service. At Lakelands, good customer services is 
described as: "Understanding our residents and anticipating their needs." (Table 3.1).

To monitor routines, managers can conduct ongoing or periodic reviews. This could consist of a Residents Committee mandated to identify routines that promote or hinder good customer service. Topics could include the impact of day-to-day routines on client rights, privacy, friendships, choice, the ability to live as one wishes, and moral or ethical issues. If management conducts a formal review, participatory action research methods could be used to involve and empower clients (Coghlan \& Brannick, 2007; McIntyre, 2008; Reason \& Bradbury, 2001; Stringer, 2007).

In addition to the importance of routines for client agency, the study suggests that in the future North American Baby Boomers may have the potential to produce discontinuous or transformational organizational change (Drucker, 1994; Romanelli \& Tushman, 1994) in all types of residential settings. The findings indicate that respondents at Lakelands are passive consumers, which may be attributable to generational characteristics. Empirical research on the Baby Boomer generation suggests that they are less respectful of authority and more avid consumers than the Mature generation (Lyons, Higgins \& Duxbury, 2007) - the generational cohort currently living at Lakelands. The research describes Baby Boomers as "non-conformist,", and "distrustful of authority figures" (Lyons, Higgins \& Duxbury, 2007, p. 342). Perhaps Baby Boomers, having witnessed the Civil Rights and Feminist Movements, may next turn their attention to the issue of ageism. This may affect the day-to-day management of residential organizations as well as industry standards. This potential for change is further supported by Giddens' (1991) theory of life politics, which predicts that life politics may gain importance in the 
coming years. In addition to their political ideals, Baby Boomers are avid consumers. The research suggests they have a "psychology of entitlement", are "pleasure-seeking" and "expect prosperity and satisfaction in their lives" (Lyons, Higgins \& Duxbury, 2007, p. 342). This would suggest that they may be demanding clients, but also loyal clients of well-run communal lifestyle organizations.

This research on North American generational cohorts (Lyons, Higgins \& Duxbury, 2007) would suggest that the potential for discontinuous transformative change may be greatest in residential settings that do not promote emancipatory, life political ideals or consumerism. Since the ideal communal lifestyle organization model promotes these values, it may experience less change than other residential settings.

This section points to an increasingly sophisticated and fragmented market in residential organizations; one that emphasizes lifestyle as a means for defining selfidentity. While there is the potential for tremendous economic growth, there is also the risk of disruption if entrepreneurs, marketers and managers neglect the issue of resident self-identity.

\section{Implications for governments}

In addition to implications for entrepreneurs, marketers and managers, the study has two key implications for governments: communal lifestyle organizations have the potential to preserve people's rights and self-identity, an issue of concern to democratic governments; and, these organizations do not exist in sufficient numbers to be accessible or affordable to most people. 
First, communal lifestyle organizations can promote people's rights and selfidentity. The literature review and the findings suggest that historically Western residential organizations for older persons have been repressive organizations and that this situation continues to exist. Although private sector residential organizations tolerate abuses (DuHigg, 2007c, September 23; McKie, 2009), so do public sector organizations (Davies, 2001; Goffman, 1961; Katz, 2005; Phillipson, 1998; Slack, 1995; Stearns, 2001; Townsend, 1962; Wagner, 2005). This makes governments directly responsible for these failings through their day-to-day management of these residential organizations. In Canada, recent news reports describe older Canadians living in under staffed and sometimes dangerous institutions (Canadian Broadcasting Corporation Marketplace, 2007a, 2007b; Canadian Broadcasting Corporation News, 2008a, 2008b; Canadian Broadcasting Corporation News, 2010).

A second implication of this study for governments is that although communal lifestyle organizations promote people's rights and self-identity, they do not yet exist in sufficient numbers to be accessible or affordable to most people. If governments wish to promote this model, or its management practices, especially to protect vulnerable groups such as older persons, they need to develop both short and long-term strategies. In the short term, they could establish standards of management conduct for all residential organizations through legislation. In the long term they need to promote the growth of this organizational model through incentives such as tax breaks or grants.

To support communal lifestyle organization management practices - especially respect for emancipatory and life-political ideals - governments could establish standards 
of management conduct for public and private organizations. These standards could support client agency and limit the potential for management and staff abuse of power. These standards should be concrete. They could include compliance or monitoring mechanisms, such as a requirement for ongoing or periodic reviews of routines as described in the previous section. Over time, governments might decide to attach penalties to violation of these standards - limitations on government financial support, permits and licensing restrictions, or civil and criminal penalties depending on the nature and gravity of the situation. The specific nature of these standards goes beyond the bounds of the current study but could be pursued in future research.

In addition to establishing standards of conduct for residential organizations, especially those serving vulnerable groups such as older persons, governments could encourage growth in the supply and competition in the communal lifestyle industry. The objective would be to make this type of accommodation more common and more financially accessible to more people. The findings suggest that prices in many locations in Canada are high, compared to prices at Lakelands (Table 3.2). This suggests a potential for greater competition. To encourage growth and competition, governments might consider subsidizing builders who build communal lifestyle organizations that are affordable to a greater segment of the population - perhaps in the three to four star category. As well, governments might consider subsidizing clients. Golant (2001) notes that in the United States, governments are considering subsidies for assisted living clients. Other types of direct and indirect government support could include grants, personal and corporate tax deductions and credits. 
To support the growth of the communal lifestyle industry, especially for older persons, governments might also consider location issues - land availability and the renovation of buildings in cities and towns. The study suggests that people would like to move to places that are close to their family, close to their current neighbourhood, that have access to transportation and that include a natural park-like setting. To meet these needs, developers may need vacant land to build new buildings or they may need to renovate existing buildings in cities and towns where most people live. In the case of gated communities, large tracts of vacant land are usually required. Support might include freeing up government lands and vacant buildings and modifying zoning and building permit regulations.

The benefits of supporting this strategy, apart from promoting accessibility and affordability, is that governments can limit growth in government long-term care costs. In Canada for instance, a Statistics Canada study argues that many people living in nursing homes do not need the nursing services provided by these facilities: "While health status was strongly associated with residence in a long-term health care facility, the absence of a spouse, low income, low education, and advanced age were also significant" (Berthelot, Houle, Légaré, Martel \& Trottier, 2000, p. 49). By promoting alternatives, governments free up space in nursing homes, and limit the costs of building new long-term care facilities to meet the needs of an aging population.

These two government strategies - standards of conduct for residential organizations and promoting the growth of the private sector communal lifestyle industry - could improve life for persons living in organizations, especially vulnerable older 
persons. As populations age, especially in the Western world, there will be an increased demand for residential organizations. By directing the growth and nature of this industry, governments can shape the types of models that are built as well as day-to-day management practices and their implications for human rights and self-identity.

\section{Summary}

This study discusses problems related to making one's home in an organization. As the world population ages and as people become more nomadic, it may be more common for family space to be located in organizations and for organizations to manage this space. In the past, in Western countries, this was an unenjoyable experience. This study explores older people's experiences living in a new type of organization - a communal lifestyle organization - and found that they can largely live as they like, free of undue influence from management. These findings suggest that it is possible to live as one likes in an organization - if conditions are right. In demonstrating what is possible, it is my hope that the general public, industry and government can work together to promote more humane residential organizations - organizations that promote respect for human beings and their happiness. 


\section{CHAPTER NINETEEN}

\section{References}

Abma, T. (2000). Fostering learning-in-organizing through narration; Questioning myths and stimulating multiplicity in two performing art schools. European Journal of Work and Organizational Psychology.

Adams, M. (2004). Whatever will be, will be: Trust, fate and the reflexive self. Culture \& Psychology, 10(4), 387-408.

Adler, J. (2007). Luxury living for seniors in hotel-style fashion. National Real Estate Investor, 49(3), 18-18.

Advocat Inc. (2007). Company profile, information, business description, history, background information on Advocat Inc. Retrieved December 28, 2007, from http://www.referenceforbusiness.com/history2/6/Advocat-Inc.html.

Agrest, D., \& Sennott, R. S. (2003). Encyclopedia of 20th-century architecture: Taylor \& Francis.

Air Force Village West Inc. (2010). Air Force Village West. Retrieved February 17, 2010 from http://www.afvw.com/.

ALCA. (2010). ALCA Assisted Living Consumer Alliance. Retrieved October 17, 2010, from http://www.assistedlivingconsumers.org/advocacy.

Alvesson, M., \& Willmott, H. (2002). Identity regulation as organizational control: Producing the appropriate individual. Journal of Management Studies, 39(5), 619644.

American Senior Housing Association. (2009). ASHA 50. Special information supplement, National Real Estate Investor. Retrieved August 1, 2008, from http://www.seniorshousing.org/.

Ashforth, B. E. (2000). All in a day's work. Academy of Management Review, 25(3), 472-491.

Ashforth, B. E., \& Mael, F. (1989). Social identity theory and the organization. Academy of Management Review, 14(1), 20-39.

Askegaard, S., Gertsen, M. C., \& Langer, R. (2002). The body consumed: Reflexivity and cosmetic surgery. Psychology \& Marketing, 19(10), 793-812. 
Assisted Living Concepts. (2010). Assisted Living Concepts. Retrieved February 17, 2010, from http:/www.alcco.com/.

Atkinson, R. (1998). The life story interview. Thousand Oaks, London, Delhi: Sage.

Babbie, E., \& Benaquisto, L. (2002). Fundamentals of social research (First Canadian ed.). Scarborough, ON: Thomson.

Bali, M. M., Perkins, M. M., Whittington, F. J., Hollingsworth, C., King, S. V., \& Combs, B. L. (2004). Independence in assisted living. Journal of Aging Studies, $18(4), 467-483$.

Ball, M. M., Perkins, M. M., \& Whittington, F. J. (2004). Independence in assisted living. Journal of Aging Studies, 18(4), 467-483.

Baltes, M. M. (1996). The many faces of dependency in old age. Cambridge: Cambridge University Press.

Barber, K. (Ed.). (2004). The Canadian Oxford dictionary. Don Mills, Ontario: Oxford University Press.

Barrett, M., \& Walsham, G. (1999). Electronic trading and work transformation in the London insurance market. Information Systems Research, 10(1), 1-22.

Barry, D., \& Elmes, M. (1997). Strategy retold: Toward a narrative view of strategic discourse. Academy of Management Review, 22(2), 429-452.

Baum, J. A. C., \& Rowley, T. J. (2002). Companion to organizations: An introduction. In J. A. C. Baum (Ed.), Companion to organizations (pp. 1-34). Oxford, UK. and Malden, MA USA: Wiley-Blackwell.

Bauman, Z. (1989a). Modernity and the Holocaust. Cambridge, UK: Polity.

Bauman, Z. (1989b). Legislators and interpreters. Cambridge: Polity.

Beesley, K. B. (1989). Social well being in planned retirement communities: A review and pilot study. Peterborough, ON: Dept. of Geography, Trent University.

Begovic, A. (2005). Older adults' residential moves, coping, and adaptation. Unpublished Ph.D, The University of Akron.

Belk, R. W. (1988). Possessions and the extended self. Journal of Consumer Research, $15,139-168$. 
Belk, R. W. (1995). Collecting in a consumer society. London; New York: Routledge.

Belk, R. (2003). Shoes and self. Advances in Consumer Research, 30(1), 27-33.

Belk, R. W., \& Ger, G. (1997). Consumer desire in three cultures: Results from projective research. Advances in Consumer Research, 24(1), 24-28.

Bernard, M., Bartlam, B., Sim, J., \& Biggs, S. (2007). Housing and care for older people: Life in an English purpose-built retirement village. Ageing \& Society, 27(4), 555578.

Berthelot, J.-M., Houle, C., Légaré, J., Martel, L., \& Trottier, H. (2000). Living at home or in an institution: What makes the difference for seniors? Ottawa ON: Statistics Canada: Health Reports May 29, 2000.

Biggs, S. (1999). The mature imagination: Dynamics of identity in midlife and beyond. Buckingham: Open University Press.

Biggs, S., Bernard, M., Kingston, P., \& Nettleton, H. (2000). Lifestyles of belief: Narrative and culture in a retirement community. Ageing \& Society, 20(6), 649-672.

Biggs, S., Estes, C., \& Phillipson, C. (2003). Social theory, social policy and ageing. Maidenhead: Open University Press.

Bitner, M. J., Booms, B. H., \& Tetreault, M. S. (1990). The service encounter: Diagnosing favorable and unfavorable incidents. Journal of Marketing, 54(1), 7184.

Blakely, E., \& Snyder, G. (1999). Fortress America: Gated communities in the United States. Washington, DC: Brookings Institution Press.

Blaikie, A. (1999). Ageing and popular culture. Cambridge: Cambridge University Press.

Blanchard, J. D., \& Warren, R. L. (1975). Role stress of dormitory aides at an offreservation boarding school. Human Organization, 35(1), 41-50.

Blazer, D. G., Sachs-Ericsson, N., \& Hybels, C. F. (2005). Perception of unmet basic needs as a predictor of mortality among community-dwelling older adults. American Journal of Public Health, 95(2), 299-304.

Bonnet, C., Gobillon, L., \& Laferrère, A. (2010). The effect of widowhood on housing and location choices. Journal of Housing Economics, 19(2), 106-120. 
Bohuslawsky, M. (1989). Inside Canada's nursing homes: End of the line. Toronto, ON: James Lorimer \& Company.

Boje, D. M. (1995). Stories for the storytelling organization: A postmodern analysis of Disney as 'Tamara-Land'. Academy of Management Journal, 38(4), 997-1035.

Boje, D. M. (2001). Narrative methods for organizational and communication research. London; Thousand Oaks, CA: Sage.

Borawski-Clark, E. A. (1992). Predictors, components and sequelae of social integration of the aged within age-homogeneous environments. Unpublished Ph.D, Case Western Reserve University.

Brewis, J., Hampton, M., \& Stephen, L. (1997). Unpacking Priscilla: Subjectivity, identity, and the organisation of gendered appearance. Human Relations, 50(10), 1275-1304.

Brown, A. D., \& Jones, M. R. (1998). Doomed to failure: Narratives of inevitability and conspiracy in a failed is project. Organization Studies, 19, $73-88$.

Brown, A. D., \& Humphreys, M. (2003). Epic and tragic tales: Making sense of change. Journal of Applied Behavioral Science, 39(2), 121-144.

BUPA. (2008). About BUPA. Retrieved January 15, 2008, from http://www.bupa.co.uk/ about $/$.

Calogridis, M. (2006). What are the minimum requirements to enable a successful pricing strategy? Journal of Revenue \& Pricing Management, 5(3), 184-187.

Canada Mortgage and Housing Corporation. (2001). Report highlights: User satisfaction study of housing options for older Canadians. Retrieved August 1, 2008, from https://www03.cmhc-schl.gc.ca/b2c/b2c/init.do?language=en\&shop= Z01EN\&areaID $=0000000034 \&$ productID $=00000000340000000030$.

Canadian Broadcasting Corporation Marketplace. (2001, March 20). Subsidizing longterm care facilities: Do campaign contributions count? In H. Berkal (Producer). Retrieved September 15, 2009, from http://www.cbc.ca/marketplace/pre2007/files/health/nursinghomes/.

Canadian Broadcasting Corporation Marketplace. (2007a, October 17). Grey, black and blue. Retrieved November 17, 2007, from http://www.cbc.ca/marketplace/grey_black_and_blue/. 
Canadian Broadcasting Corporation Marketplace. (2007b, October 22). CBC News In Depth: Nursing homes: Fear and violence.. Retrieved December 28, 2007, from http://www.cbc.ca/news/background/nursing-homes/.

Canadian Broadcasting Corporation News. (2008a, July 2). 75\% of nursing homes cited for not meeting some provincial standards. Retrieved September 15, 2010, from http://www.cbc.ca/canada/toronto/story/2008/07/02/nursinghomes.html\#ixzz0zdPLnMKX.

Canadian Broadcasting Corporation News. (2008b, October 29). Staff shortages a chronic problem at Manitoba nursing homes. Retrieved September 15, 2010, from http://www.cbc.ca/canada/manitoba/story/2008/10/29/nursing-homes.html.

Canadian Broadcasting Corporation News. (2010, August 19). Nursing home cuts forced caregiver to quit. Retrieved September 14, 2010, from http:/www.cbc.ca/ canada/edmonton/story/2010/08/19/edmonton-health-aide-nursing-homecuts.html.

Canadian Institute of Health Research, Natural Sciences and Engineering Research Council of Canada, \& Social Sciences and Humanities Research Council of Canada. (2005). Tri-Council policy statement. Ethical conduct for research involving humans. Retrieved November 12, 2008, from http://www.pre.ethics.gc.ca/english/pdf/TCPS\%20October\%202005_E.pdf.

Canadian Gated Communities Research Project. (2006). Canadian gated communities. Research highlights. Private streets in the Canadian context. Retrieved October 15, 2010, from http://gated.architectureandplanning.dal.ca/papers.htm.

Care Planning Partners Inc. (2010). The Care Guide source for seniors. Retrieved October 15, 2010, from www.thecareguide.com.

Carlson, E. A. (2001). The unfit: A history of a bad idea. Woodbury, NY: CSHL Press.

Chartwell Seniors Housing REIT. (2010). The most trusted name in seniors housing. Retrieved March 27, 2010, from http://www.chartwellreit.ca

Classic Residence by Hyatt. (2010). Classic Residence by Hyatt. Retrieved February 17 , 2010 from http:/www.hyattclassic.com/go/senior-living.html.

Clegg, S. R. (1993). Narrative, power and social theory. In D. K. Mumby (Ed.), Narrative and social control: Critical perspectives (pp. 16 - 45.). Newbury Park: Sage. 
Clegg, S. R. (2006). Why is organization theory so ignorant? Journal of Management Inquiry, 15(4), 426-430.

Coghlan, D., \& Brannick, T. (2007). Doing action research in your own organization. Thousand Oaks, CA: Sage Publications.

Cohen, J. (1988). Statistical power analysis for the behavioral sciences (second ed.). Hillsdale, NJ: Lawrence Erlbaum Associates.

Cole, J. E. (2006). People on the move in Europe. Identities: Global Studies in Power and Culture, 13(2), 309 - 325.

Cole, T. R. (1992). The journey of life: A cultural history of aging in America. Cambridge: Cambridge University Press.

Collopy, B. J. (1988). Autonomy in long-term care: Some crucial distinctions. The Gerontologist, 28, 10-27.

Conlon, D. E., Van Dyne, L., Milner, M., \& Ng, K. Y. (2004). The effects of physical and social context on evaluations of captive, intensive service relationships. Academy of Management Journal, 47(3), 433-445.

Community Care and Assisted Living Act [SBC 2002] Chapter 75, (2002).

Correctional Services of Canada. (1997). Human rights and corrections: A strategic model. Retrieved September 8, 2010, from http:/www.cscscc.gc.ca/text/pblct/rights/human/im4630-02-eng.shtml.

Craig, R. T. (1981). Generalization of Scott's index of intercoder agreement. Public Opinion Quarterly, 45(2), 260-264.

Czarniawska, B. (1997). Narrating the organization: Dramas of institutional identity. Chicago and London: The University of Chicago Press.

Czarniawska, B. (1998). A narrative approach to organization studies. Thousand Oaks, London, New Delhi: Sage.

Davies, M. J. (2001). Renovating the Canadian old age home: The evolution of residential care facilities in B.C., 1930-1960. Journal of the Canadian Historical Association, 12., 155-175. 
Del Webb. (2010). Del Webb. Retrieved February 17, 2010 from www.delwebb.com.

The Economist. (2008, December 30). Demographics Greying globe. Retrieved

November 15, 2010, from http://www.economist.com/node/12847201.

Denzin, N. K. (2000). Preface. In M. Andrews, S. D. Sclater, C. Squire \& A. Treacher (Eds.), Lines of narrative: Psychosocial perspectives (pp. xi-xiii). New York: Routledge.

Drucker, P. (1994). The theory of the business. Harvard Business Review, 72(5), 95-104.

Dube, R. (2008, May 27). Mean girls, but with walkers. Globe and Mail.

DuHigg, C. (2007a, November 16). Washington scrutinizes nursing homes. New York Times. Retrieved January 15, 2008, from http://www.nytimes.com/2007/11/16/ business/16care.html?_r=1\&oref =slogin.

DuHigg, C. (2007b, October 24). Inquiries at investor-owned nursing homes. New York Times. Retrieved January 15, 2008, from http://query.nytimes.com/gst/ fullpage.html?res=9507E2DA1E39F937A15753C1A9619C8B63.

DuHigg, C. (2007c, September 23). At many homes, more profit and less nursing. New York Times. Retrieved January 15, 2008, from http://www.nytimes.com/2007/09/23/business/23nursing.html.

Jeon, H.-S., \& Dunkle, R. E. (2009). Stress and depression among the oldest-old: A longitudinal analysis. Research on Aging, 31(6), 661-687.

Julier, A. P. (2006). Hospitality and its discontents: Beyond bowling alone. Appetite, 47(3), 391-391.

Edwards, D. J. (2007, August). Outing the issue: Gay and lesbian residents are seeing the development of long-term care communities marketed for them - and opportunities for existing ones to make them feel more welcome. Nursing Home Magazine. Retrieved November 17, 2007, from http://www.nursinghomesmagazine.com/Past_Issues.htm?ID=387

Eisenhardt, K. M. (1989). Building theories from case study research. Academy of Management Review, 14(4), $532-550$.

Eisenhardt, K. M. (1991). Better stories and better constructs: The case for rigor and comparative logic. Academy of Management Review, 16(3), 620-627. 
Ekerdt, D. J. (1986). The busy ethic: Moral continuity between work and retirement. The Gerontologist, 26(3), 239-244.

Ekinci, Y., Dawes, P. L., \& Massey, G. R. (2008). An extended model of the antecedents and consequences of consumer satisfaction for hospitality services. European Journal of Marketing, 42(1/2), 35-68.

Erceg-Hurn, D., \& Mirosevich, V. (2008). Modern robust statistical methods: An easy say to maximize the accuracy and power of your research. American Psychologist, 63(7), 591-601.

Erikson, E. H. (1959). Identity and the life cycle. New York: Norton.

Erickson, M. A., Krout, J., Ewen, H., \& Robison, J. (2006). Should I stay or should I go? Moving plans of older adults. Journal of Housing for the Elderly, 20(3), 5-22.

Escalas, J. E. (2004). Narrative processing: Building consumer connections to brands. Journal of Consumer Psychology, 14(1-2), 168-180.

Estes, C. L., \& Associates. (2001). Social policy and aging. A critical perspective. Thousand Oaks, CA: Sage Publications Inc.

Everingham, C. (2003). 'Self-actualisation' and the ageing process from an intergenerational lifecourse perspective. Ageing and Society, 23(2).

Ferrell, O. C. (2004). Business ethics and customer stakeholders. Academy of Management Executive, 18(2), 126-129.

Fitzgerald, F. (1986). Cities on a hill: A journey through contemporary American culture. New York: Simon and Schuster.

Follett, M. P. (1973). Dynamic administration; the collected papers of Mary Parker Follett. London: Pitman.

Folts, W. E., \& Muir, K. B. (2002). Housing for older adults: New lessons from the past. Research on Aging, 24(1), 10-28.

Folts, W. E., \& Streib, G. F. (1994). Leisure-oriented retirement communities. In W. E. Folts \& D. E. Yeatts (Eds.), Housing and the aging population. Options for the new century. New York: Garland Press.

Foucault, M. (1975). Discipline and punishment. New York: Random House. 
Foucault, M. (1997). On the government of the living. In P. Rabinow (Ed.), Ethics: Subjectivity and truth (pp. 81 - 85). London: Allen Lane.

Frank, J. B. (2002). Paradox of aging in place in assisted living. Westport, CT: Bergin \& Garvey.

Freedman, M. (1999). Prime time: How Baby Boomers will revolutionize retirement and transform America. New York: Public Affairs.

Gardner, I. L., Browning, C. \& Kendig, H. (2005). Accommodation options in later life: Retirement village or community living? Australasian Journal on Ageing, 24(4), 188-195.

Garfinkel, H. (1967). Studies in ethnomethodology. Englewood Cliffs, NJ: Prentice-Hall.

Gay Retirement Guide. (2008). Gay retirement guide. Retrieved August 1, 2008, from http://www.gayretirementguide.com/

Gergen, K. J. (1991). The saturated self: Dilemmas of identity in contemporary life. Basic Books.

Giddens, A. (1991). Modernity and self-identity. Self and society in the late modern age. Cambridge: Polity Press.

Giddens, A., \& Pierson, C. (1998). Conversations with Anthony Giddens: Making sense of modernity. Cambridge: Polity.

Giarchi, G. G. (2002). A conspectus of types, options and conditions of elderaccommodation in the European continent. Innovation: The European Journal of Social Sciences, 15(2), 99-119.

Gibler, K. M., Moschis, G. P., \& Lee, E. (1998). Planning to move to retirement housing. Financial Services Review, 7(4), 291.

Gilpin, A. R. (1993). Table for conversion of Kendall's Tau to Spearman's Rho within the context of measures of magnitude of effect for meta-analysis. Educational and Psychological Measurement, 53, 87-92.

Gitelson, R. K., \& Douglas L. (2005). Gender differences in social adaptation to a retirement community: Longitudinal changes and the role of mediated communication. Journal of Applied Gerontology, 24(4), 283-298.

Goffman, E. (1961). Asylums. Essays on the social situation of mental patients and other inmates. Garden City, NY: Anchor Books Doubleday \& Company, Inc. 
Goffman, E. (1963). Stigma: Notes on the management of spoiled identity. New York: Simon \& Schuster.

Goffman, E. (1969). Strategic interaction. Philadelphia: University of Pennsylvania Press.

Golant, S. (2001). Assisted living: A potential solution to Canada's long-term care crisis. Vancouver, BC: Simon Fraser University. Centre for Gerontology Research.

Golant, S. M., \& Salmon, J. R. (2004). The unequal availability of affordable assisted living units in Florida's counties. Journal of Applied Gerontology, 23(4), 349369.

Goodwin, C., \& Spiggle, S. (1989). Consumer complaining: Attributions and identities. Advances in Consumer Research, 16(1), 17-22.

Gouverneurs Inc. (2008). LuxGouverneurs. Retrieved June 30, 2007, from www.luxgouverneur.ca.

Gould, J. (2009). Heimish and home-ish: Aging, Jewishness and the creation of "home" at a Toronto assisted-living residence, the Terraces of Baycrest. Unpublished Ph.D, Memorial University of Newfoundland.

Grant, B. C. (2007). Retirement villages: More than enclaves for the aged. Activities, Adaptation \& Aging, 31(2), 37-55.

Grey, C. (2005). A very short, fairly interesting and reasonably cheap book about studying organizations. London: Sage.

Groger, L., \& Kinney, J. (2006). CCRC here we come! Reasons for moving to a continuing care retirement community. Journal of Housing for the Elderly, 20(4), 79-101.

Gross, N., \& Simmons, S. (2002). Intimacy as a double-edged phenomenon? An empirical test of Giddens. Social Forces, 81(2), 531-555.

Gubrium, J. F. (1986). Living and dying at Murray Manor. New York: St. Martin.

Gubrium, J., \& Holstein, J. A. (2006). Biographical work and the future of the ageing self. In J. A. Vincent, C. Phillipson \& M. Downs (Eds.), The futures of old age (pp. 117-124). London, Thousand Oaks, New Delhi: Sage Publications.

Gubrium, J. F., \& Holstein, J. A. (2008). Analyzing narrative reality. London: Sage Publications. 
Guimont, L. (2007, 16 et 17 juin). Le club Med à domicile. Une résidence pour babyboomers retraités. Le Devoir, p. G3.

Haggard, L. M., \& Williams, D. R. (1992). Identity affirmation through leisure activities: Leisure symbols of the self. Journal of Leisure Research, 24(1), 1-18.

Harrington, A. K. (1994). Assisted living in alternative residential environments. In S. B. Goldsmith (Ed.), Essentials of long-term care administration (pp. 296-322). Gaithersberg, Maryland: Aspen Publishers.

Harvard University. Joint Center for Housing Studies. (2000). Housing America's seniors. Retrieved March 10, 2008, from http://64.233.167.104/ search?q=cache:r9qWEbrPwD8J:www.jchs.harvard.edu/publications/seniors/hou sing_americas_seniors.pdf $+\% 22$ Housing + America $\% 27 \mathrm{~s}+$ seniors $\% 22 \& \mathrm{hl}=$ en \&ct $=\mathrm{clnk} \& \mathrm{~cd}=1 \& \overline{\mathrm{gl}}=\mathrm{ca}$.

Hauge, Å. L. (2007). Dwelling as an expression of identity. A comparative study among residents in high-priced and low-priced neighbourhoods in Norway. Housing, Theory \& Society, 24(4), 272-292.

Hays, R. B., \& Oxley, D. (1986). Social network development and functioning during a life transition. Journal of Personality and Social Psychology, 50(2), 305-313.

Heracleous, L., \& Hendry, J. (2000). Discourse and the study of organization: Toward a structurational perspective. Human Relations, 53(10), 1251-1286.

Hershatter, G. (1986). The workers of Tianjin, 1900 - 1949. Palo Alto, CA: Stanford University Press.

Holiday Retirement Homes. (2010). Holiday Retirement. Retrieved February 17, 2010 from http://www.holidaytouch.com/

Holstein, J. A., \& Gubrium, J. F. (2000). The self we live by: Narrative identity in a postmodern world. New York: Oxford University Press.

Hong, L. K., \& Duff, R. W. (1994). Widows in retirement communities: The social context of subjective well-being. The Gerontologist, 34(3), 347-352.

Hong, L. K., \& Duff, R. W. (1997). Relative importance of spouses, children, and friends in the life satisfaction of retirement community residents. Journal of Clinical Geropsychology, 3(4), 275-282.

Hopkins, N., \& Dixon, J. (2006). Space, place, and identity: Issues for political psychology. Political Psychology, 27(2), 173-185. 
Humphreys, M., \& Brown, A. D. (2002). Narratives of organizational identity and identification: A case study of hegemony and resistance. Organization Studies (Walter de Gruyter GmbH \& Co. KG.), 23(3), 421.

Hunt, M. E., Feldt, A. G., Marans, R. W., Pastalan, L. A., \& Vakalo, K. L. (1984). Retirement communities: An American original. New York: Haworth Press.

Jacobs, J. (1974). Fun city: An ethnographic study of a retirement community. New York: Holt, Rinehart and Winston.

Jafari, A. (2008). The impact of cultural globalisation on the interrelatedness of identity construction and consumption practices of Iranian youth. Advances in Consumer Research - European Conference Proceedings, 8, 539-541.

Jary, D., \& Bryant, C. G. A. (Eds.). (1996). Anthony Giddens: Critical assessments. London: Routledge.

Jeon, H.-S., \& Dunkle, R. E. (2009). Stress and depression among the oldest-old: A longitudinal analysis. Research on Aging, 31(6), 661-687.

Jones, V. L. (1994). Sun City Center retirement community: An alternative to aging-inplace? Unpublished Arch.Dr, University of Michigan.

Kaffenberger, K. R. (2000). Nursing home ownership: An historical analysis. Journal of Aging and Social Policy, 12(1), 35-48.

Karn, V. (1980). Retirement resorts in Britain. Successes and failures. Gerontologist, $20(3 \mathrm{I}), 331-341$.

Katz, S. (1996). Disciplining old age: The formation of gerontological knowledge. Charolottesville, VA: University of Virginia Press.

Katz, S. (1999). Old age as lifestyle in an active society: Occasional papers, B. Townsend Centre for the Humanities, University of California.

Katz, S. (2000). Busy bodies: Activity, aging, and the management of everyday life. Journal of Aging Studies, 14(2), 135-152.

Katz, S. (2005). Cultural aging: Life course, lifestyle and senior worlds. Peterborough, Ontario, Canada: Broadview.

Kelly, J. R., Steinkamp, M. W., \& Kelly, J. R. (1987). Later-life satisfaction: Does leisure contribute? Leisure Sciences, 9(3), 189 - 199. 
Kim, D., Fisher, D., \& McCalman, D. (2009). Modernism, Christianity, and business ethics: A worldview perspective. Journal of Business Ethics, 90(1), 115-121.

Kleine, I., Robert E. (2006). Exploring the co-evolution of possession constellations, self, and identity. Advances in Consumer Research, 33(1), 256-257.

Kleinsorge, I. K., \& Koenig, H. F. (1991). The silent customers: Measuring customer satisfaction in nursing homes. Journal of Health Care Marketing, 11(4), 12-16.

Kontos, P. C. (1998). Resisting institutionalization: Constructing old age and negotiating home. Journal of Aging Studies, 12(2), 167-184.

Kreiner, G. E., Hollensbe, E. C., \& Sheep, M. L. (2006). Where is the "me" among the "we"? Identity work and the search for optimal balance. Academy of Management Journal, 49(5), 1031-1057.

Krout, J. A., Moen, P., Holmes, H. H., Oggins, J., \& Bowen, N. (2002). Reasons for relocation to a continuing care retirement community. Journal of Applied Gerontology, 21(2), 236-256.

Krippendorff, K. (2004). Reliability in content analysis. Human Communication Research, 30(3), 411-433.

Labov, W. (1972). Language in the inner city: University of Pennsylvania Press.

Labov, W., \& Waletzky, J. (1967). Narrative analysis: Oral versions of personal experience. In J. Helm (Ed.), Essays on the verbal and visual arts (pp. 12-44). Seattle: American Ethnological Society/University of Washington Press.

Laposa, S. P., \& Singer, H. N. (1999). Size, scope and performance of the seniors housing and care industry. Journal of Real Estate Portfolio Management, 5(3), 211-224.

Laslett, P. (1989). A fresh map of life: The emergence of the third age. London: Weidenfeld and Nicolson.

Laws, G. (1995). Embodiment and emplacement: Identities, representation and landscape in Sun City retirement communities. International Journal of Aging and Human Development, 40(4), 253-280.

Laws, G. (1996). "Shot of economic adrenalin": Reconstructing "the elderly" in the retiree-based economic development literature. Journal of Aging Studies, 10(3), 171-188. 
Laws, G. (1997). Spatiality and age relations. In A. Jamieson, S. Harper \& C. Victor (Eds.), Critical approaches to ageing and later life (pp. 90-100). Buckingham: Open University Press.

Layder, D. (1993). New strategies in social research. Cambridge, UK: Polity Press.

Le Bourdais, C. (2010). Entre famille et vieillissement: impact des transformations familiales aux âges avancés/Families and ageing: The impact of family transformations on the aged. Paper presented at the International Council for Canadian Studies Conference, Ageing Societies. The Dynamics of Demographic Change in Canada, Concordia University, Montreal, PQ.

Lee, H. (2003). Independent living of the elderly in senior co-op and rental housing: Residential mobility and satisfaction. Unpublished $\mathrm{PhD}$, University of Minnesota, Ph.D.

Lee, G. R., \& DeMaris, A. (2007). Widowhood, gender, and depression: A longitudinal analysis. Research on Aging, 29(1), 56-72.

Leisure Care. (2010). Retrieved February 17, 2010, from http://www.leisurecare.com/

Leonard, N. H., Beauvais, L. L., \& Scholl, R. W. (1999). Work motivation: The incorporation of self-concept-based processes. Human Relations, 52(8), 969-998.

Lindquist, L. A., \& Golub, R. M. (2004). Cruise ship care: A proposed alternative to assisted living facilities. Journal of the American Geriatrics Society, 52(11), 1951-1954.

Lofland, J., \& Lofland, L. H. (1995). Analyzing social settings: A guide to qualitative observation and analysis. Belmont, CA: Wadsworth.

Lombard, M., Snyder-Duch, J., \& Bracken, C. C. (2002). Content analysis in mass communication: Assessment and reporting of intercoder reliability. Human Communication Research, 28(4), 587-604.

Lombard, M., Snyder-Duch, J., \& Bracken, C. C. (2004). A call for standardization in content analysis reliability. Human Communication Research, 30(3), 433-437.

Longino, C. F., Jr. (1995). Retirement migration in America. Houston, TX: Vacation.

Lovegreen, L. D. (2007). Characteristics and antecedents of residential moves made by retirement community dwelling elders in late life. Unpublished Ph.D, Case Western Reserve University. 
Low, S. (2001). The edge and the center: Gated communities and the discourse of urban fear. American Anthropologist, 103(1), 45-58.

Lucas, S. (2002). From Levittown to Luther Village: Retirement communities and the changing suburban dream. Canadian Journal of Urban Research, 11(2), 323 352.

Lyons, S. T., Higgins, C., \& Duxbury, L. (2007). An empirical assessment of generational differences in basic human values. Psychological Reports, 101(2), 339-352.

MacNeill, D. (1991). Locus-of-control attitudes among residents in continuing care retirement communities. Unpublished $\mathrm{Ph} . \mathrm{D}$, The Fielding Institute.

Madsen, B., \& Willert, S. (1996). Survival in the organization: Gunnar Hjelholt looks back at the concentration camp from an organizational perspective. Aarhus, Denmark: Aarhus University Press.

Manulife Financial. (2010a). Long term care in Ontario 2009. Retrieved September 6, 2010, from https://hermes.manulife.com/canada/repsrcfm-dir.nsf/Public/ ThecostoflongtermcareinOntario/\$File/ONTARIO_LTC_CostReport.pdf.

Manulife Financial. (2010b). Long term care in Manitoba 2009. Retrieved September 6, 2010, from https://hermes.manulife.com/canada/repsrcfm-dir.nsf/Public/ ThecostoflongtermcareinManitoba/SFile/MANITOBA_LTC_CostReport.pdf.

Manulife Financial. (2010c). Long term care in British Columbia 2009. Retrieved September 6, 2010, from https://hermes.manulife.com/canada/repsrcfm-dir.nsf/ Public/ThecostoflongtermcareinBritishColumbia/\$File/BC_LTC_CostReport.pdf.

Mangum, W. P. (1994). Planned housing for the elderly since 1950: History, policies, and practices. In W. E. Folts \& D. E. Yeatts (Eds.), Housing and the aging population: Options for the new century (pp. 25-58). New York: Garland Press.

Manzi, T. (2005). Gated communities as club goods: Segregation or social cohesion? Housing Studies, 20(2), 345-359.

Marans, R. W., Feldt, A. G., Pastalan, L. A., Hunt, M. E., \& Vakalo, K. L. (1983). Retirement communities; Present and future. Washington DC: The Urban Land Institute.

Marascuilo, L. D., \& McSweeney, M. (1977). Nonparametric and distribution-free methods for the social sciences. Monterey, CA: Brooks/Cole Publishing Company. 
Martin, P. Y. (1984). Research note: Trade unions, conflict, and the nature of work in residential service organizations. Organization Studies, 5(2), 169-185.

McHugh, K. E. (2003). Three faces of ageism: Society, image and place. Ageing and Society, 23(2), 165-185.

McHugh, K. E., \& Larson-Keagy, E. M. (2005). These white walls: The dialectic of retirement communities. Journal of Aging Studies, 19(2), 241-256.

McDaniel, S. A. (1999). Untangling love and domination: Challenges of home care for the elderly in a reconstructing Canada. Journal of Canadian Studies, 34(3), 191213.

McIntyre, A. (2008). Participatory action research. Thousand Oaks, CA.: Sage Publications.

McKie, D. (2009, March 23). Advocates demand inquiry into Ontario's costly handling of Royal Crest nursing-home failure Bankruptcy of nursing-home chain cost feds, province, unions tens of millions of dollars. Retrieved September 15, 2010, from http://www.cbc.ca/canada/story/2009/03/23/ontario-royal-crest-nursinghome.html\#ixzz0zdVTncUf.

McMillan Heintz, K. (1976). Retirement communities. New Brunswick, NJ: The Center for Urban Policy Research, Rutgers University.

McQuillen, A. D., Licht, M. H., \& Licht, B. G. (2001). Identity structure and life satisfaction in later life. Basic \& Applied Social Psychology, 23(1), 65-72.

Menzies Malvern. (2010). Menzies Malvern. Retrieved February 18, 2010 from http://www.menziesmalvern.com.

McHugh, K. E. (2000). The "ageless self"? Emplacement of identities in Sun Belt retirement communities. Journal of Aging Studies, 14(1), 103-115.

McHugh, K. E. (2003). Three faces of ageism: Society, image and place. Ageing and Society, 23(2), 165-185.

McHugh, K. E., \& Larson-Keagy, E. M. (2005). These white walls: The dialectic of retirement communities. Journal of Aging Studies, 19(2), 241-256.

McMillan Heintz, K. (1976). Retirement communities. New Brunswick, NJ: The Center for Urban Policy Research, Rutgers University. 
Mellor, P. A., \& Shilling, C. (1993). Modernity, self-identity and the sequestration of death. Sociology, 27(3), 411-431.

Mertens, D. (2005). Research and evaluation in Education and Psychology. Thousand Oaks: Sage.

Meyer, J. C. (1995). Tell me a story: Eliciting organizational values from narratives. Communication Quarterly, 43, 210-224.

Miles, M. B., \& Huberman, A. M. (1994). Qualitative data analysis. Thousand Oaks, London, New Delhi: Sage Publications.

Mitchell, J. M., \& Kemp, B. J. (2000). Quality of life in assisted living homes: a multidimensional analysis. Journals of Gerontology: Series B: Psychological Sciences and Social Sciences, 55(2), P117-P127.

Moen, P., Erickson, M. A., \& Dempster-McClain, D. (2000). Social role identities among older adults in a continuing care retirement community. Research on Aging, 22(5), 559-579.

Mohr, L. A., \& Bitner, M. J. (1991). Mutual understanding between customers and employees in service encounters. Advances in Consumer Research, 18(1), 611617.

National Association of Home Builders. (2007). 2007 CCRC/Congregate living/assisted living/special needs. The Best of 50+ Housing Awards. Retrieved September 21, 2007, from http://www.nahb.org/generic.aspx?genericContentID=81093.

Nelson, H. C. (2001). Residential mobility in later life: A study of the moving decisions of older people in Newcastle upon Tyne. Unpublished Ph.D. Dissertation, University of Northumbria at Newcastle (United Kingdom).

Nelson, H. W. (2000). Injustice and conflict in nursing homes: toward advocacy and exchange. Journal of Aging Studies, 14(1), 39-61.

Nencel, L. (2010). 'Que viva la minifalda!' Secretaries, miniskirts and daily practices of sexuality in the public sector in Lima. Work \& Organization, 17(1), 69-90.

Newcomer, R. J., \& Weeden, J. P. (1986). Perspectives on housing needs and the continuum of care. In R. J. Newcomer, M. P. Lawton \& T. O. Byerts (Eds.), Housing an aging society: Issues, alternatives, and policy (pp. 3-9). New York: Van Nostrand Reinhold. 
New York Times. (2007, January 15, 2008). World business briefing; British insurer buys care homes, from http:/query.nytimes.com/gst/fullpage.html?res= 9E05E7DA1639F937A35753C1A9619C8B63.

Nielsen, S. T. P. (1992). Life events as determinants of wisdom in older adults. Unpublished Ph.D, The University of Arizona.

Ngai, P. (1999). Becoming Dagongmei: The politics of identity and difference in reform China. The China Journal, 42(1), 1-19.

Ngai, P. (2007). Gendering the dormitory labor system: Production, reproduction, and migrant labor in south China. Feminist Economics, 13(3/4,), 239-258.

Norena, C. G. (1970). Juan Luis Vives (Vol. 34). The Hague: Martinus Nijhoff.

Oldman, C., \& Quilgars, D. (1999). The last resort? Revisiting ideas about older people's living arrangements. Ageing \& Society, 19(3), 363-384.

Onwuegbuzie, A. J., \& Daniels, L. G. (2002). Uses and misuses of the correlation coefficient. Research in the Schools, 9, 73-90.

Osgood, N. J. (1982). Senior settlers: Social integration in retirement communities. New York, N.Y.: Praeger, 1982.

Peconic Landing. (2010). Peconic Landing. Retrieved February, 17, 2010, from http://www.peconiclanding.com.

Pentland, B. T. (1999). Building process theory with narrative: From description to explanation. Academy of Management Review, 24(4), 711-724.

Perkinson, M. A., \& Rockemann, D. D. (1996). Older women living in a continuing care retirement community: Marital status and friendship formation. In Relationships between women in later life. New York, NY: England: Harrington Park Press/Haworth Press.

Peterson, A. L. (2005). Seeds of the Kingdom: Utopian communities in the Americas. New York: Oxford University Press.

Phillipson, C. (1998). Reconstructing old age: New agendas in social theory and practice: Sage Publications.

Phillipson, C. (1999). Changing attitudes toward family care for the elderly in Great Britain (Cohort flow and the consequences of population ageing, An international analysis and review). Ottawa: Statistics Canada. 
Phillipson, C. (2007). The 'elected' and the 'excluded': Sociological perspectives on the experience of place and community in old age. Ageing and Society, 27(3), 321342.

Plumridge, L., \& Thomson, R. (2003). Longitudinal qualitative studies and the reflexive self. International Journal of Social Research Methodology, 6(3), 213-222.

Polity Press, 2007. Anthony Giddens. Sociology 5th edition. Biography. Retrieved June 22, 2007, from http://www.polity.co.uk/giddens5/about/bio.asp.

Powell, J. L., \& Biggs, S. (2000). Managing old age: The disciplinary web of power, surveillance and normalization. Journal of Aging and Identity, 5(1), 3-13.

Powell, J. L., \& Wahidin, A. (2005). Ageing in the "risk society". International Journal of Sociology and Social Policy, 25(8), 70 - 83.

Provalis Research. (2004). QDA Miner, qualitative data analysis software: User's guide. Montreal, Canada: Provalis Research.

Rao, H., \& Giorgi, S. (2006). Code breaking: How entrepreneurs exploit cultural logics to generate institutional change. Research in Organizational Behavior, 27, 269304.

Rainbow Vision. (2010). Rainbow Vision Properties Inc. Retrieved February 17, 2010 from http://www.rainbowvisionprop.com/.

Reason, P., \& Bradbury, H. (Eds.). (2001). Handbook of action research: Participative inquiry and practice. Thousand Oaks, CA: Sage.

Reed, J., Payton, V. R., \& Bond, S. (1998a). Settling in and moving on: Transience and older people in care homes. Social Policy and Administration, 32(2), 151-165.

Reed, J., Payton, V. R., \& Bond, S. (1998b). Importance of place for older people moving into care homes. Social Science and Medicine, 46(7), 859-867.

Rentsch, T. (1997). Aging as becoming oneself: A philosophical ethics of late life. Journal of Aging Studies, 11(4), 263-271.

Residential Ocean Liners. (2010). The seven wonders of the seas luxurious ocean liners. Retrieved November 7, 2010, from http://www.residentialvessels.com/index.html.

Rhodes, C., \& Brown, A. D. (2005). Narrative, organizations and research. International Journal of Management Reviews, 7(3), 167-188. 
Riessman, C. K. (1990). Divorce talk: Women and men make sense of personal relationships. New Brunswick, NJ: Rutgers University Press.

Riessman, C. K. (1993). Narrative analysis. Newbury Park, CA: Sage.

Riessman, C. K. (2000). Stigma and everyday resistance practices: Childless women in South India. Gender and Society, 14(1), 111-135.

Riessman, C. K. (2002a). Narrative analysis. In A. M. Huberman \& M. B. Miles (Eds.), The qualitative researcher's companion. Thousand Oaks, CA: Sage.

Riessman, C. K. (2002b). Analysis of personal narratives. In J. F. Gubrium \& J. A. Holstein (Eds.), Handbook of interview research (pp. 695-710). Thousand Oaks, CA: Sage Publications.

Riessman, C. K. (2003). Performing identities in illness narrative: Masculinity and multiple sclerosis. Qualitative Research, 3(1), 5 - 33.

Riessman, C. K. (2004). Narrative interviewing. In M. S. Lewis-Beck, A. Bryman \& T. Futing Liao (Eds.), Encyclopedia of social science research methods. London, UK and Newbury Park, CA: Sage Publications.

Riessman, C. K. (2008). Narrative methods for the human sciences: Thousand Oaks, CA: Sage Publications.

Romanelli, E., \& Tushman, M. L. (1994). Organizational transformation as punctuated equilibrium: An empirical test. Academy of Management Journal, 37(5), 11411666.

Rotary International Zones 25 \& 26. (2010). Helpguide.org. A trusted non-profit source. Retrieved October 15, 2010, from http://helpguide.org/elder/ independent_living_seniors_retirement.htm.

Rowe, J. W., \& Kahn, R. L. (1997). Successful aging. The Gerontologist, 37(4), 433-440.

Rowles, G. (1978). Prisoners of space? Exploring the geographical experience of older people. Boulder, Colorado: Westview.

Rowland, W. (Writer) (2007). Living forever: The longevity revolution series. The Nature of Things with David Suzuki. [Television]. In Canadian Broadcasting Corporation (Producer). 
Rudman, D. L. (2006). Shaping the active, autonomous and responsible modern retiree: An analysis of discursive technologies and their links with neo-liberal political rationality. Ageing and Society, 26(2), 181-201.

Rudman, D. L., Friedland, J., Chipman, M., \& Sciortino, P. (2006). Holding on and letting go: The perspectives of pre-seniors and seniors on driving self-regulation in later life. Canadian Journal on Aging/Revue canadienne du vieillissement, $25(1), 65-76$.

Rutes, W. A., Penner, R. H., \& Adams, L. (2001). Hotel design, planning, and development. London and New York City: W. W. Norton \& Company.

Saren, M. (2007). To have is to be? A critique of self-creation through consumption. Marketing Review, 7(4), 343-354.

Sayre, S., \& Horne, D. (1996). I shop, therefore I am: The role of possessions for self definition. Advances in Consumer Research, 23(1), 323-328.

Scherwitz, L., Pullman, M., McHenry, P., Gao, B., \& Ostaseski, F. (2006). A contemplative care approach to training and supporting hospice volunteers: A prospective study of spiritual practice, well-being, and fear of death. The Journal of Science and Healing, 2(4), 304-313.

Shenkar, O. (1996). The firm as a total institution: Reflections on the Chinese state enterprise. Organization Studies (Walter de Gruyter GmbH \& Co. KG.), 17(6), 885-907.

Sherman, E., \& Cooper, P. (1988). Life satisfaction: The missing focus of marketing to seniors. Journal of Health Care Marketing, 8(1), 69-71.

Shippee, T. P. (2008). Social cohesion in communities with high residential mobility: The paradox of aging in place. Ph.D., Purdue University.

Shore, R. (2007, October 12). Company plans housing for Vancouver's gay and grey. Canada.com Retrieved November 17, 2007, from http://www.canada.com/topics/news/national/story.html?id= ddd4c8ea-bc18-4bb0-98c6-e9c348215236\&k=69251.

Siegel, S. (1956). Nonparametric statistics for the behavioral sciences: McGraw-Hill.

Siegel, S., \& Castellan, N. J. J. (1988). Nonparametric statistics for the behavioral sciences (Second ed.): McGraw-Hill. 
Sikorska-Simmons, E. (2001). Development of an instrument to measure resident satisfaction with assisted living. Journal of Applied Gerontology, 20(1), 57-73.

Slack, P. (1995). The English poor law. New studies in economic and social history 1531-1782. New York and Cambridge, England: Cambridge University Press.

Sluss, D. M., \& Ashforth, B. E. (2007). Relational identity and identification: Defining ourselves through work relationships. Academy of Management Review, 32(1), 932.

Smith, C. (2003). Living at work: Management control and the dormitory labour system in China. Asia Pacific Journal of Management, 20(3), 333-358.

Spencer, C. (2008). Aging and the law in Canada: Assisted living and retirement homes. Retrieved September 12, 2010, from http://www.canadianelderlaw.ca/ Assisted\%20Living.htm.

Statistics Canada. (2001a). 2001 Community profiles. Retrieved May 26, 2010, from http://www12.statcan.ca/english/profil01/CP01/Search/SearchForm_Results.cfm? Lang $=$.

Statistics Canada. (2001b). Age and sex: Highlight tables, 2001 Census. Retrieved May 26, 2010, from http://www12.statcan.ca/english/census01/products/highlight/ AgeSex/Page.cfm?Lang $=\mathrm{E} \& \mathrm{Geo}=\mathrm{PR} \& \mathrm{View}=1 \& \mathrm{Table}=4 \mathrm{a} \&$ StartRec $=$ $1 \&$ Sort $=2 \& B 1=$ Median $\& B 2=$ Both .

Stimson, R. J., \& McCrea, R. (2004). Push-pull framework for modelling the relocation of retirees to a retirement village: The Australian experience. Environment and Planning A: International Journal of Urban and Regional Research, 36(8), 14511470 .

Stearns, P. N. (Ed.). (2001). Encyclopedia of world history (Sixth ed.): Houghton Mifflin Company.

Stevens, J. P. (2002). Applied multivariate statistics for the social sciences (Fourth ed.). New Jersey, London: Lawrence Erlbaum Associates, Publishers.

Strauss, A., \& Corbin, J. (1998). Basics of qualitative research (Second ed.). Thousand Oaks, London, New Delhi: Sage Publications.

Streib, G. F. (2002). An introduction to retirement communities. Research on Aging, 24(1), 3-9. 
Streib, G. F., Folts, W. E., \& La Greca, A. J. (1985). Autonomy, power, and decisionmaking in thirty-six retirement communities. Gerontologist, 25(4), 403-409.

Streib, G., F. , \& Metsch, L., R. (2002). Conflict in retirement communities: Applying an analytical framework. Research on Aging, 24(1), 67-86.

Stringer, E. T. (2007). Action research (3rd ed.). Thousand Oaks, CA: Sage Publications.

Stutts, N. B., \& Barker, R. T. (1999). The use of narrative paradigm theory in assessing audience value conflict in image advertising. Management Communication Quarterly, 13(2), 209-244.

Sutton, R. P. (2004). Communal utopias and the American experience: Secular communities, 1824-2000. Westport, Conn.: Praeger Publishers.

Szymanski, D. M., \& Henard, D. H. (2001). Consumer satisfaction: A meta-analysis of the empirical evidence. Journal of the Academy of Marketing Science,, 29(1), 1635 .

Taylor, C. Sources of the moral self. Cambridge, Massachusetts: Cambridge University Press, Harvard University Press.

The Economist. (2008, December 30). Demographics greying globe. Retrieved November 15, 2010, from http://www.economist.com/node/12847201.

The Hindu India's Online Newspaper. (2003, June 25). Retirement resort. Retrieved June 30, 2007, from http://www.thehindujobs.com/thehindu/mp/2003/06/25/stories/ 2003062500050200.htm.

Timmermann, S. (2006). Housing and retirement living: Redefining the continuum. Journal of Financial Service Professionals, 60(1), 23-27.

Tinsley, H. E. A., \& Weiss, D. J. (1975). Interrater reliability and agreement of subjective judgements. Journal of Counseling Psychology, 22(4), 358-376.

Tonn, J. C. (2003). Mary P. Follett: Creating democracy, transforming management. New Haven: Yale University Press.

Townsend, P. (1962). The last refuge. A survey of residential institutions and homes for the aged in England and Wales. London: Routledge \& Kegan Paul.

Townsend, P. (1981). The structured dependency of the elderly: A creation of social policy in the twentieth century. Ageing and Society(1), 5-28. 
Trottier, H., Martel, L., Houle, C., \& Berthelot, J. M. (2000). Living at home or in an institution: What makes the difference for seniors? Health Reports, 11(4).

Truett, K. R. (1993). Age differences in conservatism. Personality and Individual Differences, 14(3), 405-411.

Tucker, K. H. J. (1998). Anthony Giddens and modern social theory. London: Sage.

Tulle, E., \& Mooney, E. (2002). Moving to "age-appropriate" housing: Government and self in later life. Sociology, 36(3), 685-702.

Turcotte, M., \& Schellenberg, G. (2007). A portrait of seniors in Canada 2006. Ottawa, ON: Statistics Canada.

Vacha-Haase, T., \& Thompson, B. (2004). How to estimate and interpret various effect sizes. Journal of Counseling Psychology, 51(4), 473-481.

Van den Hoonaard, D. K. (1992). The aging of a retirement community. Unpublished Ph.D, Loyola University of Chicago.

Van den Hoonaard, D. K. (2002). Life on the margins of a Florida retirement community. Research on Aging, 24(1), 50-66.

VanderKlippe, N. (2010, Sep. 15, 2010). Oil sands camps go five-star. The Globe and Mail. Retrieved September 16, 2010, from http:/www.theglobeandmail.com/ report-on-business/industry-news/energy-and-resources/oil-sands-camps-go-fivestar/article1709191/.

Van De Ven, A. H. (1989). Nothing is quite as practical as a good theory. Academy of Management Review, 14(4), 486-489.

Van Maanen, J. (1978). People processing: Strategies of organizational socialization. Organizational Dynamics, 7(1), 18-36.

Vogel, D. (1991). Business ethics: New perspectives on old problems. California Management Review, 33(4), 101-117.

Voss, C., Tsikriktsis, N., \& Frohlich, M. (2002). Case research in operations management. International Journal of Operations \& Production Management, 22(2), 195 - 219.

Wagner, D. (2005). The poorhouse: America's forgotten institution: Rowman \& Littlefield. 
Wallenmac, A., \& Sims, D. (1998). The struggle with sense. In D. Grant, T. Keenoy \& C. Oswick (Eds.), Discourse and organization. London, Thousand Oaks, New Delhi: Sage.

Ward, V. (2009). On Yoda, trouble, and transformation: The cultural context of therapy and supervision. Contemporary Family Therapy, 31(3), 171-176.

Waring, A. (2008). Health club use and "lifestyle": exploring the boundaries between work and leisure. Leisure Studies, 27(3), 295-309.

Wattanasuwan, K., \& Elliott, R. (1999). The Buddhist self and symbolic consumption: The consumption experience of the teenage Dhammakaya Buddhists in Thailand. Advances in Consumer Research, 26(1), 150-155.

Webb, J. (2004). Organizations, self-identities and the new economy. Sociology, 38(4), 719-738.

Weick, K. E. (1995). Sensemaking in organizations. Thousand Oaks, CA: Sage.

West, C. (1982). Why can't a woman be more like a man? Work \& Occupations, 9(1), 529.

Wilcox, B. L., \& Holahan, C. J. (1976). Social ecology of the megadorm in university student housing. Journal of Educational Psychology, 68(4), 453-458.

Williams, A., \& Guendouzi, J. (2000). Adjusting to "the home": Dialectical dilemmas and personal relationships in a retirement community. Journal of Communication, $50(3), 65-82$.

Williams, A., \& Ylänne-McEwen, V. (2000). Elderly lifestyles in the 21st century: Doris and Sid's excellent adventure. Journal of Communication, 50(3), 4-8.

Williams, D. R. (2002). Leisure identities, globalization, and the politics of place. Journal of Leisure Research, 34(4), 351-367.

Yin, R. K. (1994). Case study research: Design and methods. Thousand Oaks: Sage Publications.

Yin, R. K. (2003). Applications of case study research (Second ed. Vol. 34). Thousand Oaks, London, New Delhi: Sage Publications.

Youngblood, S. M. (2005). Widowhood: Change and well-being in a Florida leisureoriented retirement community. Unpublished Master of Arts, University of Florida, Gainesville, FL. 
Yow, V. R. (1994). Recording oral history: A practical guide for social scientists. Thousand Oaks: Sage Publications.

Ylänne-McEwen, Y. (2000). Golden times for golden agers: Selling holidays as lifestyle for the over 50s. Journal of Communication, 50(3), 83-99. 


\section{APPENDIX A}

\section{Glossary}

Abstract systems: examples include symbolic tokens (e.g., money), and expert systems (e.g., medicine, engineering, management sciences).

Agency: The ability to act and to influence. Giddens assumes that agents are active, knowledgeable and competent. Agents shape circumstances, particularly their immediate social surroundings (Giddens, 1991).

Bodily demeanours: "the stylised conduct of the individual within the contexts of day-today life, involving the use of appearance to create specific impressions of self" (Giddens, 1992. p. 242).

Communal lifestyle organization: [working definition] a planned age-restricted community with a resort-like upscale appearance and leisure lifestyle. The organization may be non-profit or revenue maximizing. Often owned and managed by corporations, communal lifestyle organizations may also be resident owned and managed.

Crises: Can be fateful moments or other events that disrupt preferred lifestyle choices, day-to-day routines, or self-identity. These crises can produce psychological discomfort and distress. Crises can occur at a particular point in time, such as a fateful moment, or may occur over lengthy periods of time such as care giver stress.

Disembedding: "the lifting out of social relationships from local contexts and their recombination across indefinite time/space distances" (Giddens, 1992. p. 242).

Emancipatory politics: "the politics of freedom from exploitation, inequality or oppression" (Giddens, 1992. p. 242).

Existential questions: "queries about basic dimensions of existence, in respect of human life as well as the material world, which all human beings 'answer' in the contexts of their day-to-day conduct" (Giddens, 1992. p. 242).

Expert systems: "systems of expert knowledge, of any type, depending on rules of procedure transferable from individual to individual" (Giddens, 1991, p. 243). Examples include medicine, engineering and management sciences.

Extrinsic criteria: "influences on social relations or social life not governed by the institutional reflexivity of modernity" (Giddens, 1992. p. 243). 
Fateful moments: "moments at which consequential decisions have to be taken or courses of action initiated" (Giddens, 1992. p. 243).

Identity switching: for entertainment a person adopts a different identity by wearing a costume, makeup, or hat and may change their behaviour accordingly.

Institutional reflexivity: "the reflexivity of modernity, involving the routine incorporation of new knowledge or information into environments of action that are thereby reconstituted or reorganised" (Giddens, 1991, p. 243).

Internally referential: "the circumstances whereby social relations, or aspects of the natural world, become organised reflexively in terms of internal criteria." (Giddens, 1991, p. 243). For example, decisions in abstract systems are guided by intrinsic criteria that are internal and perhaps unique to a system of thought, like risk calculation or control, rather than extrinsic criteria like tradition, and moral or existential issues.

Late modernity: "the current phase of development of modern institutions, marked by the radicalising and globalising of basic traits of modernity" (Giddens, 1991, p. 243).

Life-planning: "the strategic adoption of lifestyle options, organised in terms of the individual's projected lifespan, and normally focused through the notion of risk" (Giddens, 1991, p. 243).

Life politics: "the politics of self actualisation, in the context of the dialectic of the local and global and the emergence of the internally referential systems of modernity" (Giddens, 1991, p. 243).

Lifestyle: refers to a routine style of life ". . . a more or less integrated set of practices which an individual embraces, not only because such practices fulfill utilitarian needs, but because they give material form to a particular narrative of self-identity . . Lifestyles are routinised practices, the routines incorporated into habits of dress, eating, modes of acting and favoured milieu for encountering others; but the routines followed are reflexively open to change in the light of the mobile nature of self-identity" (Giddens, 1991, p. 81).

Lifestyle fit: a calculation that determines whether a person's lifestyle 'fits' an organization's lifestyle.

Lifestyle sector: "a time/space 'slice' of an individual's overall activities, within which a fairly consistent set of social practices is followed" (Giddens, 1991, p. 243).

Narrative of the self: "the story or stories by means of which self-identity is reflexively understood, both by the individual concerned and by others" (Giddens, 1991, p. 243). 
Ontological security: "a sense of continuity and order in events, including those not directly within the perceptual environment of the individual" (Giddens, 1991, p. 243).

Organization: "what distinguishes modern organisations is not so much their size, or their bureaucratic character, as the concentrated reflexive monitoring they both permit and entail. Who says modernity says not just organisations, but organisation - the regularised control of social relations across indefinite time-space distances" (Giddens, 1991, p. 16).

Place as phantasmagoric: "the process whereby local characteristics of place are thoroughly invaded by, and reorganised in terms of, distanciated social relations" (Giddens, 1991, p. 244). Characteristics, or items belonging to another place, are imported to a new local. An example would be an Egyptian bazaar in downtown Toronto.

Power: personal power is "ability" - the ability to get things done, and the ability to achieve one's wishes, even against the desires of others (Tucker, 1998 p. 82).

Powerlessness refers to the inability to achieve one's wishes: "The experience of powerlessness, considered as a psychic phenomenon, naturally always relates to aims, projects or aspirations held by the individual, as well as to the composition of the phenomenal world" (Giddens, 1991, p. 193).

Pure relationship: "a social relation which is internally referential, that is, depends fundamentally on satisfactions or rewards generic to that relationship itself" (Giddens, 1991, p. 244).

Reflexive project of the self: "The process whereby self-identity is constituted by the reflexive ordering of self-narratives" (Giddens, 1991, p. 244).

Regimes. "Regularised modes of behaviour relevant to the continuance or cultivation of bodily traits" (Giddens, 1991, p. 244).

Self-identity: "the self as reflexively understood by the individual in terms of his or her biography" (Giddens, 1991, p. 244).

Separation of time and space: 'the disentangling of separated dimensions of 'empty' time and 'empty' space, making possible the articulation of disembedded social relations across indefinite spans of time/space" (Giddens, 1991, p. 244). An example would be the division of the world into time meridians.

Sequestration of experience: "the separation of day-to-day life from contact with experiences which raise potentially disturbing existential questions - particularly experiences to do with sickness, madness, criminality, sexuality and death" (Giddens, 1991, p. 244).

Trajectory of the self: "the formation of a specific lifespan in conditions of modernity, by 
means of which self-development, as reflexively organised, tends to become internally referential" (Giddens, 1991, p. 244).

Total institution: a residential organization with prison-like conditions where management and staff exercise rigid control over every aspect of life, including bodily regimes (e.g., food, washing) and appearance. Goffman describes a total institution as follows: "First all aspects of life are conducted in the same place and under the same single authority. Second, each phase of the member's daily activity is carried on the company of a large batch of others, all of whom are treated alike and required to do the same thing. Third, all phases of the day's activities are tightly scheduled, with one activity leading at a prearranged time into the next, the whole sequence of activities being imposed from above by a system of explicitly formal rulings and a body of officials. Finally, the various enforced activities are brought together in a single rational plan purportedly designed to fulfill the official aims of the institution ... The handling of many human needs by the bureaucratic organization of whole blocks of people - whether or not this is necessary or an effective means of social organization in the circumstances - is the key fact of total institutions (Goffman, 1961, p. 6). 


\section{APPENDIX B}

\section{Internet Advertising: Selected Companies}

This section contains selected text from internet sites advertising gated communities, retirement resorts, assisted living, and continuing care (or lifecare) communities.

Air Force Village West Inc., Riverside California, U.S.A. "AFVW is a very unique retirement community dedicated from its origin to the well being of a very special group of people - retired or honorably discharged military officers of ALL branches of the Uniformed Services, their spouses or surviving spouses who are 55 years or better. It's for those, who through the many years of unselfish commitment of

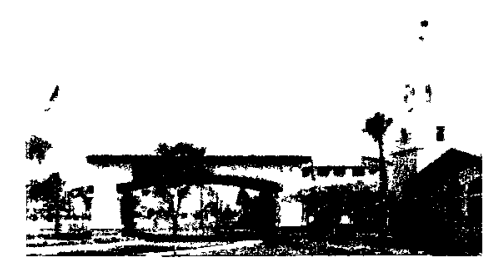
time, talent and service to our great nation. That's YOU, and we invite you to come home to AFVW. You will enjoy sharing a lifetime of memories in your new home among old friends-people like you who have come to enjoy some of the best years of their lives. It's here that the years of service are rewarded with a much deserved worry-free lifestyle where peopie care for each other and 'We I ake Care of Our Own. (Air Horce Village West Inc., 2010).

\section{Assisted Living Concepts Inc.}

"Life just got easier ...

We believe the good things you imagine for your future years are possible at Assisted Living Concepts. We are dedicated to making your life easier. Here you will find gracious living, caring help when you need it, safety and security for peace of mind, and a chance to cultivate personal interests and lasting friendships - all with unmatched ease." (Assisted Living Concepts, 2010).

\section{Classic Residence by Hyatt}

"Worry less, live more. Enjoy enriching opportunities. Experience greater peace of mind. Welcome home. For more than 20 years, Classic Residence by Hyatt retirement communities have helped residents worry less and live more. For a more predictable monthly fee than the unexpected costs of home ownership, you will enjoy a comfortable independent living home and an attentive staff to assist you - plus the added comfort of knowing that help

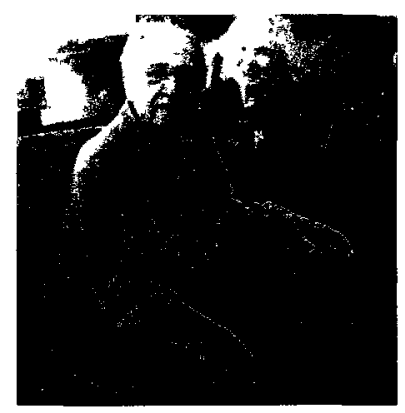
is available if the need arises. Choose the senior living option that fits your preferences and needs. Classic Residence by Hyatt features two types of retirement communities: 
rental senior living communities and continuing care retirement communities." Picture: Scottsdale Grayhawk (Classic Residence by Hyatt, 2010).

\section{Del Webb}

"The Del Webb lifestyle. Concrete steel and lumber can make the buildings but people make the community - Del Webb. At Del Webb you buy more than a home, you take ownership in a community. You embrace a way of life that allows you to live life to the fullest, to discover sides of yourself you never knew existed, to connect with a community and relate to your neighbors more meaningfully than ever. Whether you decide that a smaller setting or a

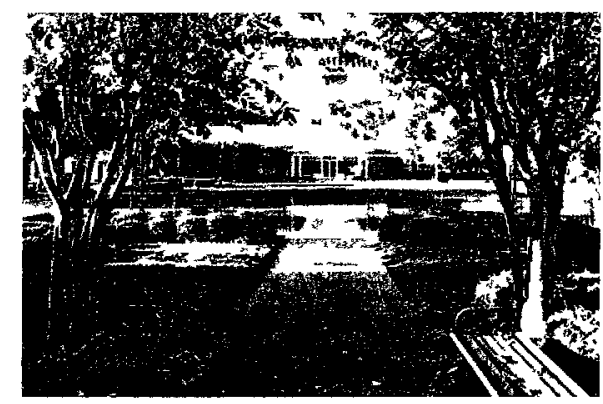
large, resort-style setting is where you're most at home, you'll meet like-minded folks with shared interests, common backgrounds, and similar values. We've seen it time and again; every Del Webb community takes on the personality of those who live there You'll have a hand in shaping that identity because everyone plays a part, everyone brings something to the party. So chart a new course, start fresh, free your inhibitions, let yourself shine at Del Webb" Pirture. Sun City Hilton Head (Del Webb, 2010),

\section{Holiday Retirement Homes}

"Independent Retirement Living for Seniors.

Since 1971, our entire focus has been on providing our residents with a physically, emotionally, and mentally enriching lifestyle. The Holiday Retirement family is over 300 retirement

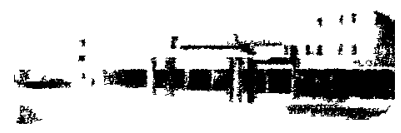
communities strong and is North America's leading provider of independent retirement living (American Senior Housing Association, 2007). Holiday Retirement provides an all-inclusive retirement living experience for seniors including 24/7 Live-In Managers, Chef Prepared Meals, Transportation, Housekeeping and even Travel Services." Picture: Amber Meadow, Winnipeg, Manitoba, Canada. (Holiday Retirement, 2010).

\section{Leisure Care Retirement Communities}

"Seriously, we dare you to call it an old folks home. Our communities are fun. Way over the top, grinning from ear-to-ear fun. They're more like luxury resorts than retirement communities. And we made them that way for one simple reason. Because, hey, you're retired. You deserve to have crazy amounts of fun. We call it Five-Star Fun. You may just call it paradise." (Leisure Care, 2010).

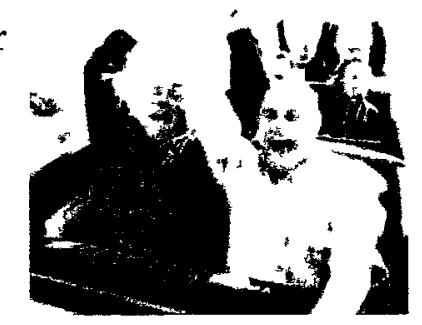


Leisure Care Retirement Communities, Tapestry at Village Gate West, Toronto, Ontario. Canada.

"Extraordinary, really. You can, within reason, live anywhere you want. So why choose a Tapestry

Retirement Community? Focus your gaze on that word "choose." At Tapestry, choice is not a luxury. It's just how you live here. Because as you've learned, ignoring the rules is much more fun. Tapestry is elegant and fun, like being at a five-star resort except you're living in your own beautiful home, with someone else doing all your chores. And you can tell your kids to relax and stop worrying as we offer a full scope of assisted living services should you require them. At Tapestry you make the rules, so you can live just as you please. Dining, health and wellness, activities, travel and more everything is precisely tailored to your idea of fun, every single day. It's about time, don't you think?" (Leisure Care, 2010).

Menzies Malvern, Melbourne, Australia.

"The time of your life. A world of sophistication and style. Menzies Malvern is an exclusive residential development for those seeking independence, security and a truly luxurious lifestyle in their senior years. Comprising spacious apartments, elegant common areas and a stunning range of facilities and services, Menzies is certain to impress even the most discerning. Located within one of

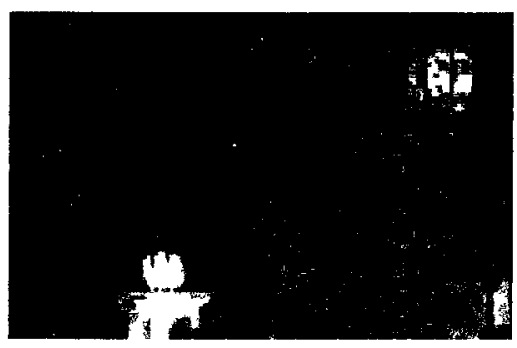
Melbourne's most desirable suburbs and only a short distance from the city centre with its vibrant arts precinct, residents can enjoy a wonderfully secure lifestyle with all of life's luxuries." (Menzies Malvern, 2010).

Peconic Landing, Greenport, Long Island, New York, U.S.A. "Life looks good from here. A breathtaking waterfront location on Long Island's North Fork, equity benefits through cooperative ownership and the opportunity and time to explore your passions make Peconic Landing an unparalleled lifecare community. Mission statement and philosophy: Peconic Landing, a not-for-profit organization, strives to be one of the preeminent continuing care retirement communities in the United States. We are achieving our goals by operating as a partnership with residents, our Board of Trustees, management and staff. (Peconic Landing, 2010).

\section{RainbowVision Properties Inc.}

"Home. There's no place like it! Your home at RainbowVision is your private oasis. Enjoy a level of resort style hospitality that can only be found at RainbowVision, the first community of its kind in the world. Experience Life

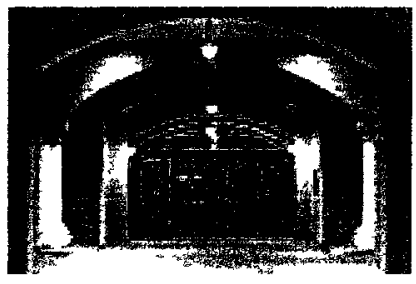


Superb amenities include concierge services, first class dining, Billie Jean King Fitness Centers/Spas/Tennis Centers, cabaret and lounge and so much more. RainbowVision- the Dream Your Heart Made Come True - now open in Santa Fe, NM and soon-to-be-open in Palm Springs, CA. See us soon in the Bay Area, CA and in Vancouver, BC, Canada with Plum Living Properties. Beautifully designed Condominium, Independent and Assisted Living options available. At Rainbow Vision it's not a lifestyle - it's your life." (Rainbow Vision, 2010). 


\section{APPENDIX C}

\section{Participant Recruitment}

\section{C.01 Letter to residents}

Date

Subject: Ph.D. Study. What is it like to live in an organization?

Dear Sir or Madame: (To people who live at Lakelands)

I am writing this letter to ask if you would be willing to participate in a study I am doing at Lakelands. I am studying the question of what it is like to "live in an organization"? Basically the question is, can people live the way they would like when their home is an organization like Lakelands? This question is important because it relates to people's happiness and self-expression.

My interest in this topic comes from visiting my mother who lived at Lakelands from 2002 to 2006. I am doing this study to fulfill the requirements of a Ph.D. in Management. In addition to a Ph.D. thesis, the results of the research may appear in articles published in academic journals, conference papers and perhaps even a book. You may receive a copy of the summary report, if you wish.

My thesis work is supervised by Dr. Lorraine Dyke, an Associate Professor at the Eric Sprott School of Business at Carleton University in Ottawa. This research has been reviewed and received ethics clearance by the Research Ethics Committee at Carleton University. Also, the research has been approved by Lakelands' owners.

In participating, you will not only be talking to me, but to a much wider audience. One of the features of this study is that I will quote people's stories, in their exact words, so that the full impact of their experience can be understood by readers. The purpose is to convey to readers the realities of day-to-day life at Lakelands. In participating, you will be helping researchers, governments and business to understand what it is like for you to live in a modern residential organization like Lakelands. This research is important since more and more people are living in organizations such as this. Although research exists on older persons' experiences in nursing homes and gated communities, none exists on organizations like Lakelands.

If you decide to participate, your identity will remain confidential. I may quote your exact words in these documents, (if you permit), but your name will never appear, nor any information that will allow people to identify you.

I will be interviewing other residents like yourself, in total about 30 people. For anyone with hearing difficulties, I can use a device to amplify my voice. If you decide to participate, I will ask you to sign the attached consent form. Then I will interview you for 
about one hour. You may decline to answer any question, as you wish. I will tape record the conversation, if you give your permission. Afterwards, I will type out the interview and give you a copy for your review and approval. At that time, you may add or delete any information. If there are any parts of the interview you would not like to see in print, you may indicate this when reviewing the interview transcript. Once the research is finished (e.g., the Ph.D. thesis, articles), I will destroy the tape. In the interim, your interview will be kept secure: locked in my apartment at Lakelands, or in my home in Clayton, Ontario.

In making your decision about whether or not to participate, you may consider whether the benefits outweigh the costs to you. For instance, you might find that talking about your move to Lakelands, or your efforts to adapt to life at Lakelands, bring to the surface difficult emotions. If so, you may decide not to participate.

If you do decide to participate, you may also change your mind. You may withdraw from the study up to 10 days after you approve the interview transcript. Should you decide to withdraw you may decide at that time if I may use the information you have provided, or you may request that it be destroyed.

I would be happy to answer any concerns or questions you might have about participating in this study. I expect to be living at Lakelands for two months, starting in room $\bullet$. As well, if you have any concerns or questions about your involvement in this study you may contact the Carleton University Ethics Chair:

Professor Antonio Gualtieri, Chair

Carleton University Research Ethics Committee

Office of Research Services

Carleton University

1125 Colonel By Drive

Ottawa, ON K1S 5B6

Telephone: 613-520-2517

E-mail: ethics@carleton.ca

In addition, you may contact my Ph.D. thesis supervisor, Dr. Lorraine Dyke, with questions. See contact information below.

Yours truly,

Margot Haug

Dr. Lorraine Dyke, Associate Professor, Eric Sprott School of Business, 1125 Colonel By Drive

Apartment at Lakelands: Carleton University, Ottawa, ON K1S 5B6 Telephone at Lakelands:

Telephone: 613-520-2600 x2389

E-mail: lorraine_dyke@carleton.ca 


\section{C.02 Letter to Lakelands' management}

Date

Subject: Ph.D. Study. What is it like to live in an organization?

Dear Sir or Madame: (to Lakelands' management)

I am writing this letter to ask if you would be willing to participate in a study I am doing at Lakelands. I am studying the question of what it is like to "live in an organization"? Basically, the question is, can people live the way they would like when their home is an organization like Lakelands? This question is important because it relates to people's happiness and self-expression.

I would appreciate your perspective to round out this study: to know how Lakelands works, and to put residents' observations into context. If you decide to participate, I will be asking you questions like: What is your role at Lakelands? Are you trying to create a certain style of life here at Lakelands? Could you give me an example of how you deal with resident complaints?

My interest in this topic comes from visiting my mother who lived at Lakelands from 2002 to 2006. I am doing this study to fulfill the requirements of a Ph.D. in Management. In addition to a Ph.D. thesis, the results of the research may appear in articles published in academic journals, conference papers and perhaps even a book. You may receive a copy of the summary report, if you wish.

My thesis work is supervised by Dr. Lorraine Dyke, an Associate Professor at the Eric Sprott School of Business at Carleton University in Ottawa. This research has been reviewed and received ethics clearance by the Research Ethics Committee at Carleton University. Also, the research has been approved by Lakelands' owners.

In participating, you will not only be talking to me, but to a much wider audience. One of the features of this study is that I will quote people's stories, in their exact words, so that the full impact of their experience can be understood by readers. The purpose is to convey to readers the realities of day-to-day life at Lakelands. In participating, you will be helping researchers, governments and business to understand what it is like to live in a modern residential organization like Lakelands. This research is important since more and more people are living in organizations such as this. Although research exists on older persons' experiences in nursing homes and gated communities, none exists on organizations like Lakelands.

If you decide to participate, I will ask you to sign the attached consent form. Then I will interview you for about one hour. You may decline to answer any question, as you wish. I will tape record the conversation, if you give your permission. Afterwards, I will type out the interview and give you a copy for your review and approval. At that time, you may add or delete any information. If there are any parts of the interview you would not like to see in print, you may indicate this when reviewing the interview transcript. Once the research is finished (e.g., the Ph.D. thesis, articles), I will destroy the tape. In the interim, your interview will be kept secure: locked in my apartment at Lakelands, or 
in my home in Clayton, Ontario.

Since there is only one person in your position, I cannot ensure you confidentiality. Your name will never appear in written documents, however, in quoting you or summarizing your answers, your organizational role may be mentioned, which means that people living and working at Lakelands will be able to identify you - if they read the documents.

In making your decision about whether or not to participate, you may consider whether the benefits outweigh the costs to you. If you do decide to participate, you may also change your mind. You may withdraw from the study up to 10 days after you approve the interview transcript. Should you decide to withdraw you may decide at that time if I may use the information you have provided, or you may request that it be destroyed.

I would be happy to answer any concerns or questions you have about participating in this study. I expect to be living at Lakelands for two months, starting in room $\bullet$. As well, if you have any concerns or questions about your involvement in this study you may contact the Carleton University Ethics Chair:

Professor Antonio Guiltier, Chair

Carleton University Research Ethics Committee

Office of Research Services

Carleton University

1125 Colonel By Drive

Ottawa, ON K1S 5B6

Telephone: 613-520-2517

E-mail: ethics@carleton.ca

In addition, you may contact my Ph.D. thesis supervisor, Dr. Lorraine Dyke, with questions. See contact information below.

Yours truly,

Margot Haug

Apartment at Lakelands:

Telephone at Lakelands:
Dr. Lorraine Dyke, Associate Professor, Eric Sprott School of Business, 1125 Colonel By Drive Carleton University, Ottawa, ON K1S 5B6 Telephone: $613-520-2600 \times 2389$ E-Mail: lorraine_dyke@carleton.ca 


\section{C.03 Consent form \#1}

\section{Consent form \#1}

(To be filled out before the interview. Original signed copy kept by researcher. Give copy to participant.)

I, have read the above letter and understand that I am participating in a research project and I voluntarily agree to participate.

Signed

Dated

Address

Permission to be tape recorded? Yes $\square \quad$ No $\square$

I would like a copy of the summary report Yes $\square$ No

Please send the report to the above postal address, or to the following address or e-mail:

Although there will be no risk to you, either psychologically or physically, you may experience a range of feelings, both positive and negative, during and after the interview. Negative feelings might include sadness. Positive feelings may include pride in your accomplishments. Should you feel uncomfortable because of any emotions that arise, you are free to withdraw from the study. 


\section{C.04 Consent form \#2}

\section{Consent form \# 2}

(To be filled out after reviewing the interview transcript. The original signed copy of this form and approved transcript goes to the researcher and a copy goes to the participant.)

I, _ have reviewed and commented on the written transcript of my interview with Margot Haug.

I give Margot Haug permission to quote this transcript in written documents on two conditions: my name does not appear in print, and the sections of the transcript I have crossed out and initialed do not appear in print.

Yes $\square \quad$ No

I understand I may withdraw from this study, and have this interview transcript destroyed, within the next ten days (until ). I understand, that after this point in time, Margot Haug may begin using this interview transcript in written reports, with the exception of any crossed out sections.

Signed

Date 


\section{APPENDIX D}

\section{Photographs of Lakelands}

Lakelands' front entrance, April 2009

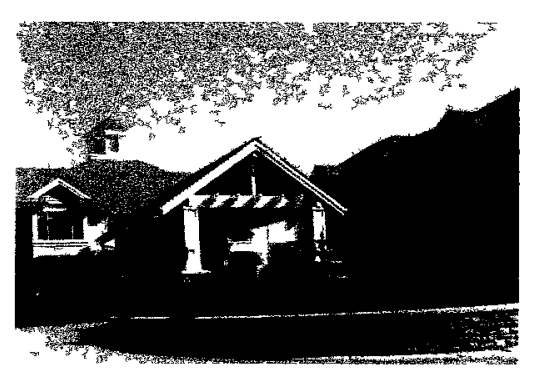

Gardens and pond, Spring 2006

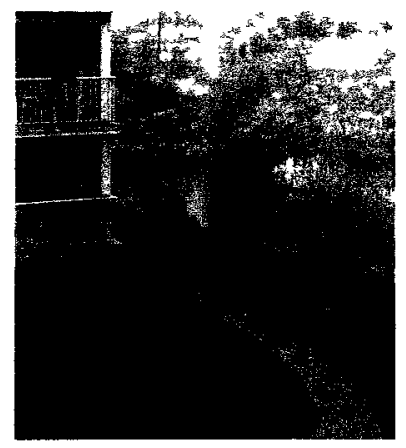

The lobby at night, April 2009
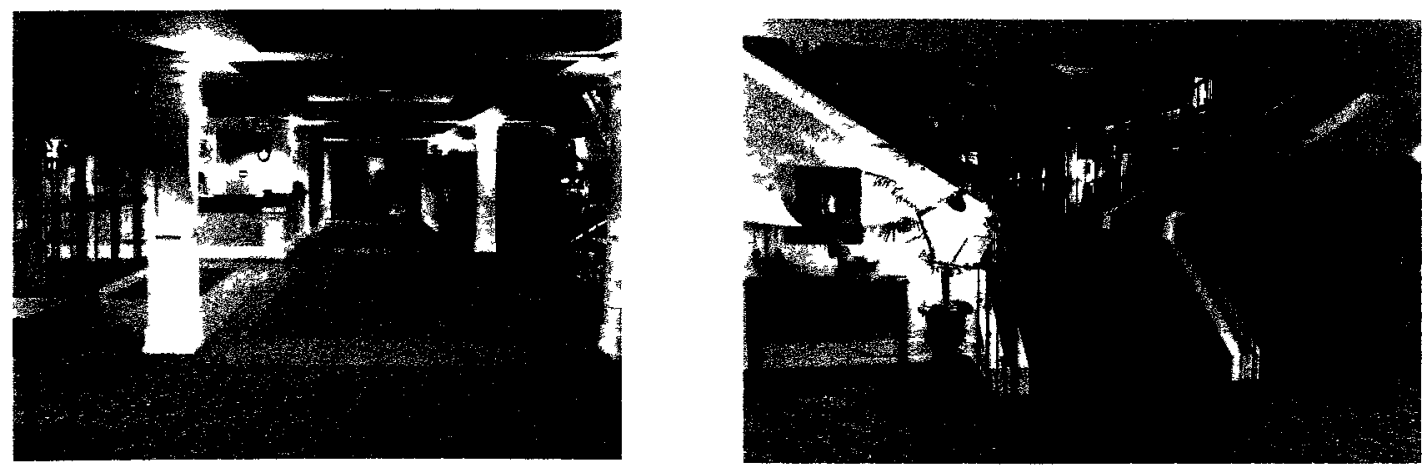
Lakelands' dining room, Christmas 2005.
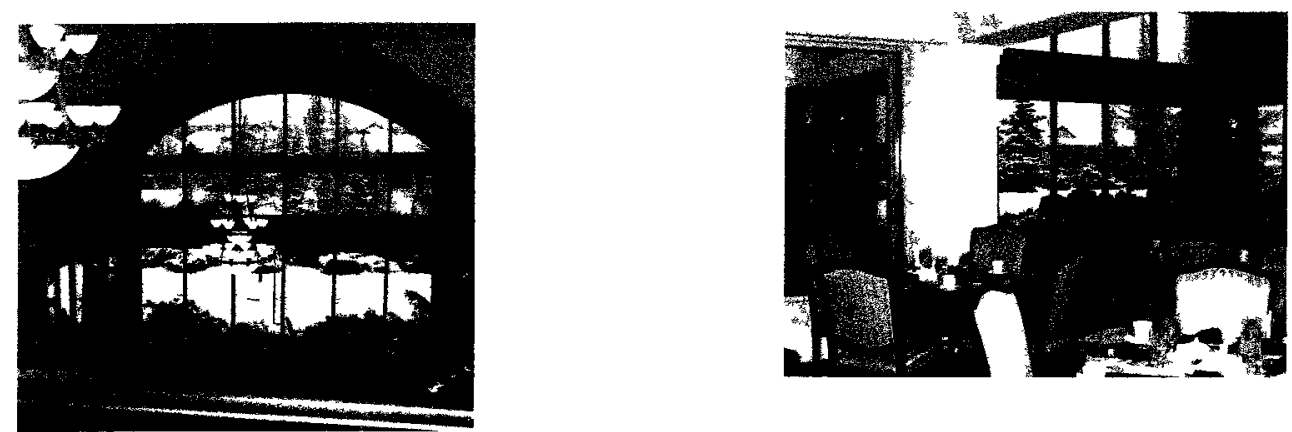

The Country Kitchen, April 2009

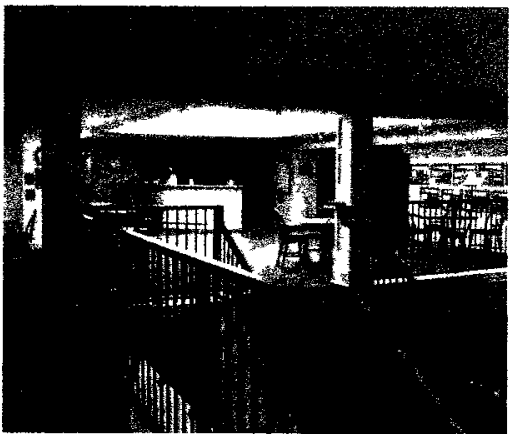

My mother's apartment, Christmas 2005

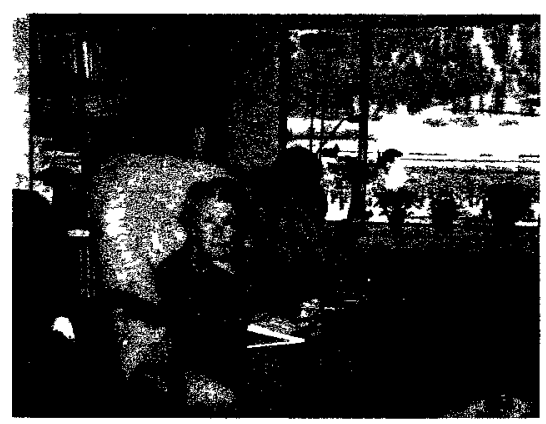

Hallway $4^{\text {th }}$ floor, April 2009

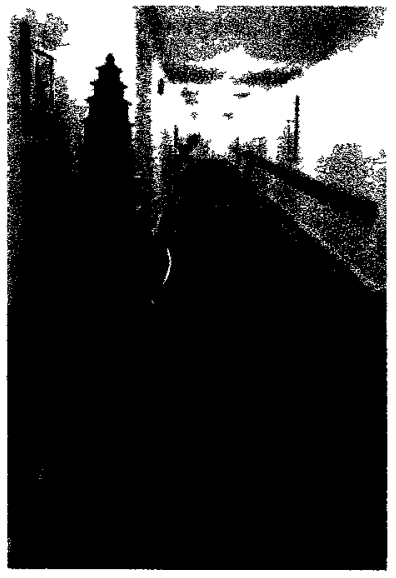


The menu, April 9, 2009.

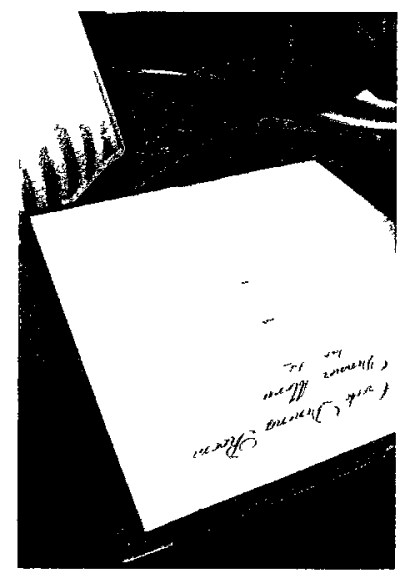

What was on the menu that day?

Soup or Salad

Green Lentil and Ham

Crisp Market Salad

Les Entrees

Filet of Salmon Blackened with a Sweet Potato Stone Mustard Glaze

Chicken Pot Pie served on Sauce supreme

Le Feature

Bar-b-Que Baby Back Ribs

Accompanied by: Whipped potatoes, Northwest Vegetable Medley Desserts

Vanilla Panna Cotta

Feature Ice Cream: Tiger

Fresh Fruit Cup, Sugar Free Jell-O

Ice Creams, Mandarin Oranges or Sugar Free Apple Sauce

Coffee and Tea Service Available

Condiments are Available on Request

Picture of the "Filet of Salmon Blackened with a Sweet Potato Stone Mustard Glaze"

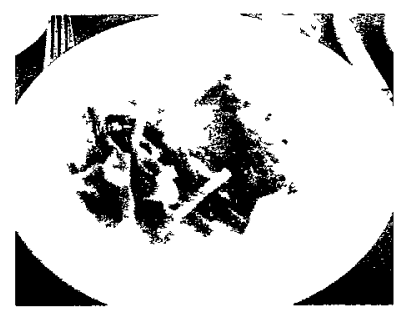




\section{APPENDIX E}

\section{Interview protocols}

\section{E.01 Interview protocol: People who live at Lakelands}

Introduction: Discuss letter. Ask for consent. Ask for permission to tape record the interview.

\section{Preamble:}

Before we begin the interview I would like to talk a little bit about this research. I am studying the question of what it is like to live in an organization. Basically, the question is, can people live the way they would like when living in an organization like Lakelands?

Therefore, I am here today to ask you for your help and guidance. I have a list of questions to ask you. This will probably take about an hour.

Since I am going to be asking you about your life, I thought you might want to know a little bit about mine. Although I live in Ottawa, I was born and raised here. I left after high school and went to university in Quebec to learn French. The man you see residing here with me is my husband, Richard. We were married here at Lakelands, on the front staircase. It was an exciting day.

My mother moved here to Lakelands in 2002. I have spent a lot of time here, living as a guest of my mother in her apartment, especially when she was not feeling well, which was quite a lot in her last years. She passed away here at Lakelands in 2006. My experience here with her prompted my interest in what it is like to live at Lakelands.

So now, lets turn to the interview. If there are questions you do not want to answer, for whatever reason, please feel free to decline. If at any time you become tired or otherwise indisposed please let me know. We will stop. Also, I have this machine, which amplifies my voice. Should we try using the machine? If no ... If you have trouble hearing me, or if I talk too quickly, please stop me and ask me to repeat. I am used to repeating things.

Before I begin the interview, do you have any questions? Would you like to begin? This is the tape recorder. I will turn it on now, if that is O.K. with you?

[Turn on tape recorder if given permission].

\section{Legend for interview questions:}

(Q1) "Who am I?"

(Q2) "Who am I when I live in an organization?" ("Who does the organization want me to be" "Where is the "me" among the "we"?)

(Q3) "Am I what I consume?"

(Q4) "How do I perceive the organization?" 


\section{Background/control variables (Q1)}

Lets start with some background information.

Do you have children? (Q1 Control Variable)

Do they live in town? (Q1 Control Variable)

Sex [observation] (Q1 Control Variable)

Age? Would you mind telling me how old you are? (Q1 Control Variable)

Marital status (Widowed, Married, Single) (Q1 Control Variable)

Am I correct in assuming you are retired? (Q1 Control Variable)

What type of work did you do before you retired? (Q1 Control Variable)

What type of work did your spouse do? (Q1 Control Variable)

\section{Moving (Q1)}

Now lets talk about the places you lived before moving to Lakelands.

Could you tell me about where you lived before coming to Lakelands; what it was

like and how you felt about it? (Q1)

\section{The organization}

Now lets talk about Lakelands.

How long have you lived at Lakelands? (Q1, Control Variable)

Why did you move to Lakelands rather than some other place? (Q3)

[Prompt] Was Lakelands' appearance a factor in deciding to move to here? If short yes answer . . could you tell me more about that? (Q3)

[Prompt] How do you feel about the physical appearance of Lakelands, the building, decorating and gardens? (Q3)

How would you describe Lakelands to someone who knows nothing about it?(Q4)

[Prompt] How would you compare it to other places you have lived? (Q4)

[Prompt] How would you describe the atmosphere or way/style of life at Lakelands? (Q3/Q4)

[Prompt] I have heard some people describe Lakelands as being "posh." Would you describe it that way? (Q3)

\section{Living in an Organization}

Now lets talk about what life is like for you here.

What is it like to live here at Lakelands? How would you describe your experience to someone who knows nothing about Lakelands? (Q2)

Can you live the way you would like here? (Q2)

[Prompt] Have you had to change or adapt to life at Lakelands?(Q2)

[Prompt] Have you had to change the way you dress? (Q2)

[Prompt] Have you gained things by moving here to Lakelands? Have there been losses?

Has living here affected the way you see yourself? If so, how? (Q2)

[Prompt/Alternative question] You live here at Lakelands. What does that mean to how you see yourself? (Q2)

What is it like living with other people? (Q2) 
[Prompt] Do you have enough privacy? (Q2)

[Prompt] Is it easy to make friends here? (Q2)

What about the rules here - Do you feel there are a lot of rules here? (Q2)

[Prompt/Alternative] What do you think about them? Are there rules you

like and rules you don't like? (Q2)

I notice people who live at Lakelands are called residents? What do you think about this? (Q2).

I notice people call each other by their first name. What do you think about this? (Q2)

Have you made suggestions to change things around here? (Q2)

[Prompt] Could you give me an example of suggestions you have made, and what happened? (Q2)

[Prompt] What role do you feel you have in deciding how things are run around here? (Q2)

[Prompt] Are there other suggestions you would like to make? (Q2)

[Prompt] How do you feel about the services and amenities? (Q2)

[Prompt] Are they sufficient? (Q2)

[Prompt] Have you made suggestions about the choices that are offered? (Q2)

[Prompt] Is there enough personal service? (Q2)

[Prompt] Have you made suggestions about changing schedules such as eating times, bus schedule, activity schedule? (Q2)

What is it like eating in the dining room? (Q2)

[Prompt] Would you prefer to eat in your apartment? (Q2)

[If the person uses the word lifestyle at anytime during the interview] ... I noticed you used the word lifestyle ... What does this word mean to you? (Q2)

\section{Prompts:}

What does that mean to you?

If person uses a figure of speech or symbol or metaphor ask them what the image/idea means to them.

\section{Closing}

Thank you. We have reached the end of the questions.

Do you have anything you would like to add? Do you have any questions for me? In the next week or so I will give you a typewritten copy of the interview. You may want to add things or change things. I will call you in a week. I would like to thank you for your help in this project. 


\section{E.02 Interview protocol: Lakelands' management and owners}

Introduction: Discuss letter. Discuss confidentiality issue. Ask for permission to tape interview. Obtain signatures.

\section{Preamble:}

Before we begin the interview I would to talk a little bit about this study. I am studying the question of what it is like to live in an organization. Basically, the question is, can people live the way they would like when they live in an organization like Lakelands?

The main focus of this study is on the people who live at Lakelands. I will be interviewing about 30 residents over the next two months. I would like your perspective to round out this study - to know how Lakelands works.

Therefore, I am here today to ask you for your help and guidance. I have a short list of questions to ask you. This will probably take about an hour.

Since I am going to be asking you about your professional life, I thought you might want to know a little bit about mine. As you know I am doing a Pd.D. in Management at the Eric Sprott School of Business at Carleton University in Ottawa. I live in Ottawa, however, I was born and raised in town. I left after high school and went to university in Quebec to learn French. The man you see residing here with me is my husband, Richard. We were married here at Lakelands, on the front staircase.

My mother moved here to Lakelands in 2002. I have spent a lot of time here, living as a guest of my mother in her apartment, especially when she was not feeling well. She passed away here at Lakelands in 2006. My experience here with her prompted my interest in what it is like to live at Lakelands.

So now, let us turn to the interview. If there are questions you do not want to answer, for whatever reason, please feel free to decline. If at any time you would like to stop the interview, please let me know. We will stop.

Before we begin the interview, do you have any questions?

Would you like to begin?

This is the tape recorder. I will turn it on now, if that is O.K. with you? [Turn on tape recorder if given permission].

\section{Legend for interview questions:}

(Q1) "Who am I?"

(Q2) "Who am I when I live in an organization?" "Who does the organization want me to be" "Where is the "me" among the "we'?")

(Q3) "Am I what I consume?"

(Q4) "How do I perceive the organization?"

(M) Questions for Manager,

(Cf) Chef

(S) Social Director

(O) Owner 


\section{Background}

I'd like to begin by asking some background information about your career and job.

MCfS

MCfS

MCfS

OMCfS

\section{The Industry}

How long have you worked at Lakelands? (Q4)

Where were you before? (Q4)

What is your job title? (Q4)

How would you describe your job to someone who knows nothing about it? (Q4)

We've talked about your job at Lakelands - now I'd like to ask you a few questions about the industry.

OM Where is the industry going in your opinion? (Q4)

Now that we've talked about the future I'd like to ask you about the past.

$\mathrm{O}$

Could you talk about the history behind Lakelands? How did it come about? (Q4)

[Prompt] Where did the idea for Lakelands come from? (Q4)

[Prompt] Is Lakelands modeled on another organization? On a type

\section{Organization} of organization? (Q4)

Now I'd like to talk about the organization in general.

OMSCf

How would you describe Lakelands to someone who knows nothing about it? (Q4)

How would you describe Lakelands:

- $\quad$ Objectives? Mission? (Q4)

- $\quad$ Service philosophy? Customer service philosophy? (Q4)

[Prompt] Is management trying to create a certain atmosphere or way/style of life at Lakelands? How would you describe it? (Q4)

\section{Social Activities}

Now that we've talked about the organization in general, I'd like to talk about social activities.

OMS

OMS

What is the rationale or purpose of having organized social activities at Lakelands? (Q2)

MS

[Prompt] What role do social activities play in Lakelands' overall objectives? (Q2)

MS

OMS

How do you decide what types of activities to offer? (Q2)

[Prompt] Are you trying to follow a particular approach or style?(Q2)

[Prompt] Is Lakelands trying to promote active retirement?(Q2)

\section{Language}

Now that we've talked about social activities, I'd like to talk about some of the words, or language that is used at Lakelands.

M I notice you sometimes use the word "home" to refer to Lakelands? What message are you trying to convey with the use of this word? (Q2) 
OMSCf I notice people call each other by their first name at Lakelands. Has this just evolved or is this part of Lakelands' strategy? (Q2)

OMSCf I notice people are called "residents"? Has this just evolved or is this part of Lakelands' strategy? (Q2)

OMSCf [If the word lifestyle is used] I notice you used the word lifestyle earlier on in the conversation. What does this word mean to you? (Q2)

\section{Suggestions for Change}

OMSCf What types of suggestions for change do residents make? (Q2)

Could you give examples of suggestions and how they were handled?(Q2)

[Prompt] What role do residents play in determining how things are run at Lakelands? (Q2)

\section{Moving}

I'd like to ask some questions about moving.

M How much resident turnover does Lakelands have? Average length of stay? (Q4)

M What are the major reasons people move from Lakelands? (Q4)

\section{Advertising and Consumers}

Now I have a few questions about advertising and consumers

OM What types of advertising does Lakelands do? (Q3)

Could you talk about the objectives of this advertising? (Q3)

[Prompt] . . compared to say advertising for your nursing homes?

[Prompt] Is Lakelands trying to convey a particular image of older people in its advertising for Lakelands? (Q3)

OM Is Lakelands trying to attract a particular type of consumer? (Q3)

[Prompt] How would you describe Lakelands' residents as consumers? (Q3)

[Prompt] How are they the same or different from younger seniors, baby boomers? (Q3)

\section{Physical appearance and decorating style}

Now I have a few questions about Lakelands' physical appearance.

Could you talk about the thinking that has gone into Lakelands' physical appearance? (Q3)

[Prompt] Was Lakelands' physical appearance modeled on another organization, or type of organization? (Q3)

[Prompt] Why was this chosen, rather than something else?](Q3)

[Prompt] Is there a rationale for Lakelands' appearance . . . the building style, decoration scheme, landscaping? (Q3)

[Prompt] What is the interior decorating style? (Q3) 
OM How important is Lakelands' physical appearance to the organization's overall goals? (Q4/Q2/Q3)

[Prompt] Is it meant to convey a particular message, or

Dining atmosphere?

Now lets talk about the food and dining service at Lakelands.

OMCf

How would you describe the type of food that is served at Lakelands to someone who knows nothing about it? (Q2) (MC)[Prompt] Could you talk about things you consider when choosing what to serve? (E.g., menu planning). How are food choices made?

[Prompt] Is there a particular style of food that is served? [Prompt] Does the type of food served play a specific role in Lakelands' overall objectives?

OMCf How would you describe the dining service at Lakelands to someone who knows nothing about it? (Q2)

[Prompt] What is the rationale for adopting this type or style of dining service?

MCf I see the La Chaine des rotissaires plaque in the lobby? What does this mean? (Q2)

\section{Closing}

Thank you. We have reached the end of the questions.

Do you have anything you would like to add?

Do you have any questions for me?

In the next week or so I will give you a typewritten copy of the interview. You may want to add things or change things. I will call you in a week.

I would like to thank you for your help in this project. 


\section{APPENDIX F}

\section{Implementing the analytical plan: Narrative analysis tasks}

The following gives examples of how the study implemented the narrative analysis tasks listed in (Table 3.6).

Task \#1 Identify themes, sequence, timing, causality, conditions.

Case summary:

- Identifies important themes, sequences, timing, potential causality and conditions.

Transcript coding (i.e., the codes in Appendix G):

- Identifies themes, causes, conditions, structures and consequences (Lofland \& Lofland, 1995).

Statistical analysis

- Identifies frequencies (Lofland \& Lofland, 1995), potential associations and causal links.

Thesis document:

- $\quad$ Chapter 3 and 4 describes processes and sequences: the moving decision making process.

- Chapter 4 discusses conditions such as sex, location of family, extrovert/introvert that may help explain study findings.

- Chapter 5, 5.01 lists factors/conditions that attracted people to Lakelands; helps to explain why people choose Lakelands over other places.

- Chapter 5 describes the process and sequence of shifting the self to make "lifestyle fit."

- Chapter 7 section 7.01 describes the process of adapting to Lakelands and the factors or conditions helping and hindering adaptation.

- Appendix M lists statistical conditions, associations and causes.

Task \#2 Identify themes in informant theories.

Case summary:

- Describes informant theories.

Transcript coding:

- Identifies informant theories.

Thesis document: (examples)

- Chapter 4: Mentions a theme that reoccurs in the data: "the risks of transformative change that results in a downgrade in lifestyle." Also talks about resident's theories as they relate to life-planning.

- Chapter 5: Mentions a common theme in the data: people do not want to live with 
their children.

- Chapter 7, section 7.01, subsection D mentions that "the ability to go out when one wants" is a common theme in the study.

- Chapter 8 mentions informant theories about the self. For example, some residents have a functionalist view of reality whereas others have a reflexive view of reality. The functionalist view does not conform to Giddens' theory.

- Chapter 11 to 13 discusses important themes such as the seating debate, active retirement and not wanting to complain.

Task \#3 Identify thematic similarities, differences (residents)

Data matrix (Appendix $\mathrm{H}$ ):

- Identifies similarities and differences between resident answers to 10 interview questions. Classifies narrative differences into three categories: typical, contrasting and discrepant narratives.

Statistical analysis:

- Identifies differences between residents on selected quantitative variables and qualitative codes.

Thesis document:

- Chapter 4. Discusses differences in resident characteristics as well as similarities.

- Chapters 7 to 15 . Discusses residents' typical, contrasting and discrepant answers to 10 interview questions.

Task \#4 Assess thematic similarities, differences between residents and management

Transcript coding:

- Reveals differences between residents and management on selected qualitative codes such as language use.

Thesis document:

- Describes, analyzes and explains conditions influencing language differences between residents and management.

Task \#5 Assess possible communal lifestyle organizational typology Transcript coding:

- Helps to determine whether or not residents and management describe Lakelands in similar ways, plus whether they make a distinction between Lakelands and institutional models.

Thesis document:

- Chapters 3 to 14 identifies examples of how Lakelands, and similar organizations, differ or resemble total institutions.

- $\quad$ Chapter 6 discusses the extent to which management and residents describe Lakelands in terms that resemble a communal lifestyle organization. Discusses explicit and implicit language use as a way to explore sub-conscious viewpoints.

- Chapter 15 describes a communal lifestyle organization typology. 


\section{Task \#6 Assess thematic consistency in the lifestyle concept}

Thesis document:

- Chapters 4 to 14 cite instances of respondents describing lifestyle in terms that differ or resemble Giddens' definition of lifestyle.

- Chapter 15 reviews Giddens' notion of lifestyle and describes how the study extends or refines this notion.

\section{Task \#7 Identify thematic gaps in Giddens' theory}

Thesis document:

- Chapters 4 to 14 document gaps in Giddens' theory, especially premises that do not apply to older persons; for example limits on power. For instance, chapter 4 discusses how respondents may experience limits on autonomy. This may violate Giddens' notion of life-planning, which assumes an autonomous decision maker.

- Chapter 15 discusses the degree to which the findings permit analytic generalization to Giddens' theory/notions. This section also discusses gaps in Giddens' theory and extends or refines some of his notions.

Task \#8 For the research question: "Who am I when I live in an organization?" (Chapters 7 to 14), structurally analyze selected typical and atypical answers to one or more of the ten major interview questions.

Case summary:

- Contains selected references to resident's use of language.

Transcript coding:

- $\quad$ Contains selected references to resident's use of language.

Thesis document:

- Contains numerous examples of structural analysis, for example:

- describes use of the word "place" and "home" (chapter 6).

- highlights use of various terms to refer to a person's accommodation at Lakelands (chapter 6).

- identifies use of a language of sequestration "in here/outside" (chapter 6).

- $\quad$ illustrates how adaptation difficulties can be reflected in a person's narrative (chapter 7).

- $\quad$ highlights how a person's narrative can become incoherent when they recount how difficult it is to deal with death and dying (Ursula, chapter 7).

- Two examples of passive voice illustrating people's acquiescence to organizational conventions (chapter 10).

- Appendix $\mathrm{K}$ contains an example of a structural analysis. 


\section{APPENDIX G}

\section{Coding: List of quantitative variables and qualitative codes}

\section{Quantitative variables}

Date of interview: day/month/year.

Interview length: size of MP3 file in megabytes.

Transcript length: size of Wordperfect file in kilobytes.

Placeint: The place where the interview took place. (Resident's apartment $=1$;

researcher's apartment $=2$; restaurant $=3$; manager's office $=4$; manager's office + restaurant $=5$ ).

Occupation 1: The resident's first occupation. These occupational categories are based on, but not identical to, Statistics Canada's occupational categories.

(Management, finance $=1$; health, science, social services, teaching $=2$; transportation and protective services $=3$; trades, farming, sales, administration $=4$; fabrication textiles, arts and crafts $=5$; homemaker $=6$; not applicable $=7$; missing $=0$ ). Occupation 2: If person had more than one occupation. (Same as occupation 1). Spouse's occupation: If resident mentions spouse's occupation. If the person had more than one spouse, this is the last occupation of the last spouse. (Same as occupation 1). Implementation experience: Does resident have management/administration experience? $(\mathrm{No}=1$; yes $=2$; missing $=0$ ).

Marital status: What is resident's current marital status? (Not married $=1$; married $=2$; missing $=0$ ).

Romantic relationship: Do single residents have a significant other of the opposite sex? $(\mathrm{No}=1 ;$ yes $=2$; missing $=0)$.

Age: $(\#$; missing $=0)$.

Years resident at Lakelands: (\#).

Sex: $($ Male $=1$; female $=2)$.

Extroversion: Is the resident an extrovert or an introvert? (Introvert $=1$; extrovert $=2$ ).

Family nearby: Does resident have family living close by: in town, or in the region? (No $=1$; yes $=2$; missing $=0$ ).

Number of daughters: How many daughters does the resident mention they have? (\#; missing $=0$ )

Helpful daughter-in-law: Does resident mention a daughter-in-law that is involved in helping them? $(\mathrm{No}=1$; yes $=2$; missing $=0)$.

Grandchildren nearby: Does resident mention grandchildren living in town, or in nearby region? $($ None $=1$; yes, males $=2$; yes, females $=3$; yes, males and females $=4$; missing $=0$ ).

Overall health problems: My observations plus what a resident says about their overall health. $($ Good $=1$; moderate $=2$; poor $=3$, missing $=0)$. 
Mobility problems: Does resident use a walking aid? If so, what type? (None $=1$; cane $=$ 2 ; walker $=3$; wheel chair $=4$; missing $=0$ ).

Eyesight problems: My observations plus what a resident says about their eyesight.

$($ Good $=1$; Moderate (difficulty reading, can't read) $=2$; Poor (macular

degeneration, partially blind, blind) $=3$; missing $=0$ ).

Hearing problems: My observations plus what a resident says about their hearing. (Good $=1$; moderate $=2$; poor $=3$; missing $=0$ ).

Memory problems: My observations plus what a resident says about their memory. $($ Good $=1 ;$ moderate $=2$; poor $=3$; missing $=0)$.

Crises before: Number of crises in the two years proceeding the move to Lakelands.

Crises include death of a spouse, close family member or friend; serious illness of a spouse, friend or family member; one's own illness; the move to Lakelands; resident mentions loss of pet as being traumatic; resident mentions loss of possessions as being traumatic; resident mentions loss of volunteer work as being traumatic. (\#).

Crises after: Number of crises after move to Lakelands. As above. (\#).

Orgexper 1: Respondent's experience living or working in a residential organization. This information came from answers to open-ended questions about people's occupational and moving history. (None $=1$, lived in condominium $=2$; lived in gated community $=3$; lived in retirement residence $=4$; worked in hospital/nursing home $=5$; worked in correctional services $=6$; lived in a boarding school $=7$; lived/worked in army $=8$; missing $=0$ ).

Orgexper2: Their second experience. (Same as 1)

Orgexper3: Their third experience. (Same as 1).

Orgexptot (\#): This is a severity of experience rating. The more residential organizations in which a person has lived or lived/worked, and the more they resemble the characteristics of a total institution, the higher the number. The rating is calculated by totaling Orgexper $1+$ Orgexper $2+$ Orgexper 3 as follows: none $=0$, lived in condominium $=1$; lived in gated community $=2$; lived in retirement residence $=3$; worked in hospital/nursing home $=4$; worked in correctional services $=5 ;$ lived in a boarding school $=6$; lived $/$ worked in army $=7$

Orgexprev: Whether or not a person moved from a gated community or retirement residence to Lakelands. (No, moved from a house, condominium or apartment = 1 ; yes, moved from a gated community or retirement residence $=2$; missing $=0$ ).

Number of previous residential organization experiences: The total number of communal organizations in Orgexp1 to 3. (\#; but no higher than 3).

Autonomous moving decision: Describes the degree to which the resident made an independent moving decision - whether or not family and friends were consulted. I did not specifically ask respondents how the decision was made. This information is based on transcript information. (Coerced/forced in (i.e., resident felts coerced or forced to move) $=1$; consulted others (i.e., resident consults others on moving decision) $=2$; own decision (i.e., resident makes decision without consulting others) $=3$; missing $=0$ ). 
Appearance: Was Lakelands' appearance a factor in the moving decision? $($ No $=1$; yes $=$ 2 ; missing $=0$ ).

Atmosphere: Was Lakelands' atmosphere a factor in the moving decision? (No $=1$; yes $=$ 2 ; missing $=0$ ).

Instantfit: Did resident immediately know whether or not their lifestyle fit that of Lakelands? $($ No $=1$; yes $=2$; missing $=0)$.

Can live as I like: Can you live the way you would like at Lakelands with no restrictions from Lakelands? (No $=1$; could if I applied myself $=2$; pretty much $=3$; yes $=4$; missing $=0$ ).

Adaptation required: Did you have to change or adapt to life at Lakelands? $($ No $=1$; small amount $=2 ;$ moderate amount $=3$; large amount $=4 ;$ missing $=0$ ).

Selfchange: Does living here affect the way you see yourself? (No $=1$; maybe $=2$; yes $=3$; missing $=0$ ).

Privacy: Do you have enough privacy at Lakelands? $($ No $=1 ;$ yes $/$ no $=2$; yes $=3$; missing $=0$ ).

Too many rules: Do you feel there are a lot of rules here? $($ No $=1$; maybe $=2$; yes $=3$; missing $=0$ ).

Not complaining: Refers to people that say they hesitate or do not want to complain, and/or to cases that say other people should not complain about life at Lakelands. $($ No mention $=1 ; \mathrm{I} /$ they should not complain $=2$ ).

Making suggestions: Have you made suggestions for change? $($ No $=1$; yes $=2 ;$ missing $=$ 0 ).

Prefer dining room: Would you prefer to dine in your apartment rather than going to the dining room? $($ No $=1$; yes and no $=2$; yes $=3$; $\operatorname{missing}=0)$.

Residents fine: What do you think about the use of the word "residents" to describe the people who live here? (Not fine $=1$; fine $=2$; missing $=0$ ).

First name fine: What do you think about everyone calling each other by their first name? (Not fine $=1$; fine $=2 ;$ missing $=0$ ).

Meal frequency: How often does resident eat in the dining room? This is based on my knowledge of the resident's meal plan (e.g., seeing them in the dining room at different times of the day). (Basic meal plan $=1$; basic plan plus lunch $=2$; all meals $=3$; missing $=0$ ).

Volunteer: Is resident involved in volunteer activities? To what degree? This is based on my observations and what the resident says about their involvement. (No $=1$; yes a little $=2$; yes moderate $=3$; yes a lot $=4$; missing $=0$ ).

Activities: Degree to which resident is involved in activities. This is based on my observations and what the resident says about their involvement. (None $=1$; low $=2$; moderate $=3$; high $=4$; missing $=0$ ).

Scooter: Resident owns and uses a scooter to drive around town. This is based on what the resident has told me. (No $=1$; Yes $=2$; missing $=0)$.

Does resident own a car? This is based on my observations and what the resident has told me. $($ No $=1$; yes $=2$; missing $=0)$.

Percentage of typical answers. This is based on results in Appendix H, Table H.01. (\#). Percentage of contrasting answers. This is based on results in Appendix H, Table H.01. 
Percentage of discrepant answers. This is based on results in Appendix H, Table H.01. (\#).

Immigrant: Does resident mention being born in Canada or outside Canada? (Canada $=1$; outside Canada $=2$; missing $=0$ ).

Similar topography. Did the resident move from a place with similar topography to Lakelands? (Different $=1$; similar $=2$; missing $=0$ ).

Language Home. Does the resident call Lakelands their home in their interview transcript? (Home, absent $=1$; home yes $=2$ ).

In Here/outside: Does resident use the term "in here" or "outside" in their interview transcript. (In here/outside absent $=1$; in here/outside, yes $=2$ ). 


\section{Qualitative codes}

\section{B. Attributes-Lakelands compared other}

- Other seniors' residences compared to Lakelands

Resident compares another communal lifestyle organization/or other retirement resident where they have lived to Lakelands. They may talk about a variety of things: e.g., adaptation differences, the building, services and staff, differences in the extent to which they are controlled, differences in the people who live there. Note: This code does not include people's observations about other communal lifestyle organizations if they have not lived in those places.

\section{B. Attributes- Lakelands' Organization Model}

- Apartment, condominium

Resident describes Lakelands as being like an apartment building or a condominium.

- Cruise ship.

Resident describes Lakelands as being like a cruise ship.

- Home

Resident uses the word "home" to describe Lakelands; e.g., it is my home. They may use "home" unconsciously to describe their apartment or suite. If they say they feel at home, this should also be coded under "Live: (negative comment) (positive comments)

- Home (not)

Resident says that Lakelands is different from your own home. They may say that if you cannot live at home then Lakelands is the best alternative.

- Hotel (not)

Resident says that Lakelands is not a hotel or they say it is more than a hotel.

- Hotel, resort-like

Lakelands is described as a holiday place or a resort.

- Institutional (not)

Lakelands is contrasted to an institution. Resident says it is not an institution.

- Old folks/nursing home

Person describes Lakelands as an old folks home, nursing home, a lodge or assisted living.

- OTHER descriptions

Other descriptions of Lakelands e.g., age ghetto, boarding school, nest, retreat, shelter, Village, army, a mob, shopping center, family, seniors residents, seniors place.

- PROC (Process) Describe Lakelands by showing In answer to question; "how would you describe to others?" resident says they "showed" people Lakelands.

\section{Move? - Decision process}

- Compared

Resident said that they (or their family/friends) looked at other retirement residents in the town (and or other places) and compared them to Lakelands. 
- Compared (didn't)

Resident didn't compare Lakelands with other places.

- Easy to decide

Resident says that it was easy to decide on Lakelands: e.g., they were enthusiastic, fell in love with the place, instantly knew.

- Hard to decide

Resident was reluctant to move to Lakelands; e.g., they were horrified, went kicking and screaming, they found it hard to admit their limits, leave their home. Their home defined them and it was hard to find a place that fit their identity.

- Influenced by others

The resident describes the family (including spouse) and other involvement/attempts to influence the resident's moving decision: e.g., they helped visit places, they agree or disagree with the resident's decision, sometimes they even make the decision for the resident

- Influenced by others (not)

Residents talk about making an autonomous moving decision rather than being influenced by others, or being forced in.

\section{Move? - Why leave previous home for Lakelands?}

- Better climate

Resident says that they decided to leave their previous home because they wanted to move to a better climate. Note: Resident may have more than one reason for moving.

- Family reasons

Resident says they decided to leave their previous home for family reasons; e.g., to be closer to family, to relieve children of burden/worry.

- FR Friend died

Resident says that they decided to leave their previous home because a friend died.

- Health

Resident says that a decline in health, or health problem precipitated the move to Lakelands.

- Housekeeping a burden

Resident explains that they decided to leave their former home because they did not want to do housekeeping any more; it is too hard, they don't want to do it anymore.

- Loneliness, depression

Resident decided to leave their former home because they were lonely or depressed living alone. Note: Resident may have more than one reason for moving.

- Not happy with home

Resident says they decided to leave previous home because they were "no longer being happy in home; or not liking where they were living (e.g., lifestyle did not fit them).

Note: Resident may have more than one reason for moving.

\section{Move? - Why pick Lakelands over alternatives?}

- Liked bid, services, model 
When talking about the move, resident describes what impressed them (or the people that influenced them) during their first visits and led them to pick Lakelands. They liked one or more of the following things: the cruise ship model, the building, the suite/apartment, the natural surroundings, the atmosphere, the food, the services. They may also say it was better than all the others. Note: They may have more than one reason.

- Liked management and staff When talking about their move, resident describes what impressed them (or the people that influenced them) during their first visits and led them to pick Lakelands: they liked the management and staff - there were friendly, welcoming, the serving staff was nice, they were down to earth. Note: They may have more than one reason.

- Liked location, familiar with it

When talking about the move, resident describes what impressed them (or the people that influenced them) during their first visits and led them to pick Lakelands. They liked Lakelands" location e.g., close to children/home, Lakelands is located in their neighbourhood, they are familiar with it, it is close to everything. Note: They may have more than one reason.

- Liked residents

When talking about the move, resident describes what impressed them (or the people that influenced them) during their first visits and led them to pick Lakelands: they liked the people who live there; there were more men, people are more sociable than other places, they were the type of people they could fit in with (e.g., friends had already lived at L). Note: They may have more than one reason.

- COST liked price

When talking about the move, resident describes what impressed them (or the people that influenced them) during their first visits and led them to pick Lakelands: little price difference with other places; more affordable than alternatives. Note: They may have more than one reason.

- DETERRANT move other

When comparing Lakelands with other places, the resident talks about things that they didn't like in these other place; e.g., the food was poor, too much traffic, wrong part of town etc.

- DETERRANT move to Lakelands

Things about Lakelands that deterred the resident from moving to Lakelands (e.g., Lakelands' price, walkers at Lakelands).

- FACTOR Won't live with child

Resident states that living with their children was not an option.

\section{Move? - Why leave Lakelands?}

- Same or better place

Resident would leave because they have found a similar or better place. They may mention others have left for this reason. Note: Resident may have more than one reason for leaving. 
- COST Finances

Resident would move out if their finances decline or costs rise at Lakelands. They may mention others have left for this reason. Note: Resident may have more than one reason for leaving.

- EMOTION Unhappy

Resident would move from Lakelands if they were unhappy e.g., unhappy with management, unable to fit in, not enjoying Lakelands. They may mention others have left for this reason. Note: Resident may have more than one reason for leaving.

- FAM Family reasons

Resident would move out for family reasons: e.g., to be closer to family, to relieve burden on family. They may mention others have left for this reason. Note: Resident may have more than one reason for leaving.

- HEALTH reasons

Resident says they would move out for health reasons; need more care that can not be provided at Lakelands cannot find a local doctor, need better health services (e.g., hospital) in another town. This includes being "evicted" due to health reasons. They may mention others have left for this reason. Note: Resident may have more than one reason for leaving.

- Temporary stay

Resident says they plan to stay at Lakelands for only a short period of time. Note:

Resident may have more than one reason for leaving.

\section{Move? - Refuse to leave Lakelands?}

- CONSUME Best place

Resident says they (or others) would not move because Lakelands is still better than other places, especially nursing homes.

- COST Lakelands is less expensive

Resident says that they (or others) would not move because Lakelands is less expensive than alternatives.

- FAM against leaving Lakelands

Resident says that they (or others) will not leave Lakelands because their family would not like them to leave.

- PEOP (People) Would miss place

Resident says that they (or others) will not move because they would miss the place - the people, the social activities, and the conveniences.

\section{Consumption?}

- COST Fair exchange?

People may talk about paying too much at Lakelands or paying too much for certain things (e.g., the Sunday brunch), they may talk about how some people get freebies - 3 months free rent, free meals for a year, but they don't get anything. Note: To eliminate duplication when residents make negative comments about the "stinginess of management" this goes under "consumption/cost fair exchange" rather than Management -ve (negative). 
- Advertising disconnect

Resident describes a "gap" between what was advertised and what they have received.

- Posh. upscale?

Residents talk about whether or not they think Lakelands is posh; high quality, a cut above the rest.

\section{Change, adapt to Lakelands?}

- MY FAULT not adapting

Residents blame themselves for their adaptation difficulties.

- FACTORS help or hinder adaptation

Residents mention things they think may help and/or hinder adaptation: e.g., attitude, ability to accept change, employing fantasy, having choices and autonomy, friends and socializing, being single, one's gender (men may have more difficulty adapting), grieving, humour, knowing Lakelands' social norms, nature and walking, time, having lived in similar accommodation, being the subject of gossip, homesickness, too many people, losses (like death of friends, spouse), etc.

- Shock, strange, hard.

Resident describes their initial reaction to Lakelands as a shock, strange, hard. They may also say they fell ill after moving in (either physically or mentally). Resident describes their initial reaction to Lakelands as a shock, strange, hard. They may also say they fell ill after moving in (either physically or mentally).

- Getting used to it.

Resident says they are getting used to Lakelands Note distinction with "used to it" where resident has completely adapted. Here resident is still adapting.

- Settled, adapted, accept.

Resident describes themselves as being settled - as having accepted, adapted to life at Lakelands

\section{Live as you like at Lakelands}

- MY FAULT, could live as I like.

Resident says that it is their fault that they are not living as they like. They could live as they like if circumstances changed, or they changed their behaviour.

- MISS $\backslash$ LIMITED by Lakelands

Resident describes missing things or being limited by something at Lakelands that affects their ability to live the way they would wish. e.g., Lakelands' rules and norms, Lakelands' services etc.

- MISSILIMITED by things outside Lakelands' control.

Residents mention things that they miss or that constrain them which are outside Lakelands' control. These things affect their ability to live the way they wish. e.g., health, age, no longer have a car. This code contrasts with "Limited by Lakelands." 


\section{Live: (-ve negative comment) (+ve positive comment) Experiences, Lakelands'} effects on resident

- -ve (negative comment) Experiences.

Resident describes a negative experience or effect that Lakelands has on them personally: Examples include: feel alone, upset, things bother the, constrained, regimented, disappointed, upset, dull, boring, not having fun, feel like they are visiting, unhappy, unnatural situation. Negative effects related to the deaths of people at Lakelands are coded under "crisis/death. "

- EX (experiences) Autonomous, independent, choices.

Resident describes being independent, autonomous, having choices and being/feeling free from the control of others.

- EX Comfortable, happy, wonderful

Resident says they are comfortable, pleased, satisfied, content, happy, enjoy it, glad, feel at home, life is wonderful at Lakelands This is a general comment about life at Lakelands. If they are talking about activities and say they had a wonderful time during a particular activity then this is an instance of $\mathrm{AC}+$.

- EX Doesn't bother me, no worry

Resident talks about having no worries, things not bothering them.

- EX Easy, less work

Residents say life at Lakelands is easy, or easier often because it relieves them of the responsibility of owning a house and doing household chores: e.g., gardening, housework, making meals.

- EX Fun, funny

Resident talks about fun experiences at Lakelands or funny, humourous things that happen at Lakelands

- EX Fortunate

Resident feels lucky, fortunate, "blessed"; grateful.

- EX Healing

Describes way in which Lakelands helps heal people; e.g., they may lose excess weight, may help them overcome grief.

- EX Not lonely

Resident says they don't feel alone, or feel lonely.

- EX Opened up, life giving

Resident describes life as having significantly changed for them as a result of moving to Lakelands. For example: they have changed their opinion of people (now positive); they now socialize a lot, their personality has changed (e.g., they have become more extroverted).

- EX Supported, protected

Resident says that they feel supported, helped, protected by people at Lakelands, residents, staff and the services. 


\section{E. Self view changes?}

- IMPACT Feel better, proud

Residents talk about feeling better about themselves - having a more positive attitude, being happier. They may, or may not, mention this in response to the question "how living at Lakelands changed the way you feel about yourself?"

- IMPACT Important (Not as)

Resident mentions that they feel less important They may, or may not, mention this in response to the question "how living at Lakelands changed the way you feel about yourself?"

- IMPACT Less selfish, more accepting

Resident say they have become less selfish and more accepting/tolerant of people's behaviours, and life's difficulties. They may, or may not, mention this in response to the question "how living at Lakelands changed the way you feel about yourself?"

- IMPACT Feel old

Resident says that they now see themselves as old. They may, or may not, mention this in response to the question "how living at Lakelands changed the way you feel about yourself?"

- Illness/age affects identity

Residents talks about illness or age affecting self-identity. They may, or may not, mention this in response to the question "how living at Lakelands changed the way you feel about yourself?"

- Dressing "up".

Resident talks about the importance of dressing up to go to the dining room, especially for dinner. One may feel one has to present a certain "identity" in the Lakelands' dining room; that ones everyday wear - what one wears in ones house/apartment - is not sufficient for dinner. They may, or may not, mention this in response to the question "how living at Lakelands changed the way you feel about yourself?"

- Property owner (Not a).

The resident says they are no longer a property owner. They may, or may not, mention this in response to the question "how living at Lakelands changed the way you feel about yourself?"

- WALKERS.

Residents talk about walkers: e.g., the increasing number of walkers at Lakelands; the potential impact on their self-identity; getting used to walkers; walkers as a deterrent to moving in to Lakelands; walkers as a cause of people leaving Lakelands; hope never have to use one; now using one etc.

\section{Living with others? - General}

- ANSWER OK, don't mind living with people

In answer to question, "what is it like living with other people ?" I interpret the resident to say that they don't mind living with other people. Same code as variable. Note that these are not exclusive categories. e.g., people may say it is ok plus they may say they are not living with others. These answer codes are not mutually exclusive (e.g., \#6 is coded in two different categories). 
- ANSWER Not living with others

In answer to the question "Do you mind living with other people?" I interpret the resident to say that one is not really living with other people; e.g., one has ones own apartment that one can retreat to. Same coding as variable.

- ANSWER Mixed response

In response to the question "what is it like living with other people?" residents says positive and negative things about living with other people. For example, they raise privacy issues, problems with abnormal behaviour, nasty people, people die etc. Same coding as variable.

- Accept, ignore behaviour

Residents talk about how they accept or ignore others behaviour that they don't agree with.

- Acquaintances, companionship

People talk about people who are acquaintances (not friends) and companionship e.g., male companionship, neighbours, seeing people frequently builds closer ties.

- Cliques, couples

Residents talk about people who have exclusive social groups - they do not mix a lot with others. Couples tend to fall into this category at dinner time.

- Fitting and not fitting in

Residents talk about "fitting in" to Lakelands and not fitting in; e.g., with the people, with the way of life, with communal living, with the type of people that live at Lakelands (right and wrong type of people). They talk about themselves, other residents and staff and the factors that make fitting in easier (e.g being an extrovert). There is some overlap with "factors that help and hinder adaptation": The emphasis here is not on adaptation, but rather on being a part of the social fabric - part of the "group" - being accepted by others. One may have adapted but still not "fit in": They may be a loner, for example.

- Friendships

Residents talk about friendships (not acquaintances) at Lakelands: e.g., making (good) friends; friendships heal, death shapes friendships; choice of friends; staff feel like friends; romantic relationships; ready made friends; when you leave Lakelands your friends forget you.

- Resident turnover

Resident talks about how there is a lot of coming and going at Lakelands; people leave, people move in.

- Teasing, joking

Resident describes how people play with each other - teasing and joking around or resident teases and jokes during the interview.

- War and peace

Residents talk about conflicts (and lack of conflict) between residents at Lakelands. They mention that people agree with them or disagree with them at Lakelands. They may mention fights between residents, or they may talk about the way people get along with each other. 


\section{F. Living with others? - Activities, volunteering}

- AC (Activity coordinator) +ve (positive comments)

Resident describes Lakelands' activities, entertainment, and/or Activity Coordinators in a positive light. As well, they describe positive impacts (e.g., build positive atmosphere, integrate newcomers, keeps people busy).

- AC (Activity coordinator) -ve (negative comment)

Residents make negative comments about activities at Lakelands and/or the Activity Coordinator. As well, they describe negative impacts; e.g., place becomes like a morgue, people don't mix.

- RANGE INVOLV Participation in Lakelands' activities

Resident describes themself as doing a lot of activities that Lakelands organizes.

- RANGE INVOLV Entertain self

Resident says they don't do a lot of Lakelands' activities. They spend a lot of time in their apartments, they like to read for example, and they like to entertain themselves.

- RANGE INVOLV Dropped AC

Resident talks about dropping out of a social activity at Lakelands.

- MYFAULT don't participate

Resident says it is their fault that they don't participate in more activities.

- FACTORS hinder AC participation

Residents talk about the things that hinder their participation in activities: age, health, spouses illness, weather.

- Volunteering

Residents talk about volunteering; why they volunteer; the benefits; volunteer opportunities; how much they volunteer, why they don't volunteer anymore (or do less volunteering).

\section{F. Living with others? - People's characteristics}

- PEOP Apathetic, passive

Residents describe themselves or others as apathetic, passive, or fearful of being assertive. They may say they don't care often, or occasionally. In saying I don't care they are giving up on something, either permanently or temporarily.

- PEOP Dominant, assertive

Resident describes some people as being dominant or assertive, go-getters. (Contrast with passive people).

- PEOP Happy

Resident describes people at Lakelands as being happy. Note this code is different from EX happy which describes what the resident says about themself.

- PEOP Happy (not), lonely

Resident says there is the odd person who is not happy or lonely at Lakelands.

- PEOP Interesting, variety

Residents talk about how interesting people are at Lakelands; they come from a wide range of backgrounds and accomplishments. 
- PEOP Nice (Not)

Some residents are described as not being nice. For e.g., hypocritical, two-faced, a pain, nasty.

- PEOP Nice, friendly, kind, great

Residents talk about people at Lakelands being: friendly, nice, good, kind, helpful wonderful great.

\section{G. Privacy/talk/gossip?}

- Gossip

Residents talk about gossip and the effects.

- Theft

Refers to incidents of theft or suspected theft.

\section{H. Rules, Norms, Control?}

- ANSWER Need more rules

Resident thinks there are not enough rules at Lakelands - that more are needed because...

- Control: Freedom from management/resident control

Residents say they are free from control by management/residents: e.g., free to not associate, to not participate, to voice one's opinions. People/management/staff don't come and knock at your door and bother you.

- Control: Management controls/influences resident

Residents say that management tries to control or influence resident's behaviour: e.g., discouraging or encouraging complaints, encouraging active retirement (participation, socializing, eating in dining room etc).

- Control: Resident controls resident/management

Residents try to influence or control other residents' or management's behaviour. Examples include: they support management's policy of active retirement and participation - such as eating in dining room, participating in activities. Resident discourages complaining. They support residents' efforts to resist organization control (e.g., the petition). They support staff/management that they like (e.g., bursaries, going away parties). They encourage or discourage others from moving to Lakelands. Note: "rule or norm breaking", "making suggestions", "volunteering" and "resident defend management" are specific instance of this code. When they occur, this general code is not necessary.

- POWER Resident defend management

Residents defend or support management's position on a particular issue or policy. This is a particular instance of "resident controls resident/management": Therefore, only this code need be present, not the more general code.

- Routines constrain?

Describes routines (e.g., meal schedules, bus schedules, cleaning schedule) and how they may be constraining (or not). 
- RULE, NORM BREAKING

Ways that residents break Lakelands' rules and social norms: e.g refusing to eat dinner in dining room, not participating in activities or mixing with other people, inappropriate or soiled dress, being nasty or unfriendly, not wearing name badges, giving money to staff. Note: rule or norm breaking is a specific instance of "resident controls."

resident/management: If this code is present, then the more general code is not necessary.

\section{Dining room?}

- Control: Body control

Resident says a lot of people worry about losing control of their body in public.

- DINING STAFF (positive comments)

Residents make positive comments about the servers or the dining room manager. e.g., respectful, responsive, well trained.

- DINING STAFF (negative comment)

Residents make negative comments about the servers, and/or dining room manager.

- Food (negative comment)

Residents make negative comments about the food or chef. They may explain why.

- Food (positive comments)

Residents make positive comments about the food and/or the chefs. They may also

explain why they like the food: it is appealing, good sized portions, you can have second helpings, it is varied, there is lots of food

- Seating issues, rule breaking

Residents talk about seating issues; e.g., what is better, open or fixed seating at

dinnertime; how they like to sit with friends, breaking seating rules, being limited by maitre d' etc. Note: if residents are breaking the seating rules (e.g., sitting down without being placed by the maitre d' this is a specific instance of "resident controls"

resident/management and "norm breaking". Therefore, only the seating code is necessary.

- Other dining difficulties

Residents talk about other difficulties in the dining room (apart from seating): too many people, having to carry on a conversation, being with people who do not talk, the problems that newcomers have knowing what the social norms are in the dining room. etc.

\section{N. Suggestions?}

- FACTOR Expectations

Residents remark that people will always complain because: people see things differently; people have different personalities, expertise, tastes, opinions, some are easy to please and others are not. Expectations may increase or decrease over time.

- FACTOR Labeling complainers

Resident describes how people are reluctant to complain - they do not want to be labeled as complainers - how people discourage complainers.

- OUTCOME Management/staff listens

Residents say that management/staff listens and responds or implements resident complaints, suggestions and requests. 
- OUTCOME Management/staff doesn't listen

Residents say that management does not listen - they do not implement resident suggestions, complaints and requests.

- OUTCOME Management/staff sometimes listens

Residents say that management/staff implements some resident complaints, suggestions but not others.

- Suggestions - to seniors, industry

Resident suggestions to seniors about moving and retirement accommodation and to the industry about communal lifestyle organizations.

\section{O. Perform Assess}

- MGT /STAFF (positive comments) comments

Residents make positive comments about management or staff (owners, managers, Marketing Director, housekeeping, maintenance, security, front desk). Does not include the chef or dining room staff (coded under dining room), the Activity Coordinator (coded under Living with others, activities). This code includes management policies or decisions that have an effect on the Chef or the Activity Coordinator. An example would be hiring a good chef. This code does not apply to their assessment when moving to Lakelands.

- MGT/STAFF (negative comments)

Residents make negative comments about management or staff (owners, manager, marketing director, security, maintenance, housekeeping, front desk). Does not include the chef or dining room staff (coded under dining room), the Activity Coordinator (coded under Living with others, activities). This code includes management policies or decisions that have an effect on the chef or the AC (Activity Coordinator) e.g., hiring a good chef. Note: When residents make negative comments about the "stinginess of management" this goes under "consumption /cost fair exchange" rather than Management-ve. Note: This code does not apply to their assessment when moving to Lakelands.

- PL (place) + ve (positive)

Resident makes positive comments about Lakelands (now, at the current time, in contrast to what they thought about it when they moved.) This code includes comments about their apartment, the location, landscaping, decor, overall appearance, "look" or design of the place.

- PL -ve (negative)

Resident makes negative comments about the place (at the current time, in contrast to their thoughts about Lakelands when they initially moved there). This code includes comments on their apartment, the location, landscaping, decor, overall appearance, "look" or design of the place.

P. Community services - Local environment

Residents talk about the local environment: crime, the health care system, the real estate market, and local transportation. 


\section{T. Crises}

- Care giver stress

Resident talks about the burden of being a care giving spouse.

- Death

Residents talk about death.

- Fight with children

Resident describes a serious fight with children; one which produced a crisis.

- Financial crisis

Resident describes a crisis in their financial situation, or a potential crisis.

- Illness

Residents talk about serious illnesses and/or disabilities like poor eyesight and hearing (their own or other peoples).

\section{Language conventions}

- LANG Accommodation (resident)

Resident describes Lakelands as accommodation.

- LANG Accommodation (management)

Management describes Lakelands as accommodation.

- LANG Apartment $\mathrm{m}$

Management uses the word apartment to refer to resident's rooms. Note the distinction between this and apartment under "Lakelands' organization model." There, management uses the word apartment to refer to Lakelands as a whole.

- LANG Apartment (resident)

Resident uses the word apartment to refer to their rooms.

- LANG Care services (resident)

Residents says that Lakelands provides care, or care services.

- LANG Care services (management

Management says that Lakelands provides care or care services.

- LANG Community (management)

Lakelands is described as a community by management.

- LANG Community (resident)

Lakelands is described as a community by resident.

- LANG Come in, in here

Resident uses the word "come in" or "in here" to describe the move to Lakelands, or the fact that they live at (in) Lakelands.

- LANG Inside

Person, resident or management uses the term "inside Lakelands" to signify that

Lakelands is a boundaried place.

- LANG Outside

Management or residents use this term to signify things that are not part of Lakelands.

The way in which this term is used would suggest that Lakelands is a boundaried place.

- LANG Disappearing

Resident describes people getting ill and dying, or staff leaving as "disappearing". 
- LANG Establishment

Resident describes Lakelands as an establishment.

- LANG Facility (resident)

A resident uses the word "facility" to describe Lakelands.

- LANG Facility (management)

Management uses the term "facility" to refer to Lakelands.

- LANG Home management's

Resident describes Lakelands as being the home of the owners.

- LANG Home/house mine (management)

Management uses the term "house" or "home" to refer to the resident's apartment or place of abode at Lakelands.

- LANG Home/house mine (resident)

Resident describes Lakelands as my private house or home in contrast to using the word home to describe a public institution - "the home" "a home".

- LANG Institution (resident)

Resident refers to Lakelands as an institution.

- LANG Institution (management)

Management refers to Lakelands as an institution.

- LANG Language conventions (other) (management)

A term or figure of speech employed by management or staff - language conventions at Lakelands.

- LANG Language conventions (other) (resident)

A term or figure of speech - a language convention - employed by residents at Lakelands.

- LANG New/old residents

Language used to distinguish new arrivals from people who have lived at Lakelands for some time. Note: I seem to make this distinction more than residents.

- LANG Place (resident)

Residents often use the word "place" to describe Lakelands. This does not include using the word "place" to describe the rooms or apartment where the resident lives.

- LANG Place (management)

Management describes Lakelands as a place.

- LANG Room (management)

Management uses the word room to refer to a resident's apartment.

- LANG Room (resident)

Resident uses the word room to refer to their apartment.

- LANG Suite (management)

Management uses the word suite to refer to a resident's apartments. This word is similar to the term "hotel suite".

LANG Suite (resident)

Resident uses the word suite to refer to their apartment. This word is similar to the term "hotel suite".

LANG Setting (resident)

Resident uses the term setting to describe Lakelands; its surrounding area, its social setting. 


\section{APPENDIX H}

\section{Major interview questions, answers, and type of narrative}

The following table summarizes the answers to the major interview questions. Answers are listed by resident case; from case numbers 1 to 30 . The notes to the table describe the table headings and response categories. Letters used in the headings give a clue to the question. For instance, the first question category - "L" - refers to the question: "Was the look or appearance of the place a factor in choosing Lakelands?"

The table shows narrative predictions and actual narratives. For instance, before the interview I predicted that case number 1 would have a typical narrative. The actual narrative shows a large percentage of contrasting answers, although there are also a large number of typical answers: 6 typical answers. In other words, $60 \%$ of this person's narratives are typical and $30 \%$ are contrasting. 
Table H.01. Interview questions, answers and type of narrative response, by case

\begin{tabular}{|c|c|c|c|c|c|c|c|c|c|c|c|c|c|c|c|}
\hline \multirow{2}{*}{$\begin{array}{c}\text { Case \# } \\
\text { Questions }\end{array}$} & \multicolumn{10}{|c|}{$\begin{array}{c}\text { Interview questions, answers and narrative type } \\
\text { Typical }(T), \text { contrasting }(C) \text {, discrepant }(D) . \text { For other abbreviations } \\
\text { see Notes to table. }\end{array}$} & \multicolumn{5}{|c|}{$\begin{array}{l}\text { Predicted narrative type } \\
\text { and actual narratives: \% of } \\
\text { total; total \# }\end{array}$} \\
\hline & $\mathrm{L}$ & $\mathrm{F}$ & A & $\mathrm{S}$ & $\mathrm{P}^{\mathrm{r}}$ & $\mathrm{R}$ & $\Delta$ & $\mathrm{E}$ & $r$ & $\mathrm{n}$ & $\mathrm{P}$ & $\mathrm{T}$ & $\mathrm{C}$ & $\mathrm{D}$ & \\
\hline 1 Answer & YA & $\mathrm{Y}$ & $\mathrm{N}$ & NM & $\mathrm{Y}$ & $\Delta$ & NW & $\mathrm{N}$ & $\mathrm{F}$ & $\mathrm{F}$ & $\mathrm{T}$ & 60 & 30 & 10 & 100 \\
\hline Narrative & $\mathrm{C}$ & $\mathrm{T}$ & $\mathrm{T}$ & $\mathrm{T}$ & $\mathrm{T}$ & $\mathrm{C}$ & $\mathrm{D}$ & $\mathrm{T}$ & $\mathrm{C}$ & $\mathrm{T}$ & & 6 & 3 & 1 & 10 \\
\hline 2 Answer & $-A$ & $\mathrm{Y}$ & $\mathrm{N}$ & NM & $\mathrm{Y}$ & $\mathrm{N}$ & $\mathrm{N}$ & $\mathrm{N}$ & $\mathrm{F}$ ? & $\mathrm{F}$ & $\mathrm{T}$ & 80 & 20 & 0 & 100 \\
\hline Narrative & $\mathrm{C}$ & $\mathrm{T}$ & $\mathrm{T}$ & $\mathrm{T}$ & $T$ & $\mathrm{~T}$ & $\mathrm{C}$ & $\mathrm{T}$ & $\mathrm{T}$ & $\mathrm{T}$ & & 8 & 2 & 0 & 10 \\
\hline \multirow[t]{2}{*}{3 Answer } & $\mathrm{Y}$ & $\mathrm{Y}$ & $\mathrm{S}$ & YG & - & $\mathrm{N}$ & $Y$ & - & $\mathrm{F}$ & $\mathrm{F}$ & $\mathrm{T}$ & 75 & 25 & 0 & 100 \\
\hline & $\mathrm{T}$ & $\mathrm{T}$ & $\mathrm{T}$ & $\mathrm{C}$ & - & $\mathrm{T}$ & $\mathrm{T}$ & - & $\mathrm{C}$ & $\mathrm{T}$ & & 6 & 2 & 0 & 8 \\
\hline \multirow[t]{2}{*}{4 Answer } & $\mathrm{Y}$ & $\mathrm{Y}$ & $\mathrm{S}$ & $\mathrm{N}$ & $\mathrm{Y}$ & $\mathrm{N}$ & YW & $\mathrm{N}$ & $\mathrm{F}$ ? & $\mathrm{F}$ & $\mathrm{T}$ & 90 & 0 & 10 & 100 \\
\hline & $\mathrm{T}$ & $\mathrm{T}$ & $\mathrm{T}$ & $\mathrm{T}$ & $\mathrm{T}$ & $\mathrm{T}$ & $\mathrm{D}$ & $\mathrm{T}$ & $\mathrm{T}$ & $\mathrm{T}$ & & 9 & 0 & 1 & 10 \\
\hline \multirow[t]{2}{*}{5 Answer } & $\mathrm{Y}$ & $\mathrm{Y}$ & $\mathrm{S}$ & $\mathrm{NM}$ & $\mathrm{Y}$ & $\mathrm{N}$ & $\mathrm{Y}$ & $\mathrm{N}$ & $\mathrm{F} ?$ & $\mathrm{~F}$ & $\mathrm{~T}$ & 100 & 0 & 0 & 100 \\
\hline & $\mathrm{T}$ & $\mathrm{T}$ & $\mathrm{T}$ & $\mathrm{T}$ & $\mathrm{T}$ & $\mathrm{T}$ & $\mathrm{T}$ & $\mathrm{T}$ & $\mathrm{T}$ & $\mathrm{T}$ & & 10 & 0 & 0 & 10 \\
\hline \multirow[t]{2}{*}{6 Answer } & YA & $\mathrm{Y}$ & $\mathrm{N}$ & $\mathrm{NG}$ & Ys & $\mathrm{N}$ & $\mathrm{N}$ & $\mathrm{N}$ & - & - & $\mathrm{T}$ & 63 & 25 & 12 & 100 \\
\hline & $\mathrm{C}$ & $\mathrm{T}$ & $\mathrm{T}$ & $\mathrm{T}$ & $\mathrm{D}$ & $\mathrm{T}$ & $\mathrm{C}$ & $\mathrm{T}$ & - & - & & 5 & 2 & 1 & 8 \\
\hline \multirow[t]{2}{*}{7 Answer } & - & $\mathrm{Y}$ & - & - & - & $\mathrm{N}$ & - & $\mathrm{N}$ & - & - & $\mathrm{T}$ & 100 & 0 & 0 & 100 \\
\hline & - & $\mathrm{T}$ & - & - & - & $\mathrm{T}$ & - & $\mathrm{T}$ & - & - & & 3 & 0 & 0 & 3 \\
\hline
\end{tabular}




\begin{tabular}{|c|c|c|c|c|c|c|c|c|c|c|c|c|c|c|c|}
\hline \multirow{2}{*}{$\begin{array}{c}\text { Case \# } \\
\text { Questions }\end{array}$} & \multicolumn{10}{|c|}{$\begin{array}{c}\text { Interview questions, answers and narrative type } \\
\text { Typical }(T) \text {, contrasting (C), discrepant }(D) . \text { For other abbreviations } \\
\text { see Notes to table. }\end{array}$} & \multicolumn{5}{|c|}{$\begin{array}{l}\text { Predicted narrative type } \\
\text { and actual narratives: \% of } \\
\text { total; total \# }\end{array}$} \\
\hline & $\mathrm{L}$ & $\mathrm{F}$ & $\mathrm{A}$ & $\mathrm{S}$ & $\mathrm{P}^{\mathrm{r}}$ & $\mathrm{R}$ & $\Delta$ & $\mathrm{E}$ & $r$ & $\mathrm{n}$ & $\mathbf{P}$ & $\mathrm{T}$ & $\mathrm{C}$ & $\mathrm{D}$ & \\
\hline \multirow[t]{2}{*}{8 Answer } & $\mathrm{Y}$ & $Y$ & M & YO-,C & $\mathrm{Y}$ & $\mathrm{N}$ & - & - & - & - & $\mathrm{C}$ & 67 & 33 & 0 & 100 \\
\hline & $\mathrm{T}$ & $\mathrm{T}$ & $\mathrm{C}$ & $\mathrm{C}$ & $\mathrm{T}$ & $\mathrm{T}$ & - & - & - & - & & 4 & 2 & 0 & 6 \\
\hline \multirow[t]{2}{*}{9 Answer } & $\mathrm{Y}$ & $\mathrm{Y}$ & - & $\mathrm{Y}, \mathrm{PC}$ & $\mathrm{Y}$ & $\mathrm{N}$ & NW & $\mathrm{N}$ & $\mathrm{F}$ & $\mathrm{F}$ & $\mathrm{T}$ & 67 & 11 & 22 & 100 \\
\hline & $\mathrm{T}$ & $\mathrm{T}$ & - & D & $\mathrm{T}$ & $\mathrm{T}$ & $\mathrm{D}$ & $\mathrm{T}$ & $\mathrm{C}$ & $\mathrm{T}$ & & 6 & 1 & 2 & 9 \\
\hline \multirow[t]{2}{*}{10 Answer } & - & $\mathrm{P}$ & MR & $\mathrm{Y}, \mathrm{C}$ & - & - & $\mathrm{N}$ & $\mathrm{Nc}$ & $\mathrm{F}$ & $\mathrm{F}$ & $\mathrm{T}$ & 14 & 71 & 14 & 100 \\
\hline & - & $\mathrm{C}$ & $\mathrm{C}$ & $\mathrm{C}$ & - & - & $\mathrm{C}$ & $\mathrm{D}$ & $\mathrm{C}$ & $\mathrm{T}$ & & 1 & 5 & 1 & 7 \\
\hline \multirow[t]{2}{*}{11 Answer } & $Y$ & $\mathrm{Y}$ & $\mathrm{N}$ & $\mathrm{Y}, \mathrm{PC}$ & - & $\mathrm{N}$ & $\mathrm{Y}$ & $\mathrm{N}$ & $\mathrm{F} ?$ & $\mathrm{~F}$ & $\mathrm{~T}$ & 89 & 0 & 11 & 100 \\
\hline & $\mathrm{T}$ & $\mathrm{T}$ & $\mathrm{T}$ & $\mathrm{D}$ & - & $\mathrm{T}$ & $\mathrm{T}$ & $\mathrm{T}$ & $\mathrm{T}$ & $\mathrm{T}$ & & 8 & 0 & 1 & 9 \\
\hline \multirow[t]{2}{*}{12 Answer } & YA & $\mathrm{Y}$ & $\mathrm{S}$ & NP & $\begin{array}{c}\mathrm{YN} \\
\mathrm{m}\end{array}$ & $\mathrm{N}$ & $\mathrm{Y}$ & $\mathrm{N}$ & $\mathrm{F}$ & $\mathrm{F}$ & $\mathrm{TC}$ & 70 & 30 & 0 & 100 \\
\hline & $\mathrm{C}$ & $\mathrm{T}$ & $\mathrm{T}$ & $\mathrm{T}$ & $\mathrm{C}$ & $\mathrm{T}$ & $\mathrm{T}$ & $\mathrm{T}$ & $\mathrm{C}$ & $\mathrm{T}$ & & 7 & 3 & 0 & 10 \\
\hline \multirow[t]{2}{*}{13 Answer } & $\mathrm{Y}$ & $\mathrm{Y}$ & $\mathrm{N}$ & YHC & $\mathrm{Y}$ & - & $N$ & $\mathrm{~N}$ & - & - & $\mathrm{TC}$ & 71 & 29 & 0 & 100 \\
\hline & $\mathrm{T}$ & $\mathrm{T}$ & $\mathrm{T}$ & $\mathrm{C}$ & $\mathrm{T}$ & - & $\mathrm{C}$ & $\mathrm{T}$ & - & - & & 5 & 2 & 0 & 7 \\
\hline \multirow[t]{2}{*}{14 Answer } & $\mathrm{Y}$ & $\mathrm{Y}$ & $\mathrm{N}$ & YG & $\mathrm{Y}$ & $\mathrm{N}$ & No & $\mathrm{N}$ & $\mathrm{F}$ & $\mathrm{F}$ & $\mathrm{TC}$ & 70 & 30 & 0 & 100 \\
\hline & $\mathrm{T}$ & $\mathrm{T}$ & $\mathrm{T}$ & $\mathrm{C}$ & $\mathrm{T}$ & $\mathrm{T}$ & $\mathrm{C}$ & $\mathrm{T}$ & $\mathrm{C}$ & $\mathrm{T}$ & & 7 & 3 & 0 & 10 \\
\hline
\end{tabular}




\begin{tabular}{|c|c|c|c|c|c|c|c|c|c|c|c|c|c|c|c|}
\hline \multirow{2}{*}{$\begin{array}{c}\text { Case \# } \\
\text { Questions }\end{array}$} & \multicolumn{10}{|c|}{$\begin{array}{c}\text { Interview questions, answers and narrative type } \\
\text { Typical }(T), \text { contrasting }(C) \text {, discrepant }(D) . \text { For other abbreviations } \\
\text { see Notes to table. }\end{array}$} & \multicolumn{5}{|c|}{$\begin{array}{l}\text { Predicted narrative type } \\
\text { and actual narratives: \% of } \\
\text { total; total \# }\end{array}$} \\
\hline & $\mathrm{L}$ & $\mathrm{F}$ & A & $S$ & $\mathrm{P}^{\mathrm{r}}$ & $\mathrm{R}$ & $\Delta$ & $\mathrm{E}$ & $r$ & $\mathrm{n}$ & $\mathrm{P}$ & $\mathrm{T}$ & $\mathrm{C}$ & $\mathrm{D}$ & \\
\hline \multirow[t]{2}{*}{15 Answer } & $\mathrm{Y}$ & $\mathrm{Y}$ & $\mathrm{L}$ & $\mathrm{N}$ & $\mathrm{Y}$ & $\mathrm{N}$ & $\mathrm{N}$ & $\mathrm{N}$ & - & $\mathrm{Ff}$ & $\mathrm{TC}$ & 67 & 22 & 11 & 100 \\
\hline & $\mathrm{T}$ & $\mathrm{T}$ & $\mathrm{D}$ & $\mathrm{T}$ & $\mathrm{T}$ & $\mathrm{T}$ & $\mathrm{C}$ & $\mathrm{T}$ & - & $\mathrm{C}$ & & 6 & 2 & 1 & 9 \\
\hline \multirow[t]{2}{*}{16 Answer } & - & $\mathrm{Y}$ & $\mathrm{N}$ & - & $\mathrm{Y}$ & - & $Y$ & - & - & - & $\mathrm{TC}$ & 100 & 0 & 0 & 100 \\
\hline & - & $\mathrm{T}$ & $\mathrm{T}$ & - & $\mathrm{T}$ & - & $\mathrm{T}$ & - & - & - & & 4 & 0 & 0 & 4 \\
\hline \multirow[t]{2}{*}{17 Answer } & - & $\mathrm{YC}$ & MR & YP & $\mathrm{Ng}$ & $\mathrm{N}$ & - & $\mathrm{YNc}$ & - & - & $\mathrm{TC}$ & 17 & 66 & 17 & 100 \\
\hline & - & $\mathrm{C}$ & $\mathrm{C}$ & $\mathrm{C}$ & $\mathrm{C}$ & $\mathrm{T}$ & - & $\mathrm{D}$ & - & - & & 1 & 4 & 1 & 6 \\
\hline \multirow[t]{2}{*}{18 Answer } & - & $\mathrm{N}$ & $\mathrm{Lm}$ & - & Ns & $\mathrm{N}$ & NWm & $\mathrm{N}$ & $\mathrm{N}$ & $\mathrm{F}$ & $\mathrm{TC}$ & 38 & 0 & 62 & 100 \\
\hline & - & $\mathrm{D}$ & $\mathrm{D}$ & - & $\mathrm{C}$ & $\mathrm{T}$ & $\mathrm{D}$ & $\mathrm{T}$ & $\mathrm{D}$ & $\mathrm{T}$ & & 3 & 0 & 5 & 8 \\
\hline \multirow[t]{2}{*}{19 Answer } & $\mathrm{Y}$ & $\mathrm{Y}$ & $\mathrm{S}$ & - & $\mathrm{Y}$ & $\mathrm{N}$ & $\mathrm{Ys}$ & $\mathrm{N}$ & - & - & $\mathrm{TC}$ & 86 & 14 & 0 & 100 \\
\hline & $\mathrm{T}$ & $\mathrm{T}$ & $\mathrm{T}$ & - & $\mathrm{T}$ & $\mathrm{T}$ & $\mathrm{T}$ & $\mathrm{T}$ & - & - & & 6 & 1 & 0 & 7 \\
\hline \multirow[t]{2}{*}{20 Answer } & $\mathrm{Y}$ & $Y$ & M & $\mathrm{YO}+\mathrm{PC}$ & $\mathrm{Y}$ & $\mathrm{N}$ & $Y$ & $\mathrm{YN}$ & $\mathrm{F}$ ? & $\mathrm{F}$ & $\mathrm{T}$ & 67 & 33 & 0 & 100 \\
\hline & $\mathrm{T}$ & $\mathrm{T}$ & $\mathrm{C}$ & $\mathrm{C}$ & $\mathrm{T}$ & $\mathrm{T}$ & $\mathrm{T}$ & $\mathrm{C}$ & $\mathrm{T}$ & $\mathrm{T}$ & & 6 & 3 & 0 & 9 \\
\hline \multirow[t]{2}{*}{21 Answer } & $\mathrm{Y}$ & $\mathrm{Y}$ & $\mathrm{Lm}$ & YO- & $\mathrm{Yg}$ & $\mathrm{N}$ & $\mathrm{N}$ & YN & $\mathrm{F}$ ? & $\mathrm{F}$ & $\mathrm{C}$ & 50 & 40 & 10 & 100 \\
\hline & $\mathrm{T}$ & $\mathrm{T}$ & $\mathrm{D}$ & $\mathrm{C}$ & $\mathrm{C}$ & $\mathrm{T}$ & $\mathrm{C}$ & $\mathrm{C}$ & $\mathrm{T}$ & $\mathrm{T}$ & & 5 & 4 & 1 & 10 \\
\hline
\end{tabular}




\begin{tabular}{|c|c|c|c|c|c|c|c|c|c|c|c|c|c|c|c|}
\hline \multirow{2}{*}{$\begin{array}{c}\text { Case \# } \\
\text { Questions }\end{array}$} & \multicolumn{10}{|c|}{$\begin{array}{c}\text { Interview questions, answers and narrative type } \\
\text { Typical }(T), \text { contrasting }(C) \text {, discrepant }(D) . \text { For other abbreviations } \\
\text { see Notes to table. }\end{array}$} & \multicolumn{5}{|c|}{$\begin{array}{l}\text { Predicted narrative type } \\
\text { and actual narratives: \% of } \\
\quad \text { total; total \# }\end{array}$} \\
\hline & $\mathrm{L}$ & $\mathrm{F}$ & A & $S$ & $\mathrm{P}^{\mathrm{r}}$ & $\mathrm{R}$ & $\Delta$ & $\mathrm{E}$ & $\mathrm{r}$ & $\mathrm{n}$ & $\mathrm{P}$ & $\mathrm{T}$ & $\mathrm{C}$ & $\mathrm{D}$ & \\
\hline \multirow[t]{2}{*}{22 Answer } & - & $\mathrm{Y}$ & $\mathrm{Lm}$ & YO- & $\mathrm{Y}$ & $\mathrm{N}$ & $\mathrm{N}$ & $\mathrm{YN}$ & $\mathrm{F}$ ? & $\mathrm{F}$ & $\mathrm{C}$ & 56 & 33 & 11 & 100 \\
\hline & - & $\mathrm{T}$ & $\mathrm{D}$ & $\mathrm{C}$ & $\mathrm{T}$ & $\mathrm{T}$ & $\mathrm{C}$ & $\mathrm{C}$ & $\mathrm{T}$ & $\mathrm{T}$ & & 5 & 3 & 1 & 9 \\
\hline \multirow[t]{2}{*}{23 Answer } & $\mathrm{Y}$ & $\mathrm{Y}$ & $\mathrm{LF}$ & - & - & - & $\mathrm{Y}$ & $\mathrm{N}$ & - & - & $\mathrm{D}$ & 80 & 0 & 20 & 100 \\
\hline & $\mathrm{T}$ & $\mathrm{T}$ & $\mathrm{D}$ & - & - & - & $\mathrm{T}$ & $\mathrm{T}$ & - & - & & 4 & 0 & 1 & 5 \\
\hline \multirow[t]{2}{*}{24 Answer } & - & $\mathrm{P}$ & $\mathrm{N}$ & $\begin{array}{c}\mathrm{YO}, \\
\mathrm{PC}, \mathrm{V}\end{array}$ & $\mathrm{Y}$ & $\mathrm{N}$ & - & $\mathrm{N}$ & $\mathrm{F}$ & $\mathrm{F}$ & $\mathrm{D}$ & 63 & 37 & 0 & 100 \\
\hline & - & $\mathrm{C}$ & $\mathrm{T}$ & $\mathrm{C}$ & $\mathrm{T}$ & $\mathrm{T}$ & - & $\mathrm{T}$ & $\mathrm{C}$ & $\mathrm{T}$ & & 5 & 3 & 0 & 8 \\
\hline \multirow[t]{2}{*}{25 Answer } & $\mathrm{Y}$ & $\mathrm{Y}$ & $\mathrm{S}$ & $\mathrm{N}$ & $\mathrm{Y}$ & $\mathrm{N}$ & $\mathrm{Y}$ & $\mathrm{N}$ & $\mathrm{F}$ ? & $\mathrm{F}$ & $\mathrm{TC}$ & 100 & 0 & 0 & 100 \\
\hline & $\mathrm{T}$ & $\mathrm{T}$ & $\mathrm{T}$ & $\mathrm{T}$ & $\mathrm{T}$ & $\mathrm{T}$ & $\mathrm{T}$ & $\mathrm{T}$ & $\mathrm{T}$ & $\mathrm{T}$ & & 10 & 0 & 0 & 10 \\
\hline \multirow[t]{2}{*}{26 Answer } & $\mathrm{Y}$ & $\mathbf{P}$ & $\mathrm{S}$ & $\mathrm{N}$ & $\mathrm{Y}$ & $\mathrm{N}$ & $\mathrm{Y}$ & $\mathrm{N}$ & $F ?$ & $\mathrm{~F}$ & $\mathrm{~T}$ & 90 & 10 & 0 & 100 \\
\hline & $\mathrm{T}$ & $\mathrm{C}$ & $\mathrm{T}$ & $\mathrm{T}$ & $\mathrm{T}$ & $\mathrm{T}$ & $\mathrm{T}$ & $\mathrm{T}$ & $\mathrm{T}$ & $\mathrm{T}$ & & 9 & 1 & 0 & 10 \\
\hline \multirow[t]{2}{*}{27 Answer } & - & $\mathrm{Y}$ & $\mathrm{N}$ & $\mathrm{YC}$ & $\mathrm{Yg}$ & $\mathrm{N}$ & $\mathrm{Y}$ & $\mathrm{N}$ & - & - & $\mathrm{C}$ & 71 & 29 & 0 & 100 \\
\hline & - & $\mathrm{T}$ & $\mathrm{T}$ & $\mathrm{C}$ & $\mathrm{C}$ & $\mathrm{T}$ & $\mathrm{T}$ & $\mathrm{T}$ & - & - & & 5 & 2 & 0 & 7 \\
\hline \multirow[t]{2}{*}{28 Answer } & - & $\mathrm{Y}$ & $\mathrm{S}$ & $\mathrm{N}$ & $\mathrm{Y}$ & $\mathrm{N}$ & $Y$ & $\mathrm{~N}$ & - & - & $\mathrm{TC}$ & 100 & 0 & 0 & 100 \\
\hline & - & $\mathrm{T}$ & $\mathrm{T}$ & $\mathrm{T}$ & $\mathrm{T}$ & $\mathrm{T}$ & $\mathrm{T}$ & $\mathrm{T}$ & - & - & & 7 & 0 & 0 & 7 \\
\hline
\end{tabular}




\begin{tabular}{|c|c|c|c|c|c|c|c|c|c|c|c|c|c|c|c|}
\hline \multirow{2}{*}{$\begin{array}{c}\text { Case \# } \\
\text { Questions }\end{array}$} & \multicolumn{10}{|c|}{$\begin{array}{c}\text { Interview questions, answers and narrative type } \\
\text { Typical }(T), \text { contrasting }(C) \text {, discrepant }(D) \text {. For other abbreviations } \\
\text { see Notes to table. }\end{array}$} & \multicolumn{5}{|c|}{$\begin{array}{l}\text { Predicted narrative type } \\
\text { and actual narratives: \% of } \\
\text { total; total \# }\end{array}$} \\
\hline & $\mathrm{L}$ & $\mathrm{F}$ & $\mathrm{A}$ & $\mathrm{S}$ & $\mathrm{P}^{\mathrm{r}}$ & $\mathrm{R}$ & $\Delta$ & $\mathrm{E}$ & $\mathrm{r}$ & $\mathrm{n}$ & $\mathrm{P}$ & $\mathrm{T}$ & $\mathrm{C}$ & $\mathrm{D}$ & \\
\hline \multirow[t]{2}{*}{29 Answer } & $\mathrm{Y}$ & $\mathrm{P}$ & $\mathrm{N}$ & $\mathrm{N}$ & $\mathrm{Y}$ & $\mathrm{N}$ & $\mathrm{Y}$ & $\mathrm{N}$ & $\mathrm{F}$ & $\mathrm{F}$ & $\mathrm{D}$ & 80 & 20 & 0 & 100 \\
\hline & $\mathrm{T}$ & $\mathrm{C}$ & $\mathrm{T}$ & $\mathrm{T}$ & $\mathrm{T}$ & $\mathrm{T}$ & $\mathrm{T}$ & $\mathrm{T}$ & $\mathrm{C}$ & $\mathrm{T}$ & & 8 & 2 & 0 & \\
\hline \multirow[t]{2}{*}{30 Answer } & $\mathrm{Y}$ & $\mathrm{YC}$ & $\mathbf{M}$ & $\mathrm{N}, \mathrm{O}$ & $\mathrm{Y}$ & $\mathrm{N}$ & $\mathrm{N}$ & $\mathrm{N}$ & $\mathrm{F}$ ? & $\mathrm{N}$ & $\mathrm{C}$ & 60 & 30 & 10 & 100 \\
\hline & $\mathrm{T}$ & $\mathrm{C}$ & $\mathrm{C}$ & $\mathrm{T}$ & $\mathrm{T}$ & $\mathrm{T}$ & $\mathrm{C}$ & $\mathrm{T}$ & $\mathrm{T}$ & D & & 6 & 3 & 1 & 10 \\
\hline
\end{tabular}

Notes. See next page. 
Notes. Case \# = The number assigned to a case.

Abbreviations for interview questions and answers:

L The "image": Answer to the question: Was the appearance or image (i.e., look of the place) a factor in your decision to move to Lakelands? $\mathrm{Y}=$ yes. $\mathrm{N}=$ no.

F Freedom: Answer to the question: Can you live the way you would like to live at Lakelands (free of restrictions from Lakelands)? $\mathrm{Y}=$ yes - no restrictions from Lakelands. $\mathrm{P}=$ pretty much or mostly. $\mathrm{C}=$ could live as I wish if I applied myself. $\mathrm{N}=$ no. Lakelands places restrictions on my ability to live the way I wish.

A Adaptation. Answer to the question: Have you had to change or adapt? $\mathrm{N}=$ No. Resident says they did not have to adapt to Lakelands. $\mathrm{S}=$ Small adaptation. Resident says they had to adapt a little. $\mathrm{M}=$ Medium adaptation. Resident says adaptation was required and describes a number of things that made it somewhat difficult to adapt, for example having to change their personal meal schedule, having to adapt to a new town, new friends or the like.

$\mathrm{L}=$ Large adaptation. Resident says they found it hard to adapt to life at Lakelands. Also, they may say that they cannot remember the period of time after their move. They may say it is taking (or took) a long time to adapt. They may say they are still having trouble adapting. They may say they are thinking seriously about moving because they cannot adapt, or they may say they would like to move, but cannot due to health problems.

$\mathrm{F}=$ Forgot first year.

$\mathrm{m}=$ Thinking of moving, or would like to move if they could.

$\mathrm{R}=$ Had to change meal times to fit Lakelands' schedule.

S Self-identity. Answer to the question: Does living here affect the way you see yourself?

$\mathrm{N}=$ No. $\mathrm{M}=\mathrm{I}$ am who I am. I haven't changed.

$\mathrm{Y}=$ Yes.

$\mathrm{C}=$ More conscious of others.

$\mathrm{G}=$ Feel good, better about self, proud.

$\mathrm{H}=\mathrm{I}$ no longer feel as important. I am more humble. This is interpreted by the resident as a good thing or interpreted as being neither good nor bad.

$\mathrm{P}=\mathrm{I}$ am no longer a property owner. This is interpreted in a neutral manner.

$\mathrm{O}-=$ Feeling old . This is interpreted by the resident as a negative change.

$\mathrm{O}+=$ Feeling old. This is interpreted by the resident as a positive or neutral change.

$\mathrm{PC}=$ Identity has changed as a result of a crisis, like a decline in health. $\mathrm{V}=$ No longer a volunteer.

$\mathrm{P}^{\mathrm{r}} \quad$ Privacy. Answer to the question: Do you have enough privacy? $\mathrm{Y}=$ Yes. $\mathrm{N}=$ No. $\mathrm{YN}=$ Yes and no. $\mathrm{s}=$ Someone has stolen things from my apartment.

$\mathrm{m}=$ Would like more time alone. $\mathrm{g}=$ Have experienced malicious gossip.

$\mathrm{R} \quad$ Rules. Answer to the question: Do you feel there are a lot of rules here? $\mathrm{Y}=$ Yes. $\mathrm{N}=$ No. $\Delta=$ Rules keep changing. 
$\Delta \quad$ Change. Answer to the question: Have you made suggestions for change? $\mathrm{Y}=$ Yes. $\mathrm{N}=\mathrm{No}$. $\mathrm{W}=$ Management doesn't listen; or doesn't make changes, so why make suggestions? $\mathrm{o}=$ Have been asked for our opinion and have given it. $\mathrm{m}$ $=$ Don't find resident meetings useful. $\mathrm{s}=$ spouse made suggestion on respondent's behalf

E Eating. Answer to the question: Would you prefer to eat in your apartment rather than eating in the dining room? $\mathrm{Y}=$ Yes. $\mathrm{N}=$ No. $\mathrm{YN}=$ Yes and no. Sometimes I like to eat in the dining room and sometimes in my apartment. $\mathrm{c}=$ required major change in personal eating schedule to accommodate Lakelands' dining room schedule.

$\mathrm{r} \quad$ Residents. Answer to the question: What do you think about the use of the word "residents?" $\mathrm{F}=$ Fine $\mathrm{N}=$ Not fine. ? = Makes a suggestion for an alternative.

$\mathrm{n} \quad$ Names. Answer to the question: What do you think about everyone calling each other by their first name?

$\mathrm{F}=$ Fine. $\mathrm{N}=$ Not fine. $\mathrm{f}=$ Some naming habits are funny like calling residents "you guys."

\section{Predicted and actual narratives}

Percent of total $=$ Percentage of total answers that are either typical, contrasting or discrepant narratives.

Total number $=$ Total number of answers that are either typical, contrasting and discrepant narratives.

$\mathrm{P} \quad$ Predicts, before the interview takes place, the type of narrative the resident is likely to produce. This prediction is based on Table 3.7 and 3.8. 


\section{APPENDIX I}

\section{Creating narrative categories}

The table in this appendix defines what constitutes a typical, contrasting or discrepant narrative for 10 major interview questions. This table operationalizes the narrative definitions in Table 3.7 for each question. To illustrate, a typical narrative for the first question Table I.01 was "yes." Eighteen persons said that the "look or the appearance of the place" was a factor in moving to Lakelands. Since "yes" is the most frequent response, it is defined as the typical narrative. The contrasting narrative, which is defined as being less frequent than typical narratives, but more frequent than discrepant narratives, was "atmosphere was important." Four persons had this narrative. There were no discrepant answers for this question. A discrepant answer might have been: "I don't consider atmosphere to be important," however, no one expressed this opinion. 
Table I.01. Typical, contrasting and discrepant narratives for 10 major interview questions

\begin{tabular}{|c|c|c|c|c|c|}
\hline \multirow{2}{*}{$\begin{array}{l}\text { Questions } \\
\quad \& \\
\text { Responses }\end{array}$} & \multicolumn{4}{|c|}{ Narratives } & \multirow[b]{2}{*}{$\begin{array}{l}\text { Total } \\
\text { cases }\end{array}$} \\
\hline & Typical & Contrasting & Discrepant & Missing $^{a}$ & \\
\hline $\begin{array}{l}\text { Was the look or } \\
\text { appearance of } \\
\text { the place a } \\
\text { factor in } \\
\text { moving here? }\end{array}$ & Yes. & $\begin{array}{l}\text { Atmosphere } \\
\text { important. }\end{array}$ & $\begin{array}{c}\text { Not } \\
\text { applicable. }\end{array}$ & & \\
\hline $\begin{array}{l}\text { Responses } \\
\text {-Total } \\
\text {-Minus missing } \\
\text { responses }\end{array}$ & $\begin{array}{c}17 \\
(57 \%) \\
17 \\
(81 \%) \\
\end{array}$ & $\begin{array}{c}4 \\
(13 \%) \\
4 \\
(19 \%) \\
\end{array}$ & 0 & $\begin{array}{c}9 \\
(30 \%)\end{array}$ & $\begin{array}{c}30 \\
(100 \%) \\
21 \\
(100 \%) \\
\end{array}$ \\
\hline $\begin{array}{l}\text { Have you had } \\
\text { to change or } \\
\text { adapt? }\end{array}$ & $\begin{array}{c}\text { No. Yes, } \\
\text { small amount. }\end{array}$ & $\begin{array}{c}\text { Yes, } \\
\text { moderate } \\
\text { amount. E.g., } \\
\text { Have had to } \\
\text { change meal } \\
\text { schedule. }\end{array}$ & $\begin{array}{l}\text { Yes, large } \\
\text { amount. } \\
\text { E.g., Want } \\
\text { to move } \\
\text { out. }\end{array}$ & & \\
\hline $\begin{array}{l}\text { Responses } \\
\text { - Total } \\
\text { - Minus } \\
\text { missing } \\
\text { responses }\end{array}$ & $\begin{array}{c}18 \\
(60 \%) \\
18 \\
(64 \%)\end{array}$ & $\begin{array}{c}5 \\
(17 \%) \\
5 \\
(18 \%)\end{array}$ & $\begin{array}{c}5 \\
(17 \%) \\
5 \\
(18 \%)\end{array}$ & $\begin{array}{c}2 \\
(6 \%) \\
-\end{array}$ & $\begin{array}{c}30 \\
(100 \%) \\
28 \\
(100 \%)\end{array}$ \\
\hline $\begin{array}{l}\text { Does living } \\
\text { here affect the } \\
\text { way you see } \\
\text { yourself? }\end{array}$ & No. & Yes. & $\begin{array}{l}\text { Poor health } \\
\text { changes } \\
\text { identity. }\end{array}$ & & \\
\hline $\begin{array}{l}\text { Responses } \\
\text {-Total } \\
\text {-Minus missing } \\
\text { responses }\end{array}$ & $\begin{array}{c}12 \\
(40 \%) \\
12 \\
(48 \%)\end{array}$ & $\begin{array}{c}11 \\
(36 \%) \\
11 \\
(44 \%)\end{array}$ & $\begin{array}{c}2 \\
(7 \%) \\
2 \\
(8 \%)\end{array}$ & $\begin{array}{c}5 \\
(17 \%) \\
-\end{array}$ & $\begin{array}{c}30 \\
(100 \%) \\
25 \\
(100 \%)\end{array}$ \\
\hline
\end{tabular}




\begin{tabular}{|c|c|c|c|c|c|}
\hline \multirow{2}{*}{$\begin{array}{l}\text { Questions } \\
\quad \& \\
\text { Responses }\end{array}$} & \multicolumn{5}{|c|}{ Narratives } \\
\hline & Typical & Contrasting & Discrepant & Missing $^{a}$ & $\begin{array}{l}\text { Total } \\
\text { cases }\end{array}$ \\
\hline $\begin{array}{l}\text { What do you } \\
\text { think about } \\
\text { everyone } \\
\text { calling each } \\
\text { other by their } \\
\text { first name? }\end{array}$ & Fine. & $\begin{array}{c}\text { Fine, but } \\
\text { some other } \\
\text { naming } \\
\text { habits are } \\
\text { funny (e.g., } \\
\text { "you guys"). }\end{array}$ & Not fine. & & \\
\hline $\begin{array}{l}\text { Responses } \\
\text { - Total } \\
\text { - Minus } \\
\text { missing } \\
\text { responses }\end{array}$ & $\begin{array}{c}18 \\
(60 \%) \\
18 \\
(90 \%)\end{array}$ & $\begin{array}{c}1 \\
(3 \%) \\
1 \\
(5 \%)\end{array}$ & $\begin{array}{c}1 \\
(3 \%) \\
1 \\
(5 \%)\end{array}$ & $\begin{array}{c}10 \\
(30 \%) \\
- \\
-\end{array}$ & $\begin{array}{c}30 \\
(100 \%) \\
20 \\
(100 \%)\end{array}$ \\
\hline $\begin{array}{l}\text { What do you } \\
\text { think about use } \\
\text { of the word } \\
\text { "residents"? }\end{array}$ & Fine. & $\begin{array}{c}\text { Fine. } \\
\text { Suggests } \\
\text { alternative } \\
\text { names. }\end{array}$ & Not fine. & & \\
\hline $\begin{array}{l}\text { Responses } \\
\text { - Total } \\
\text { - Minus } \\
\text { missing } \\
\text { responses }\end{array}$ & $\begin{array}{c}10 \\
(33 \%) \\
10 \\
(53 \%)\end{array}$ & $\begin{array}{c}8 \\
(27 \%) \\
8 \\
(42 \%)\end{array}$ & $\begin{array}{c}1 \\
(3 \%) \\
1 \\
(5 \%)\end{array}$ & $\begin{array}{c}11 \\
(37 \%) \\
- \\
-\end{array}$ & $\begin{array}{c}30 \\
(100 \%) \\
19 \\
(100 \%)\end{array}$ \\
\hline $\begin{array}{l}\text { Do you have } \\
\text { enough } \\
\text { privacy? }\end{array}$ & Yes & $\begin{array}{l}\text { Problems: } \\
\text { gossip; want } \\
\text { more time } \\
\text { alone. }\end{array}$ & $\begin{array}{l}\text { Problems: } \\
\text { theft. }\end{array}$ & & \\
\hline $\begin{array}{l}\text { Responses } \\
\text { - Total } \\
\text { - Minus } \\
\text { missing } \\
\text { responses }\end{array}$ & $\begin{array}{c}19 \\
(63 \%) \\
19 \\
(76 \%)\end{array}$ & $\begin{array}{c}4 \\
(13 \%) \\
4 \\
(16 \%)\end{array}$ & $\begin{array}{c}2 \\
(7 \%) \\
2 \\
(8 \%)\end{array}$ & $\begin{array}{c}5 \\
(17 \%) \\
-\end{array}$ & $\begin{array}{c}30 \\
(100 \%) \\
25 \\
(100 \%)\end{array}$ \\
\hline
\end{tabular}




\begin{tabular}{|c|c|c|c|c|c|}
\hline \multirow{2}{*}{$\begin{array}{l}\text { Questions } \\
\quad \& \\
\text { Responses }\end{array}$} & \multicolumn{5}{|c|}{ Narratives } \\
\hline & Typical & Contrasting & Discrepant & Missing $^{a}$ & $\begin{array}{l}\text { Total } \\
\text { cases }\end{array}$ \\
\hline $\begin{array}{l}\text { Would you } \\
\text { prefer to eat in } \\
\text { your apartment } \\
\text { rather than eat } \\
\text { in the dining } \\
\text { room? }\end{array}$ & No. & $\begin{array}{l}\text { Yes and No. } \\
\text { Sometimes I } \\
\text { like eating in } \\
\text { at my place } \\
\text { when sick } \\
\text { for example. }\end{array}$ & $\begin{array}{c}\text { Yes or No. } \\
\text { Changed } \\
\text { personal } \\
\text { eating } \\
\text { schedule. }\end{array}$ & & \\
\hline $\begin{array}{l}\text { Responses } \\
\text { - Total } \\
\text { - Minus } \\
\text { missing } \\
\text { responses }\end{array}$ & $\begin{array}{c}22 \\
(73 \%) \\
22 \\
(82 \%)\end{array}$ & $\begin{array}{c}3 \\
(10 \%) \\
3 \\
(11 \%)\end{array}$ & $\begin{array}{c}2 \\
(7 \%) \\
2 \\
(7 \%)\end{array}$ & $\begin{array}{c}3 \\
(10 \%) \\
- \\
-\end{array}$ & $\begin{array}{c}30 \\
(100 \%) \\
27 \\
(100 \%)\end{array}$ \\
\hline $\begin{array}{l}\text { Do you feel } \\
\text { there are a lot } \\
\text { of rules? }\end{array}$ & No. & $\begin{array}{l}\text { No. Rules } \\
\text { change, not } \\
\text { definite. }\end{array}$ & Yes. & & \\
\hline $\begin{array}{l}\text { Responses } \\
\text { - Total } \\
\text { - Minus } \\
\text { missing } \\
\text { responses } \\
\end{array}$ & $\begin{array}{c}25 \\
(83 \%) \\
25 \\
(96 \%)\end{array}$ & $\begin{array}{c}1 \\
(3 \%) \\
1 \\
(4 \%)\end{array}$ & 0 & $\begin{array}{c}4 \\
(13 \%) \\
- \\
-\end{array}$ & $\begin{array}{c}30 \\
(100 \%) \\
26 \\
(100 \%)\end{array}$ \\
\hline $\begin{array}{l}\text { Can you live } \\
\text { the way you } \\
\text { want - free of } \\
\text { restrictions } \\
\text { from } \\
\text { Lakelands? }\end{array}$ & $\begin{array}{l}\text { Yes. No } \\
\text { restrictions } \\
\text { from } \\
\text { Lakelands. } \\
\text { Other } \\
\text { restrictions } \\
\text { may exist } \\
\text { e.g., health. }\end{array}$ & $\begin{array}{l}\text { Pretty much } \\
\text { (a few limits } \\
\text { from } \\
\text { Lakelands). }\end{array}$ & No. & & \\
\hline Responses & $25(83 \%)$ & $4(13 \%)$ & $1(3 \%)$ & 0 & $\begin{array}{c}30 \\
(100 \%)\end{array}$ \\
\hline
\end{tabular}




\begin{tabular}{|c|c|c|c|c|c|}
\hline \multirow{2}{*}{$\begin{array}{l}\text { Questions } \\
\quad \& \\
\text { Responses }\end{array}$} & \multicolumn{4}{|c|}{ Narratives } & \multirow[b]{2}{*}{$\begin{array}{l}\text { Total } \\
\text { cases }\end{array}$} \\
\hline & Typical & Contrasting & Discrepant & Missing ${ }^{a}$ & \\
\hline $\begin{array}{l}\text { Have you made } \\
\text { suggestions for } \\
\text { change? }\end{array}$ & Yes. & No. & $\begin{array}{l}\text { Yes or no, } \\
\text { Mgt. } \\
\text { doesn't } \\
\text { listen. }\end{array}$ & & \\
\hline $\begin{array}{l}\text { Responses } \\
\text {-Total } \\
\text { - Minus } \\
\text { missing } \\
\text { responses }\end{array}$ & $\begin{array}{c}13 \\
(43 \%) \\
13 \\
(50 \%)\end{array}$ & $\begin{array}{c}9 \\
(30 \%) \\
9 \\
(35 \%)\end{array}$ & $\begin{array}{c}4 \\
(13 \%) \\
4 \\
(15 \%)\end{array}$ & $\begin{array}{c}4 \\
(13 \%) \\
- \\
-\end{array}$ & $\begin{array}{c}30 \\
(100 \%) \\
26 \\
(100 \%)\end{array}$ \\
\hline
\end{tabular}

Note. ${ }^{a}$ Either I did not ask the resident this question, or they did not directly answer the question. 


\section{APPENDIX J}

\section{Narrative types: Creating a case level measure}

This study uses two methods to classify narratives: a measure that predicts a respondent's narrative before the interview takes place - typical, contrasting or discrepant narratives and a second measure that classifies narratives after the interview. Whereas the first measure classifies narratives at the case level, the second classifies narratives for interview question responses. This appendix describes a method for aggregating question responses to the case level. The purpose was to be able to draw a random sample of cases to test the intercoder reliability of qualitative electronic codes.

The following table shows cut-offs for determining whether or not a case falls into a typical, contrasting or discrepant narrative. The cut-offs for typical and contrasting cases were chosen so as to roughly correspond with the values in Table 3.13 - the frequency of typical, contrasting and discrepant answers to the 10 interview questions. The cut-off for discrepant narratives was set higher so as to reduce the number of cases that would meet more than one cut-off.

Table J.01. Classifying narratives at the case level: Decision rules

\begin{tabular}{ll}
\hline Narrative & Decision rules \\
\hline Typical & $\begin{array}{l}\text { Classify a case as a typical narrative if } 75 \% \text { or more of answers to } \\
\text { interview questions are typical answers. }\end{array}$ \\
Contrasting & $\begin{array}{l}\text { Classify a case as contrasting if } 29 \% \text { or more of answers are } \\
\text { contrasting. }\end{array}$ \\
Discrepant & $\begin{array}{l}\text { Classify a case as discrepant if } 20 \% \text { or more of answers are } \\
\text { discrepant. }\end{array}$ \\
\hline
\end{tabular}

Note. Sometimes none of these rules apply to a case, or a case can meet more than one decision rule. In these instances, choose the narrative where percentages most exceed the decision rules. 


\section{APPENDIX K}

\section{An Example of Structural Analysis}

Legend: Labov's narrative codes

\begin{tabular}{|c|c|c|}
\hline $\operatorname{Abstract}(\mathrm{A})$ & What was this about? & Summary and/or point of the story. \\
\hline Orientation $(\mathrm{O})$ & $\begin{array}{l}\text { Who, when, what, } \\
\text { where? }\end{array}$ & $\begin{array}{l}\text { Orientation to time, place, characters, } \\
\text { situation. }\end{array}$ \\
\hline $\begin{array}{l}\text { Complicating } \\
\text { action (CA,) }\end{array}$ & Then what happened? & $\begin{array}{l}\text { Event sequence, plot, usually with a } \\
\text { crisis or turning point. }\end{array}$ \\
\hline Evaluation (E) & So what? & $\begin{array}{l}\text { The soul of the narrative. Narrator } \\
\text { steps back from action, conveys } \\
\text { emotions, comments on meaning. }\end{array}$ \\
\hline $\begin{array}{l}\text { Result, resolution } \\
\text { ( R) }\end{array}$ & $\begin{array}{l}\text { What finally } \\
\text { happened? }\end{array}$ & The plot outcome. \\
\hline Coda (C) & $\begin{array}{l}\text { Is meant to put off the } \\
\text { 'So what?' question. }\end{array}$ & $\begin{array}{l}\text { Ends the story, brings action back to } \\
\text { the present. }\end{array}$ \\
\hline
\end{tabular}

\section{The seating debate}

Margot: Now, I wanted to know. . . have you made suggestions to change things around here?

1 Henrietta: [long pause] Change ... [long pause] . . .

we had trouble here for a while,

A, R

2 with our tables, you know.

A

3 We like to sit together.

A

4 with the ones that we sat from beginning on.

A

5 We like to sit together all at once.

6 It came about ...

7 everything is changeable.

8 You can sit by any table or,

9 or anyplace you want, you know.

10 And that part, I didn't like.

11 I didn't like that, that part. 
12 I was together with [names of people]. $\quad \mathrm{O}$

13 We sat together at that, at that table, for years.

14 Together, you know. $\quad O$

15 Now, [they] left. $\quad$ CA

16 Now that space was empty, $\quad$ CA

17 and anybody would come and sit there, $\quad$ CA

18 you know ... $\quad O$

19 and even take my place, $\quad$ CA

20 or take [name's] place ... $\quad$ CA

21 And that part, I don't like. $\quad$ E

22 I don't. [Discussion] $\mathrm{E}$

[Personal discussion]

23 So that part... $\quad O$

24 should be people like to sit all the time where they sit E

25 and leave them alone, you know.

26 But no, they change, and now you can sit anywhere ...

27 and they sure do! $\quad$ CA

28 Anybody comes and sits in my place $\quad$ CA

29 and ... I don't like that. E

M: Yes ... yeah.

30 And we can't sort of stop it somehow. . . R, Coda

31 but I don't know. . .

Coda

\section{Structural analysis}

\section{General}

This is a story about organizational routines - how routines can impact a client's friendships and ability to live as they wish. Henrietta describes a situation where the reflexive relationship between agency and structure is blocked. Henrietta is unable to influence these routines. Although she said in other narratives that she has spoke to the Maître d' about not being able to have her table, this narrative suggests she has been unable to influence the Maître d's behaviour to the point where things have returned to the way they were done before. Despite this, Henrietta has not given up. By speaking to me, Henrietta is talking advantage of another opportunity to influence Lakelands' routines.

Henrietta is a skilled story teller. She uses short sentences and a great deal of repetition to create drama.

Note that there is no real resolution to this story, other than to say that there was trouble in the past, and that the troubles continue, albeit in diminished form. 
The researcher is largely absent from this story. Henrietta repeatedly says "you know," which is intended to draw the researcher into the story.

The complicating action in this story is made up of two waves. Lines 15-20 and lines 2628 say essentially the same thing. Both are followed by evaluative phrases (coded "E"). The first wave and the first evaluation are longer and more detailed than the second wave, and the second evaluation. This suggests that the second wave serves as emphasis.

\section{Line by line analysis}

1 Henrietta begins by sayings that a problem existed in the past, suggesting that the problem no longer exists.

3-7 Henrietta contrasts routine and change; how a routine was disrupted.

5 "We like to sit together all at once." This is an unusual sentence construction. Henrietta is making the point that as old friends they do not want to be split up between tables.

6. Henrietta uses the phrase "it came about" to announce the beginning of the complicating action.

10,11 Henrietta emphasizes how she does not like the new policy by repeating twice that 'I didn't like that'. She reverses the sentence structure in the second sentence, but uses the same words. It gives a nice flow and rhythm to her story. By reversing the sentence structure she reinforces the message that she disapproves of what happened.

12-14 Henrietta uses the word "together" three times to emphasize how things were unchanged for years. Henrietta is pointing to the importance of friendships in her life. Dinner time is an opportunity to renew these friendships. This is an example of how friendships become almost like family at Lakelands. In nuclear families one eats dinner daily with one's family. Henrietta is eating daily with her close friends, just as one would do in a family.

15 Henrietta signals that the situation changes abruptly when one of the table members leaves.

15 "Now, [they] left. Now that space was empty." Henrietta's short sentence suggests that they left suddenly. The cadence mirrors what happened. Note how Henrietta repeats the word "now." It signals a turning point in the story.

16-20 Chaos follows a period of long stability. People sit in the friend's place, and her place as well. Note the repeated use of the term 'place'. (2x) 
17 "and anybody would come and sit there." Use of the word "anybody" suggests that the group that is left has no control over who they sit with. "Anybody" suggests that this person is not important to the group at the table.

18. "You know" Henrietta is encouraging the listener to empathize with her.

21 Change in tense from line 20 - from past to present tense. Signals a shift in the story to the evaluation (coded "E").

21 and 22. Henrietta repeats the phrase "I don't like...I don't" to emphasize her point.

24,25 Henrietta is arguing for individual choice.

28 (and 17) Henrietta refers to strangers as "anybody" or "they." She gives a name to her friend. These naming conventions underline an important distinction in Henrietta's mind between close friends - her circle - and person's that fall outside this circle.

30 This line points to a loss of agency, an inability to resolve this situation in a way that Henrietta would like. The sentence structure and the terms used are passive, rather than active or direct, indicating that Henrietta has tried to stop this practice but has been unable to do so. It suggests at some level she has given up. This points to how difficult it can be to oppose management routines. This line contradicts line 1, which suggests that the problem has been resolved. Perhaps this line suggests that the problem is not as bad as it was. 


\section{APPENDIX L}

\section{Statistical relationships with contrasting answers}

Table L.01. Associations with "contrasting narrative"

\begin{tabular}{lc}
\hline Variables & Contrasting Narrative \\
Years resident & $-.51^{*}$ \\
& $(\mathrm{n}=30)$ \\
Independent moving decision & $-.54^{*}$ \\
& $(\mathrm{n}=30)$ \\
Making suggestions & $-.50^{*}$ \\
& $(\mathrm{n}=26)$ \\
Prefer dining room & $.54^{*}$ \\
& $(\mathrm{n}=27)$ \\
Selfview changed & $.56^{*}$ \\
& $(\mathrm{n}=25)$ \\
\hline
\end{tabular}

Note. ${ }^{\dagger} p<.10 .{ }^{*} p<.05$. Two-tailed test. Since these variables have abnormal distributions, I used a nonparametric correlation coefficient Spearman's rho. 


\section{APPENDIX M}

\section{Summary of significant statistical relationships}

The following is a list of significant statistical relationships identified in Chapters 6 to 14 . These relationships are grouped by respondent characteristics.

\section{Gender}

Women are likely to be unmarried and men married (Table 3.11). Gender is not associated with variables in the data set that describe living at Lakelands (Chapter 17). It is associated with marital status.

\section{Marital status}

Single persons are more likely than married persons to use the "in here/outside" (Table 6.6).

Age

The greater a person's age the more likely they are to have typical narratives (for the 10 interview questions) (Table 14.1).

Extroversion

Extroverts are more likely than introverts to call Lakelands "home" (Table $6.3)$.

Family nearby

Respondents with family living nearby are more likely than people who do not have family nearby to say they can live as I like (Table 12.4).

Health

The better a person's overall health the more likely they are to call Lakelands "home" (Chapter 6).

The worse a respondent's hearing the more likely they are to have typical narratives (Table 14.1).

The better a person's eyesight the more likely they are to say they can live as they like (Table 12.4).

The better a person's memory the more likely they are to say they can live as they like (Table 12.4). 
Crises

The more crises a person experiences before the move:

- the greater the adaptation required (Table 7.5).

- the more likely they are to report a change in self-identity (Table 8.2).

Experience in residential organizations

The greater the number of previous residential organizations in which a person has lived or worked:

- the more likely they are to use the term "in here/outside" (Table 6.7).

- the more likely they are to report a change in self-identity (Table 8.2).

The greater the number of years resident at Lakelands:

- the greater the likelihood a person will use the term "in here/outside" (Table 6.7).

- the less a person reports severe adaptation problems (Table 7.5).

- the fewer the reported crises before the move (Table 7.5).

- the greater the percentage of typical narratives (answers to the 10 interview questions) (Table 14.1).

\section{Naming conventions}

If a respondent says the term "resident" is fine, they are more likely to say "I can live as I like" than someone who does not agree with this naming convention (Table 12.4).

If a respondent says first names are fine, they are more likely to say "I can live as I like" than someone who does not agree with this naming practice (Table 12.4).

\section{Complaining}

A person is less likely to make suggestions to management if they say that they, or others, should not complain (Table 13.2). 